Flávia Gadêlha Martins

\title{
GESTÃO E GERENCIAMENTO DE RESÍDUOS DA CONSTRUÇÃO CIVIL EM OBRAS DE GRANDE PORTE - ESTUDOS DE CASO
}

Dissertação apresentada ao Departamento de Hidráulica e Saneamento, como parte dos requisitos exigidos para obtenção do Título de Mestre em Ciências, Programa de Engenharia Hidráulica e Saneamento.

Área de Concentração: Hidráulica e Saneamento

Orientador: Prof. Assoc. Valdir Schalch

\section{VERSÃO CORRIGIDA}

São Carlos - SP 
AUTORIZO A REPRODUÇÃO E DIVULGAÇÃO TOTAL OU PARCIAL DESTE TRABALHO, POR QUALQUER MEIO CONVENCIONAL OU ELETRÔNICO, PARA FINS DE ESTUDO E PESQUISA, DESDE QUE CITADA A FONTE.

Ficha catalográfica preparada pela Seção de Atendimento ao Usuário do Serviço de Biblioteca - EESC/USP

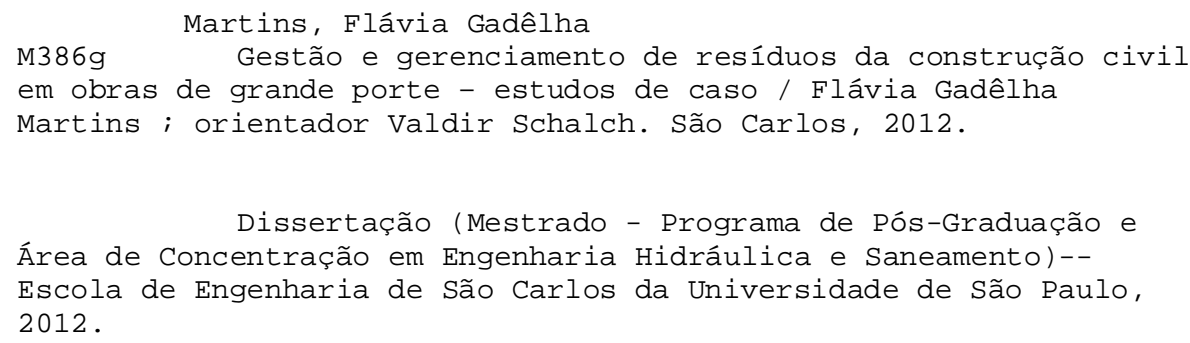

1. Resíduos da construção civil.

2. Gerenciamento de resíduos da construção civil.

3. Obras de grande porte. I. Título. 


\section{FOLHA DE JULGAMENTO}

Candidata: Engenheira FLÁVIA GADELHA MARTINS.

Título da dissertação: "Gestão e gerenciamento de resíduos da construção civil em obras de grande porte - estudos de caso".

Data da defesa: 08/06/2012

Comissão Julgadora:

Prof. Associado Valdir Schalch (Orientador)

(Escola de Engenharia de São Carlos/EESC)

Prof. Dr. Javier Mazariegos Pablos

(Instituto de Arquitetura e Urbanismo/IAU)

Prof. Dr. Wellington Cyro de Almeida Leite

(Universidade Estadual Paulista "Júlio de Mesquita Filho"/UNESP- campus de Guaratinguetá)

Coordenador do Programa de Pós-Graduação em Engenharia Hidráulica e Saneamento:

Prof. Titular Edson Cezar Wendland

Suplente do Presidente da Comissão de Pós-Graduação em Exercício: Prof. Titular Denis Vinicius Coury

APROVAOO
Resultado:

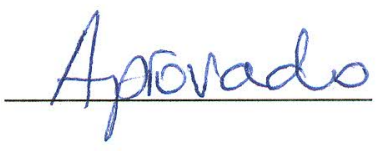




\section{AGRADECIMENTOS}

Para a conclusão deste trabalho foi indispensável a colaboração e o incentivo de diversas pessoas e entidades, que direta ou indiretamente contribuíram para a concretização de mais essa etapa. Assim, muitos são os agradecimentos que precisam ser feitos.

Primeiramente, aos meus pais, Frederico Mesquita Martins e Maria de Fátima Gadêlha Martins, pelo amor e carinho em toda a minha vida, pelos incansáveis esforços empregados na minha educação, pelo exemplo de integridade que sempre me foi dado, por terem sempre acreditado no meu potencial e pelos inestimáveis conselhos que me conduziram sempre a decisões coerentes e corretas, transformando-me na pessoa que sou.

Ao meu irmão Fredinho pelo companheirismo, incentivo, amizade e, assim como meus pais, por também representar para mim um exemplo de caráter, dignidade e grandeza.

Ao meu orientador Professor Doutor Valdir Schalch, pela paciência e competência com as quais conduziu minha orientação, sempre com muita sabedoria e otimismo, principalmente, pela confiança no meu trabalho.

À Professora Doutora Maria Bernadete Fernandes Vieira de Melo, pelo apoio incondicional na fase de elaboração da qualificação, incentivando e direcionando para a coerência e clareza do material, o que foi muito importante para atingir essa conquista atual.

Ao Conselho Nacional de Desenvolvimento Científico e Tecnológico (CNPq) e à Coordenação de Aperfeiçoamento de Pessoal de Nível Superior (CAPES) pelo suporte financeiro concedido para a realização do trabalho.

A todos os docentes do curso de Pós-Graduação em Hidráulica e Saneamento da EESC/USP, pelos conhecimentos profissionais e acadêmicos transmitidos e pela receptividade.

Ao Professor Doutor Javier MazariegosPablose ao Professor Doutor Wellington Cyro de Almeida Leite, pelas observações e sugestões no exame de qualificação.

Ao Rodrigo Eduardo Córdoba, pelas correções, ensinamentos, presteza, esclarecimento de dúvidas e paciência na elaboração do trabalho.

À equipe da Arena Fonte Nova, pela colaboração, apoio, informações e cooperação em todas as etapas de coleta de dados, em especial ao engenheiro Rildo Gomes e à técnica Renata Ribeiro, que, com sua equipe competente e pró-ativa, foram extremamente importantes à conclusão deste estudo. 
À equipe da Arena Pernambuco, pelas informações e dados fornecidos, em especial às engenheiros Romero Ribeiro, Ana Carolina Pedrosa, Izabelle Arcanjo pela disponibilidade e apoio sempre que foram necessários.

Ao líder e amigo engenheiro José Érico Eloi Dantas, pelo apoio em todos os momentos do curso e da elaboração da dissertação, pela colaboração técnica, apoio e incentivo oferecido e pela confiança em todos os trabalhos que desempenho.

Aos amigos e colegas de trabalho da Odebrecht Infraestrutura, pela paciência, apoio, amizade, compreensão e companheirismo em todos os momentos da minha carreira profissional e, principalmente, nessa reta final da dissertação, e pelo reconhecimento do meu trabalho desde o início.

Aos amigos da Construtora OAS que direta e indiretamente me ajudaram no fornecimento do material da Arena Fonte Nova.

Aos colegas e amigos do Programa de Pós-Graduação em Hidráulica e Saneamento da EESC/USP, pelas dicas, conselhos, apoio e companheirismo nesse período, em especial à Elaine Schornobay, Filipe Vasconcelos, Lívia Botta, Luciano do Vale, Edilincon Albuquerque, Irene Monteiro, Gabriela Palhuzi, Natália Benatto e Narumi Abe. Sou muito grata a todos vocês.

À Escola de Engenharia de São Carlos da Universidade de São Paulo, pela oportunidade de qualificação oferecida nessa fase da minha carreira de profissional.

A todos os funcionários e professores do Departamento de Hidráulica e Saneamento, da Escola de Engenharia de São Carlos (USP), pelo apoio, amizade, presteza, colaboração e eficiência com que sempre me atenderam, durante todo o meu período de estudo, em especial à funcionária Rosemeire Aparecida de Jesus e às secretárias Maria Auxiliadora de C. Altieri Pin e Pavlovna Damião Rocha Bueno do Departamento de Hidráulica e Saneamento (SHS).

Aos amigos da Hisa Engenharia Ltda., por todo o apoio e colaboração, principalmente pelo fornecimento de material didático e técnico, importantes desde o processo seletivo para o curso de Pós-Graduação até a sua conclusão. Em especial, meu agradecimento ao economista Luís Formiga, por ter sido um grande amigo, pelo apoio e por ter contribuído tanto para a realização de todo o tratamento dos dados da pesquisa de campo.

A todos os meus amigos e familiares que, somente com a amizade e carinho, contribuíram de forma imensurável para a concretização de mais esse desafio.

Enfim, agradeço a todas as pessoas que de alguma forma contribuíram para a realização deste trabalho. 


\section{SUMÁRIO}

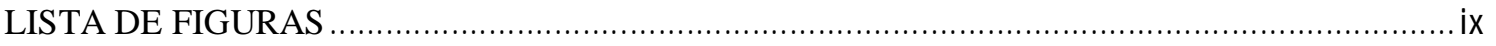

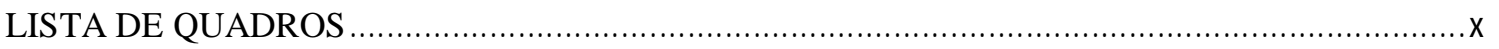

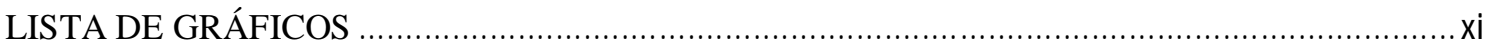

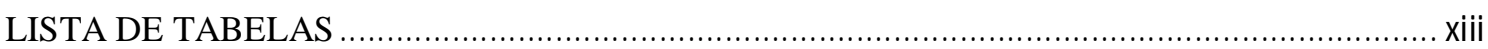

LISTA DE ABREVIATURAS, SIGLAS E SÍMBOLOS ....................................................... XVi

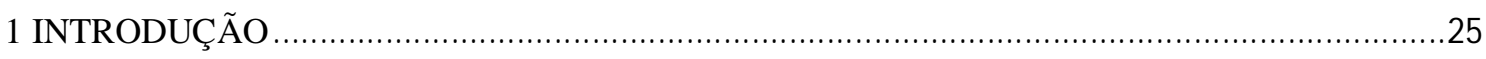

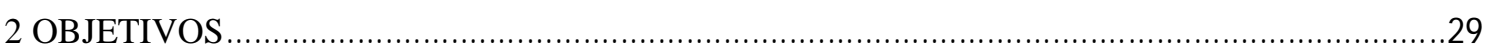

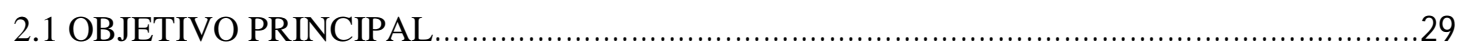

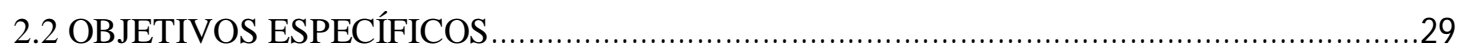

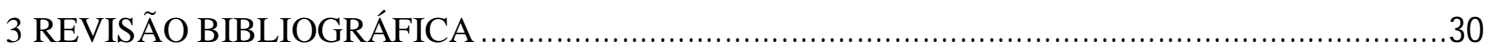

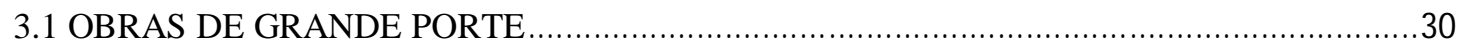

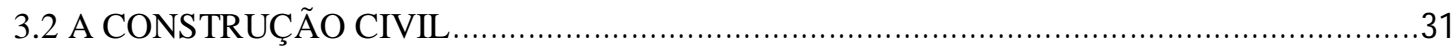

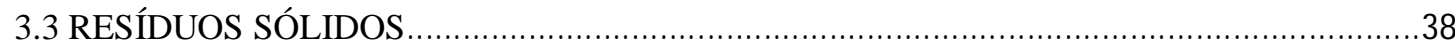

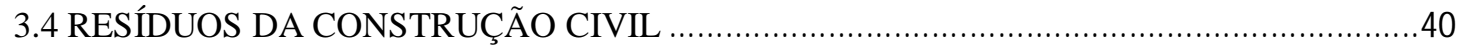

3.4 GESTÃO E GERENCIAMENTO DOS RESÍDUOS DE CONSTRUÇÃO CIVIL ...................45

3.5 A IMPORTÂNCIA DO GERENCIAMENTO DE RESÍDUOS DA CONSTRUÇÃO...............49

CIVIL SER INICIADO NA FASE DE CONCEPÇÃO DO PROJETO ..........................................49

3.6 A IMPORTÂNCIA DA INDUSTRIALIZAÇÃO DA CONSTRUÇÃO CIVIL NO..................53

GERENCIAMENTO DOS RESÍDUOS SÓLIDOS ........................................................... 53

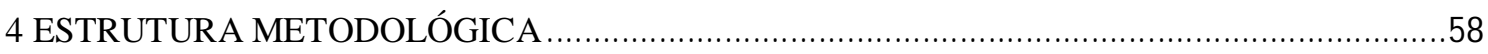

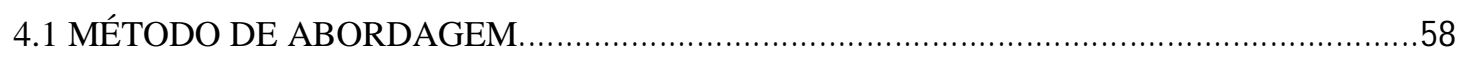

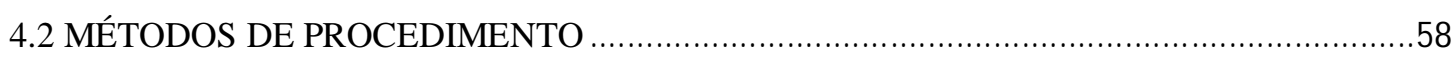

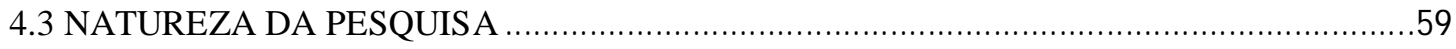

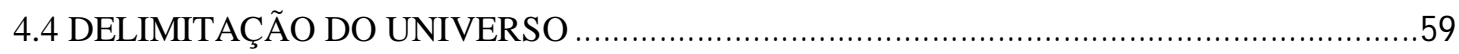

4.5 IDENTIFICAÇÃO DAS VARIÁVEIS E INDICADORES............................................66

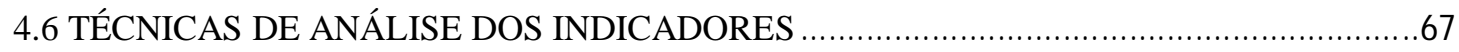

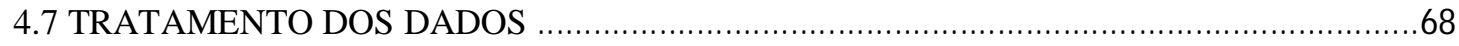

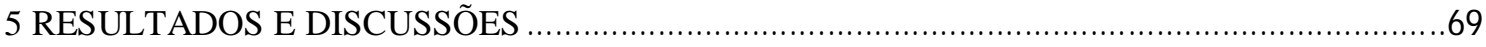

5.1 GESTÃO E GERENCIAMENTO DOS RCC DA OBRA DA FONTE NOVA .......................70

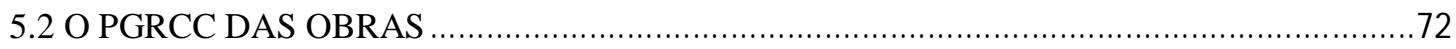

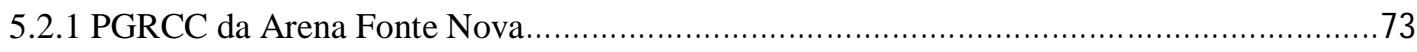


5.2.1.1 Plano de movimentação de resíduos 78

5.2.1.2 Medidas mitigadoras...... 80

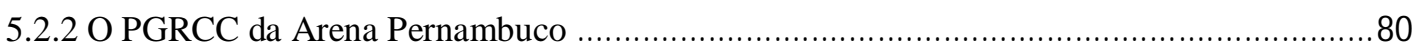

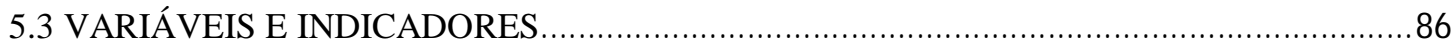

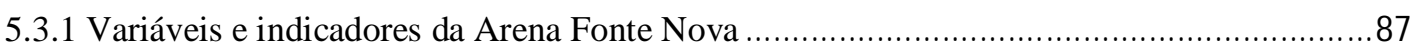

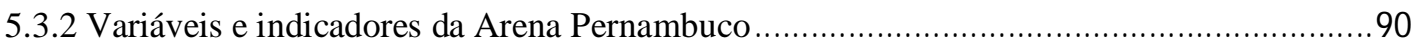

5.4 GRCC DAS ARENAS VERSUS RESOLUÇÃO CONAMA No 307/2002 e PNRS .................93

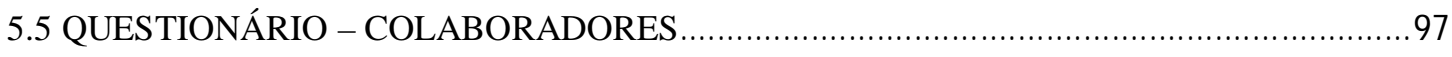

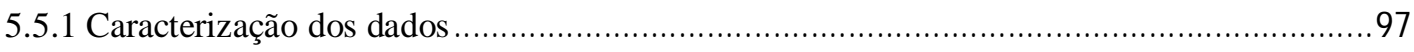

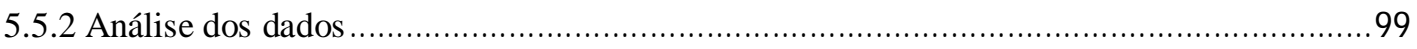

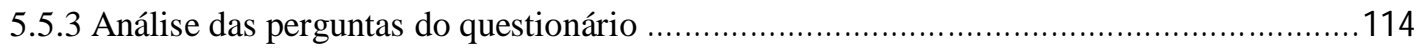

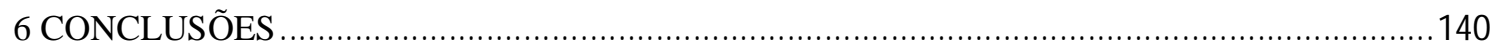

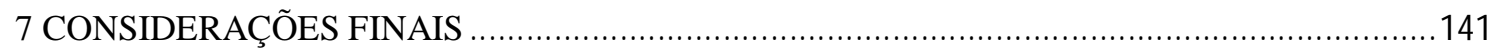

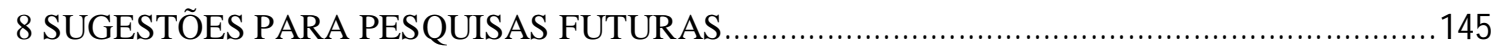

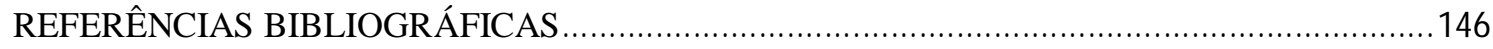

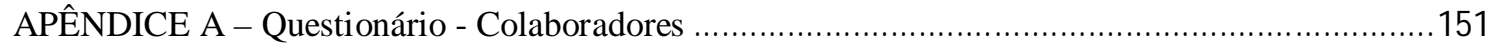

ANEXO A - Plano de Gerenciamento dos Resíduos da Construção Civil da Arena Fonte Nova...... 154

ANEXO B - Programa de Gerenciamento dos Resíduos Sólidos da Arena Pernambuco ..................174 


\section{LISTA DE FIGURAS}

Figura 1 - Estratégias para a gestão e o gerenciamento integrado dos resíduos sólidos..........48

Figura 2 - Etapas da gestão e do gerenciamento dos resíduos da construção civil (RCC).......49

Figura 3 - Localização da obra de reconstrução do estádio da Fonte Nova (Octávio Mangabeira), Salvador-BA.......................................................................61

Figura 4 - Implosão do estádio da Fonte Nova (Octávio Mangabeira), Salvador-BA............61

Figura 5 - Estádio da Fonte Nova (Octávio Mangabeira), após a implosão.............................62

Figura 6 - Situação da obra da Arena Fonte Nova em abril de 2012 ...................................62

Figura 7 - Localização da obra de construção da Arena Multiuso Pernambuco, São Lourenço

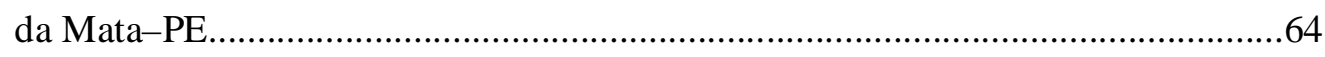

Figura 8 - Área desmatada para construção da Arena Multiuso Pernambuco, São Lourenço

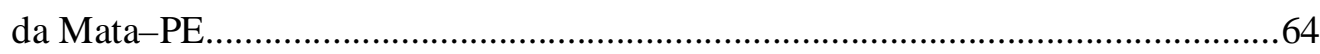

Figura 9 - Situação da obra da Arena Pernambuco em março de 2012 - 1...........................65

Figura 10 - Situação da obra da Arena Pernambuco em março de 2012 - 2 .........................65

Figura 11 - Sequência de execução da demolição e implosão do antigo estádio da Fonte

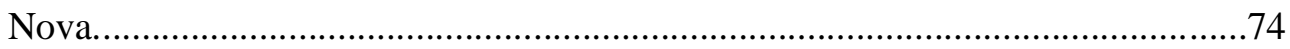

Figura 12 - Fluxograma do gerenciamento dos resíduos da Arena Pernambuco.....................86 


\section{LISTA DE QUADROS}

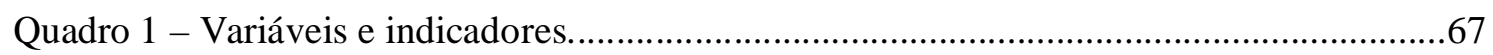

Quadro 2 - Resíduos gerados na fase I - demolição (mecanizada e implosão) da Arena Fonte

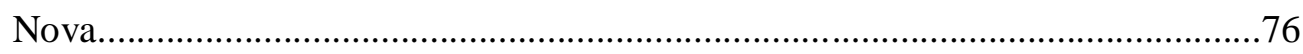

Quadro 3 - Resíduos gerados na fase II - canteiro de obras, terraplenagem e construção da Arena Fonte Nova

Quadro 4 - Movimentação de resíduos gerados na fase I - demolição (mecanizada e implosão) da Arena Fonte Nova...

Quadro 5 - Movimentação dos resíduos gerados na fase II -canteiro de obras, terraplenagem e construção da Arena Fonte Nova..............................................79

Quadro 6 - Tipos de resíduo, classificação e destinação final.................................................83

Quadro 7 - Quantidade de resíduos recicláveis gerados na Arena Fonte Nova em 2011........87

Quadro 8 - Quantidade de resíduos recicláveis gerados na Arena Fonte Nova em 2012........87

Quadro 9 - Quantidade de resíduos não recicláveis gerados na Arena Fonte Nova

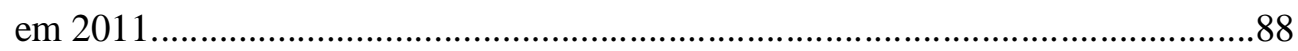

Quadro 10 - Quantidade de resíduos não recicláveis gerados na Arena Fonte Nova em 2012. .88

Quadro 11 - Quantidade Total de resíduos sólidos recicláveis gerados na Arena

Pernambuco. 


\section{LISTA DE GRÁFICOS}

Gráfico 1 - Composição da cadeia produtiva da construção civil - 2009................................31

Gráfico 2 - Pessoal ocupado na cadeia de construção, participação (\%) no total, 2009..........34

Gráfico 3 - Geração de resíduos sólidos urbanos.................................................................42

Gráfico 4 - Coleta de resíduos sólidos urbanos no Brasil.......................................................43

Gráfico 5 - Total de RCC coletados por região e Brasil em 2010 e 2009...............................44

Gráfico 6 - Frequências absoluta e relativa por faixa etária - Arena Fonte Nova.................100

Gráfico 7 - Frequências absoluta e relativa por faixa etária - Arena Pernambuco................101

Gráfico 8 - Frequências absoluta e relativa por faixa etária - Total (Arena Fonte Nova e

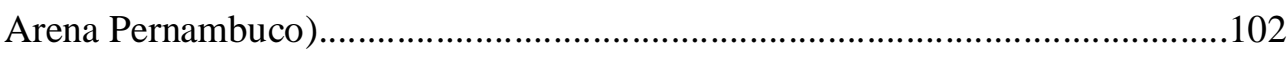

Gráfico 9 - Tempo que trabalha com construção civil - Arena Fonte Nova..........................105

Gráfico 10 - Tempo que trabalha com construção civil - Arena Pernambuco......................106

Gráfico 11 - Tempo que trabalha com construção civil - Total (Arena Fonte Nova e Arena

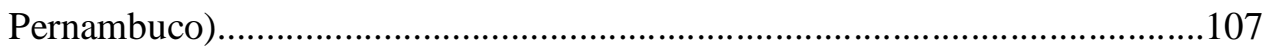

Gráfico 12 - Escolaridade da mão de obra - porcentagem em relação ao total de

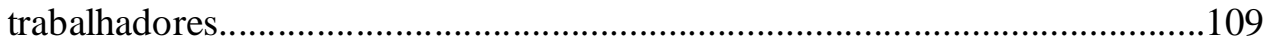

Gráfico 13 - Escolaridade dos entrevistados na Arena Fonte Nova....................................110

Gráfico 14 - Escolaridade dos entrevistados na Arena Pernambuco....................................111

Gráfico 15 - Escolaridade de todos os entrevistados........................................................113

Gráfico 16 - Principais preocupações do trabalhador do setor da construção civil - Arena

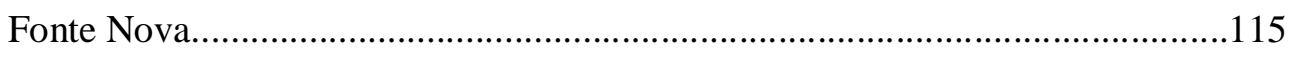

Gráfico 17 - Principais preocupações do trabalhador do setor da construção civil - Arena

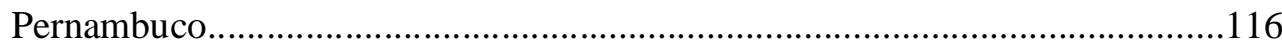

Gráfico 18 - Principais preocupações do trabalhador do setor da construção civil - Total

(Arena Fonte Nova e Arena Pernambuco)......................................................117

Gráfico 19 - Separação do lixo em casa - Arena Fonte Nova.............................................118

Gráfico 20 - Separação do lixo em casa - Arena Pernambuco............................................119

Gráfico 21 - Separação do lixo em casa - Total (Arena Fonte Nova e Arena

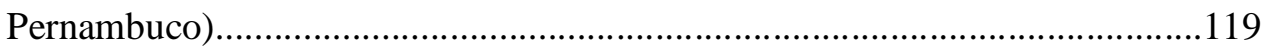

Gráfico 22 - Escolaridade x separação do lixo em casa - Arena Fonte Nova.......................121

Gráfico 23 - Escolaridade x separação do lixo em casa - Arena Pernambuco.......................122

Gráfico 24 - Escolaridade x separação do lixo em casa - Total (Arena Fonte Nova e Arena

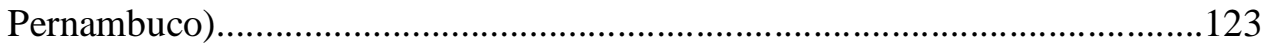


Gráfico 25 - Quantidade de lixo gerado na obra da Arena Fonte Nova...............................124

Gráfico 26 - Quantidade de lixo gerado na obra da Arena Pernambuco................................125

Gráfico 27 - Quantidade de lixo gerado nas obras da Arena Fonte Nova e da Arena Pernambuco.

Gráfico 28 - Gerenciamento dos resíduos da construção civil, segundo os entrevistados da Arena Fonte Nova.

Gráfico 29 - Gerenciamento dos resíduos da construção civil, segundo os entrevistados da Arena Pernambuco

Gráfico 30 - Gerenciamento dos resíduos da construção civil, segundo todos os entrevistados

Gráfico 31 - Fatores que dificultam a separação do lixo gerado durante a execução dos serviços na obra da Arena Fonte Nova.

Gráfico 32 - Fatores que dificultam a separação do lixo gerado durante a execução dos serviços na obra da Arena Pernambuco.

Gráfico 33 - Fatores que dificultam a separação do lixo gerado durante a execução dos serviços nas obras da Arena Fonte Nova e da Arena Pernambuco.

Gráfico 34 - Fatores que dificultam o correto armazenamento do lixo no canteiro de obras da Arena Fonte Nova. 132

Gráfico 35 - Fatores que dificultam o correto armazenamento do lixo no canteiro de obras da Arena Pernambuco

Gráfico 36 - Fatores que dificultam o correto armazenamento do lixo no canteiro de obras da Arena Fonte Nova e da Arena Pernambuco.....................................................134

Gráfico 37 - Destino que deveria ser dado ao lixo da obra da Arena Fonte Nova.................135

Gráfico 38 - Destino que deveria ser dado ao lixo da obra da ArenaPernambuco.................136

Gráfico 39 - Destino que deveria ser dado ao lixo das obras da Arena Fonte Nova e da Arena Pernambuco. 137

Gráfico 40 - Frequência de limpeza da obra da Arena Fonte Nova.....................................138

Gráfico 41 - Frequência de limpeza da obra da Arena Pernambuco.....................................138

Gráfico 42 - Frequência de limpeza das obras da Arena Fonte Nova e da Arena Pernambuco 


\section{LISTA DE TABELAS}

Tabela 1 - Participação (\%) do PIB da construção civil no PIB total do Brasil -

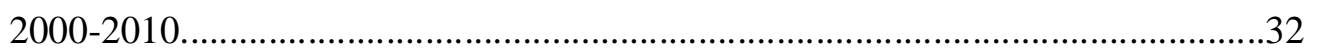

Tabela 2 - Dados gerais da indústria da construção - Brasil - 2008-2009..............................35

Tabela 3 - Produção, renda e ocupação na cadeia da construção, 2009, em R \$ milhões..........36

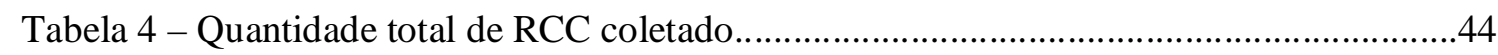

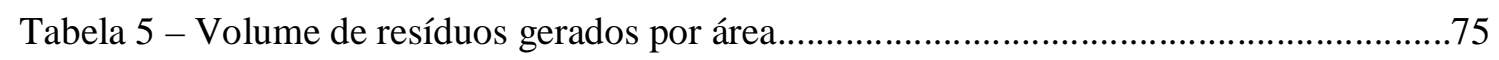

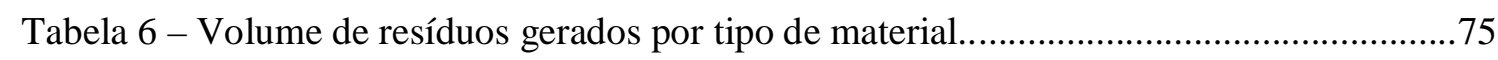

Tabela 7 - Faixa etária dos entrevistados na Arena Fonte Nova.........................................100

Tabela 8 - Descritivo: dados estatísticos, calculados em função da frequência absoluta da

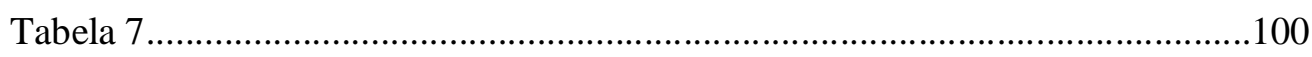

Tabela 9 - Faixa etária dos entrevistados na Arena Pernambuco......................................101

Tabela 10 - Descritivo: dados estatísticos, calculados em função da frequência absoluta da

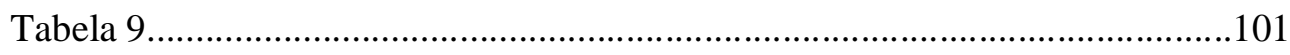

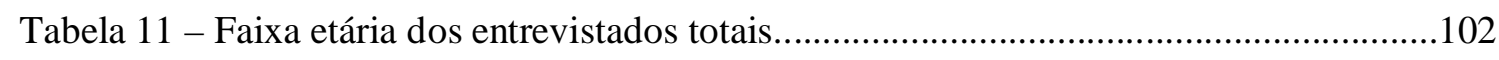

Tabela 12 - Descritivo: dados estatísticos, calculados em função da frequência absoluta da Tabela 11 102

Tabela 13 - Principais problemas apontados por firmas da construção civil (em \% de firmas

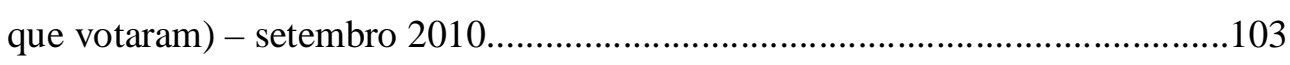

Tabela 14 - Tempo que trabalha com construção civil - Arena Fonte Nova.........................105

Tabela 15 - Tempo que trabalha com construção civil - Arena Pernambuco.........................106

Tabela 16 - Tempo que trabalha com construção civil - Total (Arena Fonte Nova e Arena

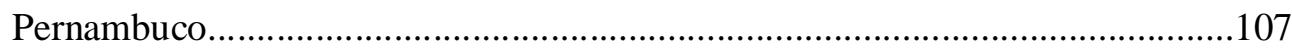

Tabela 17 - Escolaridade dos entrevistados na Arena Fonte Nova.....................................110

Tabela 18 - Descritivo: dados estatísticos, calculados em função da frequência absoluta da

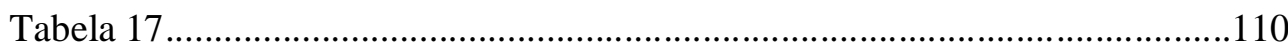

Tabela 19 - Escolaridade dos entrevistados na Arena Pernambuco........................................111

Tabela 20 - Descritivo: dados estatísticos, calculados em função da frequência absoluta da

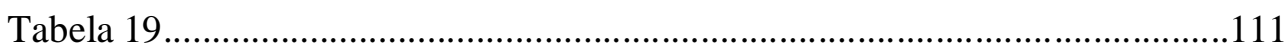

Tabela 21 - Escolaridade de todos os entrevistados..........................................................112

Tabela 22 - Descritivo: dados estatísticos, calculados em função da frequência absoluta da

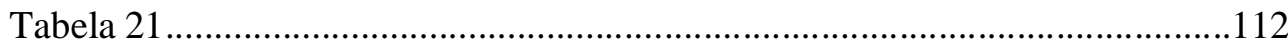

Tabela 23 - Função dos colaboradores entrevistados nas obras...........................................114 
Tabela 24 - Principais preocupações do trabalhador do setor da construção civil - Arena Fonte Nova.....

Tabela 25 - Principais preocupações do trabalhador do setor da construção civil - Arena Pernambuco

Tabela 26 - Principais preocupações do trabalhador do setor da construção civil - Total

(Arena Fonte Nova e Arena Pernambuco)

Tabela 27 - Separação do lixo em casa - Arena Fonte Nova..

Tabela 28 - Separação do lixo em casa - Arena Pernambuco.

Tabela 29 - Separação do lixo em casa - Total (Arena Fonte Nova e Arena Pernambuco)..119

Tabela 30 - Escolaridade x separação do lixo em casa - Arena Fonte Nova.

Tabela 31 - Escolaridade x separação do lixo em casa - Arena Pernambuco.

Tabela 32 - Escolaridade x separação do lixo em casa - Total (Arena Fonte Nova e Arena

Pernambuco).

Tabela 33 - Quantidade de lixo gerado na obra da Arena Fonte Nova.

Tabela 34 - Quantidade de lixo gerado na obra da Arena Pernambuco.

Tabela 35 - Quantidade de lixo gerado nas obras da Arena Fonte Nova e da Arena

Pernambuco.

Tabela 36 - Gerenciamento dos resíduos da construção civil, segundo os entrevistados da Arena Fonte Nova.

Tabela 37 - Gerenciamento dos resíduos da construção civil, segundo os entrevistados da Arena Pernambuco.

Tabela 38 - Gerenciamento dos resíduos da construção civil, segundo todos os entrevistados

Tabela 39 - Fatores que dificultam a separação do lixo gerado durante a execução dos serviços na obra da Arena Fonte Nova.

Tabela 40 - Fatores que dificultam a separação do lixo gerado durante a execução dos serviços na obra da Arena Pernambuco

Tabela 41 - Fatores que dificultam a separação do lixo gerado durante a execução dos serviços nas obras da Arena Fonte Nova e da Arena Pernambuco.

Tabela 42 - Fatores que dificultam o correto armazenamento do lixo no canteiro de obras da Arena Fonte Nova.

Tabela 43 - Fatores que dificultam o correto armazenamento do lixo no canteiro de obras da Arena Pernambuco. 133

Tabela 44 - Fatores que dificultam o correto armazenamento do lixo no canteiro de obras da 
Arena Fonte Nova e da Arena Pernambuco........................................................134

Tabela 45 - Destino que deveria ser dado ao lixo da obra da Arena Fonte Nova..................135

Tabela 46 - Destino que deveria ser dado ao lixo da obra da Arena Pernambuco..................136

Tabela 47 - Destino que deveria ser dado ao lixo das obras da Arena Fonte Nova e da Arena

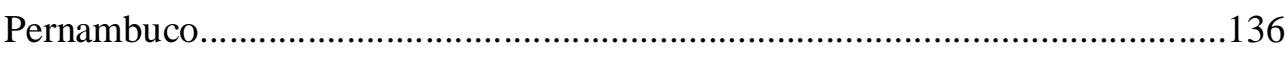

Tabela 48 - Frequência de limpeza da obra da Arena Fonte Nova....................................137

Tabela 49 - Frequência de limpeza da obra da Arena Pernambuco.....................................138

Tabela 50 - Frequência de limpeza das obras da Arena Pernambuco e da Arena

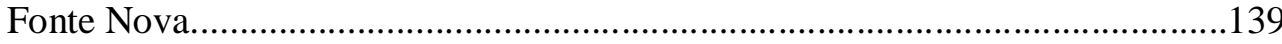




\section{LISTA DE ABREVIATURAS, SIGLAS E SÍMBOLOS}

ABNT - Associação Brasileira de Normas Técnicas

ABRELPE - Associação Brasileira de Empresas de Limpeza Pública e Resíduos Especiais AFN - Arena Fonte Nova

ANVISA - Agência Nacional de Vigilância Sanitária

AP - Arena Pernambuco

BB - Bombona

BNDES - Banco Nacional de Desenvolvimento Econômico e Social

CAGED - Cadastro Geral de Empregados e Desempregados

CAPES - Coordenação de Aperfeiçoamento de Pessoal de Nível Superior

CBIC - Câmara Brasileira da Indústria da Construção

CD - Central Decantador

CE - Caixa Estacionária

CII - Instituto da Indústria da Construção (Construction Industry Institute)

CNAE - Classificação Nacional de Atividades Econômicas

CNI - Confederação Nacional da Indústria

CNPq - Conselho Nacional de Desenvolvimento Científico e Tecnológico

CONAMA - Conselho Nacional do Meio Ambiente

CPRH - Agência Estadual de Meio Ambiente (Estado de Pernambuco)

CR - Central de Resíduos

CT - Contentor

EESC - Escola de Engenharia de São Carlos

EPI - Equipamento de Proteção Individual 
FGTS - Fundo de Garantia do Tempo de Serviço

FIFA - Federação Internacional de Futebol e Associados (Fédération Internationale de Football Association)

GRCC - Gerenciamento dos Resíduos da Construção Civil

IBGE - Instituto Brasileiro de Geografia e Estatística

IDH - Índice de Desenvolvimento Humano

IGLC - Grupo Internacional de Construção Enxuta (InternationalGroup for Lean Construction)

IGP-DI - Índice Geral de Preços - Disponibilidade Interna

INCC - Índice Nacional de Custo da Construção

INEMA - Instituto do Meio Ambiente e Recursos Hídricos (Estado da Bahia)

IPI - Imposto sobre Produtos Industrializados

JIT - Produção por Demanda (Just In Time)

$\mathrm{kg}$ - Quilograma

L - Litro

$\mathrm{m}^{2}$ - Metro quadrado

$\mathrm{m}^{3}-$ Metro cúbico

MMA - Ministério do Meio Ambiente

NBR - Norma Brasileira Registrada

OECD - Organização para a Cooperação e o Desenvolvimento Econômico (Organization for

Economic Co-operation and Development)

PAC - Programa de Aceleração do Crescimento

PCA - Plano de Controle Ambiental

PGRCC - Plano de Gerenciamento dos Resíduos da Construção Civil 
PGRS - Plano de Gerenciamento de Resíduos Sólidos

PI - Procedimentos Internos

PIB - Produto Interno Bruto

PMI - Instituto de Gerenciamento de Projetos (Project Management Institute)

PNRS - Política Nacional de Resíduos Sólidos

PNUD - Programa das Nações Unidas para o Desenvolvimento

PPP - Parceria Público Privada

PVC - Policloreto de Polivinila

RCC - Resíduos da Construção Civil

RDC - Resolução da Diretoria Colegiada

RSU - Resíduos Sólidos Urbanos

SENAI - Serviço Nacional de Aprendizagem Industrial

SHS - Departamento de Hidráulica e Saneamento (da EESC)

SINDUSCON - Sindicato da Indústria da Construção Civil

SINEBahia - Serviço Estadual de Intermediação para o Trabalho (Estado da Bahia)

SINIR - Sistema Nacional de Informação sobre a Gestão de Resíduos Sólidos

SMA - Superintendência do Meio Ambiente (Prefeitura de Salvador - Bahia)

SNVS - Sistema Nacional de Vigilância Sanitária

SPE - Sociedade de Próposito Específico

SQ - Sanitário Químico

SSTMA - Saúde, Segurança do Trabalho e Meio Ambiente

$\mathrm{t}$ - Tonelada

TAC - Termo de Acordo e Compromisso 
TB - Tambor

TQM - Gestão da Qualidade Total (Total Quality Management)

un - Unidade

USP - Universidade de São Paulo

VC - Veículo 


\section{RESUMO}

MARTINS, F. G. (2012). Gestão e gerenciamento de resíduos da construção civil em obras de grande porte - estudos de caso. 2012. 177 p. Dissertação (Mestrado) - Escola de Engenharia de São Carlos, Universidade de São Paulo, São Carlos, 2012.

O crescimento da economia brasileira proporcionou uma intensificação na quantidade de obras de infraestrutura iniciadas no país nos últimos anos. A adoção e ampliação de estratégias utilizadas pelo governo para combater os efeitos da crise internacional sobre a economia e as obras necessárias ao país, em razão de eventos internacionais que acontecerão, como a Copa do Mundo de Futebol em 2014, e de programas como o Programa de Aceleração do Crescimento (PAC), foram uma resposta às atuais necessidades do Brasil. Com essas inúmeras obras, houve um crescimento na geração dos resíduos da construção civil (RCC), o que fez com que autoridades, pesquisadores e a sociedade voltassem seus esforços para enfrentar as dificuldades de manejo e disposição final adequada desses resíduos. A ausência de políticas públicas que promovessem a fiscalização do gerenciamento desses resíduos, em relação aos geradores, provocava diversos impactos como, por exemplo, o surgimento de vários depósitos clandestinos nas áreas mais afastadas do perímetro urbano e gastos por parte da administração pública com modelos de gestão corretiva. Contudo, com a elaboração da Resolução CONAMA n 307/2002 e da Política Nacional de Resíduos Sólidos, Decreto no $7.404 / 2010$ que regulamenta a Lei $\mathrm{n}^{\circ}$ 12.305, ficou instituído que os geradores devem ser responsáveis pelos resíduos das atividades voltadas à construção civil, contemplando, assim, a minimização dos impactos causados ao meio ambiente e à saúde humana. Dessa forma, esse quadro de descaso com a situação dos resíduos começou a mudar. Com a intenção de contribuir com essa área de conhecimento, esta pesquisa teve como finalidade estudar a situação do sistema de gerenciamento de RCC de obras de grande porte, após a regulamentação da Resolução CONAMA no 307/2002 e do Decreto no 7.404/2010, que regulamenta a Lei n⿳ 12.305, referente à Política Nacional de Resíduos Sólidos. Para tanto, foi realizado um estudo da situação da gestão e do gerenciamento dos RCC na demolição e construção da Arena Fonte Nova, em Salvador-BA, e na construção da Arena Pernambuco, em São Lourenço da Mata-PE, realizadas para a Copa do Mundo de Futebol de 2014, por meio de três etapas de estudo: análise das variáveis e indicadores locais; caracterização qualitativa dos resíduos; e, por fim, comparação do gerenciamento da obra com o preconizado em ambas as leis. Esta pesquisa utilizou metodologia de classificação qualitativa do RCC, por 
meio de observações e entrevistas de campo, com o objetivo de identificar e analisar sua gestão e seu gerenciamento nessas obras, e teve como principal importância ajudar as empresas construtoras de obras de grande porte a fazerem uma autoavaliação de sua gestão e gerenciamento dos resíduos sólidos. Portanto, concluiu-se que as obras pesquisadas atendem às exigências das leis e que, para que haja um efetivo sistema de gestão e gerenciamento dos resíduos da construção civil, deve-se influenciar a mudança cultural das pessoas, visando a efetiva compreensão e concordância das necessidades ambientais.

Palavras-chave: Resíduos da construção civil. Gerenciamento de resíduos da construção civil. Obras de grande porte. 


\begin{abstract}
MARTINS, F. G. (2012). Civil Construction Waste Management in Large Construction Works - Case Studies. 2012. 177 p. Thesis (MA) - São Carlos School of Engineering, São Paulo University (USP), São Carlos, 2012.
\end{abstract}

The Brazilian economy has provided an enhancement in the amount of infrastructure works initiated in the country in recent years. The adoption and expansion of strategies used by the government to combat the effects of global crisis on the economy and the works necessary for the country due to international events that will happen as the FIFA World Cup in 2014 and programs such as PAC (Program Growth Acceleration), were a response to the current needs of Brazil. With these numerous works, there was an increase in the generation of civil construction waste $(\mathrm{CCW})$, which meant that the authorities, researchers and society return their efforts to face the difficulties of handling and final disposal of such waste. The absence of public policies that promote the monitoring of waste management in relation to generators, caused many impacts, for example, the emergence of several underground deposits in the areas furthest from the urban perimeter and spending by the public administration models corrective management. However, the drafting of the CONAMA Resolution 307/2002 and the National Policy on Solid Waste Decree 7.404/2010 which regulates Law 12,305, it was established that the generators should be responsible for waste from activities related to construction, encompassing thus minimizing the impacts to the environment and human health. Thus, this picture of neglect with the waste situation began to change. Intending to contribute to this area of knowledge, the present study was aimed to study the situation of the CCW management system for large works, after the implementation of Resolution CONAMA 307/2002 and Decree regulating 7.404/2010 Law 12,305, on the National Policy on Solid Waste. To that end, a study of the CCW management situation was conducted in the demolition and construction of the Arena Fonte Nova in Salvador - Bahia, and in the construction of the Arena Pernambuco in São Lourenço da Mata - PE, performed for the FIFA World Cup 2014, through three stages of study: analysis of variables and local indicators, qualitative characterization of the waste and, finally, comparing the $\mathrm{CCW}$ management as recommended in both laws. This research used the qualitative methodology of the $\mathrm{CCW}$, through field observations and interviews, in order to identify and analyze the management of these same works and its main importance to help manufacturers of major works to make a self- evaluation of its management and solid waste management. Therefore, 
it was concluded that the works researched met the requirements of laws and that to have an effective management system of civil construction waste, must influence cultural change in the people, in order to enhance comprehension and compliance of environmental needs.

Keywords: Civil construction waste. Civil construction waste management. Large construction works. 



\section{INTRODUÇÃo}

A indústria da construção exerce uma grande contribuição para o desenvolvimento das economias dos países, principalmente se considerada a quantidade de empregos gerados e a influência direta em todos os setores que produzem insumos, equipamentos e serviços para utilização no seu processo produtivo.

Conforme Melo (2001), no âmbito nacional, a construção civil sempre foi considerada muito importante para a economia do país e sua importância está vinculada a fatores tais como elevado emprego de mão de obra - o que representa uma das poucas saídas aceitáveis para um grupo de trabalhadores subescolarizados -, além de exercer grande participação na formação bruta de capital fixo e na geração do Produto Interno Bruto (PIB). Além disso, pode-se considerar a construção civil como uma indústria marcada pela inconstância, em virtude de sucessivas alterações nos projetos executivos, de cenários de trabalho que variam de obra para obra, da temporariedade dos empregos, da falta de padronização do processo produtivo, da grande quantidade de equipes trabalhando num mesmo espaço e, em algumas situações, das severas condições de trabalho, com maior exposição a riscos do que grande parte de outros setores de atividades.

De acordo com a Pesquisa Anual da Indústria da Construção de 2008 (IBGE, 2008), a expansão do setor da construção acompanhou o crescimento de 5,1\% do PIB, a atividade de construção cresceu 8,9\% e a elevação real da formação bruta de capital fixo avançou 13,8\%, maior desenvolvimento desde 1996. A atividade empresarial da construção foi influenciada, positivamente, por um conjunto de fatores diretamente relacionados à dinâmica do setor, tais como: crescimento da renda familiar e do emprego; aumento nas operações de crédito direcionadas à habitação; e a estratégia do governo federal na redução do Imposto sobre Produtos Industrializados (IPI) de diversos insumos da construção.

Atualmente, mesmo com um considerável número de obras de infraestrutura em andamento em todo o país, impulsionadas, principalmente, pelo Programa de Aceleração do Crescimento (PAC) do governo federal, segundo a $44^{\text {a }}$ Sondagem Nacional da Indústria da Construção do SINDUSCON-SP (SINDUSCON, 2011), as empresas acreditam que o crescimento do país atingiu um patamar elevado e deve se acomodar em breve. Esse fato está fortemente relacionado à própria capacidade do país de suportar o ritmo registrado no primeiro semestre do ano de 2010, em que um novo salto irá requerer um esforço adicional em várias frentes, como maiores investimentos em capacitação de mão de obra e em tecnologia. 
Por outro lado, de acordo com o Estudo Setorial da Construção Civil (DIEESE, 2010), a indústria da construção, em razão do seu desempenho favorável, promete ser o motor de crescimento da economia nos próximos anos. Motivado pelas obras do Programa Minha Casa Minha Vida, pela Copa do Mundo de 2014, Jogos Olímpicos de 2016, planos de investimentos da Eletrobrás e Petrobras, além do Programa de Aceleração do Crescimento (PAC) 1 e 2, o setor espera retomar o ciclo de crescimento interrompido pela crise financeira mundial, iniciada em 2008, e a crise da comunidade europeia (OECD), iniciada no segundo semestre de 2010.

Duas das muitas obras a serem executadas para a Copa do Mundo de 2014 serão utilizadas como referência para essa pesquisa: a construção da Arena Pernambuco, em São Lourenço da Mata-PE, e a demolição e construção da Arena Fonte Nova, em Salvador-BA.

Os altos números de obras que serão executadas no país têm, em sua maioria, a característica de serem de grande porte, em virtude das quantidades de insumos envolvidos para a execução dos serviços, sejam eles materiais, equipamentos ou mão de obra.

As obras de grande porte ou construções pesadas são executadas por grandes empresas, definidas assim por empregarem mais de 250 pessoas e apresentarem um volume de negócios que excede 100 milhões de reais (DCCE, 2003). Como construções pesadas, podem-se considerar as construções de infraestrutura, urbanas e industriais; obras estruturais e de saneamento básico; barragens e usinas geradoras de energia, dentre outras (SENAI, 1995).

Em geral, cada obra pode ser definida como um projeto, em razão do esforço temporário empreendido para criar um produto, serviço ou resultado exclusivo (PMI, 2008), e seu gerenciamento pode ser aplicado e integrado a cinco grupos de processos, sendo eles: iniciação; planejamento; execução; monitoramento e controle; e encerramento.

A arte de gerenciar envolve diversos fatores, sejam eles tangíveis ou intangíveis. Os fatores tangíveis - técnicos - englobam as especificações necessárias, metodologias aplicáveis e informações importantes que possam influenciar nas tomadas de decisões. Os fatores humanos, aqueles intangíveis, dependem da habilidade do gerente em liderar sua equipe com características e qualidades diferentes que podem vir a provocar divergências se não forem orquestradas da melhor forma (CHAGAS, 2008).

O planejamento da obra, segundo Mattos (2010), é um dos principais aspectos do gerenciamento. A deficiência no planejamento, e no seu controle e acompanhamento, está entre as principais causas da baixa produtividade do setor da construção, de suas elevadas perdas e da baixa qualidade de seus produtos, o que acaba trazendo consequências desastrosas para uma obra e, por extensão, para as empresas que a executam. 
A geração dos resíduos da construção civil pode ser considerada como uma consequência dessas deficiências no planejamento, uma vez que a falta de definição de etapas e atividades gera desperdícios e perdas.

Para que a obra evite essas perdas e desperdícios, faz-se necessário, então, realizar a gestão e o gerenciamento dos resíduos da construção civil (RCC), que pode ser tratado como uma habilidade de se gerir os diversos recursos da construção civil de forma a minimizar e até eliminar a geração dos resíduos, administrando a disposição daqueles que não puderem ser tratados ou reutilizados e evitando o menor prejuízo possível ao meio ambiente. Nesse gerenciamento, os aspectos intangíveis estariam contemplados na mão de obra utilizada para a execução dos serviços de engenharia, ou seja, aqueles trabalhadores da área de produção da obra, e na mão de obra necessária para fazer a separação dos resíduos gerados na própria obra. Os aspectos tangíveis abrangeriam todas as técnicas utilizadas nessa execução e separação.

Contudo, nas obras de grande porte, é elevado o número de variáveis envolvidas. São aquelas relacionadas não apenas com a natureza do projeto, mas também com as diversas metodologias construtivas utilizáveis para a execução de cada um, em que todas elas são bastante dinâmicas e com seus respectivos graus de risco (CHAGAS, 2008).

Uma boa gestão seguida de um gerenciamento adequado da obra conduz à separação dos resíduos de construção civil na fonte, fator essencial para viabilizar a implantação de procedimentos de reutilização e reciclagem, conforme preconizado na Resolução do Conselho Nacional do Meio Ambiente (CONAMA). Caso isso não ocorra, alguns problemas poderão ser gerados nessas obras de grande porte, como gastos com transporte, aluguel de caçambas, disposição final em aterros de RCC, além de prejuízos causados pela perda de materiais novos.

Com isso, faz-se necessário antever o desenvolvimento de todo o projeto, identificando e ordenando as variáveis supracitadas, de tal forma que se possam facilitar todas as etapas do gerenciamento, ou seja, planejar toda a execução do empreendimento.

Diante do exposto, esta pesquisa visa analisar o gerenciamento dos resíduos de construção civil para obras de grande porte, envolvendo os serviços preliminares de preparação do terreno, demolição e da construção propriamente dita, com reutilização e reciclagem dos insumos de projeto.

A importância de fazer esse gerenciamento pode ser estabelecida abordando os seguintes aspectos: ambiental, social, econômico e empresarial.

Do ponto de vista ambiental, o gerenciamento está diretamente relacionado ao meio ambiente, que sofre com os efeitos nocivos da geração dos resíduos sólidos, principalmente se 
considerada a exploração das jazidas naturais e sua disposição inadequada, além de considerarmos a necessidade de grandes áreas para a disposição final, visto que os RCC são volumosos, o que acaba se transformando em grandes gastos para as empresas geradoras.

Esses prejuízos ambientais acabam se refletindo no âmbito social, uma vez que a sociedade sofrerá direta e indiretamente com os problemas supracitados, além da multiplicação de vetores e doenças nas áreas de descarte inadequado. Segundo Marques Neto (2009), outro problema social observado está relacionado às pessoas que têm como única forma de sobrevivência a atividade de catação de lixo, vivendo, muitas delas, próximas às áreas de deposição. Além disso, há o aumento da função de catadores autônomos na área de coleta de resíduos recicláveis, o que indiretamente influencia a economia local.

Do ponto de vista econômico, ainda segundo Marques Neto (2009), estão todos os custos de limpeza pública para remoção eficiente e disposição adequada dos resíduos sólidos, que são serviços executados pelas prefeituras de forma corretiva. Além disso, há os gastos com saúde pública, devido à multiplicação de vetores e doenças nas áreas de descarte inadequado de resíduos, conforme supracitado. Esses custos acabam refletindo em toda a sociedade pela utilização do dinheiro público para fins que poderiam ser evitados ou minimizados.

Finalmente, no âmbito empresarial, observa-se a sustentabilidade econômica e ambiental das empresas e sua imagem perante a sociedade, uma vez que, conforme a Resolução CONAMA, é de obrigação do gerador a destinação final dos resíduos. Logo, a falta de gerenciamento dos RCC levará a um maior custo com a administração desses resíduos, seja ele relacionado ao descarte correto ou à reutilização e reciclagem dos mesmos. A relação é direta: quanto maior a geração de resíduos, maiores os custos com eles.

Além disso, esta pesquisa tem como importância ajudar as empresas a fazerem uma autoavaliação de seu gerenciamento de resíduos sólidos. Por se tratar de um tema inserido em uma das linhas de pesquisa do curso de Hidráulica e Saneamento da Escola de Engenharia de São Carlos, é importante para a universidade, por serem raros os trabalhos que associam o gerenciamento de RCC com obras de grande porte. E para o pesquisador, a importância está no enriquecimento e aprofundamento dos conhecimentos técnicos ao realizar uma pesquisa bibliográfica nesse tema. Consequentemente, seus resultados trarão benefícios para o pesquisador, a universidade, as empresas e a sociedade, uma vez que outras instituições poderão utilizar as informações coletadas e as conclusões do trabalho em questão. 


\section{OBJETIVOS}

\subsection{OBJETIVO PRINCIPAL}

Analisar o gerenciamento dos resíduos da construção civil (GRCC) adotado em duas obras de grande porte: construção da Arena Pernambuco-PE e da Arena Fonte Nova-BA, após a regulamentação das Resoluções CONAMA no 307/2002, 431/2011 e 448/2012 e da Política Nacional de Resíduos Sólidos, Decreto $n^{\circ} 7.404 / 2010$ que regulamenta a Lei $n^{\circ}$ 12.305 .

\subsection{OBJETIVOS ESPECÍFICOS}

a) Verificar a existência de projeto de gerenciamento de resíduos da construção civil nas obras em estudo. No caso de haver o projeto, analisá-lo, criticamente, à luz da Resolução CONAMA no 307/2002 e suas atualizações;

b) Definir os principais indicadores e técnicas de avaliação do gerenciamento dos resíduos da construção civil (GRCC) adotado nas duas obras em estudo;

c) Proceder à análise comparativa do modelo de gerenciamento de RCC adotado nas obras e o preconizado pela literatura existente. 


\section{REVISÃO BIBLIOGRÁFICA}

\subsection{OBRAS DE GRANDE PORTE}

As obras de grande porte ou construções pesadas são assim consideradas em razão de grandes quantidades de insumos envolvidos para a execução dos serviços, sejam eles materiais, equipamentos ou mão de obra. Estas obras são executadas por grandes empresas, definidas como empresas que empregam mais de 250 pessoas e cujo volume de negócios excede 100 milhões de reais (DCCE, 2003).

De acordo com Laufer e Tenah (1985), uma empresa de porte médio é considerada como aquela que gerencia de cinco a dez projetos simultaneamente, cada um representando um total de 200 mil a 1 milhão de homem-hora. Logo, podemos definir uma empresa de grande porte como aquela que gerencia mais de dez projetos simultaneamente, sendo cada projeto com um número superior a 1 milhão de homem-hora.

Nas atividades da construção pesada, de acordo com o Estudo Setorial da Construção Civil, realizado pelo SENAI (1995), estão incluídas as construções de infraestrutura, urbanas e industriais; obras estruturais e de saneamento básico; barragens e usinas geradoras de energia, dentre outras.

Segundo a Pesquisa Anual da Indústria da Construção de 2008 (IBGE, 2008), obras de infraestrutura são caracterizadas pela presença de médias e grandes empresas. As construções pesadas são caracterizadas por diversos tipos de construção, os quais compreendem as obras de infraestrutura - autoestradas, vias urbanas, pontes, túneis, ferrovias, metrôs, pistas de aeroportos, portos e projetos de abastecimento de água, sistemas de irrigação, sistemas de esgoto, instalações industriais, redes de transporte por dutos (gasodutos, minerodutos, oleodutos) e linhas de eletricidade, instalações esportivas -, além das construções de estruturas pré-fabricadas in loco para fins diversos, de natureza permanente ou temporária, exceto edifícios.

No âmbito geral, cada obra de construção civil pode ser definida como um projeto, por se tratar de um esforço temporário empreendido para criar um produto, serviço ou resultado exclusivo (PMI, 2008), e seu gerenciamento pode ser realizado com base na aplicação e integração de cinco grupos de processos, sendo eles: iniciação; planejamento; execução; monitoramento e controle; e encerramento, no qual há definições e escolhas significativas para o gerenciamento da obra. 


\subsection{A CONSTRUÇÃO CIVIL}

O setor da construção civil engloba as edificações, obras viárias e a construção pesada, sendo esta última considerada como obra de grande porte. $\mathrm{O}$ seu macrossetor é definido como o setor da construção civil, acrescido dos segmentos fornecedores de matérias-primas e equipamentos para a construção e dos setores de serviços e distribuição ligados à construção. Por meio deste conceito é possível avaliar os efeitos multiplicadores setoriais da indústria de construção sobre o processo produtivo, sua enorme capacidade de realização de investimentos, o seu potencial de criação de empregos (diretos e indiretos), além de seus efeitos benéficos sobre a balança comercial e sobre o nível de inflação (CBIC, 1998).

Ainda que o macrossetor da construção civil seja composto por diversos segmentos, a construção em si possui maior importância na cadeia produtiva, se considerada sua representatividade de $65 \%$ na composição da cadeia produtiva e o fato dela ser a principal consumidora dos demais materiais e serviços componentes desta cadeia, conforme pode ser observado no Gráfico 1 do banco de dados do CBIC (2010).

Gráfico 1 - Composição da cadeia produtiva da construção civil - 2009

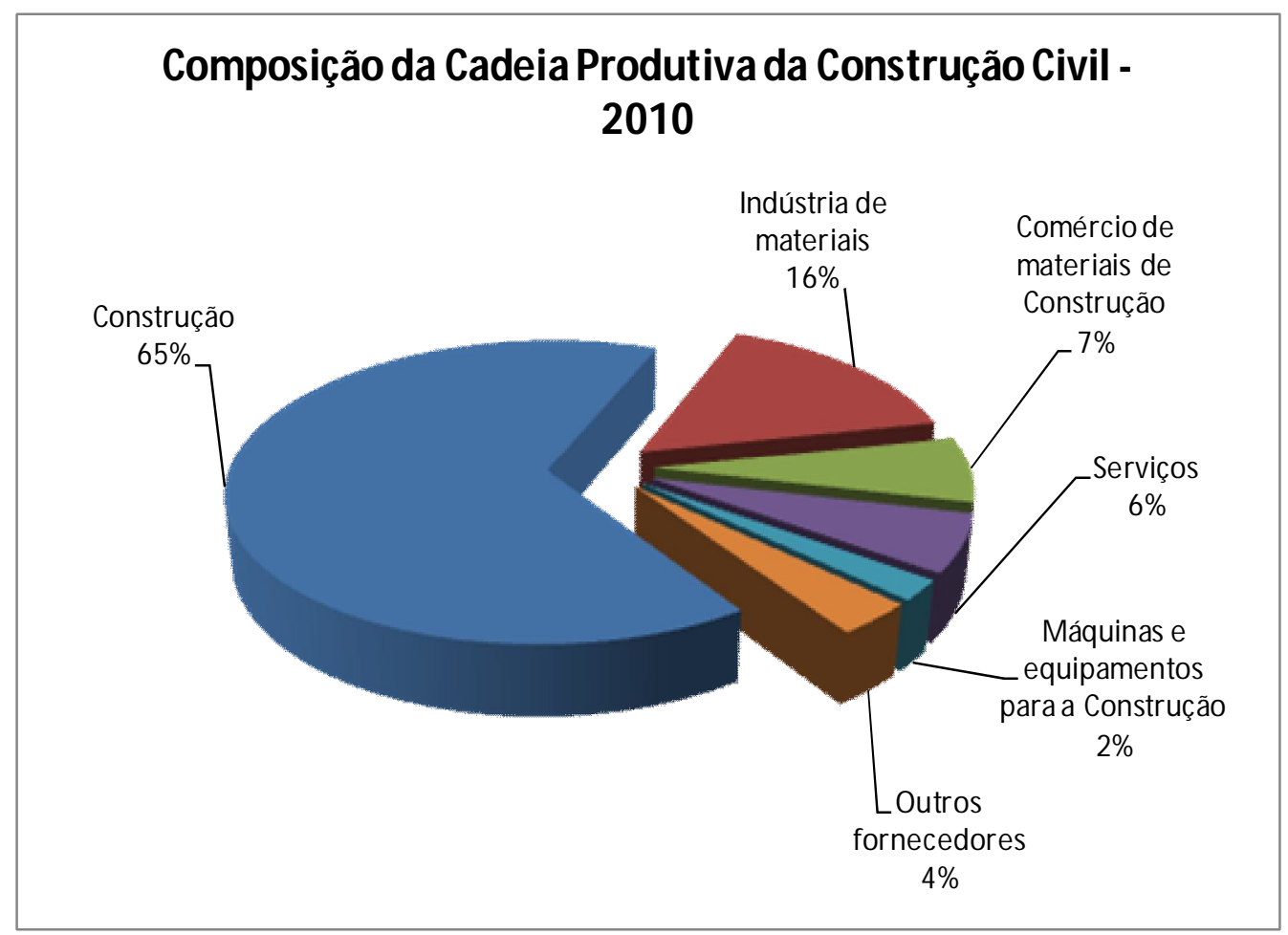

Fonte: CBIC (2010). 
A importância desse macrossetor pode ser retratada em números, e sua participação no Produto Interno Bruto da economia pode ser analisada na Tabela 1.

Tabela 1 - Participação (\%) do PIB da construção civil no PIB total do Brasil 2000-2010

\begin{tabular}{|c|c|}
\hline Ano & Construção Civil no Brasil (\%) \\
\hline 2000 & 5,5 \\
2001 & 5,3 \\
2002 & 5,3 \\
2003 & 4,7 \\
2004 & 5,1 \\
2005 & 4,9 \\
2006 & 4,7 \\
2007 & 4,9 \\
2008 & 4,9 \\
2009 & 5,3 \\
2010 & 5,3 \\
\hline
\end{tabular}

Fonte: IBGE (2010).

A construção civil foi um dos principais motores do setor industrial no segundo trimestre de 2010. Em relação ao segundo trimestre de 2009, o segmento cresceu 16,4\%. Com isso, as atividades de construção civil apresentaram variação recorde na série iniciada em 1996. Dessa forma, pela ótica da produção, foi o principal setor que impulsionou o PIB no segundo trimestre de 2010 (IBGE, 2010).

A força da impulsão do negócio da cadeia da construção, também conhecido como construbusiness, representa uma participação expressiva nos investimentos globais do país. Além disso, o construbusiness gera extraordinários efeitos multiplicadores sobre os demais setores de atividade, em que o índice de encadeamento da construção ocupa o $4^{\circ}$ lugar no ranking da economia nacional e o setor construtor movimenta cerca de $\mathrm{R} \$ 48$ bilhões no seu encadeamento para frente (CBIC, 1998).

Em 2009, as despesas com produtos da construção somaram R 244 bilhões. Isso significa que o total de investimentos realizados no país em estradas, aeroportos, redes de esgoto, enfim, em toda a infraestrutura, consideradas como obras de grande porte, e mais em escolas, hospitais, casas e edifícios residenciais e comerciais, indústrias, obras de manutenção 
e reformas, atingiu $46,4 \%$ do total do investimento realizado no país, ou $9,2 \%$ do PIB brasileiro no ano de 2009 (CADERNO..., 2010).

O PIB, por definição, mede toda riqueza gerada por uma economia em um período. Dessa forma, a elevação do valor do PIB é interpretada como crescimento econômico. Contudo, tal crescimento não assegura desenvolvimento. Desenvolvimento econômico é um conceito mais amplo, que além do crescimento do produto interno, está relacionado ao nível de desigualdade e de bem-estar da população, como o Índice de Desenvolvimento Humano (IDH) (OLIVEIRA; MATA; CUNHA, 2011).

O conceito de Desenvolvimento Humano, que é a base do conceito do IDH, parte do pressuposto de que para aferir o avanço na qualidade de vida de uma população é preciso ir além do viés puramente econômico e considerar três dimensões básicas do desenvolvimento humano: renda, saúde e educação (PNUD, 2012).

A renda, saúde e educação são os três pilares que constituem o IDH, e, atualmente, são mensurados da seguinte forma: o padrão de vida (renda) é medido pela Renda Nacional Bruta (RNB) per capita, uma vida longa e saudável (saúde) é medida pela expectativa de vida e o acesso ao conhecimento (educação) é medido pela média de anos de educação de adultos, que é o número médio de anos de educação recebidos durante a vida por pessoas a partir de 25 anos; e pela expectativa de anos de escolaridade para crianças na idade de iniciar a vida escolar, que é o número total de anos de escolaridade que um criança na idade de iniciar a vida escolar pode esperar receber se os padrões prevalecentes de taxas de matrículas específicas por idade permanecerem os mesmos durante a vida da criança (PNUD, 2012).

O objetivo da criação do IDH foi o de oferecer um contraponto a outro indicador muito utilizado, o Produto Interno Bruto (PIB) per capita, que considera apenas a dimensão econômica do desenvolvimento. Ele pretende ser uma medida geral, sintética, do desenvolvimento humano. Apesar de ampliar a perspectiva sobre o desenvolvimento humano, o IDH não abrange todos os aspectos de desenvolvimento e não é uma representação da "felicidade" das pessoas, nem indica "o melhor lugar no mundo para se viver" (PNUD, 2012).

Na Ciência Econômica, o PIB é tido como um indicador de desempenho econômico. É válido refletir a importância dada ao PIB para a mensuração do crescimento de um país ou localidade. Diante do crescimento do PIB, diz-se que a economia está aquecida. As consequências diretas são o crescimento dos postos de trabalho com redução da taxa de desemprego e elevação do poder de compra. Por outro lado, verifica-se também a tendência de aumento da taxa de inflação. No final das contas, o crescimento do PIB é interpretado como algo positivo e altamente desejável (OLIVEIRA; MATA; CUNHA, 2011). 
Com todos os investimentos realizados no país, a despesa em produtos da construção por habitante atingiu $\mathrm{R} \$ 1.276,06$. Por sua vez, as remunerações do trabalho atingiram $\mathrm{R} \$$ 93,9 bilhões, ou 42\% da renda gerada na cadeia da construção civil. O excedente operacional bruto, que é um valor residual da renda que contabiliza a remuneração do capital (juros, lucros e aluguéis), foi, em 2009, de R \$ 128,2 bilhões (CADERNO..., 2010).

Em especial, vale destacar a potência do setor da construção na geração de empregos na economia. No que se refere ao emprego, chegou-se a um número histórico, uma vez que as atividades da cadeia da construção ocuparam 10 milhões de pessoas em todo o país.(CADERNO..., 2010).

A maior parcela da renda da cadeia da construção - 61\%, ou $\mathrm{R} \$ 137,378$ bilhões, em 2009 - foi gerada no setor da construção, formado pelos segmentos de autogestão e autoconstrução e pelas construtoras que executam obras ou etapas das obras de engenharia. É esse segmento que determina o ritmo de atividade dos demais elos da cadeia. Por ser muito intensivo em mão de obra, o setor da construção respondeu pela maior parcela de ocupados na cadeia, 69\%, ou 6,9 milhões, como mostra o Gráfico 2 (CADERNO..., 2010).

Gráfico 2 - Pessoal ocupado na cadeia de construção, participação (\%) no total, 2009

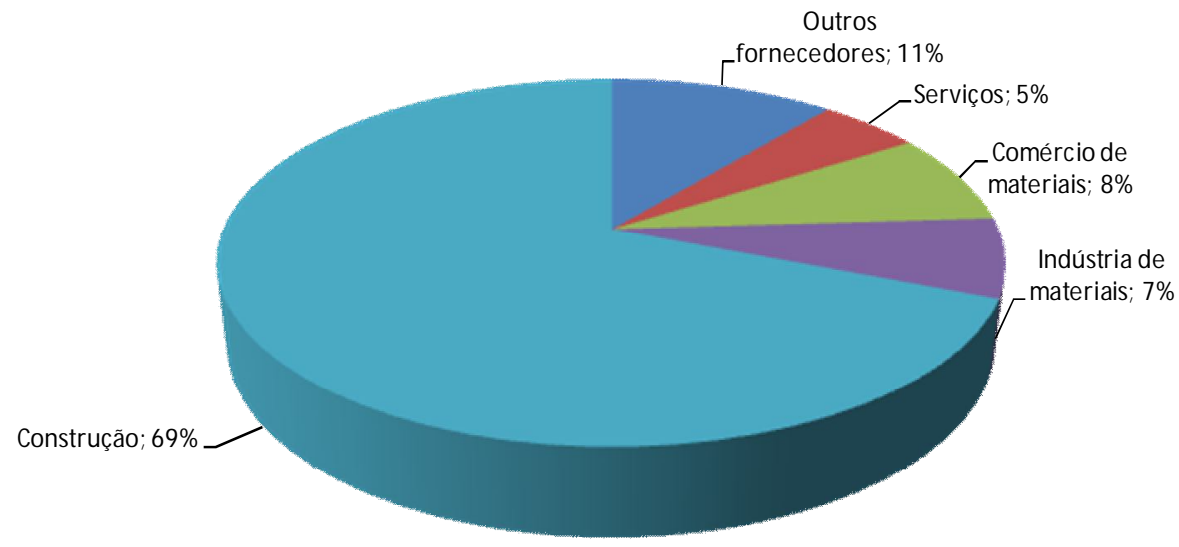

Fonte: IBGE (2010).

De acordo com a Pesquisa Anual da Indústria da Construção (IBGE, 2009), em 2009, o universo de empresas da indústria da construção abrangeu em torno de 64 mil empresas ativas, que empregaram cerca de 2 milhões de pessoas. $\mathrm{O}$ gasto total com mão de obra correspondeu a 30,3\% do total dos custos e despesas das empresas de construção, resultado superior à participação em 2008 (29,2\%), e atingiu o valor de $\mathrm{R} \$ 48,3$ bilhões, dos quais $\mathrm{R} \$$ 31,8 bilhões foram em salários, retiradas e outras remunerações. O salário médio mensal 
avançou 9,2\%, passando de $\mathrm{R} \$ 1.095,00$ em 2008, para $\mathrm{R} \$ 1.196$ em 2009, entretanto, em relação aos salários mínimos, houve ligeira queda, de 2,7 para 2,6 salários mínimos mensais, que não deve ser entendida como perda de poder aquisitivo, mas sim como consequência do reajuste de $12,6 \%$ do valor do salário mínimo, que obteve ganho real de 7,9\% entre esses dois anos.

Conforme pode ser observado na Tabela 2, as empresas de construção realizaram incorporações, obras e serviços no valor de R\$199,5 bilhões, registrando expansão na comparação com o ano anterior. Excluindo-se as incorporações, o valor das obras e serviços da construção atingiu R $\$ 193,7$ bilhões, sendo, deste montante, $\mathrm{R} \$ 85,5$ bilhões vindos das obras contratadas por entidades públicas, que representaram $44,1 \%$ do total das construções, participação ligeiramente maior do que a verificada em 2008 (43,2\%), e a receita operacional líquida avançou entre 2008, com R \$ 154,6 bilhões, e 2009, R \$ 189,0 bilhões (IBGE, 2009).

Tabela 2 - Dados gerais da indústria da construção - Brasil - 2008-2009

\begin{tabular}{|c|c|c|c|c|c|c|c|c|c|}
\hline \multirow{3}{*}{ Ano } & \multicolumn{9}{|c|}{ Dados gerais da indústria da construção } \\
\hline & $\begin{array}{c}\text { Número de } \\
\text { empresas } \\
\text { ativas }\end{array}$ & $\begin{array}{l}\text { Pessoal } \\
\text { ocupado }\end{array}$ & $\begin{array}{c}\text { Salários, } \\
\text { retiradase } \\
\text { outras } \\
\text { remunerações }\end{array}$ & $\begin{array}{c}\text { Gastos com } \\
\text { pessoal }\end{array}$ & $\begin{array}{l}\text { Total dos } \\
\text { custos e } \\
\text { despesas }\end{array}$ & \begin{tabular}{|c|} 
Valor das \\
incorporações, \\
obras e \\
serviçoes \\
\end{tabular} & $\begin{array}{c}\text { Valos das } \\
\text { obras e/ou } \\
\text { serviços }\end{array}$ & \begin{tabular}{|c|} 
Construções \\
para \\
entidades \\
públicas \\
\end{tabular} & $\begin{array}{l}\text { Receita } \\
\text { operacional } \\
\text { líquida }\end{array}$ \\
\hline & \multicolumn{2}{|c|}{1.000} & \multicolumn{7}{|c|}{$1.000 .000 \mathrm{R} \$$} \\
\hline 2008 & 57 & 1.806 & 25.718 & 38.725 & 132.830 & 163.109 & 158.693 & 68.607 & 154.597 \\
\hline 2009 & 64 & 2.048 & 31.847 & 48.288 & 159.171 & 199.547 & 193.747 & 85.490 & 189.031 \\
\hline
\end{tabular}

Fonte: IBGE (2009).

A indústria de materiais é o segundo setor que mais adicionou valor dentro da cadeia: foram R\$ 40,4 bilhões, ou $18 \%$ do PIB da cadeia gerados por 616 mil pessoas. Depois da construção civil, a comercialização de materiais de construção - representada pelo comércio atacadista e varejista - possui o maior número de ocupados, 811,6 mil pessoas, que em 2009 geraram um valor adicionado de $\mathrm{R} \$ 20,503$ bilhões, ou 9,1\% do total gerado na cadeia (CADERNO..., 2010).

As atividades de prestação de serviços, que compreendem a incorporação, a compra e a venda de imóveis, o aluguel de máquinas e equipamentos e os serviços técnicos profissionais, como os de projetos de engenharia e arquitetura, geraram $\mathrm{R} \$ 17,4$ bilhões, ou 7,7\% do PIB da cadeia, e foram responsáveis por 5\% dos ocupados, ou 505 mil pessoas. Esses dados podem ser analisados na Tabela 3 (CADERNO..., 2010). 
Tabela 3 - Produção, renda e ocupação na cadeia da construção, 2009, em R\$ milhões

\begin{tabular}{|c|c|c|c|c|c|}
\hline & \multicolumn{5}{|c|}{ Elos de produção } \\
\hline & \multirow{2}{*}{$\begin{array}{l}\text { Outros elos } \\
\text { (A) }\end{array}$} & \multicolumn{2}{|c|}{ Indústria } & \multirow{2}{*}{$\begin{array}{c}\text { Construção } \\
\text { Civil (D) }\end{array}$} & \multirow{2}{*}{$\begin{array}{c}\text { Total da Cadeia } \\
(A+B+C+D)\end{array}$} \\
\hline & & $\begin{array}{l}\text { de máquinas e } \\
\text { equipamentos (B) }\end{array}$ & $\begin{array}{c}\text { de materiais } \\
\text { (C) }\end{array}$ & & \\
\hline Valos adicionado, PIB & 41.667 & 4.859 & 40.393 & 137.378 & 224.297 \\
\hline Remunerações & 24.371 & 2.290 & 15.253 & 51.967 & 93.881 \\
\hline Excedente operacional bruto e rendimento misto bruto & 16.314 & 2.508 & 24.434 & 84.901 & 128.157 \\
\hline Outros impostos sobre a produção e subsídios & 982 & 61 & 706 & 510 & 2.259 \\
\hline Consumo intermediário & 59.463 & 7.670 & 53.812 & 106.987 & 227.932 \\
\hline Valor da produção & 101.131 & 12.529 & 94.204 & 244.365 & 452.229 \\
\hline Fator trabal ho (ocupações) & 2.413 .789 & 46.355 & 615.715 & 6.942 .644 & 10.018 .503 \\
\hline
\end{tabular}

Fonte: IBGE (2010).

A receita tributária oriunda das atividades da cadeia da construção civil somou $R$ \$ 45,9 bilhões em 2009, o que representou 20,5\% do seu PIB. Somente o setor da construção respondeu por 56,6\% da carga total, ou R \$ 25,9 bilhões (CADERNO..., 2010).

Outra característica importante da construção é o seu reduzido coeficiente de importação, que alcança menos que $2 \%$ de sua demanda total. Dessa forma, o crescimento do setor não pressiona a balança comercial e o balanço de pagamentos do país. Em princípio, a construção é uma indústria que não depende de financiamentos externos, e os incrementos dos custos da construção são perfeitamente compatíveis com a taxa média da inflação brasileira (CBIC, 1998).

A atividade empresarial da construção foi influenciada positivamente por um conjunto de fatores diretamente relacionados com a dinâmica do setor, tais como: crescimento da renda familiar e do emprego; acréscimo no consumo das famílias; aumento do crédito; maior oferta de crédito imobiliário; crescimento nos desembolsos do Banco Nacional de Desenvolvimento Econômico e Social (BNDES); expansão das obras realizadas pelo Programa de Aceleração do Crescimento (PAC), que impulsionaram principalmente as obras de infraestrutura; e a redução do Imposto sobre Produtos Industrializados (IPI) de diversos materiais de construção (IBGE, 2009).

Os números de 2009 são resultados de um ciclo de crescimento iniciado em 2005 e que alcançou seu auge em 2008. A crise financeira internacional teve, em 2009, reflexos expressivos no desempenho de toda a cadeia, mas não mudou a trajetória de longo prazo. Entre 2005 e 2009, os investimentos em construção passaram de R \$ 167,7 bilhões para R \$ 244,4 bilhões, um crescimento acumulado de $46 \%$ (10,3\% ao ano), o que representou um aumento de 5,2\% acima do Índice Geral de Preços - Disponibilidade Interna (IGP-DI). O PIB da cadeia produtiva, por sua vez, cresceu $48,5 \%$ nesse período, e as atividades da construção 
cresceram ainda mais: $52,3 \%$, ou 18,2\% acima do índice Nacional de Custo da Construção (INCC) (CADERNO..., 2010).

O crescimento expressivo da cadeia traduziu-se em mais postos de trabalho: entre 2005 e 2009, foi gerado 1,46 milhão de novos empregos. O setor da construção, por ser um dos mais intensivos em mão de obra, respondeu por $73 \%$ desse total. É importante observar que o crescimento da ocupação deu-se com um forte movimento de formalização das atividades, o que se refletiu no aumento expressivo do número de empregados com carteira de trabalho. De dezembro de 2005 a dezembro de 2009, o emprego com carteira no setor da construção registrou crescimento de 45\%, ou 10\% ao ano (CADERNO..., 2010).

A crise financeira internacional, que teve seu momento mais crítico em setembro de 2008, não mudou o sentido do movimento iniciado em 2005, provocando apenas uma redução no ritmo de crescimento. Nesse período, a cadeia participou ativamente na política anticíclica criada para recuperar a rota do crescimento de toda a economia. Dessa forma, a criação do Programa Minha Casa Minha Vida, que veio a se somar ao Programa de Aceleração do Crescimento, e a desoneração de uma cesta de materiais de construção contribuíram efetivamente para a geração de renda e emprego na economia (CADERNO..., 2010).

Em 2009, as atividades da construção foram responsáveis pela criação de 154 mil postos de trabalho formais. Enquanto o PIB da economia permaneceu estagnado, praticamente no mesmo patamar de 2008, o setor da construção apresentou crescimento de 3,8 pontos percentuais acima do INCC. Ainda assim alguns elos da cadeia, como a indústria e o comércio, registraram forte retração no ano. Enquanto no comércio varejista houve declínio de $3,43 \%$ nas vendas, na indústria o faturamento real apresentou queda de $12 \%$ (CADERNO..., 2010).

Portanto, pode-se concluir que a indústria da construção nacional impulsiona a grande maioria dos segmentos produtivos e funciona como força motriz para o desenvolvimento sustentado do país.

Contudo, o construbusiness apresenta importantes impactos ambientais em todas as etapas do seu processo: extração de matérias-primas, produção de materiais, construção, uso e demolição. Esses grandes impactos decorrem de diferentes fatores, entre os quais o enorme peso do macrossetor da construção civil na economia, conforme citado anteriormente. Ele é um dos maiores consumidores de matérias-primas naturais e de enormes quantidades de materiais com significativo conteúdo energético, que necessitam ser transportados a grandes distâncias (CARNEIRO ET AL, 2001). 
As atividades de produção de matérias-primas, de canteiro e até mesmo de manutenção e demolição geram impactos ambientais como resíduos, ruído, poeira, além dos poluentes industriais. Historicamente, a atividade construtora sempre se caracterizou como grande geradora de resíduos e também como potencial consumidora dos resíduos gerados por ela mesma ou por outras atividades humanas de transformação. As características dos resíduos removidos de obras ou recebidos de pequenos coletores revelam uma grande predominância da fração mineral, viabilizadora da introdução de processos sustentáveis, como a reciclagem (CARNEIRO ET AL, 2001).

O macrossetor da indústria da construção civil é o principal gerador de resíduos da economia. De maneira geral, estima-se que ele seja responsável por cerca de $40 \%$ dos resíduos gerados na economia. Segundo Carneiro et al (2001), a redução do impacto ambiental da construção civil é tarefa complexa, tornando-se necessário agir em várias frentes de maneira combinada e simultânea:

a) Minimizar o consumo de recursos (conservar);

b) Maximizar a reutilização de recursos (reutilizar materiais e componentes);

c) Usar recursos renováveis ou recicláveis (renovar / reciclar);

d) Proteger o meio ambiente (proteção da natureza);

e) Criar um ambiente saudável e não tóxico (utilizar não tóxicos);

f) Buscar a qualidade na criação do ambiente construído (aumentar a qualidade).

\subsection{RESÍDUOS SÓLIDOS}

Os resíduos sólidos são gerados em todas as atividades humanas. São subprodutos dos processos econômicos, os quais incluem atividades extrativistas, produção industrial e de serviços, além do consumo e, até mesmo, de preservação ambiental (CARNEIRO ET AL, 2001). Durante muito tempo não havia nenhum cuidado em relação aos seus impactos ao meio ambiente, muito menos à sua destinação final.

A característica típica das deposições irregulares, resultantes da então inexistência de soluções para a captação dos resíduos sólidos, era resultante de uma conjunção de efeitos deteriorantes do ambiente local, incluindo a multiplicação de vetores de doenças (MARQUES NETO, 2009).

Contudo, esse cenário começou a mudar, provocando uma crescente preocupação da sociedade com relação às questões ambientais e ao desenvolvimento sustentável. Diante disso, a Associação Brasileira de Normas Técnicas (ABNT) elaborou critérios de definição e 
classificação dos resíduos sólidos, através da NBR 10.004 (ABNT, 2004), visando fornecer subsídios para o seu gerenciamento e amenizar seus impactos ambientais:

Resíduos nos estados sólido ou semi-sólido, que resultam de atividades de origem industrial, doméstica, hospitalar, comercial, agrícola, de serviços e de varrição. Ficam incluídos nesta definição os lodos provenientes de sistemas de tratamento de água, aqueles gerados em equipamentos e instalação de controle de poluição, bem como determinados líquidos cujas particularidades tornem inviável o seu lançamento na rede pública de esgotos ou corpos de água, ou exijam para isso soluções técnicas e economicamente inviáveis em face à melhor tecnologia disponível.

O significativo impacto ambiental dos resíduos sólidos tem levado diferentes países a adotarem políticas ambientais e atuarem de forma mais rigorosa em relação ao assunto. No Brasil, nos últimos anos, foram elaborados quatro marcos regulatórios que visam oferecer um respaldo legal consistente na gestão e no gerenciamento dos resíduos sólidos no país. Segundo Córdoba (2010), são eles:

a) Lei do Saneamento Básico ${ }^{\circ} 11.445 / 2007$;

b) Lei dos Consórcios Públicos no 11.107/2005 (regulamentado pelo Decreto $\mathrm{n}^{\mathrm{o}}$ 6.071/2007);

c) Lei das Parcerias Público-Privadas nº 11.179/2004;

d) Decreto $n^{\circ}$ 7.404, de 23 de dezembro de 2010, que institui a Lei ${ }^{\circ}$ 12.305/2010, referente à Política Nacional de Resíduos Sólidos.

Segundo a Política Nacional de Resíduos Sólidos, Lei n 12.305/2010, os resíduos sólidos são definidos como

[...] material, substância, objeto ou bem descartado resultante de atividades humanas em sociedade, a cuja destinação final se procede, se propõe proceder ou se está obrigado a proceder, nos estados sólido ou semissólido, bem como gases contidos em recipientes e líquidos cujas particularidades tornem inviável o seu lançamento na rede pública de esgotos ou em corpos d'água, ou exijam para isso soluções técnica ou economicamente inviáveis em face da melhor tecnologia disponível. (BRASIL, 2010).

Essa política classifica os resíduos sólidos segundo alguns critérios:

a) Quanto à origem:

- Resíduos domiciliares;

- Resíduos de limpeza urbana;

- Resíduos sólidos urbanos;

- Resíduos de estabelecimentos comerciais e prestadores de serviços;

- Resíduos dos serviços públicos de saneamento básico; 
- Resíduos industriais;

- Resíduos de serviços de saúde;

- Resíduos da construção civil;

- Resíduos agrossilvopastoris;

- Resíduos de serviços de transportes;

- Resíduos de mineração.

b) Quanto à periculosidade:

- Resíduos perigosos;

- Resíduos não perigosos.

Dessa forma, é possível observar que há necessidade de um planejamento urbano sustentável, para que se obtenha melhorias no meio ambiente e na saúde pública.

\subsection{RESÍDUOS DA CONSTRUÇÃO CIVIL}

Conforme explanado anteriormente, o macrossetor da indústria da construção civil é o principal gerador de resíduos da economia. Esses resíduos gerados são denominados de resíduos da construção civil e definidos pela Política Nacional de Resíduos Sólidos, Lei no 12.305/2010 como:

os resíduos gerados nas construções, reformas, reparos e demolições de obras de construção civil, incluídos os resultantes da preparação e escavação de terrenos para obras civis. (BRASIL, 2010).

A Resolução CONAMA n 307/2002, elaborada "considerando a necessidade de implementação de diretrizes para a efetiva redução dos impactos ambientais gerados pelos resíduos oriundos da construção civil” (BRASIL, 2002), define de forma mais detalhada os resíduos de construção civil como

[...] os provenientes de construções, reformas, reparos e demolições de obras de construção civil, e os resultantes da preparação e da escavação de terrenos, tais como: tijolos, blocos cerâmicos, concreto em geral, solos, rochas, metais, resinas, colas, tintas, madeiras e compensados, forros, argamassa, gesso, telhas, pavimento asfáltico, vidros, plásticos, tubulações, fiação elétrica, etc., comumente chamados de entulhos de obras, caliça ou metralha. (BRASIL, 2002).

Vale informar que o conjunto de normas da Associação Brasileira de Normas Técnicas - NBR 15.112, NBR 15.113, NBR 15.114, NBR 15.115, NBR 15.116 (ABNT, 2004a, 2004b, 
2004c, 2004d, 2004e) - que se referem a esses resíduos reafirmam essa definição, analogamente à disposta na Resolução CONAMA no 307/2002 (CÓRDOBA, 2010).

Além disso, segundo o artigo $3^{\circ}$ e a alteração ocorrida em 24 de maio de 2011, através da Resolução $n^{\circ}$ 431, que estabeleceu nova classificação para o gesso, essa resolução classifica os resíduos da construção civil da seguinte forma,:

I - Classe A - são os resíduos reutilizáveis ou recicláveis como agregados, tais como:

a) De construção, demolição, reformas e reparos de pavimentação e de outras obras de infraestrutura, inclusive solos provenientes de terraplenagem;

b) De construção, demolição, reformas e reparos de edificações: componentes cerâmicos (tijolos, blocos, telhas, placas de revestimentos etc.), argamassa e concreto;

c) De processo de fabricação e/ou demolição de peças pré-moldadas em concreto (blocos, tubos, meios-fios etc.) produzidas nos canteiros de obras;

II - Classe B - são os resíduos recicláveis para outras destinações, tais como: plásticos, papel, papelão, metais, vidros, madeiras e gesso;

III - Classe C - são os resíduos para os quais não foram desenvolvidas tecnologias ou aplicações economicamente viáveis que permitam a sua reciclagem ou recuperação, tais como as louças sanitárias;

IV - Classe D - são os resíduos perigosos oriundos do processo de construção, tais como: tintas, solventes, óleos e outros, ou aqueles contaminados oriundos de demolições, reformas e reparos de clínicas radiológicas, instalações industriais e outros. (BRASIL, 2002).

No país, há uma grande dificuldade de conhecimento e unificação dos dados, através de inventários e levantamentos, relacionados aos resíduos sólidos de maneira geral. Isso pode ser comprovado por meio da implantação, até dezembro de 2012, do Sistema Nacional de Informação sobre a Gestão de Resíduos Sólidos (SINIR), que será coordenado pelo Ministério do Meio Ambiente, agregando as informações da União, Estados, Distrito Federal e Municípios. Este Sistema será um dos instrumentos da Política Nacional de Resíduos Sólidos (PNRS) (Lei 12.305/2010 e Decreto 7.404/2010). O SINIR terá como objetivo a coleta e sistematização de dados relativos à prestação de serviços públicos e privados de gestão e gerenciamento de resíduos; a disponibilização de estatísticas, indicadores e informações que facilitem a caracterização da oferta e da demanda dos serviços necessários; a promoção do acesso, organização e disseminação das informações, de acordo com a importância e confidencialidade necessárias; o monitoramento e a avaliação da eficiência da prestação dos serviços públicos de limpeza urbana e manejo de resíduos sólidos. Além disso, o monitoramento e a avaliação dos resultados, impactos e metas dos planos e ações de gestão nos diversos níveis, incluindo os sistemas de logística reversa, informando a sociedade, periodicamente, acerca da situação dos resíduos sólidos no país e das atividades realizadas 
para a implantação plena da PNRS. Este sistema será muito importante, pois ajudará na realização de um gerenciamento de resíduos mais adequado, o que não tem ocorrido.

Entretanto, atualmente, a entidade que atualiza a situação do setor com informação sobre os resíduos sólidos no Brasil, facilitando a consulta de dados, projeções e análises, apresentando a dimensão, os avanços e os atuais problemas do setor, de maneira a possibilitar um melhor equacionamento para as soluções demandadas, é a Associação Brasileira de Empresas de Limpeza Pública e Resíduos Especiais (ABRELPE). Ela divulga anualmente o Panorama dos Resíduos Sólidos no Brasil. Em 2011, foram divulgados alguns dados de 2010 relevantes para esta pesquisa. Esses dados, que são comparativos dos anos de 2009 e 2010, mostram alguns avanços significativos na qualidade dos serviços relacionados à gestão de resíduos, além de revelar a grande dimensão dos trabalhos que deverão ser realizados para se atingir a universalização de toda a cadeia (ABRELPE, 2010).

Em relação às perspectivas trazidas pela PNRS, um novo cenário se delineia no horizonte nacional e, certamente, abrirá novos caminhos e trará novos desafios para todos os setores envolvidos, que contam com um importante instrumento para auxiliá-los nesse processo de mudança. (ABRELPE, 2010)

A geração de resíduos sólidos urbanos (RSU) no Brasil registrou um crescimento expressivo de 2009 para 2010, superando a taxa de crescimento populacional urbano, que foi de cerca de $1 \%$ no período, conforme demonstram os dados apresentados no Gráfico 3. A comparação da quantidade total gerada em 2010 com o total de resíduos sólidos urbanos coletados, indicado no Gráfico 4, mostra que 6,7 milhões de toneladas de RSU deixaram de ser coletados no ano de 2010, e, por consequência, tiveram destino impróprio (ABRELPE, 2010).

Gráfico 3 - Geração de resíduos sólidos urbanos

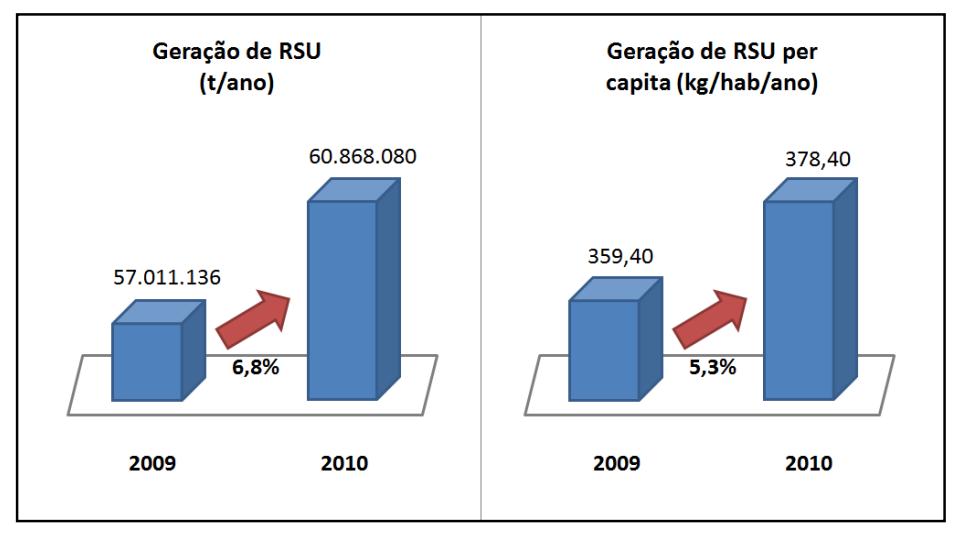

Fonte: ABRELPE (2010). 
O Gráfico 4 mostra que houve um aumento de $7,7 \%$ na quantidade de RSU coletados em 2010, conforme demonstrado pela comparação com o total coletado em 2009. Na comparação entre o índice de crescimento da geração de RSU e o índice de crescimento da coleta, percebe-se que este último foi ligeiramente maior do que o primeiro, o que demonstra um discreto aumento na cobertura dos serviços de coleta de RSU no país (ABRELPE, 2010).

Gráfico 4 - Coleta de resíduos sólidos urbanos no Brasil

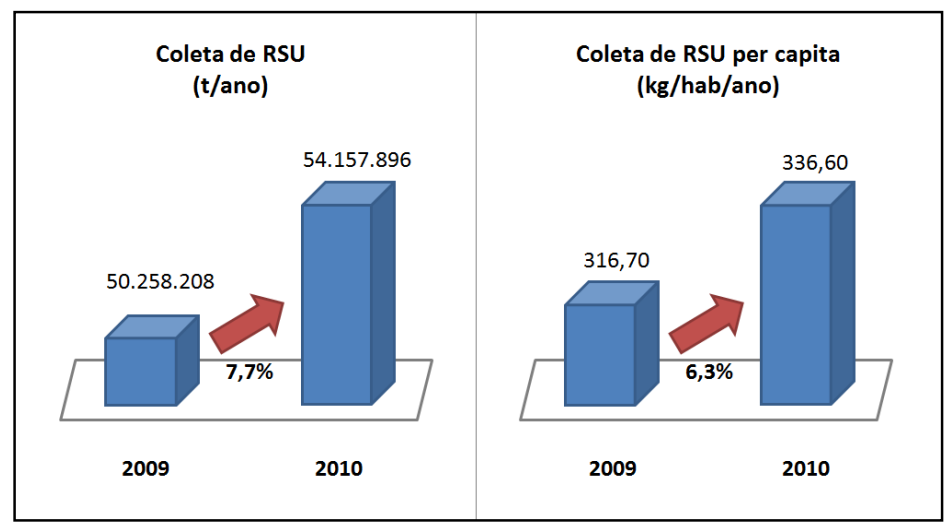

Fonte: ABRELPE (2010).

Conforme mostra o Gráfico 5, os municípios coletaram cerca de 31 milhões de toneladas de RCC - em 2010, 8,7\% a mais do que em 2009 -, e as quantidades são expressivas em todas as regiões do país, o que exige atenção especial dos municípios no destino final dado a esses resíduos, principalmente porque as quantidades reais são ainda maiores, visto que os municípios, em geral, coletam somente os RCC lançados nos logradouros públicos (ABRELPE, 2010). 
Gráfico 5 - Total de RCC coletados por região e Brasil em 2010 e 2009

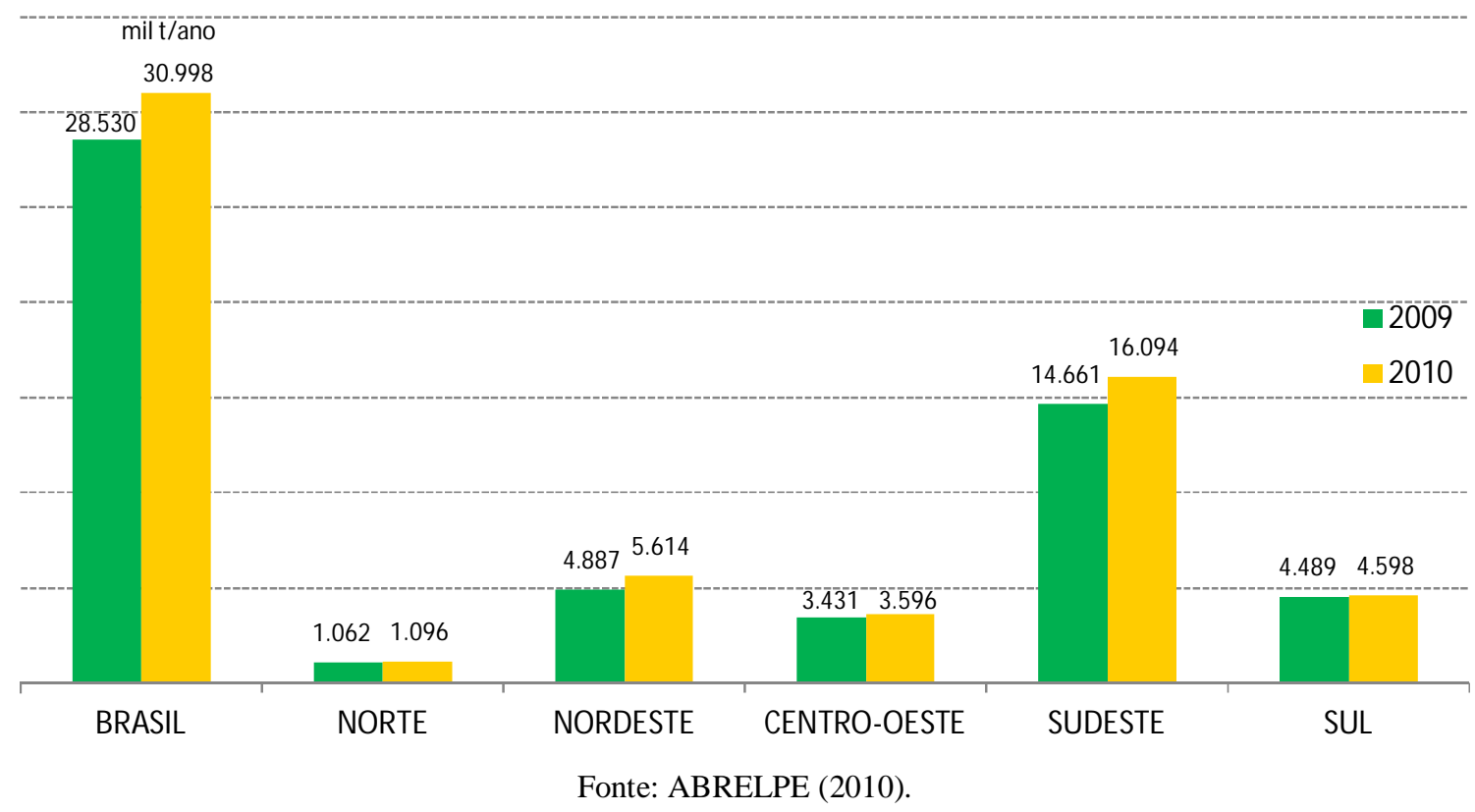

Nos termos da Política Nacional de Resíduos Sólidos, os RCC são de responsabilidade dos seus geradores. De maneira quase geral, os municípios coletam tão somente os resíduos de construção civil lançados em logradouros públicos. Independentemente da responsabilidade desses resíduos ser do gerador, é extremamente significativa a quantidade total de RCC coletada pelos municípios em 2010, como apresentado na Tabela 4, que permite a constatação de que, em 2010, os municípios brasileiros coletaram 8,7\% a mais de RCC que em 2009 (ABRELPE, 2010).

Tabela 4 - Quantidade total de RCC coletado

\begin{tabular}{|l|c|r|r|r|}
\hline \multirow{2}{*}{ Região } & \multicolumn{2}{|c|}{$\mathbf{2 0 0 9}$} & \multicolumn{3}{|c|}{$\mathbf{2 0 1 0}$} \\
\cline { 2 - 5 } & $\begin{array}{c}\text { RCD Coletado } \\
\text { (t/ dia) / Índice } \\
\text { (kg/hab/dia) }\end{array}$ & $\begin{array}{c}\text { População } \\
\text { Urbana } \\
\text { (hab) }\end{array}$ & $\begin{array}{c}\text { RCD } \\
\text { Coletado } \\
\text { (t/ dia) }\end{array}$ & $\begin{array}{c}\text { Índice } \\
\text { (kg/hab/dia) }\end{array}$ \\
\hline Norte & $3.405 / 0,297$ & 11.663 .184 & 3.514 & 0,301 \\
\hline Nordeste & $15.663 / 0,412$ & 38.816 .895 & 17.995 & 0,464 \\
\hline Centro-Oeste & $10.997 / 0,918$ & 12.479 .872 & 11.525 & 0,923 \\
\hline Sudeste & $46.990 / 0,632$ & 74.661 .877 & 51.582 & 0,691 \\
\hline Sul & $14.389 / 0,630$ & 23.257 .880 & 14.738 & 0,634 \\
\hline BRASIL & $\mathbf{9 1 . 4 4 4 / 0 , 5 7 6}$ & $\mathbf{1 6 0 . 8 7 9 . 7 0 8}$ & $\mathbf{9 9 . 3 5 4}$ & $\mathbf{0 , 6 1 8}$ \\
\hline
\end{tabular}

Fonte: ABRELPE (2010). 
Mesmo com a diversidade de resíduos de construção civil listados na Resolução CONAMA e os dados apresentados com a situação atual dos resíduos no país, não são encontrados apenas eles numa obra de construção civil. Na construção pesada, localizada longe de grandes centros, é necessário construir toda uma estrutura de apoio, contemplando canteiros de obras grandes e complexos, nos quais são construídos, além dos escritórios administrativos, almoxarifado e ambulatório, alojamentos, refeitórios dotados de cozinha industrial e centrais industriais (a depender do tipo de construção). Todas essas edificações e pessoas que delas se utilizam propiciam a geração de diversos tipos de resíduos sólidos:

a) Resíduos sólidos domiciliares (escritório administrativo, refeitório, alojamentos);

b) Resíduos da construção civil (centrais industriais - fábrica de pré-moldados em concreto - e a própria obra);

c) Resíduos de limpeza urbana, nesse caso, os de poda e capina (desmatamento, atividade preliminar aos serviços executivos);

d) Resíduos industriais (centrais industriais: pedreira - resíduos de mineração -, estaleiro de soldas, fábrica de pré-moldados);

e) Resíduos de serviços de saúde (ambulatório).

Portanto, é possível concluir que, para conter o impacto ambiental de uma grande obra de construção civil, faz-se necessária a implantação de um gerenciamento bastante efetivo, contendo, inclusive, a não geração, separação e reciclagem dos resíduos nos próprios canteiros de obras, uma vez que a Resolução CONAMA n 307/2002 esclarece que "os geradores deverão ter como objetivo prioritário a não geração de resíduos e, secundariamente, a redução, a reutilização, a reciclagem e a destinação final" (BRASIL, 2002). E estes resíduos “não poderão ser dispostos em aterros de resíduos domiciliares, em áreas de 'bota fora', em encostas, corpos d'água, lotes vagos e em áreas protegidas por Lei” (BRASIL, 2002). As empresas têm, então, de gerenciar da melhor forma a destinação de todos os resíduos gerados na obra.

\subsection{GESTÃO E GERENCIAMENTO DOS RESÍDUOS DE CONSTRUÇÃO CIVIL}

Conforme Chelsom, Payne e Reavill (2006), em termos bastantes simples, empresas e muitas outras organizações estão interessadas em obter uma recompensa por uma ideia. A forma como isso é feito é a tarefa do gerenciamento.

Então, o que é gerenciamento? Para responder a essa pergunta, pode-se considerar em primeiro lugar o que é gerenciado - isto é, os insumos -, e em segundo lugar as funções dos 
administradores em relação à sua contribuição para transformar os insumos em saídas, produtos ou serviços durante o processo (CHELSOM; PAYNE; REAVILL, 2006).

O conceito de gerenciamento refere-se aos aspectos tecnológicos e operacionais e envolve fatores administrativos, gerenciais, econômicos, ambientais e de desempenho, como a produtividade e a qualidade. É a realização do que a gestão delibera, por meio da ação administrativa de planejamento e controle de todas as etapas do processo, na qual a gestão pode ser definida como atividade relacionada à tomada de decisões estratégicas e à organização do setor para uma determinada finalidade, envolvendo instituições, políticas, instrumentos e meios (LEITE, 1997).

Durante a Revolução Industrial, surgiram as principais empresas de engenharia que pertenciam à indústria pesada, caracterizada por empresas de mineração, aciarias, indústrias navais, ferrovias, produtos químicos e têxteis, entre outros, exigindo imensos investimentos, imensos espaços e imensas forças de trabalho. O domínio da mão de obra na estrutura do custo, em contrapartida às habilidades técnicas importantes para o desenvolvimento de processos e produtos, chamou a atenção da administração para o sucesso do projeto baseado no aumento da produtividade do trabalhador ou na diminuição nos índices salariais (CHELSOM; PAYNE; REAVILL, 2006).

Os esforços iniciais para redução dos custos de mão de obra na manufatura estavam concentrados no desempenho do indivíduo, incentivando-os por meio do desenvolvimento de sistemas de pagamento. Conseguiam reduzir o custo de mão de obra direta, que é aquela ligada diretamente à linha de produção, e muitas organizações começaram a reduzir suas despesas indiretas por meio da terceirização de serviços como processamento de dados, distribuição, abastecimento, segurança, entre outros (CHELSOM; PAYNE; REAVILL, 2006).

Muitos estudos foram feitos em cima das ações dos operadores, da aceleração da produção por meio de um local de trabalho com arranjo físico mais eficiente e do desenvolvimento das habilidades manuais individuais que, de algum modo, receberam o rótulo de "administração científica". Embora na época tenha sido altamente considerado, esse tipo de gerenciamento atualmente é menos admirado e tem sido relacionado a rótulos, um tanto rejeitados, de "taylorismo" e "fordismo" (CHELSOM; PAYNE; REAVILL, 2006).

Ao longo do século $\mathrm{XX}$, os estilos de gerenciamento mudaram do dirigista, por meio do centralmente controlado, para o inclusivo ou o participativo. Contudo, nos últimos dez anos, não houve novos desenvolvimentos significativos. A criatividade e a inovação, para obterem benefício das novas tecnologias, tornaram-se mais importantes, mas se baseiam em ferramentas e técnicas bem-estabelecidas (CHELSOM; PAYNE; REAVILL, 2006). 
No entanto, análises históricas mostram que o conceito de gerenciamento pode ser mais antigo. Por exemplo, no Antigo Egito já eram empregadas técnicas de engenharia e gerenciamento bem sofisticadas para a construção de obras de grande porte, tais como sistemas de esgoto e irrigação, embarcações e canais. A própria construção das pirâmides foi um grande esforço de gerenciamento de projetos, empregando enormes recursos humanos e materiais, sendo utilizados 100 mil trabalhadores em 30 anos para a sua construção. Alguns casos de projetos da antiguidade, além das pirâmides do Egito, são a Muralha da China, o Coliseu de Roma, na Itália, e o Parthenon, em Atenas, na Grécia (VALLE ET AL, 2007).

Segundo o PMI (2008), o gerenciamento de projetos é a aplicação de conhecimentos, habilidades, ferramentas e técnicas às atividades do projeto a fim de atender aos seus requisitos, dividido em processos os quais compartilham diversas áreas de conhecimento.

Quanto à estratégia corporativa, segundo Valle et al (2007), deve-se sempre ter o alinhamento com algumas palavras-chave:

a) Meio Ambiente;

b) Atividades críticas - ações;

c) Metas / objetivos;

d) Negócio;

e) Recursos;

f) Oposição / concorrência;

g) Sobrevivência / extinção.

De maneira geral, pode-se definir gestão como um conjunto de normas e diretrizes que regulamentem os arranjos institucionais (identificação dos diferentes agentes envolvidos e seus respectivos papéis), os instrumentos legais e os mecanismos de financiamento. $\mathrm{O}$ gerenciamento, por sua vez, é a realização do que a gestão delibera, por meio de ação administrativa, de controle e planejamento de todas as etapas do processo (SCHALCH; CÓRDOBA, 2011).

No caso dos resíduos sólidos, a Política Nacional de Resíduos Sólidos (Lei $\mathrm{n}^{\mathrm{o}}$ 12.305/2010) define a gestão integrada como um conjunto de ações voltadas para a busca de soluções para os resíduos sólidos, de forma a considerar as dimensões política, econômica, ambiental, cultural e social, com controle social e sob a premissa do desenvolvimento sustentável e o seu gerenciamento como um conjunto de ações exercidas, direta ou indiretamente, nas etapas de coleta, transporte, transbordo, tratamento e destinação final dos resíduos sólidos e disposição final dos rejeitos, considerando que a destinação e disposição 
são ambientalmente adequadas, de acordo com os planos municipais de gestão integrada e de gerenciamento de resíduos sólidos, exigidos na mesma lei.

A Figura 1 mostra a situação atual e ideal, conforme o PNRS, de estratégia para a gestão e o gerenciamento integrado de resíduos sólidos. Nela, a situação atual mostra que sua prioridade está no tratamento de resíduos, com maior ocorrência, e não na prevenção da poluição, que ocorre menos, diferentemente da situação ideal, onde se deve fazer mais a prevenção da poluição com a análise do ciclo de vida e diminuir o volume de atividades de tal forma que haja muito poucos resíduos a serem tratados, sejam eles de forma física, química e/ou biologicamente, até a inexistência da disposição final.

Figura 1 - Estratégias para a gestão e o gerenciamento integrado dos resíduos sólidos

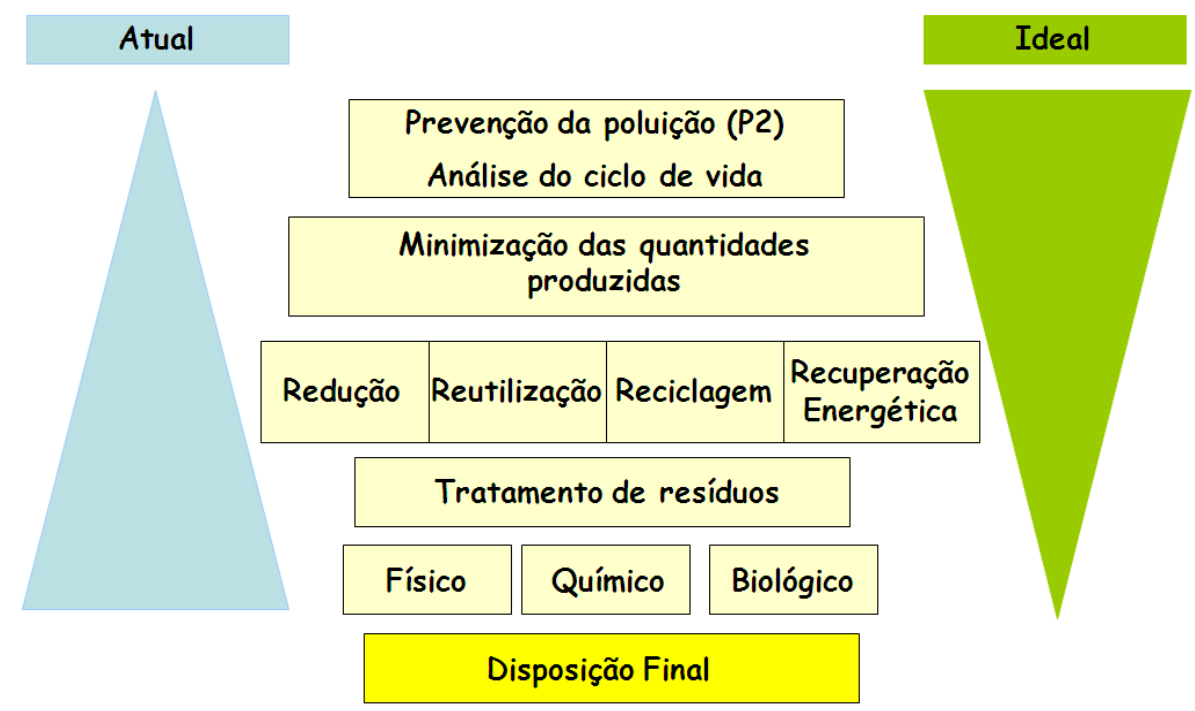

Fonte: Schalch e Córdoba (2011).

Já em relação aos resíduos de construção civil, seu gerenciamento é definido pela Resolução CONAMA n 448/2012, que alterou a definição da Resolução CONAMA no 307/2002, como

[...] conjunto de ações exercidas, direta ou indiretamente, nas etapas de coleta, transporte, transbordo, tratamento e destinação final ambientalmente adequada dos rejeitos, de acordo com plano municipal de gestão integrada de resíduos sólidos ou com plano de gerenciamento de resíduos sólidos, exigidos na forma da Lei $\mathrm{n}^{\mathrm{o}}$ 12.305, de 2 de agosto de 2010. (BRASIL, 2012).

Além disso, a Resolução CONAMA no 448/2012 inseriu uma nova definição para Gestão integrada de resíduos sólidos: 
[...] conjunto de ações voltadas para a busca de soluções para os resíduos sólidos, de forma a considerar as dimensões política, econômica, ambiental, cultural e social, com controle social e sob a premissa do desenvolvimento sustentável. (BRASIL, 2012).

Diante do exposto, independentemente da especificidade e do tipo de gestão e gerenciamento, é possível definir alguns procedimentos necessários para sua melhor realização, ao se aplicar ferramentas e técnicas, por meio de ações voltadas à concretização de metas pré-estabelecidas num determinado modelo de gestão.

A Figura 2 exemplifica as etapas da gestão e do gerenciamento dos resíduos da construção civil.

Figura 2 - Etapas da gestão e do gerenciamento dos resíduos da construção civil (RCC)

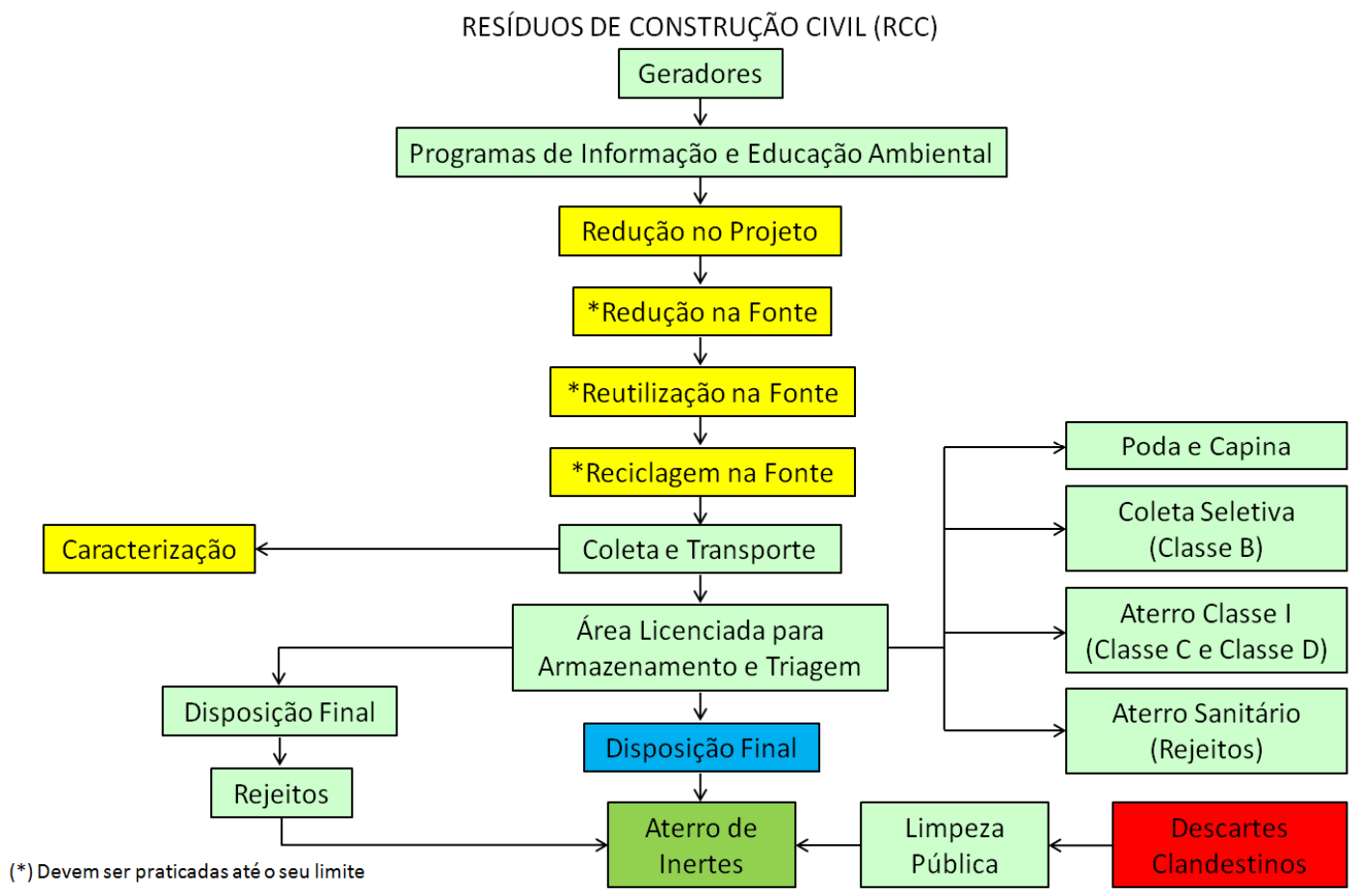

Fonte: Schalch e Córdoba (2011), adaptado pelo autor, com os créditos do Professor Javier Pablos.

\subsection{A IMPORTÂNCIA DO GERENCIAMENTO DE RESÍDUOS DA CONSTRUÇÃO CIVIL SER INICIADO NA FASE DE CONCEPÇÃO DO PROJETO}

Toda obra deve organizar-se ao máximo, para que todas as etapas construtivas sejam executadas de forma eficiente e eficaz. Considerando que o intuito do gerenciamento dos resíduos de construção civil, segundo a Resolução CONAMA, é reduzir, reutilizar ou reciclar 
resíduos, incluindo realizar o planejamento, definir as responsabilidades, práticas, procedimentos e recursos para desenvolver e implementar as ações necessárias ao cumprimento das etapas previstas em planos e programas dos projetos em questão, os projetos executivos necessários para a construção das obras a terem seus resíduos gerenciados devem ser compatibilizados e as pessoas envolvidas na elaboração dos projetos devem ter em mente um modelo de produção mais limpa.

A produção mais limpa consiste na aplicação de uma estratégia econômica, ambiental e técnica integrada a processos e produtos, cuja finalidade é aumentar a eficiência no uso de matéria-prima, água e energia, por meio da não geração, minimização ou reciclagem dos resíduos gerados, com benefícios ambientais e econômicos para os processos produtivos.

Essa visão de minimização da geração de resíduos deve estar presente tanto em projetos de construção quanto de demolição, pois, segundo Lipsmeier e Günther (2002), em projetos de demolição, modernização e reparação, o conhecimento sobre a construção permite determinar sua composição e, dessa forma, saber quais tipos de resíduos serão gerados.

Dentre as etapas de desenvolvimento de um empreendimento, a fase de concepção, na qual se incluem os estudos preliminares, anteprojeto e projeto, exerce papel determinante na qualidade, tanto do produto acabado como do processo construtivo. Dessa forma, a melhoria da qualidade do projeto pode proporcionar a obtenção de melhor qualidade, tanto do produto acabado como do processo construtivo. Além disso, muitas medidas de racionalização e praticamente todas as medidas de controle da qualidade dependem da definição do escopo do empreendimento, por meio de uma clara especificação na sua fase de concepção, uma vez que não é possível controlar uma atividade ou produto se suas características não se encontrarem perfeitamente definidas (FRANCO; AGOPYAN, 1993).

O projeto, além de ser determinante na definição do processo construtivo, baseia a elaboração do planejamento executivo da obra. Se as informações do projeto não guardarem um grau de precisão e detalhe coerentes com a execução, muitas variáveis incontroláveis são introduzidas no planejamento, contribuindo para a ocorrência de problemas futuros em diversas etapas e setores da obra (FRANCO; AGOPYAN, 1993).

Segundo Mattos (2010), o planejamento tem um papel fundamental por exercer forte impacto no desempenho da produção, uma vez que ao planejar uma obra, o gestor adquire alto grau de conhecimento do empreendimento, permitindo-lhe ser mais eficiente na condução dos trabalhos. Os principais benefícios que o planejamento traz são o conhecimento pleno da obra, detecção de situações desfavoráveis, agilidade de decisões, relação com o orçamento, otimização da alocação de recursos, referência para o acompanhamento, padronização, 
referência para metas, documentação e rastreabilidade, criação de dados históricos e profissionalismo.

Em relação aos resultados, é na fase de concepção do projeto que se tomam as decisões que trazem maior repercussão nos custos, velocidade e qualidade dos empreendimentos. As alterações, visando a racionalização, implementadas nessa fase, apresentam, de maneira geral, um custo muitas vezes menor que as implementadas nas fases posteriores. Vale salientar que qualquer medida tomada posteriormente terá uma grande interferência nas etapas de produção e, consequentemente, no custo da construção, enquanto as tomadas nessa fase têm interferência apenas no trabalho dos projetistas (FRANCO; AGOPYAN, 1993).

Lipsmeier e Günther (2002) propõem a possibilidade de se realizar uma estimativa inicial de quanto será gerado, por meio da descrição do tipo da construção e dos levantamentos quantitativos dos projetos executivos da obra. Assim, é possível realizar uma construção sustentável que visa otimizar a execução dos serviços, de forma a maximizar a produtividade deles e minimizar a geração dos resíduos.

Embora a importância da fase de concepção do empreendimento seja consenso no meio técnico, na prática observam-se muito poucas medidas de aprimoramento desta atividade. Durante a viabilização dos empreendimentos, uma grande atenção é voltada aos aspectos estratégicos do gerenciamento empresarial, como o fluxo financeiro. O projeto é muitas vezes colocado em um segundo plano, sendo elaborado com um mínimo aprofundamento das soluções construtivas, postergando-as para a solução "em campo", na etapa de construção (FRANCO; AGOPYAN, 1993).

A coordenação de projetos é outro aspecto que influencia decididamente na qualidade dos empreendimentos da construção civil. A complexidade presente nestes empreendimentos leva à especialização das atividades e dos projetistas. Assim, por mais competente e capaz que seja o projetista, cada vez torna-se mais difícil que ele tenha pleno domínio da totalidade dos conhecimentos envolvidos no empreendimento. Em geral, os projetos dos diversos subsistemas das construções são produzidos separadamente, sem a existência de uma instância que os coordene. Para tanto, é importante que haja, além da coordenação dos projetos e respectivos projetistas, a compatibilização dos mesmos (FRANCO; AGOPYAN, 1993).

Entretanto, um alto nível de qualidade dos diversos projetos, quando tomados separadamente, não garante a qualidade do todo. A construtibilidade é, dentre os princípios 
empregados para o desenvolvimento dos projetos, aquele que fundamenta grande parte das medidas de racionalização do processo construtivo (FRANCO; AGOPYAN, 1993).

A construtibilidade é definida pelo Construction Industry Institute (CII, 1986), entidade norte-americana que reúne diversas empresas do setor da construção, como "o uso otimizado do conhecimento das técnicas construtivas e da experiência nas áreas de planejamento, projeto, contratação e da operação em campo para se atingir os objetivos globais do empreendimento".

Ela pode, também, ser definida como integração do conhecimento e experiência construtiva durante as fases de concepção, planejamento, projeto e execução da obra, visando a simplificação das operações construtivas por meio de pleno conhecimento da tecnologia construtiva a ser adotada no empreendimento (SILVA; GUIMARÃES, 2006).

A incorporação dos princípios de racionalização construtiva e construtibilidade de projetos ressaltam a necessidade de se reformular a forma como os projetos vêm sendo conduzidos, ou seja, gerenciados. O principio básico da construtibilidade na gestão de projeto é procurar adequar o projeto à realidade da sua futura construção, envolvendo todas as etapas do processo construtivo (concepção, construção e uso) (SILVA; GUIMARÃES, 2006).

Considerando a construtibilidade como conceito e ferramenta para a gestão de projeto, ela está associada a diversos procedimentos de gestão e de acompanhamento do projeto, como as revisões dos aspectos construtivos do projeto, a análise da concepção de projeto, otimização dos processos ou métodos construtivos e a utilização de processos construtivos mais eficientes (SILVA; GUIMARÃES, 2006).

Portanto, deve-se enfatizar que uma das diretrizes mais eficientes para obtenção da qualidade no projeto, qualidade esta tão requisitada pelas empresas de construção, é a implementação das medidas de racionalização construtiva e construtibilidade na fase de projeto (SILVA; GUIMARÃES, 2006).

De acordo com os princípios da construtibilidade, os projetos deverão ser formulados em concordância entre os projetistas envolvidos e a equipe de execução, compatibilizando-os com o intuito de obter o desenvolvimento de sequências construtivas; padronização dos materiais; acessibilidade aos locais de trabalho; liberação das montagens em qualquer sequência executiva; eliminação de embutimentos e sobreposições de elementos construtivos; uso de materiais convencionais; e uso de materiais locais, requerendo mão de obra facilmente encontrada (SILVA; GUIMARÃES, 2006).

De maneira geral, é importante que haja mais tempo para projetar e planejar uma obra, a despeito disso não acontecer na maioria das vezes. Contudo, com a legalização das Parcerias 
Público Privadas (PPP) no país, as empresas passaram a despender um tempo maior com o estudo do empreendimento e da sua viabilidade. Com isso, passaram a analisar todas as etapas construtivas da obra, pois, nesse tipo de contratação, a empresa privada é responsável, praticamente, por todas as fases do projeto, incluindo a elaboração dos projetos conceitual, básico e executivo, e seu conseguinte planejamento e construção. Isso acaba beneficiando a maximização da produtividade e minimização da geração dos resíduos.

Em relação a todos os tipos de contratação, além da elaboração detalhada do projeto, o acompanhamento e controle contínuos do cumprimento dos objetivos propostos possibilitam a otimização da construção com maior produtividade dentro dos prazos propostos, obtendo-se uma menor geração de resíduos e, consequentemente, muito mais lucro.

\subsection{A IMPORTÂNCIA DA INDUSTRIALIZAÇÃO DA CONSTRUÇÃO CIVIL NO GERENCIAMENTO DOS RESÍDUOS SÓLIDOS}

A construção civil é uma atividade que envolve um grande número de variáveis e se desenvolve em um ambiente bastante dinâmico e mutável. Gerenciar uma obra de maneira adequada não é um dos trabalhos mais fáceis e, no entanto, ainda há muita improvisação nos canteiros por todo o mundo (MATTOS, 2010).

Ela é um dos ramos produtivos que mais vem sofrendo alterações substanciais nos últimos anos. Com o aumento da competitividade, a globalização dos mercados, a demanda por bens mais modernos, a velocidade com que surgem novas tecnologias, o aumento do grau de exigência dos clientes e a reduzida disponibilidade de recursos financeiros para a realização de empreendimentos, as empresas viram que investir em gestão e controle de processos é inevitável, pois sem essa sistemática gerencial os empreendimentos perdem de vista seus principais indicadores: o prazo, o custo, o lucro, o retorno sobre o investimento e o fluxo de caixa (MATTOS, 2010).

Se comparada com outras indústrias, a produtividade da construção é bastante inferior, a segurança no trabalho é notoriamente pior, há escassez de força de trabalho capacitada no setor e a qualidade de construção é considerada insuficiente. Uma série de soluções e visões tem sido oferecida para aliviar os problemas crônicos na construção. Industrialização (ou seja, pré-fabricação e modularização) tem sido vista, por muito tempo, como um sentido ao progresso.

Nos anos 1980, a construção com computação integrada era vista como uma forma importante de reduzir a fragmentação na construção, que era considerada uma das principais 
causas dos problemas existentes. A visão de construção robotizada e automatizada, intimamente associada à construção com computação integrada, era outra solução promovida por pesquisadores. Manufatura foi um ponto de referência e uma fonte de inovações na construção civil por muitas décadas. Por exemplo, a ideia de industrialização vem diretamente de fabricação. Computação integrada e automação também têm sua origem na indústria transformadora, em que a implementação está bem à frente em relação à construção (KOSKELA, 1992).

Em seguida, houve outra tendência desenvolvida na produção, o impacto do que parecia ser muito maior do que a de tecnologia da informação e automação. Esta tendência, que se baseia em uma nova filosofia de produção, mais do que uma nova tecnologia, salientava a importância das teorias e princípios básicos relacionados com processos de produção. No entanto, por ele ter sido desenvolvido por profissionais em um processo de tentativa e erro, a natureza dessa abordagem como uma filosofia escapou à atenção de ambos os círculos, profissional e acadêmico, até o final de 1980. Nessa época houve, na construção, pouco interesse nessa filosofia de produção (KOSKELA, 1992).

Ao longo dos anos 1990, um novo referencial teórico foi construído para a gestão de processos na construção civil, envolvendo o esforço de um grande número de acadêmicos, tanto no país como no exterior, com o objetivo de adaptar alguns conceitos e princípios gerais da área de gestão da produção às peculiaridades do setor. Este esforço foi denominado de lean construction (construção enxuta), por estar fortemente baseado no paradigma da lean production (produção enxuta), que se contrapõe ao paradigma da produção em massa (mass production), cujas raízes estão no taylorismo e fordismo (ISATTO ET AL, 2000).

As ideias desse novo paradigma surgiram no Japão, nos anos 1950, baseadas em duas filosofias básicas: as ferramentas de gestão da qualidade total (total quality management TQM) e a de produção por demanda, o just in time (JIT), onde o sistema de produção da Toyota, no Japão, teve sua aplicação mais proeminente. Dessa forma, seus conceitos e princípios básicos surgiram na própria indústria, principalmente a automotiva. Apenas na década de 1990 passou a existir um movimento entre acadêmicos para entender esse novo paradigma, com o objetivo de disseminá-lo nos mais diversos setores de atividade econômica (ISATTO ET AL, 2000).

No que tange a indústria da construção civil, esse esforço foi marcado pela publicação do trabalho "Application of the new production philosophy in the construction industry" por Lauri Koskela (1992), do Technical Research Center (VTT) da Finlândia, com base no qual foi criado o International Group for Lean Construction (IGLC), engajado na adaptação e 
disseminação do novo paradigma no setor da construção civil em diversos países (ISATTO ET AL, 2000).

De acordo com o trabalho de Koskela (1992), a construção enxuta apresenta um conjunto de princípios para a gestão de processos (ISATTO ET AL, 2000):

a) Reduzir a parcela de atividades que não agregam valor, na qual a eficiência dos processos pode ser melhorada e as suas perdas reduzidas não só por meio da melhoria da eficiência das atividades de conversão e de fluxo, mas também pela eliminação de algumas das atividades de fluxo.

b) Aumentar o valor do produto por meio da consideração das necessidades dos clientes. Este princípio está relacionado ao conceito de processo como gerador de valor. Ele estabelece que devam ser identificadas claramente as necessidades dos clientes internos e externos e esta informação deve ser considerada no projeto do produto e na gestão da produção.

c) Reduzir a variabilidade. Existem diversos tipos de variabilidade envolvidos num processo de produção: variabilidade nos processos anteriores; variabilidade no próprio processo; variabilidade na demanda. Do ponto de vista da gestão de processos, existem duas razões para a redução da variabilidade. Primeiramente, do ponto de vista do cliente, um produto uniforme, em geral, traz mais satisfação, pois a qualidade do produto efetivamente corresponde às especificações previamente estabelecidas. Em segundo lugar, a variabilidade tende a aumentar a parcela de atividades que não agregam valor e o tempo necessário para executar um produto, principalmente pela interrupção de fluxos de trabalho e pela não aceitação de produtos fora de especificação pelo cliente.

d) Reduzir o tempo de ciclo. É um princípio que tem origem na filosofia just in time. O tempo de ciclo pode ser definido como a soma de todos os tempos (transporte, espera, processamento e inspeção) para a produção de um determinado produto. A aplicação deste princípio está fortemente relacionada à necessidade de comprimir o tempo disponível como mecanismo para forçar a eliminação das atividades de fluxo. Além disso, a redução do tempo de ciclo traz outras vantagens: entrega mais rápida ao cliente; gestão mais fácil dos processos; aumento do efeito de aprendizagem; maior precisão na estimativa de futuras demandas; menor vulnerabilidade do sistema de produção às mudanças de demanda. 
e) Simplificar por meio da redução do número de passos ou partes. Princípio frequentemente utilizado no desenvolvimento de sistemas construtivos racionalizados. Quanto maior o número de componentes ou de passos num processo, maior tende a ser o número de atividades que não agregam valor. Isto ocorre em razão das tarefas auxiliares de preparação e conclusão necessárias para cada passo no processo e também pelo fato de que, na existência de variabilidade, tende a aumentar a possibilidade de interferências entre as equipes.

f) Aumentar a flexibilidade de saída está vinculado ao conceito de processo como gerador de valor. Refere-se à possibilidade de alterar as características dos produtos entregues aos clientes, sem aumentar consideravelmente seus custos.

g) Aumentar a transparência do processo tende a tornar os erros mais fáceis de serem identificados no sistema de produção, ao mesmo tempo em que facilita o trabalho ao aumentar a disponibilidade de informações necessárias para a execução das tarefas. Este princípio pode ser utilizado como um mecanismo para aumentar o envolvimento da mão de obra no desenvolvimento de melhorias.

Considerando que construtibilidade pode ser definida como a integração do conhecimento e experiência construtiva durante todas as fases da obra, visando a simplificação das operações construtivas por meio do pleno conhecimento da tecnologia construtiva a ser adotado no empreendimento (SILVA; GUIMARÃES, 2006), além dos princípios da construção enxuta, a aplicação do conceito da construtibilidade e seus princípios a um projeto de construção devem ser implantados nas diversas fases de projeto, ao longo do seu ciclo de vida, assumindo diferentes níveis de formalidade.

Segundo Silva e Guimarães (2006), os benefícios com a implementação da construtibilidade, sejam eles qualitativos ou quantitativos, podem variar em virtude de diversos fatores como:

a) capacitação da equipe de gestão de projeto;

b) melhoria das relações entre os participantes no projeto;

c) procedimentos organizacionais de registro e avaliação dos projetos;

d) redução de retrabalhos, dúvidas e revisões no projeto;

e) redução do tempo de concepção e revisão do projeto;

f) redução do custo do projeto.

As empresas devem criar bases de dados e incentivar a consulta dos registros de experiências construtivas já vivenciadas da aplicação da construtibilidade, nas quais devem ser claramente especificados os passos e os procedimentos da construção para o 
desenvolvimento de projetos futuros, desde que seja assegurado o fácil acesso a estes registros, a sua permanente atualização, bem como a qualidade dos respectivos conteúdos (SILVA; GUIMARÃES, 2006).

A busca pela melhoria da qualidade do produto no setor da construção é reflexo do precário domínio técnico e tecnológico que as empresas do subsetor detêm sobre as suas atividades produtivas, bem como de serviço de projetos pouco orientados à construtibilidade das obras e deficientes enquanto caracterização de produtos. A implementação dos princípios de racionalização construtiva e construtibilidade auxiliam na compatibilização dos projetos, proporcionando uma melhoria na qualidade e produtividade do produto e, consequentemente, maior rentabilidade de investimento (SILVA; GUIMARÃES, 2006).

De maneira geral, pode-se observar que, independente da filosofia, técnicas e processos implantados, o objetivo maior é tentar padronizar ao máximo as atividades, para que o trabalho se torne mais ágil e produtivo. Dessa forma acaba havendo a diminuição da geração dos resíduos da construção civil, uma vez que passa a haver a industrialização da construção civil, na qual a pré-fabricação e modularização promovem a diminuição e até a eliminação do desperdício e das perdas desnecessárias na execução da obra. 


\section{ESTRUTURA METODOLÓGICA}

Segundo Melo (2001), todo e qualquer trabalho científico de pesquisa necessita confrontar teorias com dados de observação e experimentação. Por meio da definição da metodologia de pesquisa é possível delinear o método de estudo e as técnicas a serem utilizados pelo pesquisador.

\subsection{MÉTODO DE ABORDAGEM}

A maioria dos especialistas distingue método de métodos, por se situarem em níveis distintos no que se refere à sua inspiração filosófica, ao seu grau de abstração, à sua finalidade explicativa, à sua ação nas etapas da investigação e ao momento em que se situam (LAKATOS; MARCONI, 2010).

Partindo dessa diferença, o método é caracterizado por uma abordagem mais ampla, em níveis de abstração mais elevados, sendo denominado de método de abordagem. Os métodos de abordagem englobam o indutivo, dedutivo, hipotético-dedutivo e o dialético (LAKATOS; MARCONI, 2010). Para o desenvolvimento deste projeto, foi utilizado um método de abordagem dedutivo, em que a Resolução do CONAMA nº 307/2002 foi utilizada como base, uma vez que este método parte de teorias e leis para predizer a ocorrência dos fenômenos particulares (LAKATOS; MARCONI, 2010).

\subsection{MÉTODOS DE PROCEDIMENTO}

Os métodos de procedimentos constituem etapas mais concretas da investigação, possuindo uma finalidade mais restrita no que se refere à explicação geral dos fenômenos menos abstratos. Pressupõem uma atitude concreta em relação ao fenômeno e estão limitadas a um domínio particular. Os principais métodos de procedimento são: histórico; comparativo; monográfico ou estudo de caso; estatístico; tipológico; funcionalista; estruturalista; e etnográfico (LAKATOS; MARCONI, 2010). Este projeto teve como métodos de procedimentos comparativos, em que as práticas exigidas pela Resolução citada foram comparadas com as práticas utilizadas pelas obras analisadas, o monográfico, ou estudo de caso, do tipo multicaso, por meio da análise de duas obras com características semelhantes, porém em etapas executivas diferentes, e o estatístico, com a análise dos dados qualitativos e quantitativos dos questionários passados aos colaboradores das obras. 


\subsection{NATUREZA DA PESQUISA}

A natureza da pesquisa pode ser quantitativa ou qualitativa. Segundo Melo (2001), o método qualitativo não emprega um instrumento estatístico paramétrico como base do processo de análise de um problema, contudo pode descrever, analisar e explicar a complexidade do problema em questão.

Estudos dirigidos à análise de atitudes, motivações, expectativas, valores etc. são situações em que se faz necessária a abordagem qualitativa (RICHARDSON, 1989 apud MELO, 2001, p. 107).

O principal objetivo deste trabalho foi a análise de procedimentos utilizados para a realização de um gerenciamento adequado dos resíduos da construção civil em relação às definições da resolução nacional apresentada, ao se aplicar ferramentas e técnicas, por meio de ações voltadas à concretização de metas pré-estabelecidas num determinado modelo de gestão. Esta pesquisa caracteriza-se como de natureza qualitativa, contudo alguns dados foram tratados estatisticamente, para facilitar a avaliação das informações.

\subsection{DELIMITAÇÃO DO UNIVERSO}

Como são raras as pesquisas científicas que delimitam o gerenciamento dos resíduos da construção civil (GRCC) em obras de grande porte e a proposta desta pesquisa foi a de analisar o GRCC adotado para a construção e demolição de obras de grande porte, o universo deste trabalho foi o conjunto de todas as obras de grande porte do país.

Conforme tratado anteriormente, esse estudo teve como método de procedimento o estudo de caso do tipo multicaso, uma vez que foram estudadas duas grandes obras de empresas de construção civil consideradas as maiores construtoras do Brasil em 2010, segundo a Câmara Brasileira da Indústria da Construção (CBIC, 2010).

As obras têm como características comuns a finalidade da construção, por se tratarem de estádios de futebol para a Copa 2014, e a ordem de grandeza da quantidade de funcionários envolvidos na execução das mesmas e do valor contratado para a sua construção. Essas obras estão sendo realizadas em estados nordestinos diferentes e suas etapas construtivas analisadas são distintas e em períodos diferentes.

Uma das obras foi a da reconstrução do estádio da Fonte Nova (Octávio Mangabeira), localizado em Salvador-BA (Figura 3). A Arena Fonte Nova terá capacidade para 50 mil 
pessoas em assentos cobertos, 90 camarotes, restaurantes panorâmicos e duas mil vagas de estacionamento. Sua estrutura abrigará sala de imprensa, quiosques, elevadores, sanitários, museu e espaços de negócios. A implosão do antigo estádio da Fonte Nova, em 29 de agosto de 2010, foi o marco principal da construção da nova arena. Todo o material da implosão foi reciclado e parte utilizada na própria construção.

O projeto prevê medidas ambientalmente responsáveis e de sustentabilidade. A estrutura utilizada na cobertura reduz o consumo de aço entre $30 \%$ e $40 \%$. O projeto atende ao Programa Green Goal da FIFA: aproveita água da chuva coletada da cobertura e utiliza energia solar para o seu aquecimento; reutiliza materiais provenientes da demolição do estádio; e implanta coleta seletiva dos resíduos sólidos, uma vez que o Green Goal é um programa da FIFA para a redução das emissões de dióxido de carbono em seus eventos. Ele tem foco em quatro pontos: água, resíduos, energia e transporte, em que todos eles têm de ser previstos desde o momento da concepção do projeto para construção do estádio. Em relação à água, recomenda a armazenagem de águas pluviais para fins de irrigação e uso nas instalações sanitárias; para limitar a geração de resíduos durante os eventos, a FIFA recomenda o reúso de copos, a coleta seletiva e a venda de comidas e produtos sem embalagem; para a economia de energia, a entidade recomenda a instalação de painéis fotovoltaicos e de mecanismos que reduzam o uso do ar-condicionado, além da construção de centrais de controle de energia para administrar o consumo em horários de pico. Por fim, ela recomenda o uso de sistemas públicos de transporte, como ônibus e trens, que podem ser projetados para um consumo eficiente de combustível e a utilização de mecanismos mais saudáveis, como bicicletas. 
Figura 3 - Localização da obra de reconstrução do estádio da Fonte Nova (Octávio Mangabeira), Salvador-BA

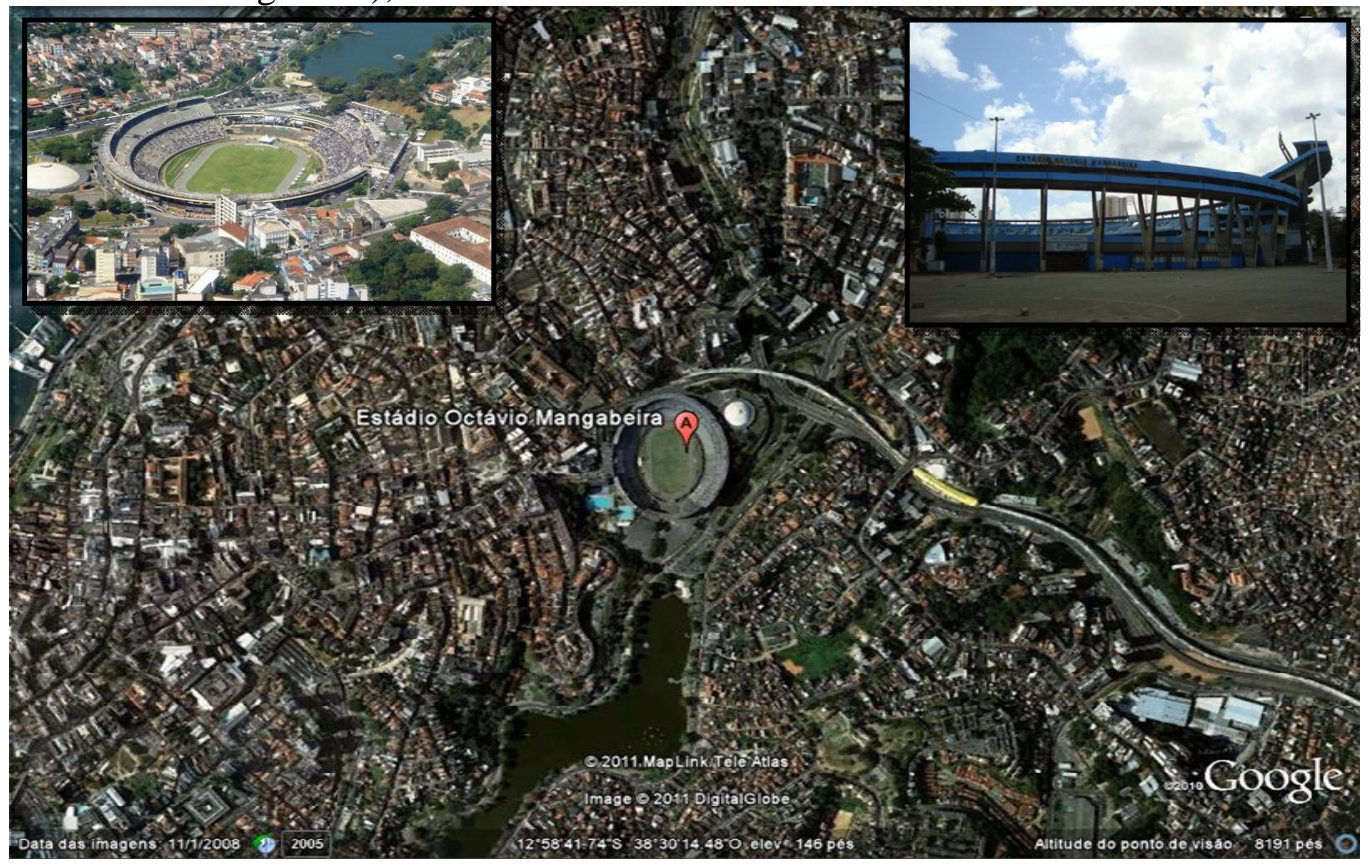

Fonte: Google Earth (2011).

Figura 4 - Implosão do estádio da Fonte Nova (Octávio Mangabeira), Salvador-BA

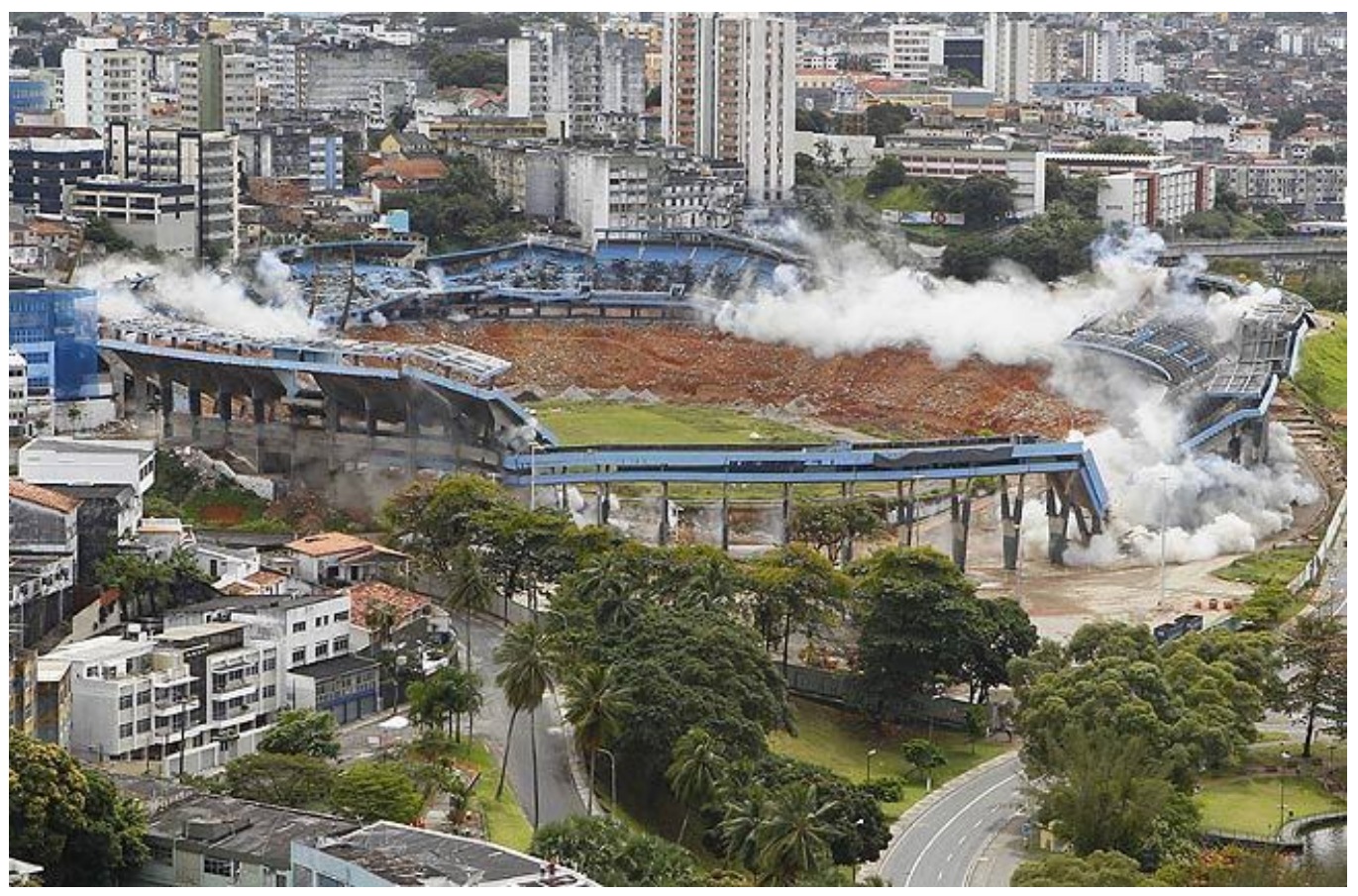

Fonte: A Tarde (2010). 
Figura 5 - Estádio da Fonte Nova (Octávio Mangabeira), após a implosão

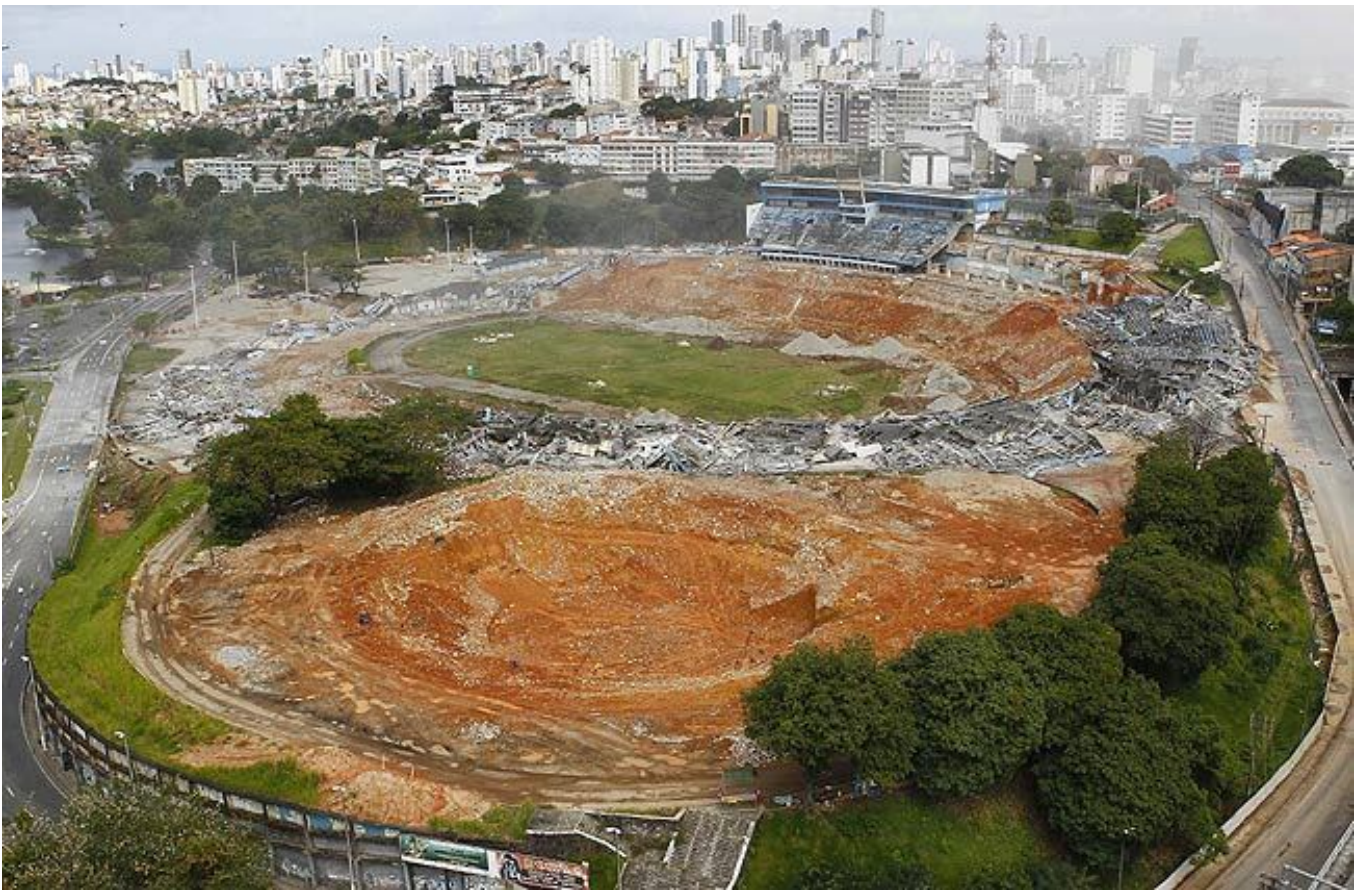

Fonte: A Tarde (2010).

Figura 6 - Situação da obra da Arena Fonte Nova em abril de 2012

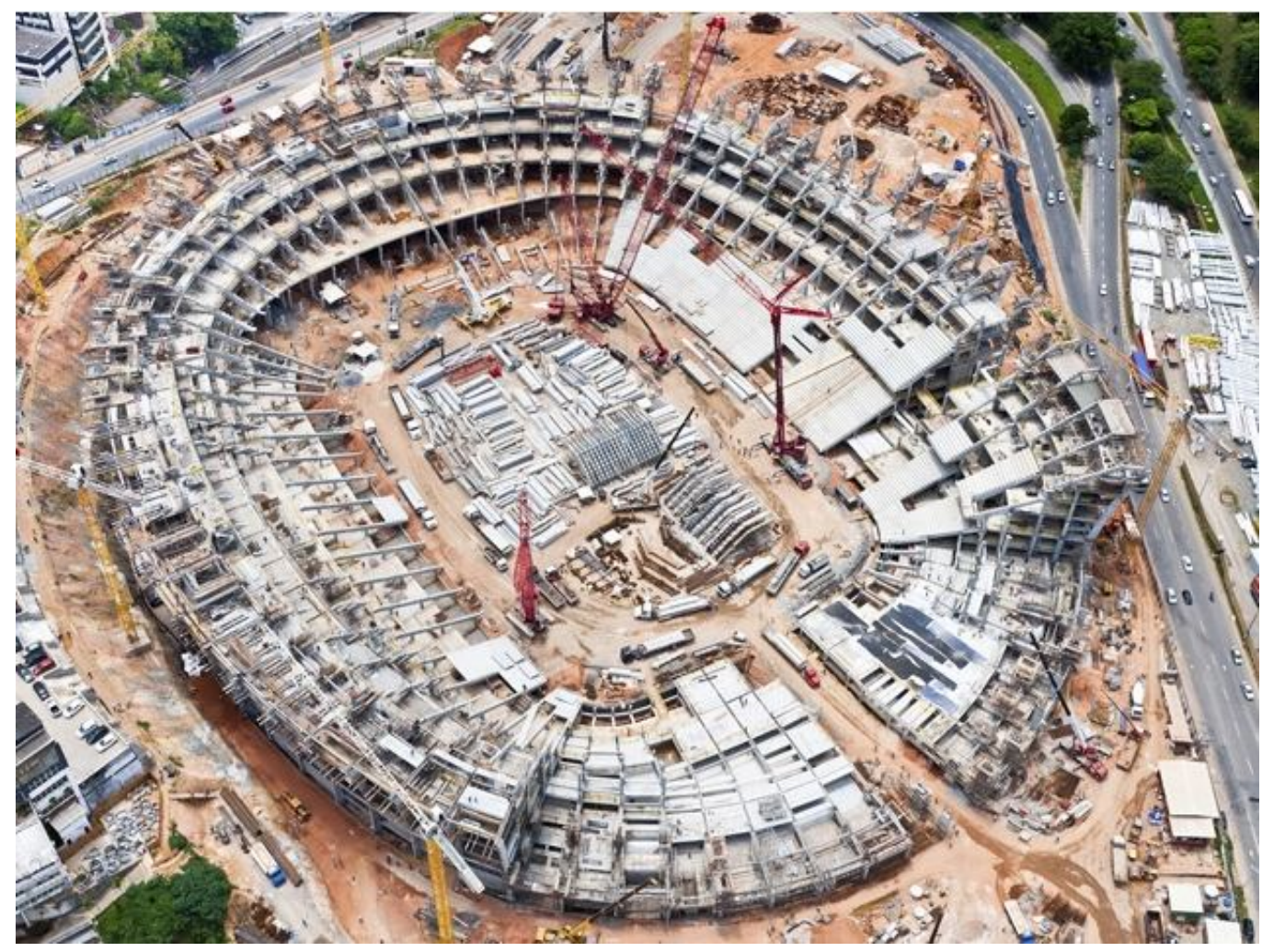

Fonte: Odebrecht (2012). 
A outra obra estudada foi a da construção da Arena Multiuso Pernambuco, que está sendo construída em São Lourenço da Mata, na zona oeste da Região Metropolitana do Recife, localizada a 19 quilômetros do Marco Zero da cidade e do Aeroporto Internacional dos Guararapes, e a $3 \mathrm{~km}$ do Terminal Integrado de Passageiros, estação Rodoviária. A escolha do local foi uma decisão estratégica para criar uma nova área de expansão para a região metropolitana (Figura 7). A obra teve seus trabalhos iniciados em novembro de 2010, com a execução inicial de serviços de desmatamento e terraplenagem.

A Arena Pernambuco terá 46 mil lugares, distribuídos em arquibancadas, camarotes e cadeiras especiais. A estrutura do estádio será adaptada para receber diversos eventos como shows, convenções e outras competições esportivas. O local terá 4.700 vagas de estacionamento, das quais 4.500 serão destinadas a veículos leves e 200 para ônibus. Ela é o ponto de partida para a Cidade da Copa, um novo núcleo urbano em São Lourenço da Mata, que reunirá áreas residenciais, de escritórios, educacional e de entretenimento, criando uma alternativa para a expansão urbana da Região Metropolitana do Recife. Serão preservados 600 mil metros quadrados de Mata Atlântica nativa existente na região e adotadas tecnologias que garantam o uso racional de recursos naturais como a reserva e utilização de água de chuva, reúso de água, energia solar e outras soluções que utilizam a luz e a ventilação naturais. 
Figura 7 - Localização da obra de construção da Arena Multiuso Pernambuco,

São Lourenço da Mata-PE

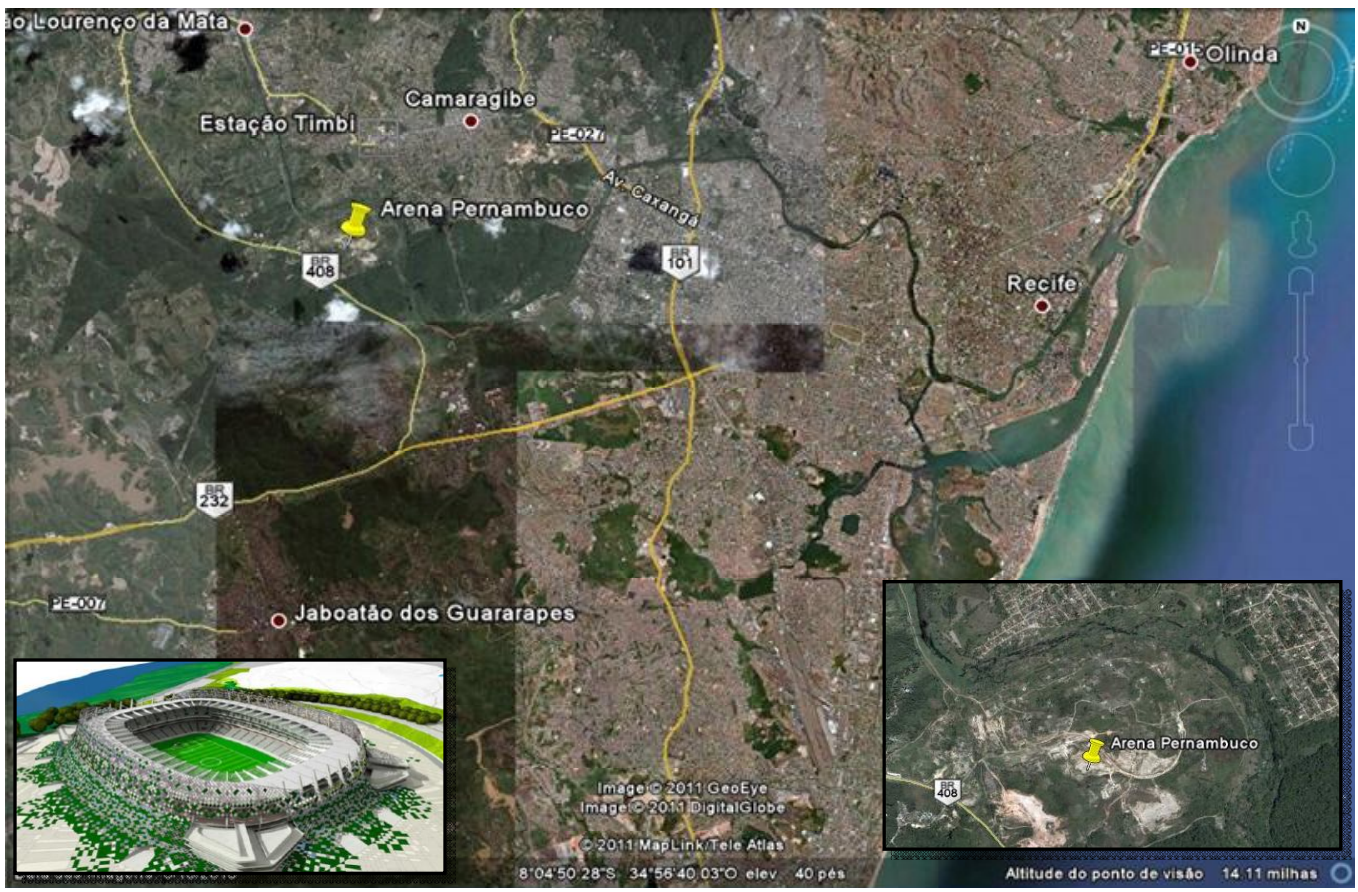

Fonte: Google Earth (2011).

Figura 8 - Área desmatada para construção da Arena Multiuso Pernambuco,

São Lourenço da Mata-PE

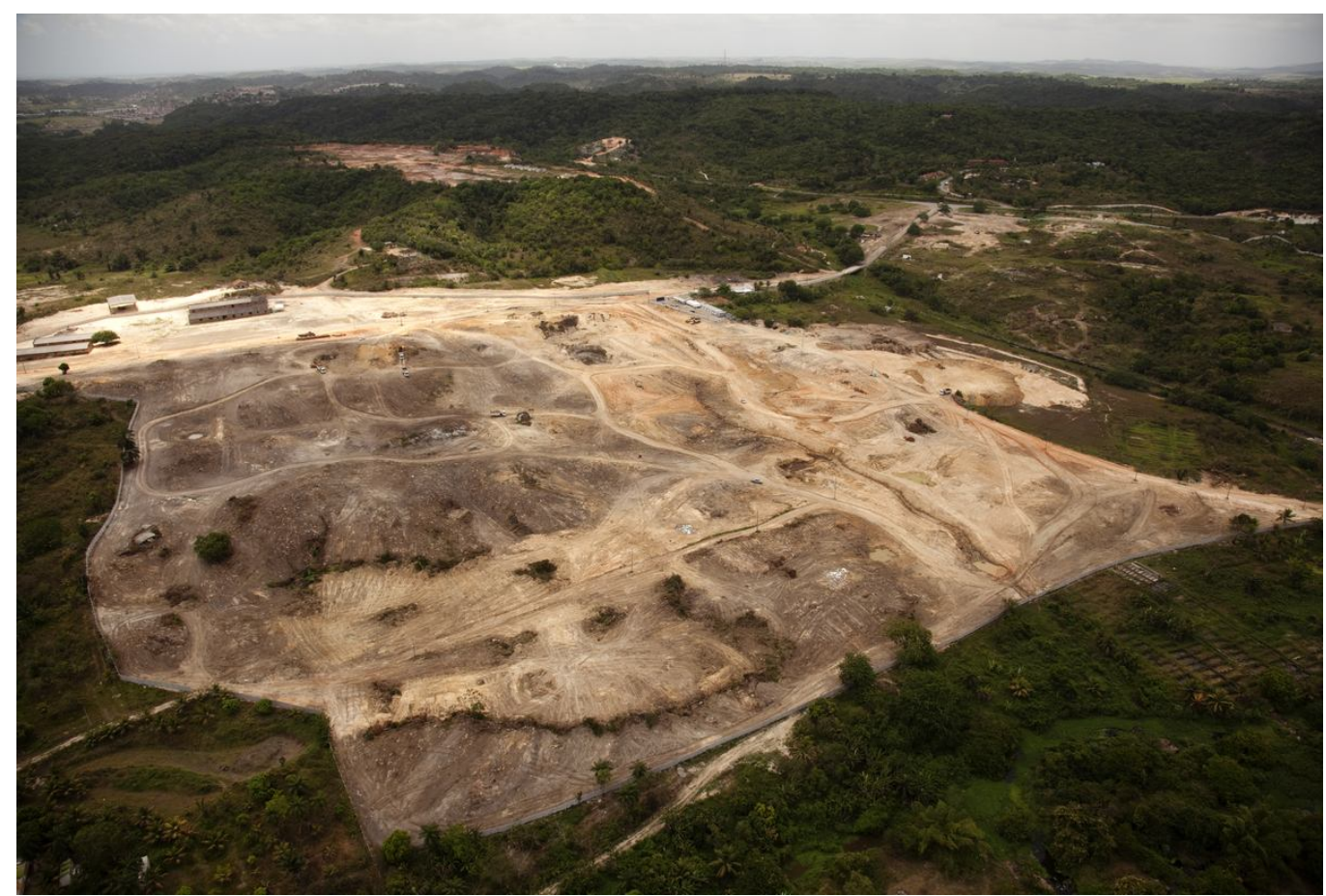

Fonte: SPE Arena Pernambuco (2010). 
Figura 9 - Situação da obra da Arena Pernambuco em março de 2012 - 1

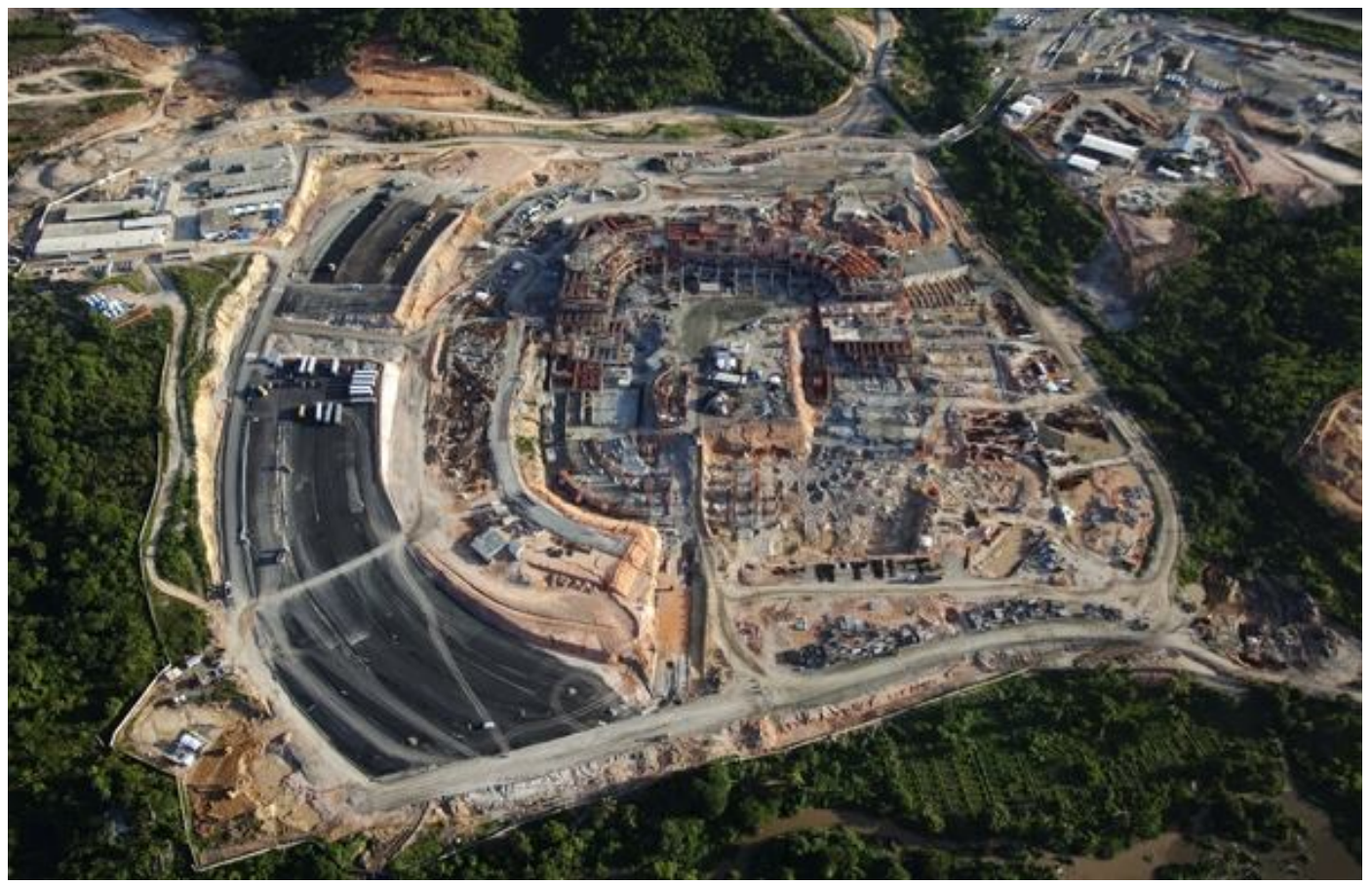

Fonte: Odebrecht (2012).

Figura 10 - Situação da obra da Arena Pernambuco em março de 2012 - 2

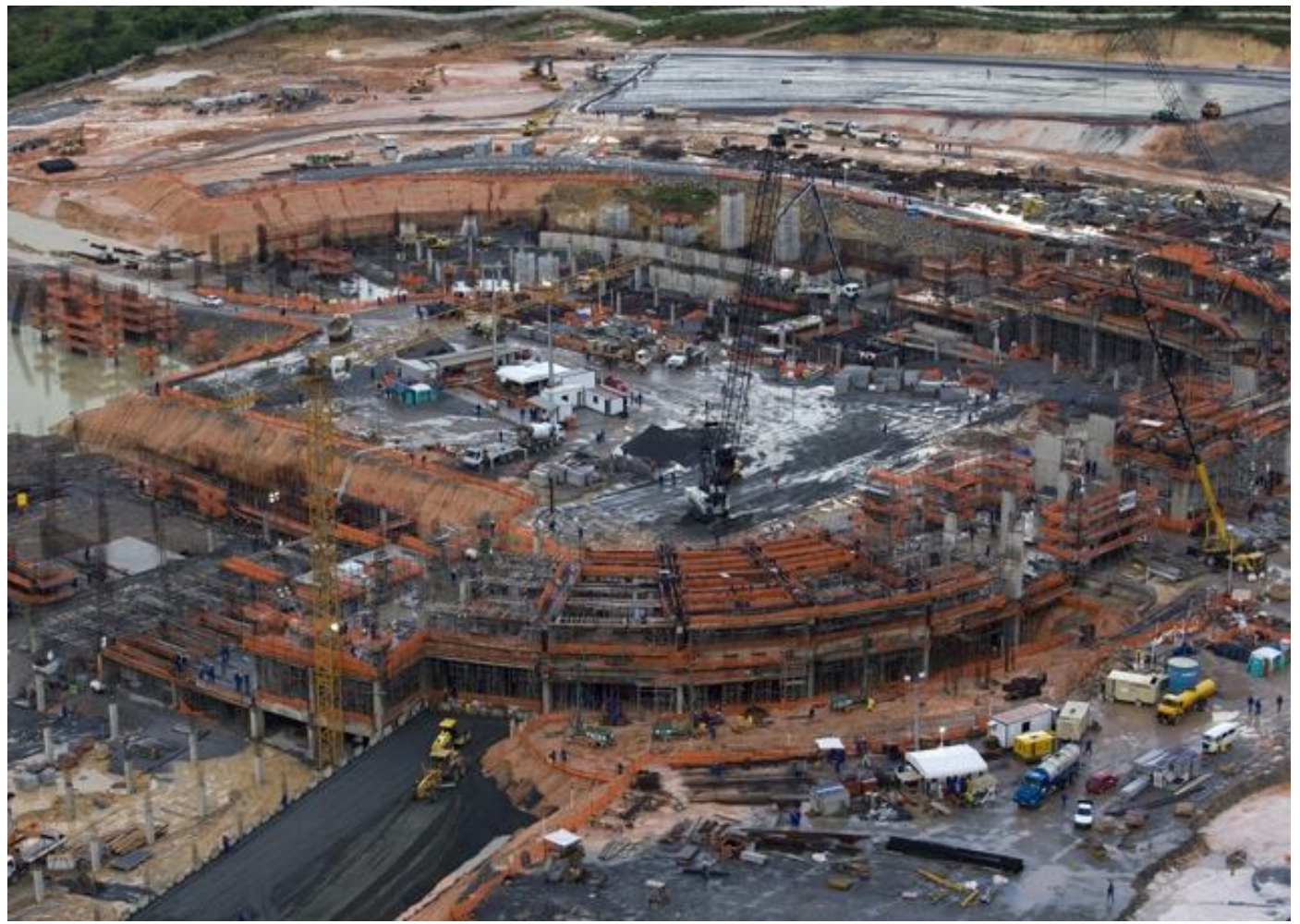

Fonte: Odebrecht (2012). 


\subsection{IDENTIFICAÇÃO DAS VARIÁVEIS E INDICADORES}

Richardson (apud MELO, 2001) afirma que qualquer trabalho científico contém variáveis e que elas podem estar inseridas nos objetivos e/ou nas hipóteses. Ele as define como características mensuráveis de um fenômeno que podem apresentar diferentes valores ou ser agrupadas por categorias.

Lakatos e Marconi (2010), por sua vez, consideram que toda hipótese é o enunciado geral de relações entre, pelo menos, duas variáveis, em que variável é definida como um conceito que contém ou apresenta valores, sendo o conceito um objeto, processo, agente, fenômeno e problema.

Segundo essas autoras, uma variável pode ser considerada uma classificação ou medida; uma quantidade que varia; um conceito, constructo ou conceito operacional que contém ou apresenta valores; aspecto, propriedade ou fator, discernível em um objeto de estudo e passível de mensuração. Estes valores que são adicionados ao conceito, constructo ou conceito operacional, para transformá-lo em variável, podem ser quantidades, qualidades, característica, magnitudes e traços, que se alteram em cada caso particular e são totalmente abrangentes e mutuamente exclusivos.

As variáveis podem ser dependentes, independentes, moderadoras, antecedentes, intervenientes etc. Melo (2001) destaca que a mensuração das variáveis é realizada por meio dos indicadores que são entendidos como fatores que possibilitam a mensuração ou indicação da variável no fenômeno. Considerando os referidos conceitos e tendo por base os objetivos e a fundamentação teórica do trabalho, são identificadas as variáveis e os respectivos indicadores apresentados no Quadro 1. 
Quadro 1 - Variáveis e indicadores

\begin{tabular}{|c|c|c|c|}
\hline Item & Variável & Definição Operacional & Indicadores \\
\hline 1 & Tamanho da Obra & $\begin{array}{c}\text { A obra pode ser de pequeno, médio } \\
\text { ou grande porte, de acordo com os } \\
\text { parâmetros observados }\end{array}$ & $\begin{array}{l}\text { Parâmetros considerados para a definição do } \\
\text { tamanho / porte das obras estudadas: } \\
\text { - № de funcionários } \\
\text { - Valor contratual } \\
\text { - Tipo de Obra } \\
\text { - Principais quantidades / serviços }\end{array}$ \\
\hline 2 & Geração de Resíduos & $\begin{array}{c}\text { Consiste na observação e } \\
\text { classificação dos diversos tipos de } \\
\text { resíduos gerados na obra, com } \\
\text { ênfase nos resíduos da construção } \\
\text { civil (RCC) }\end{array}$ & $\begin{array}{l}\text { Tipos de resíduos gerados, com a classificação dos } \\
\text { RCCs de acordo com a Resolução CONAM A no } \\
\text { 307/2002: } \\
\text { - Resíduos Sólidos Domiciliares } \\
\text { - Resíduos da Construção e Civil } \\
\text { - Resíduos de Poda e Capina } \\
\text { - Resíduos Industriais (pré-moldados) } \\
\text { - Resíduos de Serviços de Saúde } \\
\end{array}$ \\
\hline 3 & $\begin{array}{l}\text { Gerenciamento dos } \\
\text { Resíduos da } \\
\text { Construção Civil } \\
\text { (GRCC) }\end{array}$ & \begin{tabular}{|} 
Verificação da aplicação de \\
ferramentas e técnicas no GRCC, \\
através de documentos que \\
comprovem a existência do mesmo
\end{tabular} & $\begin{array}{l}\text { Documentos que comprovem a existência do } \\
\text { GRCC: } \\
\text { - Plano Integrado de GRCC dos municípios de São } \\
\text { Lourenço da Mata, Recife e Salvador } \\
\text { - Projeto de Gerenciamento de RCC da obra } \\
\text { - Cadastramento de áreas licenciadas, sendo elas } \\
\text { públicas ou privadas }\end{array}$ \\
\hline 4 & $\begin{array}{c}\text { Impacto Ambiental } \\
\text { da Obra }\end{array}$ & \begin{tabular}{|} 
Observação das atividades \\
realizadas na obra com o intuito de \\
reduzir o impacto ambiental da \\
mesma
\end{tabular} & $\begin{array}{l}\text { Ações da empresa de maneira combinada e/ ou } \\
\text { simultânea: } \\
\text { - M inimizar o consumo de recursos (conservar) } \\
\text { - M aximizar a reutilização de recursos (reutilizar } \\
\text { materiais e componentes) } \\
\text { - Usar recursos renováveis ou recicláveis (renovar / } \\
\text { reciclar) } \\
\text { - Proteger o meio ambiente (proteção da natureza) } \\
\text { - Criar um ambiente saudável e não tóxico (utilizar } \\
\text { não tóxicos) } \\
\text { - Buscar a qualidade na criação do ambiente } \\
\text { construído (aumentar a qualidade) }\end{array}$ \\
\hline
\end{tabular}

Fonte: Elaborado pela autora desta pesquisa.

\subsection{TÉCNICAS DE ANÁLISE DOS INDICADORES}

As técnicas, consideradas como um conjunto de preceitos ou processos de que se serve uma ciência, referem-se à habilidade de usar esses preceitos ou normas na obtenção de seus propósitos, correspondendo à parte prática da coleta de dados. Elas podem ser de documentação indireta (pesquisa documental e bibliográfica) e de documentação direta, esta subdividida em observação direta intensiva (observação e entrevista) e observação direta extensiva (questionário; formulário; medidas de opinião e de atitudes; testes; sociometria; análise de conteúdo; história de vida; pesquisa de mercado) (LAKATUS; MARCONI, 2010). 
Nesse caso, a pesquisa foi de documentação indireta, baseada na análise de todos os documentos relacionados ao assunto abordado, do conjunto de empresas estudadas; bibliográfica, por ter sido um estudo com base em material publicado em livros, artigos e redes eletrônicas sobre os assuntos: gerenciamento, resíduos da construção civil e obras de grande porte; e de documentação direta, por meio de observação direta intensiva com a técnica de observação individual, que "utiliza os sentidos na obtenção de determinados aspectos da realidade", e foi norteada por uma lista de verificação baseada no quadro de variáveis e indicadores (LAKATOS; MARCONI, 2010).

A observação direta extensiva foi realizada utilizando-se a técnica do formulário (Apêndice A), em que o entrevistador teve um roteiro de perguntas, preenchendo-o com a resposta do pesquisado.

\subsection{TRATAMENTO DOS DADOS}

Segundo Melo (2001), o tratamento dos dados obtidos pode ser processado de forma quantitativa, em que são utilizados procedimentos estatísticos, ou de forma qualitativa, referindo-se à interpretação e expressão dos significados lógicos das informações coletadas, tendo por base o marco teórico do trabalho.

Conforme argumentado na seção 4.3 , esta pesquisa tem como característica a natureza qualitativa, ainda que alguns dados sejam de natureza quantitativa, conforme pode ser observado no Questionário - Colaboradores (Apêndice A). Logo, com a obtenção dos dados coletados, foi possível fazer uma análise, de acordo com a fundamentação teórica deste trabalho de dissertação, e proceder à correta interpretação dos referidos dados. 


\section{RESULTADOS E DISCUSSÕES}

Tendo em vista a estrutura metodológica citada, toda a pesquisa obteve seus resultados com base no desenvolvimento de cada método descrito. Os indicadores utilizados foram ordenados por frequência, média, mediana, moda e desvio padrão e utilizados para base comparativa, baseado no quadro de variáveis e indicadores e no questionário aplicado na obra da Arena Fonte Nova e da Arena Pernambuco.

O desenvolvimento deste projeto utilizou um método de abordagem dedutivo, embasado na Resolução CONAMA n 307/2002 e na Política Nacional de Resíduos Sólidos, Decreto $\mathrm{n}^{\mathrm{o}} 7.404 / 2010$ que regulamenta a Lei $\mathrm{n}^{\mathrm{o}}$ 12.305. Com base nelas foi elaborado um questionário aplicado nos setores de Meio Ambiente das duas obras pesquisadas, tornando possível verificar a existência de Projeto de Gerenciamento de Resíduos da Construção Civil em ambas.

A pesquisa utilizou métodos de procedimentos comparativos, baseando-se nas práticas exigidas pela resolução e lei mencionadas, de forma a proceder à análise comparativa do modelo de gestão e gerenciamento de RCC adotado nas obras e o preconizado pela literatura existente: o monográfico, ou estudo de caso, do tipo multicaso, por meio da análise do modelo de gestão e gerenciamento implantado nas duas obras com características semelhantes; e o estatístico, por meio da análise dos dados qualitativos e quantitativos dos questionários passados aos colaboradores das obras.

A coleta de dados foi feita por meio de entrevistas realizadas com o gerente do setor de Saúde, Segurança do Trabalho e Meio Ambiente (SSTMA), com a técnica de Segurança, responsável pela gestão do plano de gerenciamento (Coordenadora do Setor de Meio Ambiente) e o técnico em Meio Ambiente e Saneamento da Arena Fonte Nova. Foi realizada ainda a aplicação de um questionário com colaboradores de ambas as obras - funcionários de diversas funções que trabalham na construção das Arenas (Questionário COLABORADORES) - e obtidas informações que preenchessem o quadro de variáveis e indicadores, com o Setor de Meio Ambiente das duas obras, conforme mencionado anteriormente. Foram feitas também visitas a campo para acompanhamento do processo de movimentação e aplicação dos resíduos, além da revisão bibliográfica, que permitiu a obtenção de informações referentes às exigências legais e normas técnicas pertinentes.

A definição dos principais indicadores e técnicas de avaliação do Gerenciamento dos Resíduos da Construção Civil adotado nas duas obras em estudo foi feita com base nos questionários aplicados aos colaboradores, no quadro de variáveis e indicadores, preenchidos 
pelos responsáveis dos setores ambientais das obras, e nas informações obtidas nas próprias obras, seja por meio da observação feita em visitas a campo, seja por meio dos materiais e atividades elaborados pelas obras, dando ênfase à Arena Fonte Nova, em razão do grande número de dados e informações obtidos.

Dessa forma, foi possível analisar o sistema de Gestão e Gerenciamento dos Resíduos da Construção Civil adotado na construção da Arena Pernambuco-PE e da Arena Fonte Nova-BA, após a regulamentação da Resolução CONAMA nº 307/2002 e da Política Nacional de Resíduos Sólidos, Decreto nº 7.404/2010 que regulamenta a Lei nº 12.305.

\subsection{GESTÃO E GERENCIAMENTO DOS RCC DA OBRA DA FONTE NOVA}

Conforme definido anteriormente, a gestão é um conjunto de normas e diretrizes que regulamentam os arranjos institucionais (identificação dos diferentes agentes envolvidos e seus respectivos papéis), os instrumentos legais e os mecanismos de financiamento. $\mathrm{O}$ gerenciamento, por sua vez, é a realização do que a gestão delibera, por meio da ação administrativa, de controle e planejamento de todas as etapas do processo (SCHALCH; CÓRDOBA, 2011).

Para a implantação e operação do Plano de Gerenciamento dos Resíduos da Construção Civil (PGRCC) da obra da Arena Fonte Nova, foram realizadas algumas etapas com suas respectivas atividades, as quais serão descritas a seguir.

Primeiramente, foram coletados dados da obra, por meio da análise de documentos. Em seguida, foi elaborado o planejamento do PGRCC, com a análise de documentos, requisitos legais, definição do que deveria ser feito, o motivo, as pessoas que o fariam, quando seria feito, onde, como e com quais recursos aplicáveis e necessários para tal. Depois, foi feita a elaboração do PGRCC, com a realização das atividades de análise de documentos, requisitos legais, definição do que seria feito e com quais recursos aplicáveis necessários.

A coleta de dados sobre a operacionalização do PGRCC e da reciclagem dos resíduos foi feita em seguida, com entrevistas, análise de documentos, visitas a campo e fornecedores e aplicação de questionários. Conseguinte, foi feita a implantação e operação do PGRCC com o estabelecimento de ações para evitar ou minimizar os aspectos e impactos ambientais identificados na etapa de planejamento, e a definição de ações de controle ambiental para as atividades executadas em razão da obra e dos procedimentos operacionais.

O monitoramento e medição foram feitos continuamente para que fosse possível gerenciar os aspectos e impactos ambientais. O procedimento de monitoramento e medição 
deve assegurar que sempre sejam feitas as verificações quantitativas e/ou qualitativas dos principais elementos que possam interferir no desempenho ambiental da obra. As medições também devem servir para saber se estão sendo atingidos os objetivos e metas propostos.

Por fim, foi feita, pela equipe responsável pela implantação, uma análise crítica e avaliação do PGRCC, relativas à economia, eficácia da disposição, implantação, entraves e pontos positivos, por meio da análise do próprio PGRCC, para assegurar sua eficiência e eficácia contínuas, baseada em informações e registros da gestão de resíduos, considerando os resultados obtidos.

Para a execução do Plano de Gerenciamento dos Resíduos da Construção Civil, é preciso mensurar o número de profissionais necessários de acordo com o histograma de mão de obra e tipo de projeto, ação que deverá ser conjunta com todas as equipes componentes do projeto e seus respectivos líderes.

Diversas atividades foram atribuídas à equipe de Saúde, Segurança do Trabalho e Meio Ambiente (SSTMA), com o intuito de se realizar o gerenciamento dos resíduos da forma mais correta e completa possível, facilitando o desempenho do trabalho de todos de forma unida e coesa. Essas atribuições foram definidas no PGRCC e estão transcritas a seguir:

a) Orientar e fazer cumprir as legislações pertinentes referentes ao gerenciamento de resíduos sólidos;

b) Inspecionar a realização dos devidos ensaios e testes de caracterização dos resíduos sólidos para verificação de seu potencial de poluição e definição de ações de controle;

c) Desenvolver e apoiar os gestores de processo na definição de opções de não geração, redução, reutilização, recuperação e reciclagem de resíduos sólidos;

d) Desenvolver e selecionar alternativas para o gerenciamento de resíduos sólidos com abrangência para todas as etapas do manejo sustentado;

e) Elaborar manifestos, fichas e envelopes de emergência para transporte externo dos resíduos sólidos perigosos, nos termos da legislação aplicável;

f) Obter eventuais autorizações e providenciar as comunicações necessárias aos órgãos ambientais para envio de resíduos sólidos para reciclagem, recuperação ou reutilização, tais como: manifestos, certificados, autorizações, entre outros;

g) Administrar os locais de armazenamento temporário de resíduos sólidos, denominados Centrais de Gerenciamento de Resíduos Sólidos; 
h) Definir conjuntamente com os supervisores e líderes de cada processo / atividade / frente de trabalho os locais de armazenamento interno de resíduos sólidos para coleta;

i) Inspecionar periodicamente nos locais de armazenamento temporário de resíduos sólidos;

j) Monitorar o processo de gerenciamento de resíduos e manter os registros do envio de resíduos sólidos para transporte externo, tratamento, disposição final, reciclagem, recuperação ou reutilização;

k) Aprovar, manter e revisar esse procedimento, sempre que necessário.

Pode-se observar que o planejamento, implantação e acompanhamento dos processos relacionados à gestão dos resíduos sólidos gerados na construção civil da Arena Fonte Nova contemplam a concepção do PGRCC. Dessa forma, foi possível realizar a gestão e o gerenciamento dos RCC da obra da Fonte Nova, servindo como base para a sua realização em futuras obras.

\subsection{O PGRCC DAS OBRAS}

Em Março de 2012, foi publicado pelo Ministério do Meio Ambiente (MMA) o Manual de Orientação para os Planos de Gestão de Resíduos Sólidos, com a intensão de esclarecer a um público específico - tomadores de decisão, gestores e técnicos dos estados e municípios, além de todos os envolvidos na implementação da PNRS (Lei n ${ }^{\circ}$ 12.305/2010), sobre a elaboração dos planos de gestão de resíduos sólidos, a partir de passos metodológicos que garantem a participação e o controle social e buscam o cumprimento das metas estabelecidas na lei, no Plano Nacional de Resíduos Sólidos e demais metas previstas em legislação correlata (BRASIL, 2012).

Para que isso ocorra, as ações estaduais e municipais tornam-se essenciais para o sucesso das políticas nacionais. Neste sentido, é de suma importância que os estados e municípios se engajem na construção de políticas e ações efetivas que se articulem com as nacionais para uma melhor gestão dos resíduos sólidos no Brasil.

O Manual ficou dividido em quatro partes: a primeira sobre o quadro institucional e legal; a segunda com orientações comuns a estados e municípios para a elaboração dos planos de gestão de resíduos sólidos e, por fim, as duas últimas partes apresentam um roteiro básico para os planos estaduais e os planos de gestão integrada de resíduos sólidos (BRASIL, 2012). 
Contudo, os Planos de Gerenciamento dos Resíduos da Construção Civil elaborados tanto pela Arena Fonte Nova quanto pela Arena Pernambuco não utilizaram o Manual supracitado como base, uma vez que o mesmo foi publicado após o início de ambas obras.

\subsubsection{PGRCC da Arena Fonte Nova}

O Plano de Gerenciamento dos Resíduos da Construção Civil (PGRCC) da Arena Fonte Nova foi elaborado com o intuito de contemplar os aspectos referentes à minimização na geração, segregação, acondicionamento, identificação, coleta, estocagem temporária, tratamento e disposição final dos resíduos sólidos gerados durante todas as fases da obra: demolição mecanizada e implosão do estádio, terraplanagem e implantação do novo complexo esportivo, além do escritório administrativo e canteiro de obras. Ele é atualizado mensalmente e enviado para o cliente, que envia uma cópia para a Superintendência do Meio Ambiente (SMA), órgão municipal da cidade de Salvador.

O novo estádio será constituído com dez níveis, contemplando a construção de edifício garagem, museu do futebol, lojas, salão multifuncional, restaurantes e escritórios, entre outros equipamentos associados ao empreendimento. Para que fosse realizada a sua implantação, foi necessário promover a demolição das estruturas do complexo olímpico da antiga Fonte Nova, composto pelo estádio Otávio Mangabeira, ginásio Antônio Balbino e Parque Aquático, as quais foram desmobilizadas pelo processo de demolição mecanizada e implosão, conforme Figura 11. Sua demolição foi realizada de forma seletiva, em três etapas, visando obter uma melhor qualidade dos resíduos.

A primeira etapa de demolição mecanizada das estruturas inferiores ocorreu entre os dias 20 de junho e 12 de agosto de 2010. A segunda etapa de planejamento e implantação dos materiais necessários à implosão teve início em 22 de julho de 2010 e conclusão em 28 de agosto de 2010, tendo ocorrido a implosão do estádio em 29 de agosto de 2010. A terceira etapa da demolição refere-se à tribuna de honra e foi realizada entre setembro de 2010 e novembro de 2010, concluindo-se, assim, toda a fase I da obra. 
Figura 11 - Sequência de execução da demolição e implosão do antigo estádio da Fonte Nova

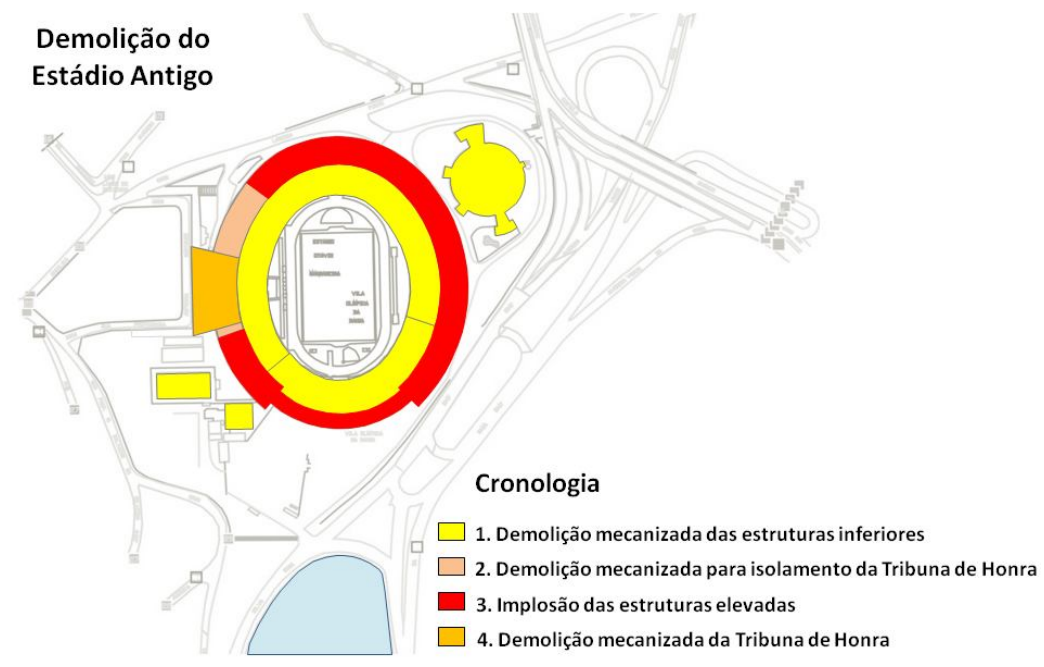

Fonte: FNP (2010).

No gerenciamento de resíduos da obra da Arena Fonte Nova foram contempladas as seguintes etapas:

a) Caracterização, com a identificação e quantificação dos resíduos;

b) Triagem e segregação, realizadas na origem da geração dos resíduos, ou nas áreas de destinação licenciadas para esta finalidade, respeitando as classes de resíduos;

c) Área de transbordo ou armazenamento temporário, onde os resíduos foram acondicionados desde a geração até a etapa de transporte;

d) Transporte, realizado em conformidade com as etapas anteriores e de acordo com as normas técnicas vigentes para transporte de resíduos;

e) Destinação final, prevista de acordo com o estabelecido na Resolução CONAMA nº 307/2002.

Com o objetivo de realizar uma melhor caracterização dos resíduos gerados na implantação da Arena Fonte Nova, o PGRCC descreve a geração dos resíduos em consonância com as fases das obras do empreendimento, que correspondem a:

a) Demolição (mecanizada e implosão);

b) Canteiro de obras, terraplenagem e construção da Arena Fonte Nova.

Os resíduos gerados na fase I - demolição (mecanizada e implosão) - correspondem ao material removido das áreas especificadas nas Tabelas 5 e 6, e estão descritos no Quadro 2, contendo o quantitativo da geração, classificação, frequência, acondicionamento, tratamento e estocagem. 
Tabela 5 - Volume de resíduos gerados por área

\begin{tabular}{lc}
\hline \multicolumn{1}{c}{ LOCAL } & VOLUME TOTAL $\left(\mathbf{m}^{3}\right)$ \\
\hline Parque Aquático & 1.495 \\
\hline Vestiários & 9.120 \\
\hline Tribuna de Honra & 1.850 \\
\hline Anel inferior & 4.691 \\
\hline Ginásio Antônio Balbino & 4.760 \\
\hline Anel superior & 11.180 \\
\hline \multicolumn{2}{c}{ TOTAL GERAL } \\
\multicolumn{2}{c}{ Fonte: FNP (2012). } \\
\hline
\end{tabular}

Tabela 6 - Volume de resíduos gerados por tipo de material

\begin{tabular}{lc}
\hline \multicolumn{1}{c}{ MATERIAIS } & VOLUME $\left(\mathbf{m}^{3}\right)$ \\
\hline Concreto & 28.852 \\
Alvenaria & 1.986 \\
Outros & 2.258 \\
\multicolumn{1}{c}{ TOTAL GERAL } & 33.096 \\
\hline
\end{tabular}

Fonte: FNP (2012). 
Quadro 2 - Resíduos gerados na fase I - demolição (mecanizada e implosão) da Arena Fonte Nova

\begin{tabular}{|c|c|c|c|c|c|c|c|c|}
\hline Item & Resíduo & Classe & Unidade/ Eq.Gerador & Período & $\begin{array}{l}\text { Acondicion/ } \\
\text { Armazen. }\end{array}$ & $\begin{array}{l}\text { Tratamento } \\
\text { adotado }\end{array}$ & $\begin{array}{l}\text { Frequência } \\
\text { de geração }\end{array}$ & $\begin{array}{c}\text { Quant. Total } \\
\text { Estimada }\end{array}$ \\
\hline 1 & $\begin{array}{l}\text { Concreto Britado } \\
\text { (brita graduada } \\
\text { simples) }\end{array}$ & A & $\begin{array}{l}\text { Demolição mecanizada } \\
\text { utilizando escavadeiras } \\
\text { hidráulicas e implosão } \\
\text { com uso de explosivos }\end{array}$ & $\begin{array}{l}\text { Jun/10 a } \\
\text { nov/10 }\end{array}$ & Pilhas & $\begin{array}{l}\text { Britagem } \\
\text { transformando } \\
\text { em brita } \\
\text { graduada } \\
\text { simples } \\
\end{array}$ & Diária & $28.852 \mathrm{~m}^{3}$ \\
\hline 2 & Alvenaria & A & $\begin{array}{l}\text { Demolição manual ou } \\
\text { mecanizada }\end{array}$ & \begin{tabular}{|l|}
$J u n / 10 a$ \\
nov/10
\end{tabular} & Pilhas & Segregação & Diária & $1.986 \mathrm{~m}^{3}$ \\
\hline 3 & $\begin{array}{l}\text { Sucata Ferrosa (aço } \\
\text { de concreto armado } \\
\text { e peças metálicas) }\end{array}$ & B & $\begin{array}{l}\text { Demolição mecanizada } \\
\text { utilizando escavadeiras } \\
\text { hidráulicas e implosão } \\
\text { com uso de explosivos }\end{array}$ & $\begin{array}{l}\text { Jun/10 a } \\
\text { nov/10 }\end{array}$ & Pilhas & Segregação & Diária & $1.400 \mathrm{~m}^{3}$ \\
\hline 4 & $\begin{array}{l}\text { Fios e cabos de } \\
\text { cobre (instalações } \\
\text { elétricas) }\end{array}$ & B & Remoção manual & $\begin{array}{l}J \text { un/10 a } \\
\text { nov/10 }\end{array}$ & Baias & Segregação & Eventual & $5 m^{3}$ \\
\hline 5 & Madeira & B & $\begin{array}{l}\text { Demolição de portas e } \\
\text { acessórios }\end{array}$ & $\begin{array}{l}\text { Jun/10 a } \\
\text { nov/10 }\end{array}$ & CE.CR & Segregação & Eventual & $3 m^{3}$ \\
\hline 6 & Madeira & B & Supressão vegetal & $\begin{array}{l}J \text { un/10 a } \\
\text { nov/10 }\end{array}$ & CE.CR & Segregação & |Eventual & $10 \mathrm{~m}^{3}$ \\
\hline 7 & Louças sanitárias & C & Demolição & $\begin{array}{l}J u n / 10 a \\
\text { nov/10 }\end{array}$ & CE.CR & Segregação & Eventual & $10 \mathrm{~m}^{3}$ \\
\hline 8 & $\begin{array}{l}\text { Esquadrias de } \\
\text { alumínio }\end{array}$ & B & Demolição & $\begin{array}{l}J u n / 10 \text { a } \\
\text { nov/10 }\end{array}$ & Baias & Segregação & |Eventual & $50 \mathrm{~m}^{2}$ \\
\hline 9 & Alvenaria de pedra & A & Demolição & $\begin{array}{l}J \text { un/10 a } \\
\text { nov/10 }\end{array}$ & Pilhas & Segregação & Eventual & $780 \mathrm{~m}^{3}$ \\
\hline \multicolumn{6}{|c|}{ Responsável pelo PRGCC: } & & & \\
\hline
\end{tabular}

Abreviações:CE=Caixa Estacinária/ CR=Central de Resíduos/ SQ=Sanitário Químico/ TB=Tambor 200lts/ CT=Contentor/ VC=Veículo/ BB=Bombona/ Papa Pilha=Recipiente/ CD=Central Decantador

RES. CONAMA 275 - Padronização de cores:Preto=madeira/ Amarelo=metal/ Cinza=Não reciclável/ Vermelho=Plástico/ Laranja=Contaminado/ Azul=Papel/ Verde=Vidro/ Marron=Orgânico

Fonte: FNP (2012).

Os resíduos gerados na fase II - canteiro de obras, terraplenagem e construção da Arena Fonte Nova- encontram-se relacionados no Quadro 3. 
Quadro 3 - Resíduos gerados na fase II - canteiro de obras, terraplenagem e construção da Arena Fonte Nova

\begin{tabular}{|c|c|c|c|c|c|c|c|c|}
\hline Item & Resíduo & Classe & Unidade/ Eq.Gerador & Período & $\begin{array}{l}\text { Acondicion } \\
\text { / Armazen. }\end{array}$ & \begin{tabular}{|c|}
$\begin{array}{c}\text { Tratamento } \\
\text { adotado }\end{array}$ \\
\end{tabular} & \begin{tabular}{|l|} 
Frequencia \\
de geração
\end{tabular} & \begin{tabular}{|c|}
$\begin{array}{c}\text { Quant. } \\
\text { Estimada }\end{array}$ \\
\end{tabular} \\
\hline \multicolumn{9}{|c|}{ RESÍDUOS DA PRODUÇÃO : } \\
\hline 1 & Material Argiloso & A & Escavação/terraplenagem & set/10 a jan/11 & Pilhas & Segregado & Diária & $300.000 \mathrm{~m}^{3}$ \\
\hline 2 & Terra Vegetal & A & Escavação/terraplenagem & set/10 a jan/11 & Pilhas & Segregado & Diária & $4.451,817 \mathrm{~m}^{3}$ \\
\hline 3 & Material Misto & A & Escavação/terraplenagem & set/10 a jan/11 & Pilhas & Segregado & Diária & $250.000 \mathrm{~m}^{3}$ \\
\hline 4 & Madeira & B & $\begin{array}{l}\text { Carpintaria e supressão } \\
\text { vegetal }\end{array}$ & $\mathrm{mai} / 10 \mathrm{a}$ dez/12 & CE. CR & Segregado & Diária & $2.000 \mathrm{~m}^{3}$ \\
\hline 5 & Gesso & $B$ & Acabamento & mai/12 a dez/12 & CE. CR & Segregado & Eventual & $10 \mathrm{~kg} /$ mês \\
\hline 6 & Saco de cimento & B & Concretagem & jun/10 a nov/ 12 & CE . CR & Segregado & Eventual & $5 \mathrm{~m}^{3} /$ mês \\
\hline 7 & Isopor & C & Concretagem & $\mathrm{mar} / 11$ a mar/ 12 & CE . CR & Segregado & Eventual & $2 \mathrm{~kg} /$ mês \\
\hline 8 & Concreto & $A$ & Concretagem & $\mathrm{mar} / 11$ a mar/ 12 & Pilhas & Reciclado & Diária & $1 \mathrm{~m}^{3} / \mathrm{mês}$ \\
\hline 9 & Tinta/solvente/estopa & D & Pintura / acabamento & $\mathrm{mai} / 10$ a nov/12 & CE. CR & Segregado & Eventual & 100latas/mês \\
\hline 10 & EPI contaminado & D & Produção & dez/10 a dez/12 & CE . CR & Segregado & Eventual & 5un/mês \\
\hline 11 & Solo contaminado & D & Produção & jul/11 a dez/12 & CE. CR & Segregado & Eventual & $5 \mathrm{~m}^{3} / \mathrm{mês}$ \\
\hline 12 & EPI não contaminado & C & Produção & jul/10 a dez/12 & $C E \cdot C R$ & Segregado & Eventual & 120un/mês \\
\hline 13 & PVC & $B$ & Instalações hidráulicas & mai/11 a out/12 & CE . CR & Segregado & Eventual & $5 \mathrm{~m}^{3} /$ mês \\
\hline 14 & Esgotamento sanitário & D & Sanitário químico & $\mathrm{mai} / 10 \mathrm{a}$ dez/12 & $S . Q$ & Segregado & Diária & $13 \mathrm{~m}^{3} /$ mês \\
\hline 15 & Óleo Diesel usados & D & $\begin{array}{l}\text { Máquinas e } \\
\text { equipamentos }\end{array}$ & mai/10 a dez/12 & TB. CR & Segregado & Eventual & $0,5 \mathrm{l} / \mathrm{mês}$ \\
\hline 16 & Óleo Vegetal Refeitório & A & Refeitório & jun/10 a dez/ 12 & BB. LOCAL & Segregado & Eventual & $0,51 /$ mês \\
\hline 17 & $\begin{array}{l}\text { Lona (manta geotêxtil não } \\
\text { tecido) }\end{array}$ & C & Produção & set/10 a dez/ 12 & CE. CR & Segregado & Eventual & $400 \mathrm{~m}^{2} /$ mês \\
\hline 18 & $\begin{array}{l}\text { Resíduos da Construção } \\
\text { Civil (diversos) }\end{array}$ & A & Produção & set/10 a dez/ 12 & CE . CR & Segregado & Eventual & $20 \mathrm{~kg} / \mathrm{mês}$ \\
\hline 19 & $\begin{array}{l}\text { Sucata Ferrosa (aço de } \\
\text { peças metálicas) }\end{array}$ & B & $\begin{array}{l}\text { Sobras de sucatas das } \\
\text { armações metálicas em }\end{array}$ & set/10 a dez/ 12 & Pilhas & Segregação & Diária & $1400 \mathrm{t}$ \\
\hline 20 & $\begin{array}{l}\text { Efluentes Central de } \\
\text { Concreto }\end{array}$ & D & Central de Concreto & mai/10 a dez/12 & S.Q & Segregado & Diária & $13 \mathrm{~m}^{3} / \mathrm{mês}$ \\
\hline \multicolumn{9}{|c|}{ RESIDUOS ADM INISTRATIVOS: } \\
\hline 1 & Plástico & B & Escritório & $\mathrm{mai} / 10$ a dez/12 & CE. CR & Segregado & Semanal & $8 \mathrm{~kg} / \mathrm{mês}$ \\
\hline 2 & Papel/papelão & B & Escritório & $\mathrm{mai} / 10$ a dez/12 & CE. CR & Segregado & Diária & $15 \mathrm{~kg} / \mathrm{mês}$ \\
\hline 3 & Papel/bloco de anotações & B & Escritório & mai/11 a dez/12 & CE. CR & Segregado & Diária & $200 \mathrm{~kg} / \mathrm{mês}$ \\
\hline 4 & Vidro & B & Escritório & $\mathrm{mai} / 10 \mathrm{a}$ dez/ 12 & CE. CR & Segregado & Eventual & $1 \mathrm{~kg} /$ mês \\
\hline 5 & Metal & B & Escritório & $\mathrm{mai} / 10 \mathrm{a}$ dez/12 & CE . CR & Segregado & Eventual & $200 \mathrm{~kg} /$ mês \\
\hline 6 & Pilhas e baterias & $\mathrm{D}$ & Escritório & set/10 a dez/ 12 & Papa pilha & Segregado & Eventual & 10un/mês \\
\hline 7 & Lâmpadas fluorescentes & D & Escritório & $\mathrm{mai} / 10$ a dez/12 & CE. CR & Segregado & Eventual & 6un/mês \\
\hline 8 & Orgânico & $\begin{array}{c}\text { II-A não } \\
\text { inerte }\end{array}$ & Copa/refeitório & $\mathrm{mai} / 10 \mathrm{a}$ dez/12 & $\mathrm{CT} . \mathrm{CR}$ & Segregado & Diária & $300 \mathrm{~kg} /$ mês \\
\hline 9 & Óleo de cozinha & $\begin{array}{c}\text { II-A não } \\
\text { inerte }\end{array}$ & Refeitório & ago/10 a dez/12 & BB. CR & Segregado & Diária & $601 /$ mês \\
\hline 10 & Papel higiênico/ absorvente & D & Banheiros & $\mathrm{mai} / 10 \mathrm{a}$ dez/ 12 & BB. CR & Segregado & Diária & $250 \mathrm{~kg} /$ mês \\
\hline \multicolumn{6}{|c|}{ Responsável pelo PRGCC: } & \multicolumn{3}{|l|}{ Assinatura: } \\
\hline
\end{tabular}

Abreviações:CE=Caixa Estacinária/ CR=Central de Resíduos/ SQ=Sanitário Químico/ TB=Tambor 200lts/ CT=Contentor/ VC=Veículo/ $\mathrm{BB}=$ Bombona/Papa Pilha=Recipiente/ $\mathrm{CD}=$ Central Decantador

RES. CONAMA 275 - Padronização de cores:Preto=madeira/ Amarelo=metal/ Cinza=Não reciclável/ Vermelho=Plástico/ Laranja=Contaminado/ Azul=Papel/ Verde=Vidro/ Marron=Orgânico

Fonte: FNP (2012), corrigido pela autora 
5.2.1.1 Plano de movimentação de resíduos

Conforme ressaltado no PGRCC da Arena Fonte Nova, toda a destinação dos resíduos só é realizada mediante prévia comprovação da regularização ambiental do receptor. Com isso, o Consórcio Arena Fonte Nova, na posição de gerador dos resíduos sólidos, garante a sua correta destinação final.

Para tanto, todos os seus resíduos, conforme informado anteriormente, após caracterização, triagem, segregação e armazenamento temporário, são destinados a diversos locais e empresas diferentes, de acordo com os Quadros 4 e 5, que se referem às fases I e II, respectivamente.

Quadro 4 - Movimentação de resíduos gerados na fase I - demolição (mecanizada e implosão) da Arena Fonte Nova

\begin{tabular}{|c|c|c|c|c|c|c|c|}
\hline \multirow{2}{*}{ Item } & \multirow{2}{*}{ Resíduo } & \multirow{2}{*}{ Classe } & \multirow{2}{*}{$\begin{array}{l}\text { Estocagem } \\
\text { temporária }\end{array}$} & \multirow{2}{*}{ Transporte } & \multicolumn{3}{|c|}{ Destino Final } \\
\hline & & & & & Quantidade & Receptor previsto & Tratamento adotado \\
\hline \multirow[b]{2}{*}{1} & \multirow{2}{*}{$\begin{array}{l}\text { Concreto Britado (brita graduada } \\
\text { simples) }\end{array}$} & \multirow[b]{2}{*}{$A$} & \multirow[b]{2}{*}{-} & \multirow[b]{2}{*}{ Caçamba } & $12.000 \mathrm{~m}^{3}$ & Empreendimento & Aplicação na própria obra \\
\hline & & & & & $192 \mathrm{~m}^{3}$ & $\begin{array}{c}\text { CONSTRUTORA NM } \\
\text { OBRA CANAL DO IMBUI/ OAS }\end{array}$ & Usos diversos em obras \\
\hline 2 & Alvenaria & A & - & Caçamba & $1.986 \mathrm{~m}^{3}$ & Bota-fora & Disposição \\
\hline 3 & $\begin{array}{l}\text { Sucata Ferrosa (aço de concreto } \\
\text { armado e peças metálicas) }\end{array}$ & B & - & Caçamba & $4.830 \mathrm{Kg}$ & MM Metais & Reciclagem \\
\hline \multirow{2}{*}{4} & \multirow{2}{*}{$\begin{array}{l}\text { Fios e cabos de cobre (instalações } \\
\text { elétricas) }\end{array}$} & \multirow{2}{*}{ B } & \multirow{2}{*}{-} & \multirow{2}{*}{ Caçamba } & $2 \mathrm{~m}^{3}$ & Canteiro de obras (Nova Fonte Nova) & Reutilizar \\
\hline & & & & & $3 m^{3}$ & Comercializado para ferro velho & Reciclagem \\
\hline \multirow{2}{*}{5} & \multirow{2}{*}{ Madeira } & \multirow{2}{*}{$B$} & \multirow{2}{*}{ - } & Caçamba & $1,5 \mathrm{~m}^{3}$ & Cerâmica Moderna (Poty) & Reutilizar \\
\hline & & & & Manual & $1,5 \mathrm{~m}^{3}$ & Canteiro de obras (Nova Fonte Nova) & Reutilizar \\
\hline 6 & Madeira & B & - & Caçamba & $10 \mathrm{~m}^{3}$ & Cerâmica M oderna (Poty) & Reutilizar \\
\hline \multirow{2}{*}{7} & \multirow{2}{*}{ Louças sanitárias } & \multirow{2}{*}{ C } & \multirow{2}{*}{ - } & \multirow{2}{*}{ Caçamba } & $1,5 \mathrm{~m}^{3}$ & Canteiro de obras (Nova Fonte Nova) & Reutilizar \\
\hline & & & & & $8,5 \mathrm{~m}^{3}$ & Bota-fora & Disposição \\
\hline 8 & Esquadrias alumínio & $\mathrm{B}$ & - & Caçamba & $12 \mathrm{~m}^{2}$ & Canteiro de obras (Nova Fonte Nova) & Reutilizar \\
\hline 9 & Alvenaria de pedra & A & - & Caçamba & $780 \mathrm{~m}^{3}$ & Outras Obras & Reutilizar \\
\hline \multicolumn{8}{|c|}{ Responsável pelo PRGCC: } \\
\hline \multicolumn{8}{|c|}{$\begin{array}{l}\text { Abreviações:CE=Caixa Estacinária/ CR=Central de Resíduos/ SQ =Sanitário Químico/ TB=Tambor 200lts/ CT=Contentor/ VC=Veículo/ BB=Bombona/Papa } \\
\text { Pilha=Recipiente/ CD=Central Decantador } \\
\text { RES. CONAMA } 275 \text { - Padronização de cores:Preto=madeira/ Amarelo=metal/ Cinza=Não reciclável/ Vermelho=Plástico/ Laranja=Contaminado/ Azul=Papel/ } \\
\text { Verde=Vidro/ Marron=0rgânico }\end{array}$} \\
\hline
\end{tabular}

Fonte: FNP (2012).

Pode-se observar no Quadro 4 que a maioria dos resíduos gerados foi reutilizada na própria obra ou em outras obras, uma parcela pequena foi disposta em áreas previamente licenciadas para descarte, realizando-se uma destinação final mais adequada para a maioria dos resíduos gerados e, desta forma, menor impacto ambiental. 
Quadro 5 - Movimentação dos resíduos gerados na fase II - canteiro de obras, terraplenagem e construção da Arena Fonte Nova

\begin{tabular}{|c|c|c|c|c|c|c|c|}
\hline \multirow{2}{*}{ Item } & \multirow{2}{*}{ Resíduo } & \multirow{2}{*}{ Classe } & \multirow{2}{*}{$\begin{array}{l}\text { Estocagem } \\
\text { temporária }\end{array}$} & \multirow{2}{*}{ Transporte } & \multicolumn{3}{|c|}{ Destino Final } \\
\hline & & & & & Quant. & Receptor & Tratamento adotado \\
\hline \multicolumn{8}{|c|}{ RESÍDUOS DA PRODUÇÃO : } \\
\hline 1 & Material Argiloso & A & - & Caçamba & - & - & - \\
\hline 2 & Material Misto & $A$ & \multirow{2}{*}{-} & Caçamba & $2475 \mathrm{~m}^{3}$ & AP. GONÇALVES & Reutilização \\
\hline 3 & Terra Vegetal & $A$ & & - & - & - & - \\
\hline 4 & Madeira & B & $10 \mathrm{~m}^{3}$ & Munck/carroc. & $21 \mathrm{~m}^{3}$ & CERÂMICA POTY & Reutilização \\
\hline 5 & Gesso & B & - & Caçamba & - & - & - \\
\hline 6 & Saco de cimento & B & $30 \mathrm{~kg}$ & Caçamba & - & - & - \\
\hline 7 & Isopor & C & $5 \mathrm{~kg}$ & Caçamba & - & - & - \\
\hline 8 & Concreto (Área geral muro) & A & - & Caçamba & - & - & - \\
\hline 9 & Tinta/solvente/ estopa & D & 120 latas & Cam.carroceria & - & - & - \\
\hline 10 & Solo contaminado & D & $1,5 \mathrm{~m}^{3}$ & Cam.carroceria & - & - & - \\
\hline 11 & EPI contaminado & D & 5 un & Munck/carroc. & - & - & - \\
\hline 12 & EPI não contaminado & C & - & Munck/carroc. & - & - & - \\
\hline 13 & Fardamento Usado & C & 200 un & Baú/Saveiro & $20 \mathrm{Kg}$ & PROJETO AXÉ & Reutilização \\
\hline 14 & PVC & B & $5 \mathrm{~kg}$ & Munck/carroc. & - & - & - \\
\hline 15 & Efluentes & D & $0,800 \mathrm{~m}^{3}$ & Cam.Sugador & $4,4 \mathrm{~m}^{3}$ & QUALYSAN / EMBASA ETE & Tratamento \\
\hline 16 & óleo Diesel usados & D & - & Munck/carroc. & - & - & - \\
\hline 17 & Óleo Vegetal Refeitório & $A$ & $120 \mathrm{~L}$ & Pick-up & - & - & - \\
\hline 18 & Lona (manta geotêxtil não tecido) & $\mathrm{C}$ & $400 \mathrm{~m}^{2}$ & Munck/carroc. & - & - & - \\
\hline 19 & Entulho & $A$ & $15 \mathrm{~m}^{3}$ & Munck/carroc. & $90 \mathrm{~m}^{3}$ & JLD - ENTULHO / REVITA & Disposição Aterro \\
\hline 20 & $\begin{array}{l}\text { Sucata Ferrosa (aço de peças } \\
\text { metálicas) }\end{array}$ & B & - & Caçamba & - & - & - \\
\hline \multicolumn{5}{|c|}{ RESÍDUOS ADMINISTRATIVOS: } & & & \\
\hline 1 & Plástico & B & $100 \mathrm{~kg}$ & Caminhão & - & - & - \\
\hline 2 & Papel/papelão & B & $20 \mathrm{~kg}$ & Caminhão & - & - & - \\
\hline 3 & Papel/bloco de anotações & B & $8 \mathrm{~kg}$ & Pick-up & $1100 \mathrm{Kg}$ & $\begin{array}{c}\text { CAS (Consórcio Arena } \\
\text { Salvador) }\end{array}$ & Reutilização pelo CAS \\
\hline 4 & Vidro & B & $40 \mathrm{~kg}$ & Caminhão & - & - & - \\
\hline 5 & Metal & B & $160 \mathrm{~kg}$ & Caminhão & - & - & - \\
\hline 6 & Pilhas e baterias & D & 30 un & Picape & - & - & - \\
\hline 7 & Lâmpadas fluorescentes & D & 45 un & Papa lâmpada & - & - & - \\
\hline 8 & Orgânico & II-A não inerte & - & Compactador & $2000 \mathrm{Kg}$ & VEGA/ REVITA & Aterro Vega \\
\hline 9 & óleo de cozinha & II-A não inerte & - & Picape & - & - & - \\
\hline 10 & Papel higiênico/ absorvente & D & - & Compactador & $1000 \mathrm{Kg}$ & VEGA/ REVITA & Aterro Vega \\
\hline \multicolumn{2}{|c|}{ Responsável pelo PRGCC: } & & & & & Assinatura: & \\
\hline
\end{tabular}

Abreviações:CE=Caixa Estacinária/ CR=Central de Resíduos/ SQ=Sanitário Químico/ TB=Tambor 200lts/ CT=Contentor/ VC=Veículo/ BB=Bombona/Papa Pilha=Recipiente/ $C D=$ Central Decantador

RES. CONAMA 275 - Padronização de cores:Preto=madeira/ Amarelo=metal/ Cinza=Não reciclável/ Vermelho=Plástico/ Laranja=Contaminado/ Azul=Papel/ Verde=Vidro/ Marron=0rgânico

Fonte: FNP (2012).

Os resíduos da fase II, diferentemente da fase I da obra, têm destinações diversificadas, de acordo com o tipo e classe, com o intuito de se realizar a reutilização da maior parte e destinação mais adequada possível de todos. Como os dados do Quadro 5 são atualizados mensalmente, muitos dos resíduos não são transportados no período e estão estocados temporariamente na obra ou não foram gerados no período, sendo este o motivo de haver lacunas. 


\subsubsection{Medidas mitigadoras}

Com o objetivo de orientar e contribuir com a minimização da geração dos resíduos, são adotadas em toda a obra as seguintes medidas, conforme apresentado no próprio PGRCC:

a) Distribuição de coletores identificados pelas áreas, visando despertar a importância da reciclagem;

b) Treinamento e conscientização com integrantes e parceiros com a divulgação dos programas, planos de gerenciamento;

c) Fomento à reutilização de resíduos, principalmente os de classe $\mathrm{A}$, bem como otimização na compra de insumos e materiais;

d) Informativos de meio ambiente em todos os coletores de resíduos, mostrando a importância de separar cada resíduo no seu local adequado.

\subsubsection{O PGRCC da Arena Pernambuco}

O Plano de Gerenciamento dos Resíduos da Construção Civil da Arena Pernambuco está inserido no seu Plano de Gerenciamento de Resíduos Sólidos (PGRS). Ele visa implantar a sistemática de gerenciamento de todos os resíduos sólidos gerados na obra da Arena Pernambuco, garantindo o adequado manuseio, armazenamento e destinação final. Como no município de São Lourenço da Mata, onde a obra está situada, não há um órgão municipal regulador, a Agência Estadual de Meio Ambiente (CPRH) é o órgão que atua na fiscalização das obras. Ela exige o PGRS e seus relatórios de monitoramento. Já o PGRCC é usualmente cobrado pelas prefeituras.

Para a elaboração do PGRS, foram utilizados os seguintes documentos de referência:

a) PI-PRE-001 - Manual do Programa Integrado de Gestão da Sustentabilidade;

b) PI-PRE-MA-001 - Programa de Identificação e Avaliação dos Impactos e Aspectos Ambientais;

c) PI-PRE-011 - Objetivos e Metas dos Programas de Gestão da Sustentabilidade;

d) PI-PRE-006 - Qualimetria;

e) PI-PRE-MA-003 - Monitoramento Ambiental;

f) PI-PRE-009 - Tratamento de não Conformidades, Ações Corretivas e Preventivas;

g) PCA - Plano de Controle Ambiental da Arena Pernambuco. 
Com exceção do Plano de Controle Ambiental (PCA), todos esses documentos fazem parte dos procedimentos internos (PI) da empresa, e todas as obras devem segui-los durante sua execução. A correta implantação e utilização dos procedimentos são verificadas constantemente por meio de auditorias internas e externas realizadas pela empresa.

No PGRS estão definidas responsabilidades para as diversas áreas e pessoas atuantes na obra:

a) Diretor de Contrato: responsável por garantir a implementação deste procedimento por meio da disponibilização de recursos financeiros, materiais e humanos.

b) Setor de Serviços Gerais: administração, limpeza predial e recolhimento dos resíduos sólidos comuns, Classe I, Classe IIA e Classe IIB gerados nas áreas administrativas, canteiros de obras, frentes de serviços, e o encaminhamento ao armazenamento temporário e destinação final, conforme recomendações do setor de Sustentabilidade.

c) Setor de Sustentabilidade

- Cumprir o Programa de Gerenciamento de Resíduos Sólidos definido no PGRS da Arena Pernambuco;

- Identificar os recursos materiais e humanos necessários e providenciá-los;

- Identificar locais adequados de destinação dos resíduos sólidos, garantindo o cumprimento da legislação pertinente;

- Analisar os resultados obtidos com os controles, realizando análise crítica para definição de ações de melhorias, quando necessário.

O gerenciamento dos resíduos da obra da Arena Pernambuco tem a seguinte sequência executiva:

- Identificação e acondicionamento;

- Coleta e armazenamento temporário;

- Tratamento e disposição final.

\section{a) Identificação e acondicionamento}

Nesta etapa, todo resíduo gerado pela obra, em qualquer setor, deve ser classificado de acordo com a Resolução CONAMA. Após a identificação do tipo de resíduo, este deve ser acondicionado em condições seguras e devidamente identificado quanto à sua natureza, grau de risco e outras orientações necessárias. 
O acondicionamento deve ser feito em recipientes específicos para cada tipo de resíduo seguindo as cores da coleta seletiva, conforme PI-PRE-MA-009 Coleta Seletiva.

\section{b) Coleta e armazenamento temporário}

Ficou definido, nesta etapa, que todo transporte de resíduo deve ser executado com prévio conhecimento dos seus riscos e suas características de manuseio.

Os colaboradores envolvidos nessa atividade devem utilizar todos os equipamentos de proteção individual (EPIs) necessários para garantir sua segurança, conforme orientação da Segurança do Trabalho.

Os resíduos passíveis de reciclagem devem ser encaminhados à baia de resíduos que se encontra na área industrial da obra, seguindo sua classificação.

Os resíduos perigosos também devem ser armazenados na baia específica para este tipo de material, sendo devidamente acondicionados em recipiente que garanta a vedação e prevenção de vazamentos e/ou contaminação do solo.

Os demais resíduos devem ser encaminhados para o aterro sanitário licenciado ou reutilizados/doados, conforme o Quadro 6.

Em se tratando de resíduos da construção civil, eles devem ser armazenados em local isolado e devidamente identificado para posterior destinação, sendo priorizada a destinação para local de reciclagem desses materiais. Caso as características do resíduo não permitam sua reciclagem, deve ser encaminhado a aterro autorizado a receber esse tipo de material.

\section{c) Tratamento e disposição final}

Nesta última etapa, ficou estabelecido que toda disposição final deve obedecer à legislação pertinente e às diretrizes básicas para o gerenciamento dos resíduos da obra.

Com base na classe do resíduo gerado, deve ser dada adequada destinação, conforme Quadro 6. 
Quadro 6 - Tipos de resíduo, classificação e destinação final

\begin{tabular}{|c|c|c|c|c|}
\hline Tipo de resíduo & Classe & Local de maior geração & $\begin{array}{l}\text { Frequência de } \\
\text { coleta }\end{array}$ & Destinação \\
\hline Orgânico & IIA & Refeitório & Diária & Aterro sanitário \\
\hline Madeira & IIA & $\begin{array}{c}\text { Frentes de services; } \\
\text { Carpintaria }\end{array}$ & 3 em 3 dias & Reuso / Reciclagem \\
\hline Metal & IIA & $\begin{array}{l}\text { Frentes de Serviço; } \\
\text { Central de armação }\end{array}$ & 3 em 3 dias & Reciclagem \\
\hline $\begin{array}{c}\text { Resíduo } \\
\text { contaminado }\end{array}$ & I & $\begin{array}{c}\text { Frentes de serviço; } \\
\text { Oficina }\end{array}$ & Demanda & Incineração \\
\hline Ambulatorial & I & Ambulatório & Quinzenal & Incineração \\
\hline Não reciclável & IIA e IIB & $\begin{array}{c}\text { Refeitório; Escritório; } \\
\text { Frentes de serviço }\end{array}$ & Diária & Aterro sanitário \\
\hline Papel / Papelão & IIA & Escritório & Diária & Reciclagem \\
\hline Plástico & IIA & Escritório & Diária & Reciclagem \\
\hline Construção Civil & Classe A & Estaca raiz; sapatas & Demanda & Reúso / Reciclagem \\
\hline
\end{tabular}

De acordo com o PGRS, seguem as definições dos resíduos gerados na obra e diretrizes básicas no tratamento a ser dado aos mesmos:

\section{a) Resíduo orgânico}

Os resíduos orgânicos são os resíduos gerados nos refeitórios, tais como restos de comida. Eles devem ser coletados diariamente, após cada refeição, acondicionados em sacos plásticos resistentes e enviados a um aterro de resíduos ou reaproveitados em pocilgas ou para compostagem, de acordo com determinações e controle do setor de Sustentabilidade.

\section{b) Madeira}

Resíduos de madeira gerados nas frentes de serviços e na carpintaria devem ser acondicionados em recipientes devidamente identificados para que sejam separados de outros tipos de resíduos. Sua coleta deve atender à demanda, não excedendo três dias. A madeira coletada pode ser armazenada, temporariamente, na baia de resíduos até que se tenha um volume significativo, sendo suas destinações locais que aproveitem esse tipo de material, tais como cerâmicas, residências com fornos a lenha, dentre outros. Vale ressaltar que toda 
entrega de material a ser reaproveitado deve ser devidamente quantificada, com declaração de recebimento e manifesto de carga, para controle interno.

\section{c) Metal}

Resíduos metálicos são gerados tanto nas frentes de serviços quanto na central de armação e canteiro de obras. Esses resíduos devem ser armazenados separadamente e devidamente identificados. Sua coleta deve acompanhar a demanda, não devendo exceder três dias nos locais de maior geração. O material metálico deve ser armazenado na baia de resíduos específica até que se tenha uma quantidade representativa, e encaminhada aos locais de reciclagem mais próximos.

\section{d) Resíduo contaminado}

Os resíduos contaminados são gerados, principalmente, na oficina, nos comboios e geradores. Trata-se de qualquer material que tenha tido contato com óleo, graxas e combustíveis. Em razão de seu potencial poluidor é considerado um resíduo perigoso. Dessa forma, deve ser separado e armazenado em recipientes devidamente identificados, sendo seu armazenamento realizado em recipientes que não possibilitem qualquer vazamento e contato com o solo. Esses materiais não devem ser armazenados por muito tempo, atentando-se principalmente à oficina, onde a geração é maior. Os resíduos oleosos devem ser encaminhados a empresas especializadas em incineração.

\section{e) Resíduo ambulatorial}

Resíduo ambulatorial consiste em todo o material proveniente de serviços de saúde. Trata-se de resíduo considerado perigoso e por isso deve ser armazenado separadamente e devidamente identificado. Deve ser manuseado com cuidado, e para isso o trabalhador deve utilizar EPIs apropriados. Esse tipo de resíduo deve ser encaminhado para empresas de tratamento específico de resíduo hospitalar.

\section{f) Material não reciclável}

Material não reciclável consiste em resíduos como plásticos, copos e papéis sujos, embalagens, dentre outros que, em virtude de suas características, não possuem locais de recebimento para reciclagem e, por isso, não precisam ser separados. Esse tipo de resíduo é caracterizado como não perigoso, sendo sua armazenagem feita em sacos plásticos resistentes e sua destinação final é o aterro sanitário. 


\section{g) Papéis, plástico e papelão}

Papelão e papéis, materiais de grande geração, principalmente nos escritórios, consistem em resíduo não perigoso e reciclável. Eles devem ser armazenados em recipientes devidamente identificados, serem coletados separadamente e armazenados na baia de resíduos para posterior encaminhamento a recicladores desse material. Toda remessa de material a ser reciclado deve ser devidamente registrado por meio do manifesto de carga.

\section{h) Resíduos de construção civil}

Resíduos de construção civil gerados nas frentes de serviços devem ser acondicionados em recipientes devidamente identificados para que sejam separados de outros tipos de resíduos. Sua coleta deve atender à demanda. O resíduo coletado pode ser armazenado, temporariamente, em caçambas estacionárias até que se tenha um volume significativo, sendo sua destinação locais que reciclem esse tipo de material. Vale ressaltar que toda remessa de material a ser reciclado deve ser devidamente registrada por meio do manifesto de carga.

De acordo com o PGRS, as pessoas envolvidas nas operações de coleta, manuseio, acondicionamento, transporte e destinação final de resíduos devem ser treinadas de modo a estarem capacitadas a desempenhar suas funções e cientes dos riscos que os resíduos representam para a saúde humana e o meio ambiente.

Segue, na Figura 12, o fluxograma do gerenciamento dos resíduos da Arena Pernambuco. 
Figura 12 - Fluxograma do gerenciamento dos resíduos da Arena Pernambuco

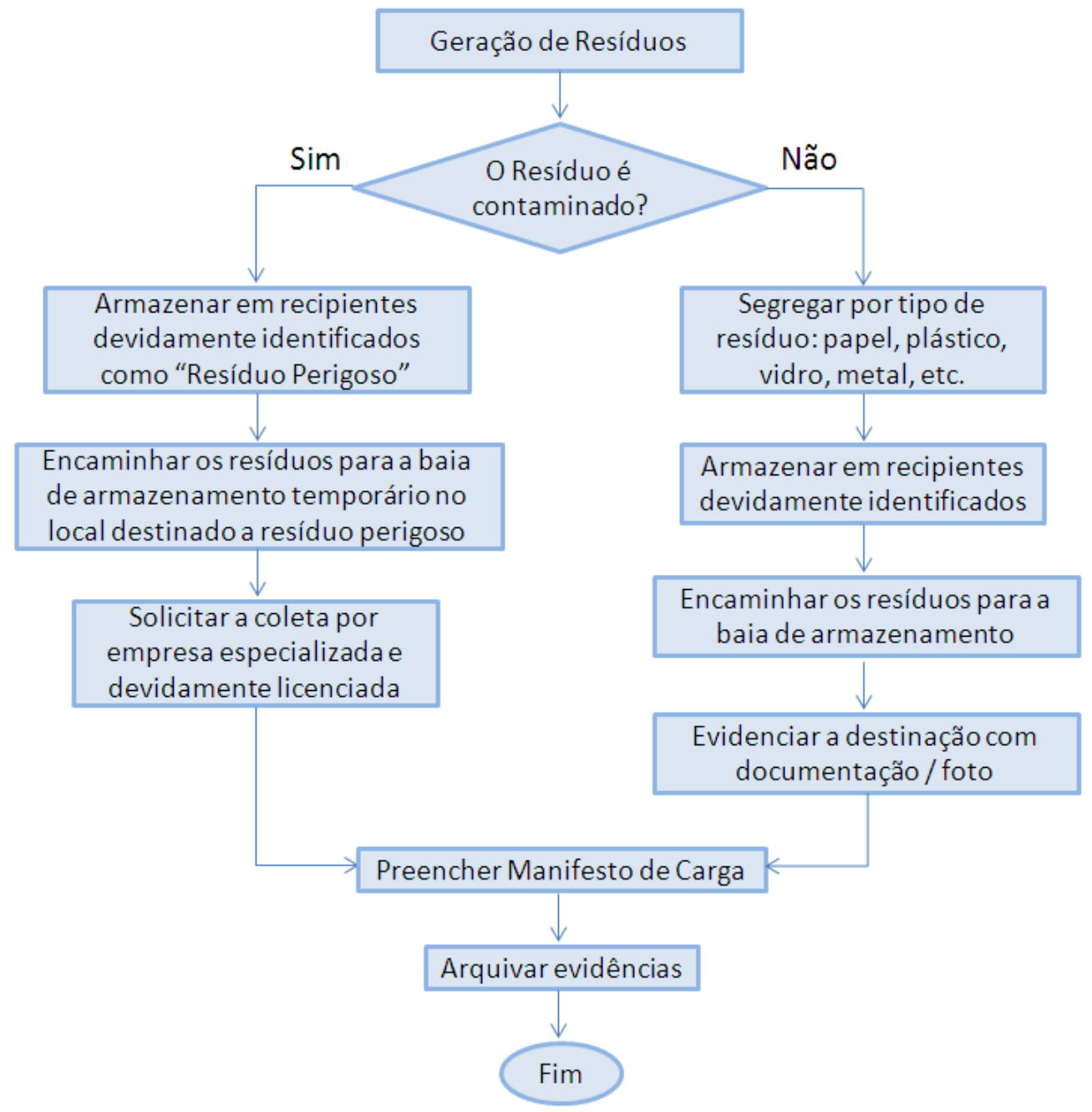

Fonte: SPE Arena Pernambuco (2011).

\subsection{VARIÁ VEIS E INDICADORES}

De acordo com o descrito na seção 4.5, IDENTIFICAÇÃO DAS VARIÁVEIS E INDICADORES, foi elaborado um quadro com variáveis e indicadores, e aplicado nas obras com o intuito de obter informações relativas ao objetivo específico da pesquisa, que é definir os principais indicadores e técnicas de avaliação do Gerenciamento dos Resíduos da Construção Civil (RCC) adotado nas duas obras em estudo. 


\subsubsection{Variáveis e indicadores da Arena Fonte Nova}

\section{a) Parâmetros considerados para a definição do tamanho / porte das obras estudadas}

- Número de funcionários: 1.641.

- Valor contratual: R \$ 673.279.186,00 (seiscentos e setenta e três milhões, duzentos

e setenta e nove mil, cento e oitenta e seis reais).

- Tipo de obra: construção de instalações esportivas e recreativas - (CNAE 42.99-

5-01).

- Serviço principal: demolição e reconstrução do estádio da Fonte Nova.

\section{b) Tipos de resíduos gerados, com a classificação dos RCCs de acordo com a}

Resolução CONAMA no 307/2002 (Identificar quais são os resíduos gerados e suas quantidades - média mensal e total):

Quadro 7 - Quantidade de resíduos recicláveis gerados na Arena Fonte Nova em 2011

\begin{tabular}{|c|c|c|c|c|c|c|c|c|c|c|c|c|c|c|}
\hline \multicolumn{12}{|c|}{ QUANTIDADE DE RESÍDUOS GERADOS } & \multicolumn{3}{|c|}{ Totais Recicláveis 2011} \\
\hline \multicolumn{15}{|c|}{ Resíduos Recicláveis } \\
\hline Meses & UND & JAN & FEV & MAR & ABR & MAI & JUN & JUL & AGO & SET & OUT & Nov & DEZ & ACUM \\
\hline Plástico & $\mathrm{Kg}$ & 287 & 297 & 235 & 0 & 210 & 520 & 302 & 420 & 280 & 0 & 200 & 0 & 2.751 \\
\hline Papel & $\mathrm{Kg}$ & 260 & 585 & 142 & 380 & 810 & 780 & 825 & 723 & 440 & 425 & 380 & 0 & 5.750 \\
\hline Madeira & $\mathrm{Kg}$ & 13.200 & 52.800 & 64.900 & 66.000 & 18.700 & 49.500 & 67.100 & 79.200 & 77.000 & 132.000 & 77.000 & 23.100 & 720.500 \\
\hline Vidros & $\mathrm{Kg}$ & 0 & 0 & 0 & 0 & 0 & 0 & 0 & 0 & 0 & 0 & 0 & 0 & 0 \\
\hline Sucata Ferrosa & $\mathrm{Kg}$ & 4.830 & 2.730 & 5.750 & 600 & 1.008 & 788 & 7.070 & 3.600 & 1.900 & 2.200 & 2.000 & 0 & 32.476 \\
\hline Concreto & $\mathrm{Kg}$ & 554.400 & 0 & 0 & 0 & 0 & 0 & 0 & 0 & 0 & 0 & 0 & 0 & 554.400 \\
\hline Material Argiloso & $\mathrm{Kg}$ & 7.422 .800 & 26.056 .800 & 10.656 .250 & 4.884 .000 & 3.049 .200 & 6.639 .600 & 11.264 .000 & 6.558 .200 & 0 & 0 & 0 & 0 & 76.530 .850 \\
\hline Material Misto & $\mathrm{Kg}$ & 9.240 .000 & \begin{tabular}{|l|}
21.221 .200 \\
\end{tabular} & 1.100 .000 & 3.432 .000 & 9.517 .200 & 493.900 & \begin{tabular}{|l|}
4.917 .000 \\
\end{tabular} & 5.832 .200 & 9.031 .000 & 704.000 & 1.064 .800 & 247.500 & 66.800 .800 \\
\hline Terra Vegetal & $\mathrm{Kg}$ & 985.600 & 0 & 0 & 0 & 0 & 0 & 0 & 0 & 0 & 0 & 0 & 0 & 985.600 \\
\hline Fardamento Usado & $\mathrm{Kg}$ & 0 & 0 & 0 & 0 & 0 & 20 & 0 & 0 & 0 & 200 & 50 & 20 & 290 \\
\hline Total Mês & $\mathrm{Kg}$ & 18.221 .377 & 47.334 .412 & 11.827 .277 & 8.382 .980 & 12.587 .128 & 7.185 .108 & \begin{tabular}{|l|}
16.256 .297 \\
\end{tabular} & 12.474.343 & 9.110 .620 & 838.825 & 1.144 .430 & 270.620 & 145.633 .417 \\
\hline
\end{tabular}

Quadro 8 - Quantidade de resíduos recicláveis gerados na Arena Fonte Nova em 2012

\begin{tabular}{|c|c|c|c|c|c|c|c|c|c|c|c|c|c|c|}
\hline \multicolumn{12}{|c|}{ QUANTIDADE DE RESÍDUOS GERADOS } & \multicolumn{3}{|c|}{ Totais Recicláveis 2012} \\
\hline \multicolumn{15}{|c|}{ Resíduos Recicláveis } \\
\hline Meses & UND & JAN & FEV & MAR & ABR & MAI & JUN & JUL & AGO & SET & OUT & NOV & DEZ & ACUM \\
\hline Plástico & $\mathrm{kg}$ & 500 & 0 & & & & & & & & & & & 500 \\
\hline Papel & $\mathrm{kg}$ & 1.000 & 0 & & & & & & & & & & & 1.000 \\
\hline Madeira & $\mathrm{Kg}$ & 26.400 & 13.200 & & & & & & & & & & & 39.600 \\
\hline Vidros & $\mathrm{kg}$ & 0 & 0 & & & & & & & & & & & 0 \\
\hline Sucata Ferrosa & $\mathrm{kg}$ & 2.400 & 0 & & & & & & & & & & & 2.400 \\
\hline Entulho & $\mathrm{kg}$ & 55.680 & 43.860 & & & & & & & & & & & 99.540 \\
\hline Concreto & $\mathrm{kg}$ & 0 & 0 & & & & & & & & & & & 0 \\
\hline Material Argiloso & $\mathrm{kg}$ & 0 & 0 & & & & & & & & & & & 0 \\
\hline Material Misto & $\mathrm{kg}$ & 5.170 .000 & 2.167 .000 & & & & & & & & & & & 7.337 .000 \\
\hline Terra Vegetal & $\mathrm{kg}$ & 0 & 0 & & & & & & & & & & & 0 \\
\hline Fardamento Usado & $\mathrm{kg}$ & 38,25 & 10 & & & & & & & & & & & 48,40 \\
\hline Total Mês & $\mathrm{kg}$ & 5.256 .018 & 2.224 .070 & & & & & & & & & & & 7.480 .088 \\
\hline
\end{tabular}


Quadro 9 - Quantidade de resíduos não recicláveis gerados na Arena Fonte Nova em 2011

\begin{tabular}{|c|c|c|c|c|c|c|c|c|c|c|c|c|c|c|}
\hline \multicolumn{12}{|c|}{ QUANTIDADE DE RESÍDUOS GERADOS } & \multicolumn{3}{|c|}{$\begin{array}{c}\text { Totais Não Recicláveis } \\
2011 \\
\end{array}$} \\
\hline \multicolumn{15}{|c|}{ Resíduos Não Recicláveis } \\
\hline Meses & UND & JAN & FEV & MAR & $\overline{A B R}$ & MAI & JUN & JUL & AGO & SET & OUT & NOV & DEZ & ACUM \\
\hline Orgânico & $\mathrm{Kg}$ & 250 & 280 & 850 & 950 & 980 & 900 & 1.020 & 1.220 & 1.360 & 1.450 & 1.600 & 2.000 & 12.860 \\
\hline Papel higiênico & $\mathrm{Kg}$ & 150 & 160 & 140 & 160 & 200 & 220 & 280 & 440 & 400 & 500 & 800 & 1.000 & 4.450 \\
\hline EPI & $\mathrm{Kg}$ & 0 & 0 & 0 & 0 & 0 & 22.000 & 11.000 & 0 & 0 & 0 & 0 & 0 & 33.000 \\
\hline Resíduos contaminados & $\mathrm{Kg}$ & 0 & 0 & 0 & 0 & 0 & 0 & 4.950 & 550 & 0 & 0 & 0 & 0 & 5.500 \\
\hline Entulho & $\mathrm{Kg}$ & 22.000 & 33.000 & 38.500 & 27.500 & 38.500 & 44.000 & 55.000 & 27.500 & 16.500 & 44.000 & 33.000 & 99.000 & 478.500 \\
\hline Efluentes & $\mathrm{Kg}$ & 2.860 & 1.980 & 2.860 & 1.980 & 2.640 & 1.540 & 2.200 & 2.640 & 1.980 & 2.640 & 284.460 & 4.840 & 312.620 \\
\hline Total Mês & $\mathrm{Kg}$ & 25.260 & 35.420 & 42.350 & 30.590 & 42.320 & 68.660 & 74.450 & 32.350 & 20.240 & 48.590 & 319.860 & 106.840 & 846.930 \\
\hline
\end{tabular}

Quadro 10 - Quantidade de resíduos não recicláveis gerados na Arena Fonte Nova em 2012

\begin{tabular}{|c|c|c|c|c|c|c|c|c|c|c|c|c|c|c|}
\hline \multicolumn{12}{|c|}{ QUANTIDADE DE RESÍDUOS GERADOS } & \multicolumn{3}{|c|}{$\begin{array}{l}\text { Totais Não Recicláveis } \\
2012 \\
\end{array}$} \\
\hline \multicolumn{15}{|c|}{ Resíduos Não Recicláveis } \\
\hline Meses & UND & JAN & FEV & MAR & ABR & MAI & JUN & JUL & AGO & SET & OUT & NOV & DEZ & ACUM \\
\hline Orgânico & $\mathrm{Kg}$ & 2.200 & 2.800 & & & & & & & & & & & 5.000 \\
\hline Papel higiênico & $\mathrm{Kg}$ & 1.200 & 1.400 & & & & & & & & & & & 2.600 \\
\hline EPI & $\mathrm{Kg}$ & 0 & 0 & & & & & & & & & & & 0 \\
\hline Resíduos contaminados & $\mathrm{Kg}$ & 0 & 0 & & & & & & & & & & & 0 \\
\hline Efluentes & $\mathrm{Kg}$ & 242.000 & 387.200 & & & & & & & & & & & 629.200 \\
\hline Total Mês & $\mathrm{Kg}$ & 245.400 & 391.400 & & & & & & & & & & & 636.800 \\
\hline
\end{tabular}

Fonte: FNP (2012).

c) Documentos que comprovem a existência do GRCC

- Licença Ambiental - Superintendência do Meio Ambiente (SMA);

- Licença Ambiental dos receptores de resíduos;

- Declaração dos receptores de reutilização de resíduos.

\section{d) Plano Integrado de GRCC de Salvador}

O Estado, por meio do Instituto do Meio Ambiente e Recursos Hídricos (INEMA), possui um modelo de PGRCC que foi utilizado como base para a elaboração do PGRCC da Arena Fonte Nova.

e) Projeto de Gerenciamento de RCC da obra (PGRCC)

SIM, possui.

f) Cadastramento de áreas licenciadas, sendo elas públicas ou privadas

- Contrato com a Revita (indústria recicladora de embalagens longa vida pré e pósconsumo);

- Declaração de empresas que reutilizaram material: argila/ terra vegetal. 


\section{g) Ações da empresa de maneira combinada e/ou simultânea}

Ações pontuais - Campanhas:

- Conscientização para uso racional: água e energia;

- Prevenção de saúde;

- Coleta seletiva de resíduos;

- Plantio de árvores;

- Carnaval sem fome;

- Incentivo à leitura;

- Motivo por não fazer: Tempo.

\section{h) Minimizar o consumo de recursos (conservar)}

O Consórcio Arena Salvador atua com treinamento e conscientização dos colaboradores para evitar o desperdício. Planejamento para eliminar o retrabalho. Transportar materiais de construção de um lado para outro da obra aumenta as estatísticas do desperdício, por isso são armazenados próximos aos locais em que serão utilizados. A areia é armazenada em um cercado coberto por lona, e em local sem declividade - isso evita que ela escoe com a água das chuvas.

\section{i) Maximizar a reutilização de recursos (reutilizar materiais e componentes)}

Reutilização: papel/ pneus/ tubo PVC/ corpos de prova/ argila/ terra vegetal/ fardamento/ madeira.

\section{j) Usar recursos renováveis ou recicláveis (renovar / reciclar)}

Metal/ papelão/ plástico.

\section{k) Proteger o meio ambiente (proteção da natureza)}

Toda ação com probabilidade de impacto ambiental é realizada com consciência e equipamentos de mitigação. Exemplos:

- O abastecimento e a manutenção de máquinas contam com bandejões de metal para conter vazamentos que venham a ocorrer;

- Erradicação de árvores: foi feito um Termo e Acordo e Compromisso (TAC), com as devidas contrapartidas (que já foram cumpridas);

- Monitoramento de poeira e ruído; 
- Entorno: monitoramento semestral é realizado nas águas do Dique do Tororó:

Bacia de Oxum, Oxalá e Oxum e Fonte das Pedras.

\section{l) Criar um ambiente saudável e não tóxico (utilizar não tóxicos)}

- As compras são cautelosas, dando preferência a produtos que agridam menos o meio ambiente;

- Os ambientes de trabalho priorizam a iluminação e ventilação naturais;

- A obra conta com os locais determinados para fumantes;

- Os refeitórios são arejados e com telas de proteção;

- Os vestiários são ventilados e os banheiros azulejados;

- A área de vivência é ampla e conta com equipamentos de entretenimento.

m) Buscar a qualidade na criação do ambiente construído (aumentar a qualidade)

O projeto conta com desempenho mínimo da qualidade do ar interno e contribuição para o conforto e bem-estar dos usuários.

\subsubsection{Variáveis e indicadores da Arena Pernambuco}

\section{a) Parâmetros considerados para a definição do tamanho / porte das obras} estudadas:

- Número de funcionários: 1.928;

- Valor contratual: R \$ 579.000.000,00 (quinhentos e setenta e nove milhões);

- Tipo de obra: construção de instalações esportivas e recreativas - (CNAE 42.99$5-01)$

- Serviço principal: implantação da Arena Multiuso Pernambuco.

b) Tipos de resíduos gerados, com a classificação dos RCC de acordo com a Resolução CONAMA no 307/2002 (Identificar quais são os resíduos gerados e suas quantidades - média mensal e total) 
Quadro 11 - Quantidade Total de resíduos sólidos recicláveis gerados na Arena Pernambuco

\begin{tabular}{|l|r|r|r|r|r|}
\hline \multicolumn{7}{|c|}{ RESIDUOS SOLIDOS RECICLADOS (toneladas) } \\
\hline & METAL & \multicolumn{1}{c|}{ M ADEIRA } & \multicolumn{1}{c|}{ PLÁSTICO } & PAPEL & TOTAL M ENSAL \\
\hline $\mathrm{abr} / 11$ & & & & & 0,84 \\
\hline $\mathrm{mai} / 11$ & 0,32 & 0,52 & 0,00 & 0,00 & 3,36 \\
\hline $\mathrm{jun} / 11$ & 0,57 & 2,72 & 0,07 & 0,00 & 1,69 \\
\hline $\mathrm{jul} / 11$ & 0,33 & 1,28 & 0,09 & 0,00 & 2,15 \\
\hline $\mathrm{ago} / 11$ & 0,60 & 1,45 & 0,10 & 0,00 & 2,93 \\
\hline $\mathrm{set} / 11$ & 1,69 & 1,18 & 0,06 & 0,00 & 3,99 \\
\hline $\mathrm{out} / 11$ & 1,35 & 2,00 & 0,22 & 0,42 & 14,33 \\
\hline $\mathrm{nov} / 11$ & 9,04 & 3,85 & 1,07 & 0,37 & 43,51 \\
\hline $\mathrm{dez} / 11$ & 21,53 & 19,97 & 1,44 & 0,57 & 0,00 \\
\hline $\mathrm{jan} / 12$ & 0,00 & 0,00 & 0,00 & 0,00 & 0,00 \\
\hline fev/12 & 0,00 & 0,00 & 0,00 & 0,00 & $\mathbf{7 2 , 7 8}$ \\
\hline total & $\mathbf{3 5 , 4 3}$ & $\mathbf{3 2 , 9 6}$ & $\mathbf{3 , 0 4}$ & $\mathbf{1 , 3 6}$ & \\
\hline
\end{tabular}

Fonte: SPE Arena Pernambuco (2011).

\section{c) Documentos que comprovem a existência do GRCC}

- Licença Ambiental - Agência Estadual de Meio Ambiente (CPRH);

- Licença Ambiental dos receptores de resíduos;

- Declaração dos receptores de reutilização de resíduos;

- Manifesto de carga;

- Certificado de destinação.

d) Plano Integrado de GRCC dos municípios de São Lourenço da Mata e Recife

São Lourenço da Mata não possui e o de Recife não se aplica. São utilizadas as diretrizes da Agência Estadual de Meio Ambiente (CPRH).

e) Projeto de Gerenciamento de RCC da obra (PGRCC)

SIM, possui.

f) Cadastramento de áreas licenciadas, sendo elas públicas ou privadas

Não foi realizado

g) Ações da empresa de maneira combinada e/ou simultânea (quais ações são realizadas - explicar - e aquelas que não são, o motivo por não estarem sendo feitas)

Ações pontuais - Campanhas: 
- Conscientização para uso racional: água e energia;

- Prevenção de saúde;

- Coleta seletiva de resíduos;

- Plantio de árvores;

- Reutilização de materiais (resíduos de construção civil).

h) Minimizar o consumo de recursos (conservar)

A Arena Pernambuco atua com treinamento e conscientização dos colaboradores para evitar o desperdício. Planejamento para eliminar o retrabalho. Transportar materiais de construção de um lado para outro da obra aumenta as estatísticas do desperdício, por isso são armazenados próximos aos locais em que serão utilizados. A areia é armazenada em um cercado coberto por lona, e em local sem declividade - isso evita que ela escoe com a água das chuvas.

i) Maximizar a reutilização de recursos (reutilizar materiais e componentes)

Reutilização: papel/ tubo PVC/ corpos de prova/ argila/ terra vegetal/ madeira/ material do desmonte de rocha.

j) Usar recursos renováveis ou recicláveis (renovar / reciclar)

Metal/ papelão/ plástico/ madeira.

\section{k) Proteger o meio ambiente (proteção da natureza)}

Todo ação com probabilidade de impacto ambiental é realizada com consciência e equipamentos de mitigação:

- Abastecimento e manutenção de máquinas: contam com bandejões de metal para conter vazamentos que venham a ocorrer;

- Monitoramento de poeira e ruído;

- Entorno: monitoramento semestral é realizado nas águas do Rio Capibaribe e afluentes.

\section{1) Criar um ambiente saudável e não tóxico (utilizar não tóxicos)}

- As compras são cautelosas, dando preferência para produtos que agridam menos o meio ambiente;

- Os ambientes de trabalho priorizam a iluminação e ventilação naturais; 
- Os refeitórios são climatizados e com telas de proteção;

- Os vestiários são ventilados e os banheiros azulejados;

- A área de vivência é ampla e conta com equipamentos de entretenimento.

\section{m) Buscar a qualidade na criação do ambiente construído (aumentar a qualidade)}

O projeto conta com desempenho mínimo da qualidade do ar interno e contribuição para o conforto e bem-estar dos usuários.

Após a análise das informações relacionadas acima, referentes ao quadro de variáveis e indicadores, é possível concluir que ambas as obras são de grande porte, possuem seus Planos de Gerenciamento de Resíduos da Construção Civil, seguem a Resolução CONAMA n $307 / 2002$ e PNRS, por meio de suas ações durante a Gestão e o Gerenciamento dos Resíduos das obras das duas Arenas, e estão alinhadas no intuito de minimizar o consumo de recursos, maximizar a reutilização de recursos, usar recursos renováveis ou recicláveis, proteger o meio ambiente, criar um ambiente saudável e não tóxico e buscar a qualidade na criação do ambiente construído.

\subsection{GRCC DAS ARENAS VERSUS RESOLUÇÃO CONAMA No 307/2002 e PNRS}

Após a descrição dos Planos de Gerenciamento de Resíduos da Construção Civil das obras pesquisadas e da análise das variáveis e indicadores qualitativos das mesmas, foi possível avaliar o sistema de Gestão e Gerenciamento da Arena Fonte Nova e Arena Pernambuco à luz da Resolução CONAMA nº 307/2002 e da Política Nacional de Resíduos Sólidos, Decreto nº 7.404/2010 que regulamenta a Lei $\mathrm{n}^{\circ} 12.305$.

A Resolução CONAMA, no tocante ao modelo de Gerenciamento de Resíduos da Construção Civil, estabelece que os geradores de resíduos da construção civil devem ser responsáveis pelos seus resíduos e que a gestão integrada de resíduos da construção civil deverá proporcionar benefícios de ordem social, econômica e ambiental.

Ela define que o gerenciamento de resíduos é o sistema de gestão que visa reduzir, reutilizar ou reciclar resíduos, incluindo todas as atividades necessárias para tal feito, e que os Projetos de Gerenciamento de Resíduos da Construção Civil de médios e grandes geradores terão como objetivo estabelecer os procedimentos necessários para o manejo e destinação ambientalmente adequados dos resíduos. Esses projetos deverão contemplar as etapas de caracterização, triagem, acondicionamento, transporte e destinação. 
Por sua vez, a Política Nacional dos Resíduos Sólidos detalha mais a forma como deve ser elaborado o Plano de Gerenciamento de Resíduos Sólidos, definindo o seu conteúdo mínimo, ao qual as empresas de construção civil, nos termos do regulamento ou de normas estabelecidas pelos órgãos do Sistema Nacional do Meio Ambiente (SISNAMA), estão sujeitas.

Foi definido conteúdo mínimo para o plano de resíduos sólidos e este servirá como base para a comparação dos dois sistemas de Gestão e Gerenciamento de Resíduos da Construção Civil estudados.

\section{a) Descrição do empreendimento ou atividade}

No PGRCC da Arena Fonte Nova é feita a descrição do empreendimento por meio da identificação do gerador e descrição da atividade que engloba todos os serviços necessários para a execução da Arena propriamente dita.

Já o PGRS da Arena Pernambuco, que tem inserido o PGRCC, não faz essa descrição.

b) Diagnóstico dos resíduos sólidos gerados ou administrados, contendo a origem, o volume e a caracterização dos resíduos, incluindo os passivos ambientais a eles relacionados

Em ambos os planos de gerenciamento é feito o diagnóstico, contendo a origem e caracterização dos resíduos, contudo o volume não é detalhado no PGRS da Arena Pernambuco e ambos os planos não citam os passivos ambientais a eles relacionados.

c) Observadas as normas estabelecidas pelos órgãos do SISNAMA, do Sistema Nacional de Vigilância Sanitária (SNVS) e do Suasa, e, se houver, o plano municipal de gestão integrada de resíduos sólidos

No PGRCC da Arena Fonte Nova é informada a legislação básica incidente, a qual foi utilizada como referência para a elaboração do mesmo:

- RESOLUÇÃO CONAMA no 307, de 5 de julho de 2002, que estabelece diretrizes, critérios e procedimentos para a gestão dos resíduos da construção civil.

- RESOLUÇÃO CONAMA n 275, de 25 de abril de 2001, que estabelece o código de cores para os diferentes tipos de resíduos, a ser adotado na identificação de coletores e transportadores, bem como nas campanhas informativas para a coleta seletiva.

- RESOLUÇÃO RDC/ANVISA 306/04, Resolução da Diretoria Colegiada, de 7 
de dezembro de 2004, que estabelece a classificação dos resíduos do Serviço de Saúde.

- RESOLUÇÃO CONAMA no 358, de 29 de abril de 2005, que dispõe sobre o tratamento e a disposição final dos resíduos dos serviços de saúde e dá outras providências.

- NBR-10004 da ABNT - Classificação dos Resíduos Sólidos.

- NBR-13221 da ABNT - Classificação do Transporte Terrestre.

- Lei Estadual no 10.431/06, regulamentada pelo Decreto Estadual no 11.235/08, que dispõe sobre a Política de Meio Ambiente e de Proteção à Biodiversidade do Estado da Bahia e dá outras providências.

No PGRS da Arena Pernambuco é informada a utilização de documentação de referência, a qual está baseada nos procedimentos internos da empresa, além de um Plano de Controle Ambiental da Obra Arena Pernambuco. Os procedimentos internos da empresa foram elaborados em consonância com as normas brasileiras vigentes.

Ademais, são estabelecidos dois subitens que devem ser atendidos neste próprio item:

- Explicitação dos responsáveis pelas etapas do gerenciamento de resíduos sólidos

Em ambos os planos são definidas as responsabilidades pelas etapas do gerenciamento. Cada obra possui uma sistemática diferente, pois na Arena Pernambuco as responsabilidades não cabem apenas ao setor de Sustentabilidade (Saúde, Segurança do Trabalho e Meio Ambiente - SSTMA), e na Arena Fonte Nova a responsabilidade de todas as atividades relativas ao plano de gerenciamento é do próprio setor de Sustentabilidade.

- Definição dos procedimentos operacionais relativos às etapas do gerenciamento de resíduos sólidos sob responsabilidade do gerador

Ambos os planos definem detalhadamente os procedimentos operacionais relativos às etapas do gerenciamento de resíduos sólidos.

d) Identificação das soluções consorciadas ou compartilhadas com outros geradores

Não se aplica ao tipo de obra, pois há um único gerador de resíduos sólidos.

e) Ações preventivas e corretivas a serem executadas em situações de gerenciamento incorreto ou acidentes 
No PGRCC da Arena Fonte Nova há um item relativo às medidas mitigadoras, a serem adotadas durante toda a obra, como forma de minimizar a geração dos resíduos. No PGRS da Arena Pernambuco não há informações referentes a ações preventivas ou corretivas.

f) Metas e procedimentos relacionados à minimização da geração de resíduos sólidos e, observadas as normas estabelecidas pelos órgãos do Sisnama, do SNVS e do Suasa, à reutilização e reciclagem

No PGRCC da Arena Fonte Nova foi definida meta para a geração de $75 \%$ de resíduos recicláveis e $25 \%$ de resíduos não recicláveis. Essa meta já foi atingida e encontra-se com os seguintes percentuais: $92,2 \%$ de resíduos recicláveis e 7,8\% de resíduos não recicláveis gerados na obra. Os procedimentos encontram-se descritos no próprio plano. Vale ressaltar que os benefícios são visíveis e ocorrem em grande escala na obra, não apenas a redução dos resíduos gerados, como também a redução dos desperdícios e consumo de materiais, melhoria nas relações e contribuição para conscientização dos envolvidos.

No PGRS da Arena Pernambuco não há nenhuma informação referente a metas e nem procedimentos relacionados à minimização da geração de resíduos sólidos.

g) Se couber, ações relativas à responsabilidade compartilhada pelo ciclo de vida dos produtos, na forma do art. 31.

Não se aplica ao tipo de produto e resíduo gerado.

h) Medidas saneadoras dos passivos ambientais relacionados aos resíduos sólidos

Estas informações não constam em nenhum dos dois planos.

i) Periodicidade de sua revisão, observado, se couber, o prazo de vigência da respectiva licença de operação a cargo dos órgãos do Sisnama

O PGRCC da Arena Fonte Nova é atualizado mensalmente e uma cópia é enviada à Superintendência de Meio Ambiente (SMA), conforme informado pela equipe responsável pelas atualizações. Contudo, essa informação não foi passada pela Arena Pernambuco e a única versão do PGRS obtida foi a inicial, contrariamente à Arena Fonte Nova, que disponibilizou todas as revisões para análise.

O prazo de vigência da licença de operação é referente a todo o período de execução da obra, sendo um documento importante e limitante para o início dos serviços. Todas as 
obras têm de ter essa licença, independente do tipo de serviço de construção civil a ser realizado.

Foi possível observar que ambas as arenas seguiram a maioria das recomendações e determinações de ambas as leis, contudo a Arena Fonte Nova destacou-se com o número de informações constantes e o atendimento a praticamente todos os itens exigidos. Os dois planos de gerenciamento atendem às exigências dos órgãos ambientais e tiveram uma boa gestão, que, por sua vez, deliberou o gerenciamento dos resíduos da construção civil das obras em questão. Entretanto, o nível de clareza do PGRCC da Arena Fonte Nova e o número de informações contidas propiciam um gerenciamento mais coeso e relativamente fácil de ser realizado.

Logo, verificou-se que há a aplicação da Resolução CONAMA e da Política Nacional de Resíduos Sólidos pelas empresas responsáveis pela construção da Arena Fonte Nova no município de Salvador-BA e da Arena Pernambuco no município de São Lourenço da MaraPE.

\subsection{QUESTIONÁRIO - COLABORADORES}

O Questionário - COLABORADORES (Apêndice A) foi aplicado com o intuito de verificar o grau de compreensão dos funcionários da obra em relação a assuntos relacionados à gestão e ao gerenciamento dos resíduos da construção civil. Ele propiciou uma análise geral da cultura e não só do grau de conhecimento de cada um. Por meio desse questionário foi possível obter diversas informações, desde o perfil dos entrevistados (idade, tempo que trabalha com construção civil, função e formação), até sua educação ambiental, seja ela em casa ou no trabalho.

Com o objetivo de obter grande diversidade nas informações obtidas, foram levantados dados em diversos locais e setores da obra.

\subsubsection{Caracterização dos dados}

\section{a) Coleta e interpretação dos dados}

Para coleta de dados, inicialmente, foram feitas reuniões, realizadas para auxiliar na pesquisa, com os engenheiros e técnicos de meio ambiente e de segurança do trabalho, que são os envolvidos no processo e fazem parte do setor de Sustentabilidade da obra, que engloba as áreas de Saúde, Segurança do Trabalho e Meio Ambiente (SSTMA). Parte das 
entrevistas foi realizada pelo pesquisador e outra parte foi supervisionada por ele e realizada pela equipe de SSTMA, para que pudesse haver um maior número de colaboradores entrevistados.

A obtenção das informações constantes foi bastante dificultada pelos horários disponíveis para a elaboração das entrevistas, uma vez que ficou definida a prioridade, por parte do pesquisador, de não atrapalhar as atividades desempenhadas pelos colaboradores entrevistados e, por conseguinte, os serviços das obras estudadas. Ademais, para a completa realização das entrevistas, houve uma dificuldade inicial na compreensão dos termos utilizados no questionário por parte dos entrevistados, o que provocou a complementação do questionário com palavras sinônimas ou termos mais simples com a mesma conotação.

Foi priorizada a avaliação dos dados que respondessem diretamente cada pergunta elaborada, contudo é possível realizar diversas análises por meio desses dados. A avaliação dos dados foi qualitativa e quantitativa e teve como ferramenta alguns fundamentos da estatística, os quais serão apresentados a seguir.

\section{b) Definições de estatística}

\section{- O que é Estatística?}

De acordo com Sandroni (2005), a estatística é o ramo da matemática que lida com os dados numéricos e fenômenos sociais ou naturais, com o objetivo de medir ou estimar a extensão desses fenômenos e verificar suas inter-relações.

\section{- Estatística Descritiva}

Refere-se ao ramo da estatística que cuida da classificação e apresentação dos dados estatísticos.

\section{- Estatística Indutiva}

Também chamada de inferência estatística ou estatística inferencial, é o conjunto de princípios que permite generalizar algumas características de uma "população", baseado nas características observadas de uma "amostra".

\section{- População}

Conjunto de todos os itens, objetos ou pessoas a respeito das quais a informação é desejada para a solução de um problema. 


\section{- Amostra}

Grupo de itens selecionados por um método cuidadosamente concebido e projetado com base em uma população.

\section{- Variáveis quantitativas}

Referem-se a quantidades e podem ser medidas em uma escala numérica. Exemplos:

Idade, Preço, Peso, Tempo.

\subsubsection{Análise dos dados}

Os dados usados neste trabalho são fruto de pesquisas realizadas nas duas obras estudadas: construção da Arena Pernambuco (AP) e demolição e construção da Arena Fonte Nova (AFN). Assim, foi possível ter um banco de dados gerado com base em dados reais de pesquisas feitas em ambos os locais em diferentes dias e com quantidades diferentes de colaboradores. Para este estudo foram usadas variáveis em ordem conforme consta no Questionário - Colaboradores (Apêndice A).

Foi realizada uma seleção preliminar partindo da observação de que o questionário apresenta um enorme número de variáveis que, somadas a tudo que existe efetivamente nos bancos de dados do estudo, poderiam ser avaliadas se são ou não adequadas para a obtenção do objetivo de estudo.

Após selecionadas as variáveis para serem de fato estudas no trabalho, foi realizado um conjunto de análises dessas informações.

\section{a) ANÁLISE DESCRITIVA DAS IDADES DOS COLABORADORES DA ARENA FONTE NOVA (AFN) E ARENA PERNAMBUCO (AP)}

Para análise das idades dos colaboradores da Arena Fonte Nova (AFN) e Arena Pernambuco (AP) foi criada uma classe de faixa etária, conforme apresentada nas tabelas e gráficos.

É possível verificar nas Tabelas 7 e 9 que, tanto na AFN quanto na AP, as frequências relativas das faixas etárias são muito próximas. 


\section{__Arena Fonte Nova}

Tabela 7 - Faixa etária dos entrevistados na Arena Fonte Nova

\begin{tabular}{|l|c|r|}
\hline Faixa Etária & $\begin{array}{c}\text { Frequência } \\
\text { Absoluta }\end{array}$ & $\begin{array}{c}\text { Frequência } \\
\text { Relativa (\%) }\end{array}$ \\
\hline $0 \quad-21$ anos & 7 & 4,55 \\
\hline $21 \mid-30$ anos & 62 & 40,26 \\
\hline $31 \mid-41$ anos & 47 & 30,52 \\
\hline $41 \mid-51$ anos & 24 & 15,58 \\
\hline $51 \mid-\quad$ anos & 14 & 9,09 \\
\hline Número de Amostras & 154 & 100 \\
\hline
\end{tabular}

Fonte: Elaborada pela autora desta pesquisa.

Tabela 8 - Descritivo: dados estatísticos, calculados em função da frequência absoluta da Tabela 9

\begin{tabular}{|l|r|}
\hline MÉDIA GEOMÉTRICA & 32 \\
\hline MÉDIA ARITMÉTICA & 34 \\
\hline DESVIO PADRÃO & 10 \\
\hline MENOR & 19 \\
\hline MAIOR & 64 \\
\hline ERRO-PADRÃO & 0,8319 \\
\hline
\end{tabular}

Fonte: Elaborada pela autora desta pesquisa.

Gráfico 6 - Frequências absoluta e relativa por faixa etária - Arena Fonte Nova

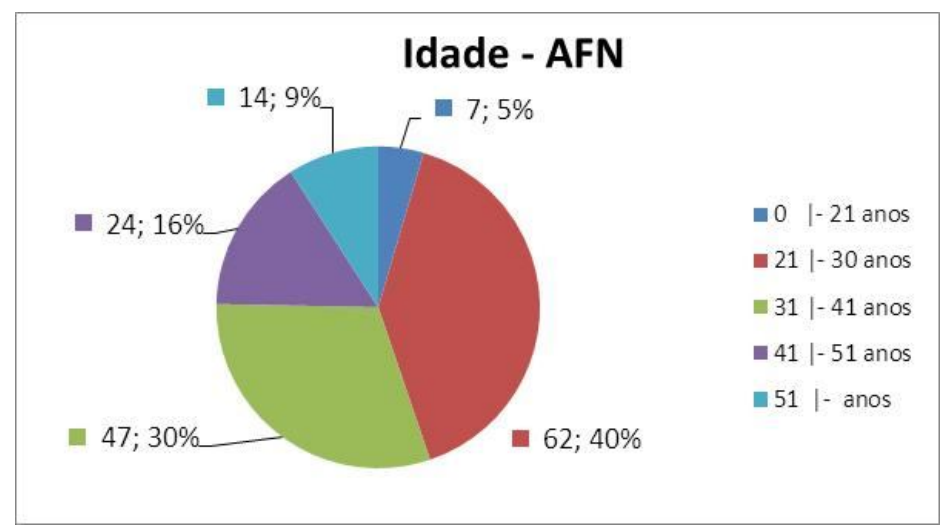

Fonte: Elaborado pela autora desta pesquisa. 


\section{- Arena Pernambuco}

Tabela 9 - Faixa etária dos entrevistados na Arena Pernambuco

\begin{tabular}{|l|c|r|}
\hline \multicolumn{1}{|c|}{ Faixa Etária } & $\begin{array}{c}\text { Frequência } \\
\text { Absoluta }\end{array}$ & $\begin{array}{r}\text { Frequência } \\
\text { Relativa (\%) }\end{array}$ \\
\hline $0 \quad-21$ anos & 1 & 2,08 \\
\hline $21 \mid-30$ anos & 22 & 45,83 \\
\hline $31 \mid-41$ anos & 17 & 35,42 \\
\hline $41 \mid-51$ anos & 5 & 10,42 \\
\hline $51 \mid-\quad$ anos & 3 & 6,25 \\
\hline Número de Amostras & 48 & 100 \\
\hline
\end{tabular}

Fonte: Elaborada pela autora desta pesquisa.

Tabela 10 - Descritivo: dados estatísticos, calculados em função da frequência absoluta da Tabela 7

\begin{tabular}{|l|r|}
\hline MÉDIA GEOMÉTRICA & 32 \\
\hline MÉDIA ARITMÉTICA & 33 \\
\hline DESVIO PADRÃO & 9 \\
\hline MENOR & 20 \\
\hline MAIOR & 59 \\
\hline ERRO-PADRÃO & 12,961 \\
\hline
\end{tabular}

Fonte: Elaborada pela autora desta pesquisa.

Gráfico 7 - Frequências absoluta e relativa por faixa etária - Arena Pernambuco

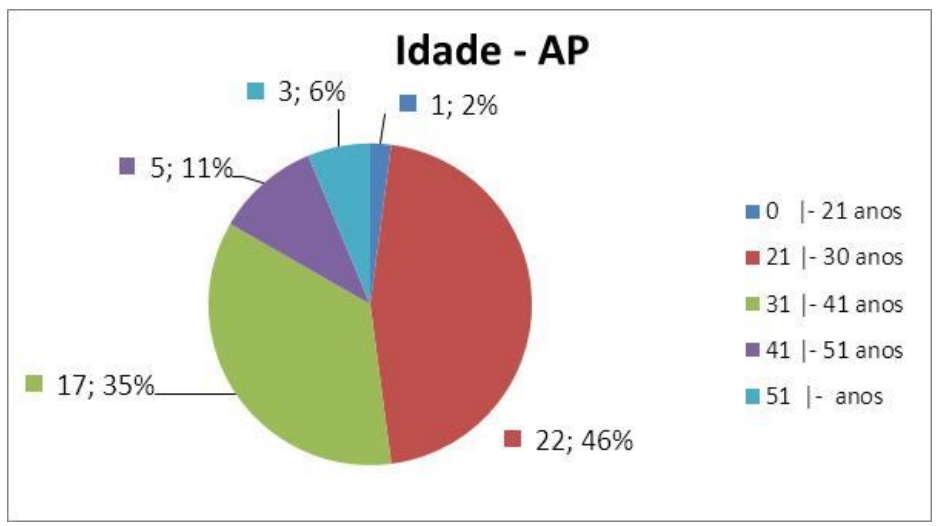

Fonte: Elaborado pela autora desta pesquisa. 


\section{- Total (Arena Fonte Nova e Arena Pernambuco)}

Tabela 11 - Faixa etária dos entrevistados totais

\begin{tabular}{|l|c|r|}
\hline Faixa Etária & $\begin{array}{c}\text { Frequência } \\
\text { Absoluta }\end{array}$ & $\begin{array}{c}\text { Frequência } \\
\text { Relativa (\%) }\end{array}$ \\
\hline $0 \quad-21$ anos & 8 & 3,96 \\
\hline $21 \mid-30$ anos & 84 & 41,58 \\
\hline $31 \mid-41$ anos & 64 & 31,68 \\
\hline $41 \mid-51$ anos & 29 & 14,36 \\
\hline $51 \mid-\quad$ anos & 17 & 8,42 \\
\hline Número de Amostra & 202 & 100 \\
\hline
\end{tabular}

Fonte: Elaborada pela autora desta pesquisa.

Tabela 12 - Descritivo: dados estatísticos, calculados em função da frequência absoluta da Tabela 11

\begin{tabular}{|l|r|}
\hline MÉDIA GEOMÉTRICA & 32 \\
\hline MÉDIA ARITMÉTICA & 34 \\
\hline DESVIO PADRÃO & 10 \\
\hline MENOR & 19 \\
\hline MAIOR & 64 \\
\hline ERRO-PADRÃO & 0,7040 \\
\hline MODA & 28 \\
\hline
\end{tabular}

Fonte: Elaborada pela autora desta pesquisa.

Gráfico 8 - Frequências absoluta e relativa por faixa etária -

Total (Arena Fonte Nova e Arena Pernambuco)

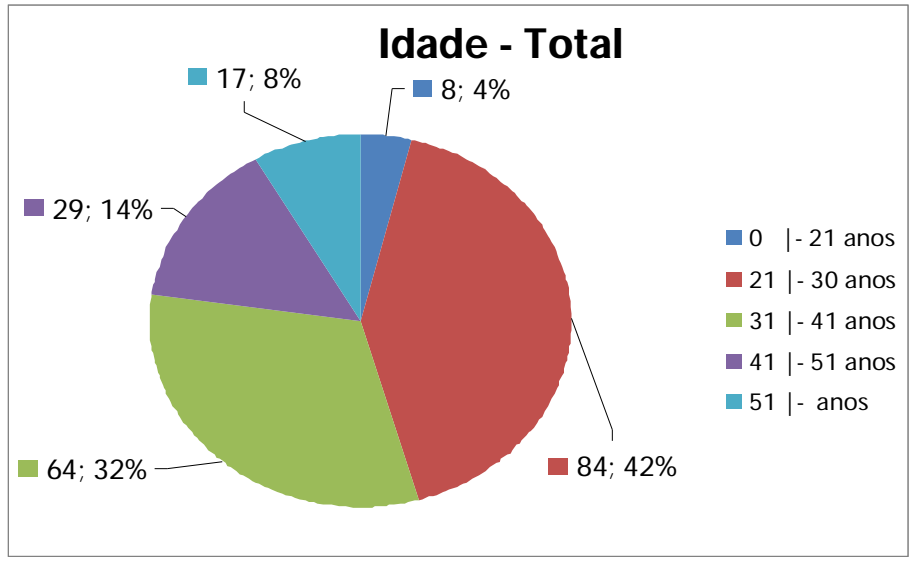

Fonte: Elaborado pela autora desta pesquisa. 


\section{b) ANÁLISE DESCRITIVA DO PERÍODO QUE OS COLABORADORES TRABALHAM COM CONSTRUÇÃO CIVIL}

A escassez de mão de obra, em todos os níveis, é um gargalo comum aos setores da cadeia da construção civil no cenário nacional (CADERNO..., 2010).

De acordo com o Caderno Técnico ConstruBusiness 2010, dados de setembro de 2010 do Cadastro Geral de Empregados e Desempregados (CAGED), criado pelo governo federal por meio da Lei $n^{\circ} 4.923 / 65$, mostram que a construção civil foi um dos setores que mais geraram empregos formais no ano. Isto totaliza 330 mil novos postos (saldo líquido entre admissões e desligamentos, conhecido como turnover), o que representa $15 \%$ dos novos postos gerados no país. A demanda fortemente aquecida, no entanto, não tem sido suficiente para atrair a mão de obra e mantê-la no segmento. Na Sondagem da Construção Civil de setembro de 2009, elaborada pela Confederação Nacional da Indústria (CNI), o maior problema apontado pela cadeia da construção foi a falta de trabalhadores qualificados (votado por $64 \%$ das empresas), como pode ser observado na Tabela 13.

Tabela 13 - Principais problemas apontados por firmas da construção civil

(em \% de firmas que votaram) - setembro 2010

\begin{tabular}{|c|c|c|c|c|c|c|c|c|}
\hline \multirow{2}{*}{ Descrição } & \multicolumn{2}{|c|}{ Total } & \multicolumn{2}{|c|}{ Pequeno } & \multicolumn{2}{|c|}{ M édio } & \multicolumn{2}{|c|}{ Grande } \\
\hline & $\%$ de firmas & ranking & $\%$ de firmas & ranking & $\%$ de firmas & ranking & $\%$ de firmas & ranking \\
\hline Falta de trabalhador qualificado & 64,0 & 1 & 63,4 & 1 & 63,8 & 2 & 68,8 & 1 \\
\hline Elevada carga tributária & 58,0 & 2 & 55,0 & 2 & 64,5 & 1 & 46,9 & 2 \\
\hline Alto custo da mão de obra & 30,2 & 3 & 34,6 & 3 & 27,0 & 3 & 18,8 & 5 \\
\hline Competição acirrada de mercado & 25,5 & 4 & 26,7 & 4 & 20,6 & 6 & 40,6 & 3 \\
\hline Taxas de juros elevadas & 21,7 & 5 & 20,4 & 6 & 22,7 & 5 & 25,0 & 4 \\
\hline Falta de capital de giro & 18,7 & 6 & 21,5 & 5 & 17,0 & 7 & 9,4 & 8 \\
\hline Inadimplência dos clientes & 18,4 & 7 & 15,7 & 7 & 23,4 & 4 & 12,5 & 6 \\
\hline Condições climáticas & 12,4 & 8 & 14,7 & 8 & 10,6 & 9 & 6,3 & 10 \\
\hline Falta de matéria prima & 11,5 & 9 & 13,6 & 9 & 9,9 & 11 & 6,3 & 10 \\
\hline Licenciamento ambiental & 10,4 & 10 & 10,5 & 10 & 9,9 & 11 & 12,5 & 6 \\
\hline Alto custo da matéria prima & 10,2 & 11 & 8,9 & 11 & 12,8 & 8 & 6,3 & 10 \\
\hline Falta de demanda & 9,6 & 12 & 8,9 & 11 & 10,6 & 9 & 9,4 & 8 \\
\hline Falta de financiamento de longo praz & 8,0 & 13 & 7,3 & 14 & 9,2 & 13 & 6,3 & 10 \\
\hline Disponibilidade de terrenos & 7,4 & 14 & 7,9 & 13 & 7,1 & 14 & 6,3 & 10 \\
\hline Outros & 3,3 & 15 & 3,7 & 16 & 3,5 & 15 & & 16 \\
\hline Falta de equipamentos de apoio & 3,0 & 16 & 4,2 & 15 & 1,4 & 16 & 3,1 & 15 \\
\hline
\end{tabular}

Fonte: Caderno Técnico ConstruBusiness 2010 (2010).

Há muitas explicações para a rotatividade do trabalho no Brasil, também conhecida como turnover. Os benefícios financeiros ao assalariado demitido (FGTS), a estrutura do mercado de trabalho, como a oferta e demanda de trabalho, seriam alguns dos motivos. A forma de regulação no mercado de trabalho tem sido responsabilizada por elevados custos, ou efeitos negativos, em três dimensões, segundo Ramos e Carneiro (2002): 
a) Desempenho macroeconômico de curto prazo;

b) Perfil distributivo;

c) Possibilidades de crescimento de médio e longo prazo.

Em relação a essas duas últimas dimensões, os benefícios financeiros oferecidos a um assalariado que é demitido (FGTS, 40\% de multa e seguro desemprego) constituem um incentivo à rotatividade. Dessa forma, o assalariado não teria incentivos para permanecer em seu posto de trabalho e, consequentemente, para o empresário não seria lucrativo investir na formação de empregados, já que há uma constante troca (RAMOS; CARNEIRO, 2002).

Entretanto, considera-se que em algumas empresas o alto índice de rotatividade pode ser saudável para a sua manutenção. Nesse sentido, as empresas de construção civil também se encontram beneficiadas pela rotatividade, se esta for considerada em razão das etapas construtivas e da necessidade de se contratar diferentes tipos de mão de obra. Em relação a isso, percebe-se uma característica específica desse tipo de acontecimento dentro das empresas, nas quais cerca de 50\% dos funcionários não ficam mais de dois anos (CINTRA; PEDROSO, 2010).

Nas empresas de construção civil há uma dificuldade maior em virtude das questões da mão de obra, já que, na maioria das vezes, ou se tem profissionais com pouco nível de instrução e pouca qualificação, ou se tem profissionais extremamente qualificados e direcionados a exercer uma atividade específica, fato este que pode ser agravado com os altos índices de rotatividade (CINTRA; PEDROSO, 2010).

Todavia, a despeito da rotatividade da construção civil ser alta, as empresas encontram-se obrigadas a realizarem alguma forma de incentivo à capacitação da mão de obra em virtude de sua baixa qualificação no mercado de trabalho. 


\section{- Arena Fonte Nova}

Tabela 14 - Tempo que trabalha com construção civil - Arena Fonte Nova

\begin{tabular}{|l|c|r|}
\hline \multicolumn{1}{|c|}{ Tempo } & $\begin{array}{c}\text { Frequência } \\
\text { Absoluta }\end{array}$ & $\begin{array}{c}\text { Frequência } \\
\text { Relativa (\%) }\end{array}$ \\
\hline$<=3$ meses & 0 & 0,00 \\
\hline 3 meses $<x<=6$ meses & 1 & 0,89 \\
\hline 6 meses $<x<=1$ ano & 17 & 15,18 \\
\hline 1 ano $<x<=5$ anos & 45 & 40,18 \\
\hline 5 anos $<x<=10$ anos & 15 & 13,39 \\
\hline 10 anos $<x<=20$ anos & 20 & 17,86 \\
\hline 20 anos $<x<=30$ anos & 9 & 8,04 \\
\hline$>30$ anos & 5 & 4,46 \\
\hline Número de Amostras & $\mathbf{1 1 2}$ & $\mathbf{1 0 0}$ \\
\hline
\end{tabular}

Fonte: Elaborada pela autora desta pesquisa.

Gráfico 9 - Tempo que trabalha com construção civil - Arena Fonte Nova

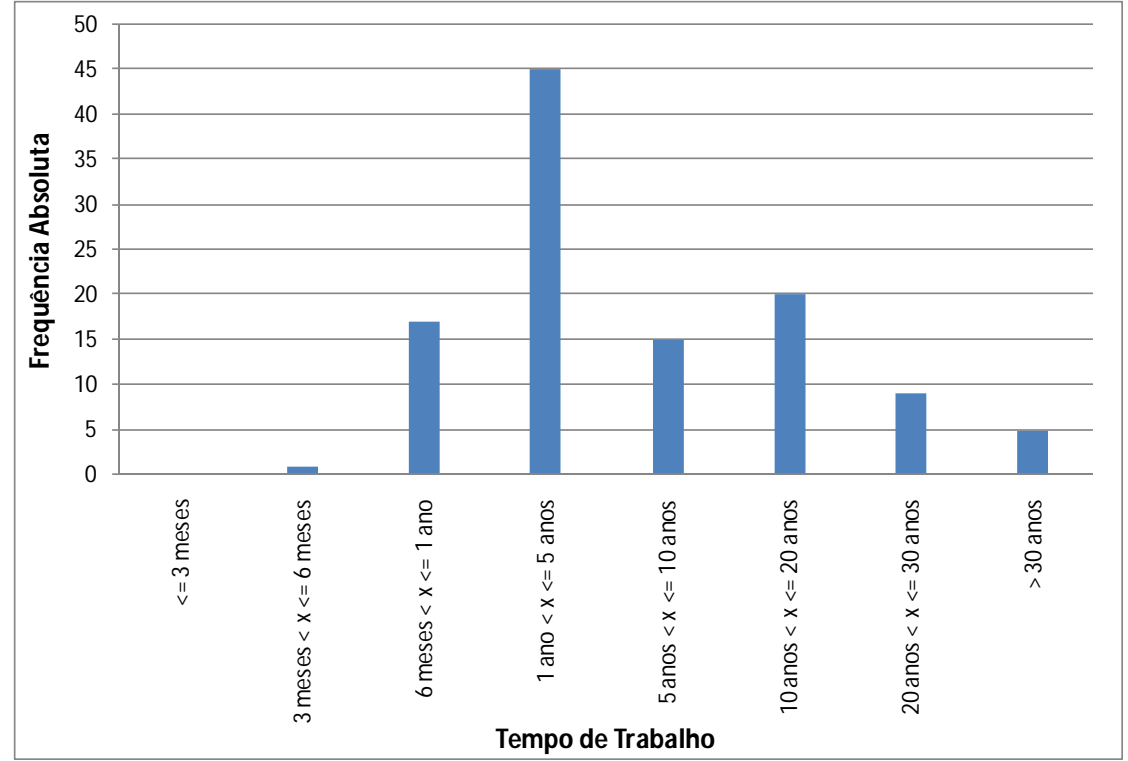

Fonte: Elaborado pela autora desta pesquisa. 


\section{- Arena Pernambuco}

Tabela 15 - Tempo que trabalha com construção civil - Arena Pernambuco

\begin{tabular}{|l|c|r|}
\hline \multicolumn{1}{|c|}{ Tempo } & $\begin{array}{c}\text { Frequência } \\
\text { Absoluta }\end{array}$ & $\begin{array}{c}\text { Frequência } \\
\text { Relativa (\%) }\end{array}$ \\
\hline$<=3$ meses & 4 & 8,33 \\
\hline 3 meses $<x<=6$ meses & 5 & 10,42 \\
\hline 6 meses $<x<=1$ ano & 16 & 33,33 \\
\hline 1 ano $<x<=5$ anos & 3 & 6,25 \\
\hline 5 anos $<x<=10$ anos & 8 & 16,67 \\
\hline 10 anos $<x<=20$ anos & 3 & 6,25 \\
\hline 20 anos $<x<=30$ anos & 7 & 14,58 \\
\hline$>30$ anos & 2 & 4,17 \\
\hline Número de Amostras & $\mathbf{4 8}$ & $\mathbf{1 0 0}$ \\
\hline
\end{tabular}

Fonte: Elaborada pela autora desta pesquisa.

Gráfico 10 - Tempo que trabalha com construção civil - Arena Pernambuco

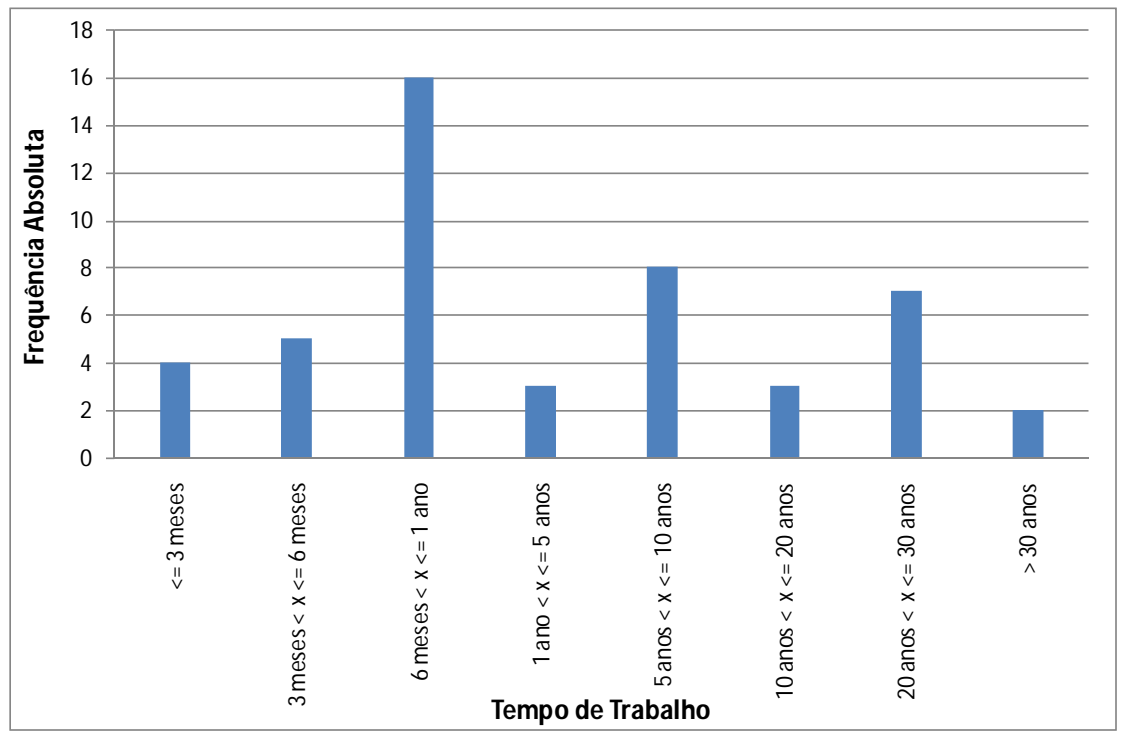

Fonte: Elaborado pela autora desta pesquisa. 


\section{- Total (Arena Fonte Nova e Arena Pernambuco)}

Tabela 16 - Tempo que trabalha com construção civil - Total

\begin{tabular}{|l|c|r|}
\hline \multicolumn{1}{|c|}{ Tempo } & $\begin{array}{c}\text { Frequência } \\
\text { Absoluta }\end{array}$ & $\begin{array}{c}\text { Frequência } \\
\text { Relativa (\%) }\end{array}$ \\
\hline$<=3$ meses & 42 & 20,79 \\
\hline 3 meses $<x<=6$ meses & 10 & 4,95 \\
\hline 6 meses $<x<=1$ ano & 25 & 12,38 \\
\hline 1 ano $<x<=5$ anos & 56 & 27,72 \\
\hline 5 anos $<x<=10$ anos & 23 & 11,39 \\
\hline 10 anos $<x<=20$ anos & 23 & 11,39 \\
\hline 20 anos $<x<=30$ anos & 16 & 7,92 \\
\hline$>30$ anos & 7 & 3,47 \\
\hline Número de Amostras & $\mathbf{2 0 2}$ & $\mathbf{1 0 0}$ \\
\hline
\end{tabular}

Fonte: Elaborada pela autora desta pesquisa.

Gráfico 11 - Tempo que trabalha com construção civil - Total (Arena Fonte Nova e Arena Pernambuco)

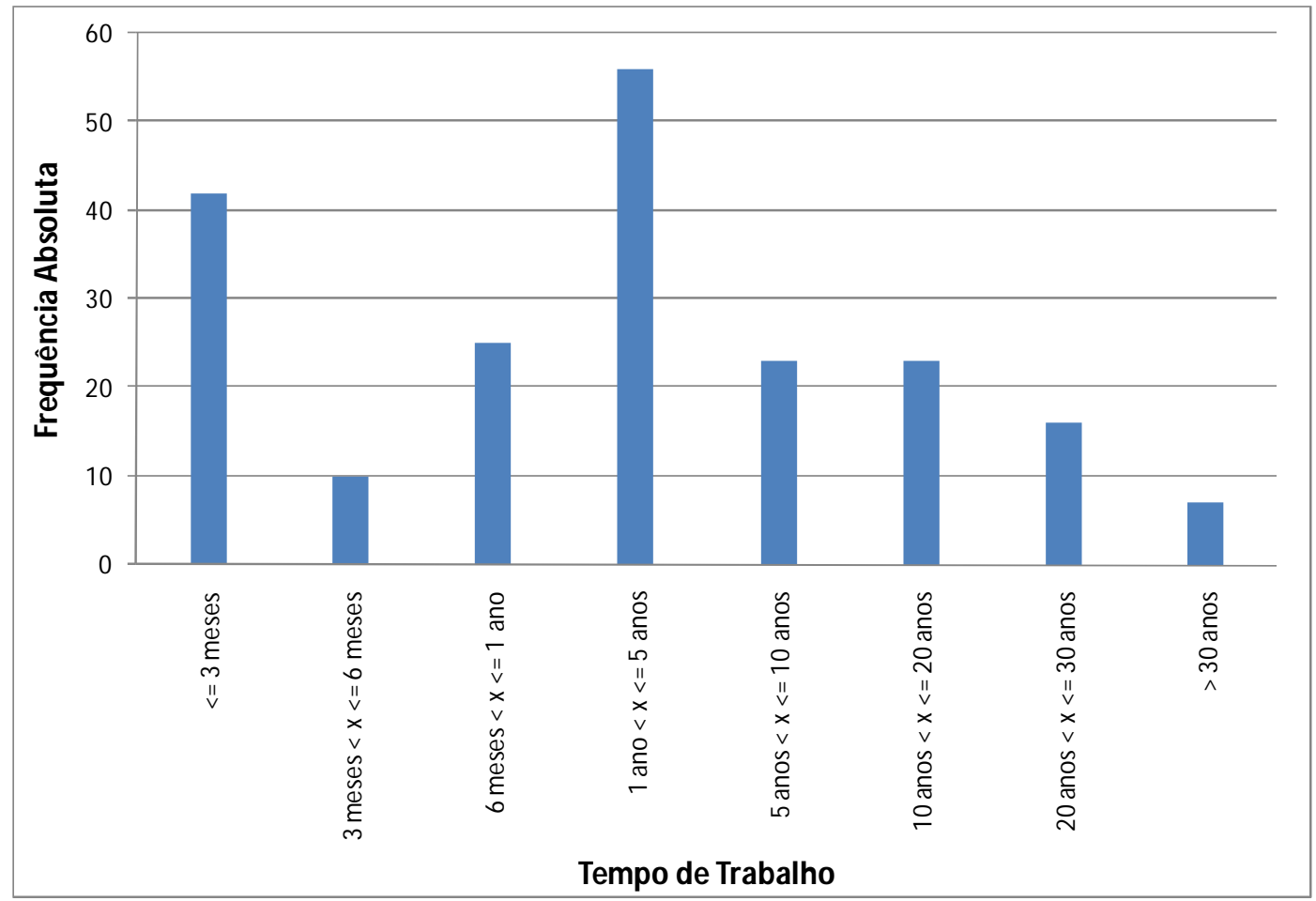

Fonte: Elaborado pela autora desta pesquisa.

Em relação às obras pesquisadas, com os dados apresentados é possível observar, nas informações relativas ao tempo que o funcionário trabalha com construção civil, que $65 \%$ dos entrevistados têm menos de cinco anos de experiência. 
O cenário dos últimos 15 anos da capital baiana é de poucas obras de infraestrutura, fazendo com que houvesse uma quantidade baixa de mão de obra disponível no mercado e um intervalo muito grande entre a mão de obra com muita e com pouca experiência na construção civil. Desta forma, pode-se observar que 56\% dos entrevistados têm menos cinco anos de experiência. Atualmente, esse cenário está mudando, principalmente em decorrência do aquecimento do mercado imobiliário e de ações da Secretaria do Trabalho com o intuito de capacitar a mão de obra do estado.

Já na Região Metropolitana do Recife, ocorreu o contrário. Nos últimos cinco anos houve um crescimento muito grande da região, com estímulos à entrada de novas empresas no estado, principalmente no Porto de Suape, gerando empregos e, consequentemente, escassez de mão de obra capacitada, mesmo com os esforços do estado em relação à capacitação da mão de obra. Sendo assim, pode-se observar que 52\% dos colaboradores entrevistados têm até um ano de experiência.

Paralelo a isso, a empresa responsável pela obra, analisando o contexto nacional de crescimento da indústria da construção civil, viu a necessidade de implantação de um programa de qualificação chamado Acreditar, no qual homens e mulheres com mais de 18 anos, que saibam ler e escrever, têm a oportunidade de aprender uma profissão e trabalhar na organização, com foco na formação em nível operacional. Esse programa tem como objetivo qualificar e preparar o cidadão para atender às demandas geradas pelos negócios da empresa e surgiu com base em uma pesquisa realizada em Porto Velho, que constatou a baixa disponibilidade de mão de obra capacitada para atender à grande demanda que a construção da hidrelétrica de Santo Antônio geraria. Para reduzir o fluxo migratório e os seus possíveis impactos sociais, a empresa desenvolveu o programa. Hoje, $90 \%$ dos trabalhadores desse empreendimento são moradores da região.

Em novembro de 2008, iniciou-se o desenvolvimento do projeto em Rondônia. Em fevereiro de 2009 foi feita a assinatura de acordo com o Ministério do Desenvolvimento Social e Combate à Fome, quando passou a haver uma parceria entre o Ministério e a empresa. E entre os meses de abril e junho de 2009 iniciou-se a expansão do programa.

Como a obra da Arena Fonte Nova está inserida na capital e tinha o benefício de ter o apoio do Serviço Estadual de Intermediação para o Trabalho (SineBahia), além de ter sido planejada e orçada antes do período de efetivação do Programa Acreditar, ele não foi previsto nem implantado. Já as obras da Arena Pernambuco foram iniciadas efetivamente no início de 2011, o que propiciou a implantação do programa. 
Logo, ambas as obras possuem mão de obra capacitada, porém com pouca experiência no ramo da construção civil.

\section{c) ANÁLISE DESCRITIVA DA ESCOLARIDADE DOS COLABORADORES DA ARENA FONTE NOVA E ARENA PERNAMBUCO}

Além da escassez de mão de obra, conforme mencionado anteriormente, ainda que houvesse quantidade suficiente de trabalhadores, a qualificação é um problema de grande importância para o setor no mercado nacional, como pode ser observado no Gráfico 12. O nível de escolaridade entre os trabalhadores da cadeia da construção ainda é muito baixo, ainda que tenha sido observada uma melhora em relação aos últimos anos. Segundo a Câmara Brasileira da Indústria da Construção (CBIC), a maior parte dos trabalhadores possui de 4 a 7 anos de estudo, ou seja, nível fundamental incompleto (CADERNO..., 2010).

Gráfico 12 - Escolaridade da mão de obra - porcentagem em relação ao total de trabalhadores

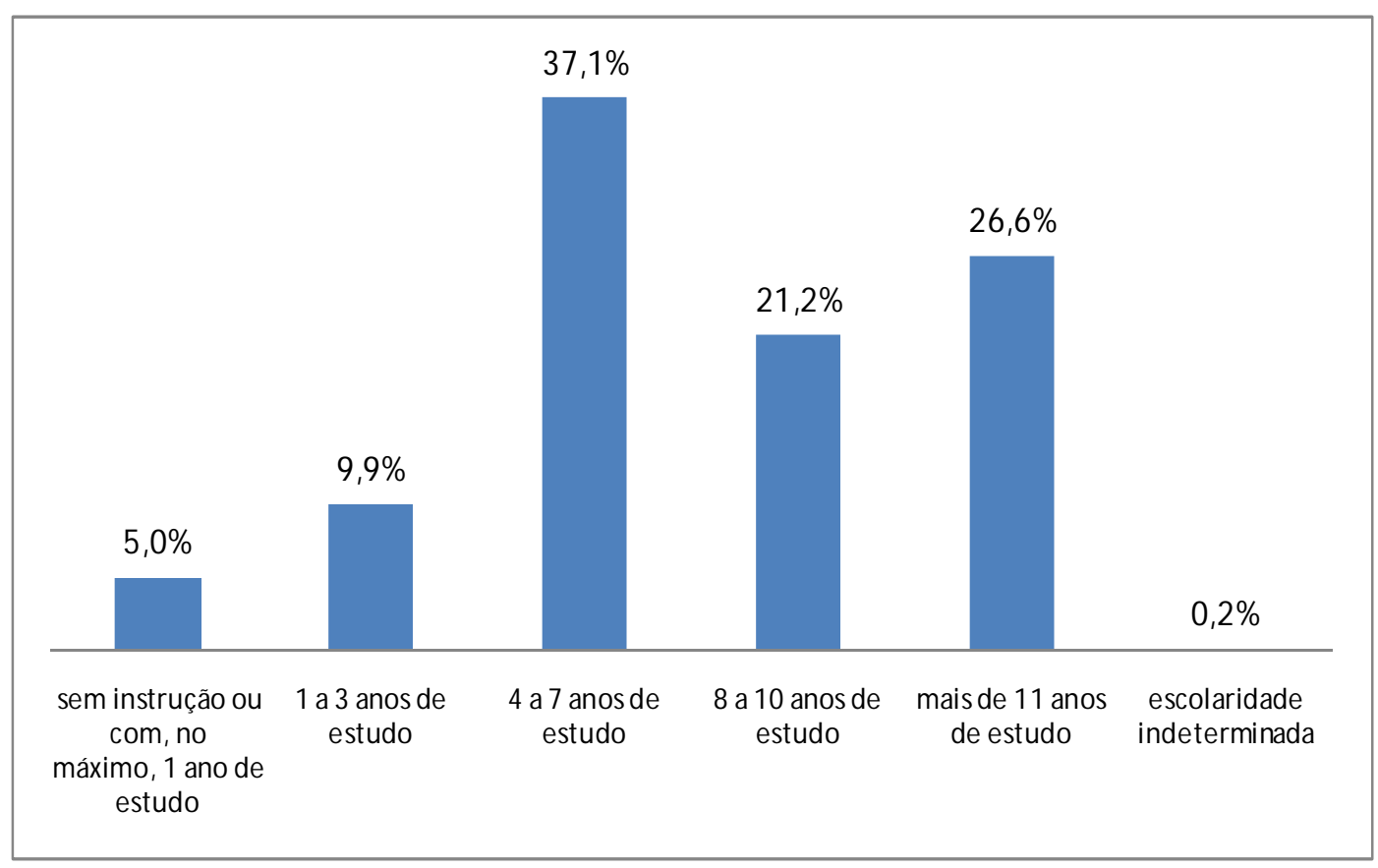

Fonte: Caderno Técnico ConstruBusiness 2010 (2010).

Em relação ao perfil dos entrevistados nas obras da Arena Fonte Nova e Arena Pernambuco, esse cenário se mostra um pouco diferente, pois a maioria dos colaboradores entrevistados possui ensino fundamental completo ou nível médio / técnico completo, conforme pode ser observado nas Tabelas 17 e 19. 


\section{- Arena Fonte Nova}

Tabela 17 - Escolaridade dos entrevistados na Arena Fonte Nova

\begin{tabular}{|l|c|r|}
\hline \multicolumn{1}{|c|}{ Nível de Escolaridade } & $\begin{array}{c}\text { Frequência } \\
\text { Absoluta }\end{array}$ & $\begin{array}{r}\text { Frequência } \\
\text { Relativa (\%) }\end{array}$ \\
\hline 1 - Analfabeto & 1 & 0,65 \\
\hline 2 - Fundamental Incompleto & 54 & 35,29 \\
\hline 3 - Fundamental Completo & 11 & 7,19 \\
\hline 4 - Médio ou Técnico Incompleto & 21 & 13,73 \\
\hline 5 - Médio ou Técnico Completo & 60 & 39,22 \\
\hline 6 - Superior Incompleto & 6 & 3,92 \\
\hline 7 - Superior Completo & 0 & 0,00 \\
\hline 8 - Indefinido & 0 & 0,00 \\
\hline Número de Amostra & $\mathbf{1 5 3}$ & $\mathbf{1 0 0 , 0 0}$ \\
\hline
\end{tabular}

Fonte: Elaborada pela autora desta pesquisa.

Tabela 18 - Descritivo: dados estatísticos, calculados em função da frequência absoluta da Tabela 19

\begin{tabular}{|l|r|}
\hline MÉDIA GEOMÉTRICA & 3,4 \\
\hline MÉDIA ARITMÉTRICA & 3,7 \\
\hline DESVIO PADRÃO & 1,4 \\
\hline MENOR & 1,0 \\
\hline MAIOR & 6,0 \\
\hline ERRO-PADRÃO & 0,114 \\
\hline
\end{tabular}

Fonte: Elaborada pela autora desta pesquisa.

Gráfico 13 - Escolaridade dos entrevistados na Arena Fonte Nova

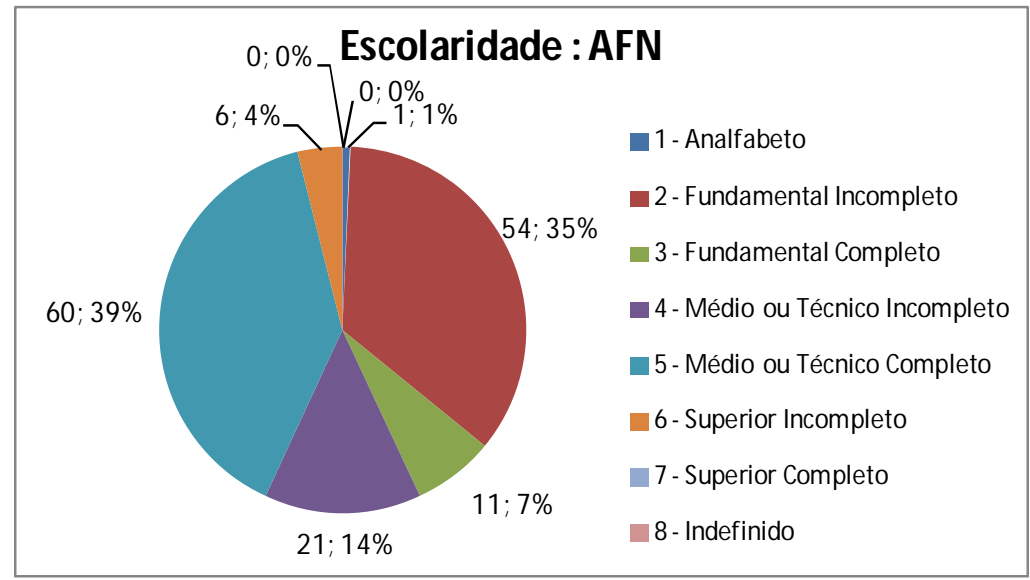

Fonte: Elaborado pela autora desta pesquisa. 


\section{- Arena Pernambuco}

Tabela 19 - Escolaridade dos entrevistados na Arena Pernambuco

\begin{tabular}{|l|c|r|}
\hline \multicolumn{1}{|c|}{ Nível de Escolaridade } & $\begin{array}{c}\text { Frequência } \\
\text { Absoluta }\end{array}$ & $\begin{array}{r}\text { Frequência } \\
\text { Relativa (\%) }\end{array}$ \\
\hline 1 - Analfabeto & 0 & 0,00 \\
\hline 2 - Fundamental Incompleto & 7 & 14,58 \\
\hline 3 - Fundamental Completo & 12 & 25,00 \\
\hline 4 - Médio ou Técnico Incompleto & 6 & 12,50 \\
\hline 5 - Médio ou Técnico Completo & 22 & 45,83 \\
\hline 6 - Superior Incompleto & 0 & 0,00 \\
\hline 7 - Superior Completo & 0 & 0,00 \\
\hline 8 - Indefinido & 1 & 2,08 \\
\hline Número de Amostra & $\mathbf{4 8}$ & $\mathbf{1 0 0 , 0 0}$ \\
\hline
\end{tabular}

Fonte: Elaborada pela autora desta pesquisa.

Tabela 20 - Descritivo: dados estatísticos, calculados em função da frequência absoluta da Tabela 17

\begin{tabular}{|l|r|}
\hline MÉDIA GEOMÉTRICA & 3,8 \\
\hline MÉDIA ARITMÉTRICA & 4,0 \\
\hline DESVIO PADRÃO & 1,3 \\
\hline MENOR & 2,0 \\
\hline MAIOR & 8,0 \\
\hline ERRO-PADRÃO & 0,186 \\
\hline
\end{tabular}

Fonte: Elaborada pela autora desta pesquisa.

Gráfico 14 - Escolaridade dos entrevistados na Arena Pernambuco

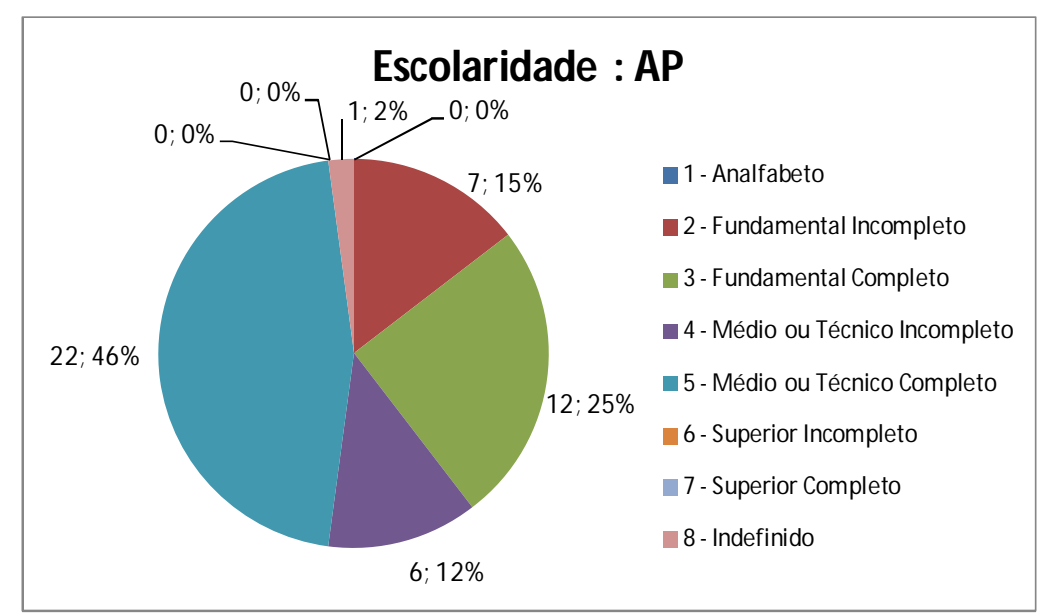

Fonte: Elaborado pela autora desta pesquisa. 
Tabela 21 - Escolaridade de todos os entrevistados

\begin{tabular}{|l|c|r|}
\hline \multicolumn{1}{|c|}{ Nível de Escolaridade } & $\begin{array}{c}\text { Frequência } \\
\text { Absoluta }\end{array}$ & $\begin{array}{r}\text { Frequência } \\
\text { Relativa (\%) }\end{array}$ \\
\hline 1 - Analfabeto & 1 & 0,50 \\
\hline 2 - Fundamental Incompleto & 61 & 30,35 \\
\hline 3 - Fundamental Completo & 23 & 11,44 \\
\hline 4 - Médio ou Técnico Incompleto & 27 & 13,43 \\
\hline 5 - Médio ou Técnico Completo & 82 & 40,80 \\
\hline 6 - Superior Incompleto & 6 & 2,99 \\
\hline 7 - Superior Completo & 0 & 0,00 \\
\hline 8 - Indefinido & 1 & 0,50 \\
\hline Número de Amostra & $\mathbf{2 0 1}$ & $\mathbf{1 0 0 , 0 0}$ \\
\hline
\end{tabular}

Fonte: Elaborada pela autora desta pesquisa.

Tabela 22 - Descritivo: dados estatísticos, calculados em função da frequência absoluta da Tabela 21

\begin{tabular}{|l|r|}
\hline MÉDIA GEOMÉTRICA & 3,5 \\
\hline MÉDIA ARITMÉTRICA & 3,8 \\
\hline DESVIO PADRÃO & 1,4 \\
\hline MENOR & 1,0 \\
\hline MAIOR & 8,0 \\
\hline ERRO-PADRÃO & 0,098 \\
\hline MODA & 5,0 \\
\hline
\end{tabular}

Fonte: Elaborada pela autora desta pesquisa. 
Gráfico 15 - Escolaridade de todos os entrevistados

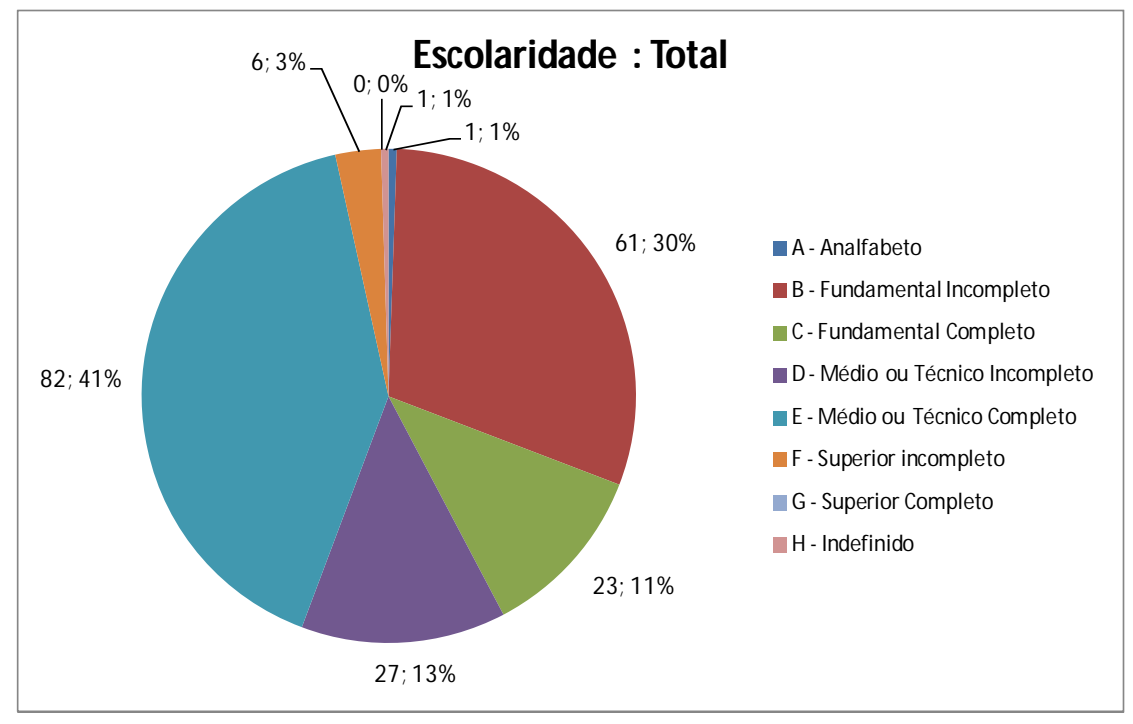

Fonte: Elaborado pela autora desta pesquisa.

Fazendo um comparativo entre o cenário nacional e os dados obtidos na pesquisa, pode-se observar que há uma aproximação nos resultados. Contudo, isso não explica completamente essa semelhança. As duas obras estão situadas em regiões com características diferentes: a Arena Fonte Nova está localizada no centro da cidade de Salvador, capital da Bahia, e a Arena Pernambuco está localizada no município de São Lourenço da Mata, na Região Metropolitana do Recife, em Pernambuco.

Considerando as regiões e as oportunidades e facilidades de acesso à educação, esperava-se que houvesse diferença entre os percentuais de escolaridade dos colaboradores da Arena Fonte Nova e da Arena Pernambuco, todavia isso não ocorreu, em razão da implantação do Programa Acreditar nesta última, conforme explanado anteriormente.

\section{d) DISTRIBUIÇÃO DOS COLABORADORES ENTREVISTADOS POR FUNÇÃO}

Como foi possível observar, ambas as obras estudadas possuem mão de obra qualificada, independente do tempo de experiência, e isso pode ser evidenciado na Tabela 23. 
Tabela 23 - Função dos colaboradores entrevistados nas obras

\begin{tabular}{|c|c|c|c|}
\hline Função & AFN & AP & Total \\
\hline Ajudante de Pedreiro / Carpinteiro / Andaime / Elétrico / Hidráulico / Produção / Lava-jato / Geral / Servente & 43 & 9 & 52 \\
\hline Auxiliar administrativo / Técnico / Segurança / Meio Ambiente & 13 & 1 & 14 \\
\hline Encarregado - Armação / Montagem / Geral / Andaime e Pedreiro & 5 & 5 & 10 \\
\hline Apropriador / Apontador & 4 & 1 & 5 \\
\hline Vigilante & 2 & 0 & 2 \\
\hline Operador de Grua / Máquinas / Retro-escavadeira / Bomba / Betoneira / Estação de Tratamento de Água & 6 & 3 & 9 \\
\hline Carpinteiro & 23 & 7 & 30 \\
\hline Ferramenteiro & 2 & 0 & 2 \\
\hline Cabo de Turma & 1 & 0 & 1 \\
\hline Soldador & 4 & 0 & 4 \\
\hline Pintor & 1 & 0 & 1 \\
\hline Marteleteiro & 1 & 0 & 1 \\
\hline Pedreiro & 9 & 6 & 15 \\
\hline Armador & 10 & 6 & 16 \\
\hline Motorista de Ambulância & 1 & 0 & 1 \\
\hline Sinaleiro & 2 & 2 & 4 \\
\hline Eletricista & 2 & 0 & 2 \\
\hline Rigger & 5 & 0 & 5 \\
\hline Técnico de Segurança & 3 & 0 & 3 \\
\hline Montador & 10 & 6 & 16 \\
\hline Encanador & 1 & 0 & 1 \\
\hline Fotógrafo & 1 & 0 & 1 \\
\hline Estagiário de Infraestrutura & 1 & 0 & 1 \\
\hline Técnico de Instalações Elétricas & 0 & 1 & 1 \\
\hline Meio Oficial de Solda & 0 & 1 & 1 \\
\hline Indefinido & 6 & 0 & 6 \\
\hline Total & 156 & 48 & 204 \\
\hline
\end{tabular}

Fonte: Elaborada pela autora desta pesquisa.

\subsubsection{Análise das perguntas do questionário}

Agora, conhecendo o perfil dos entrevistados na pesquisa, é possível compreender os resultados obtidos nas perguntas do questionário.

\section{Pergunta 1: Como trabalhador do setor da construção civil, quais são suas principais preocupações? (atribua notas 1, 2, 3, 4 e 5 para os fatores a seguir descritos, sendo 1 ao fator de menor preocupação e 5 ao de maior preocupação)}

No Quadro 28 é possível observar todas as respostas com o grau de importância dado pelo entrevistado, contudo, para efeito de análise da resposta à pergunta realizada, foram consideradas, nos gráficos, as respostas com maior grau de preocupação (5), na opinião dos entrevistados. 


\section{- Arena Fonte Nova}

Tabela 24 - Principais preocupações do trabalhador do setor da construção civil Arena Fonte Nova

Fatores

A - Acidentes de trabalho

B - Baixos salários

C - Bom relacionamento na empresa

D - Desemprego

E - Falta de incentivos

F - Falta de treinamento

G - Melhorar a produtividade

H - Problemas de saúde

I - Previdência social e aposentadoria

Média

\begin{tabular}{|c|c|c|c|c|c|c|c|c|c|}
\hline \multicolumn{5}{|c|}{ Frequência Absoluta } & \multicolumn{5}{|c|}{ Frequência Relativa * 100} \\
\hline 1 & 2 & 3 & 4 & 5 & 1 & 2 & 3 & 4 & 5 \\
\hline 11 & 4 & 7 & 16 & 116 & 7,14 & 2,60 & 4,55 & 10,39 & 75,32 \\
\hline 19 & 17 & 30 & 25 & 65 & 12,18 & 10,90 & 19,23 & 16,03 & 41,67 \\
\hline 20 & 9 & 21 & 19 & 86 & 12,90 & 5,81 & 13,55 & 12,26 & 55,48 \\
\hline 27 & 12 & 23 & 13 & 80 & 17,42 & 7,74 & 14,84 & 8,39 & 51,61 \\
\hline 32 & 18 & 39 & 18 & 48 & 20,65 & 11,61 & 25,16 & 11,61 & 30,97 \\
\hline 40 & 13 & 17 & 20 & 65 & 25,81 & 8,39 & 10,97 & 12,90 & 41,94 \\
\hline 6 & 16 & 27 & 32 & 75 & 3,85 & 10,26 & 17,31 & 20,51 & 48,08 \\
\hline 39 & 13 & 14 & 19 & 70 & 25,16 & 8,39 & 9,03 & 12,26 & 45,16 \\
\hline 18 & 8 & 24 & 23 & 81 & 11,69 & 5,19 & 15,58 & 14,94 & 52,60 \\
\hline 24 & 12 & 22 & 21 & 76 & & & & & \\
\hline
\end{tabular}

Fonte: Elaborada pela autora desta pesquisa.

Gráfico 16 - Principais preocupações do trabalhador do setor da construção civil Arena Fonte Nova

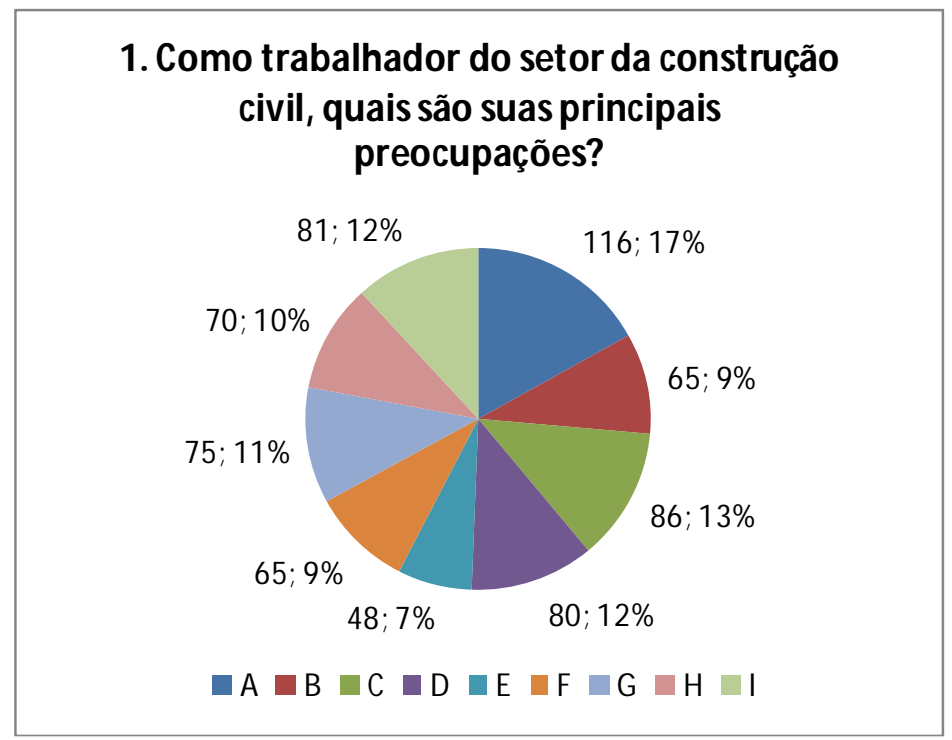

Fonte: Elaborado pela autora desta pesquisa. 


\section{- Arena Pernambuco}

Tabela 25 - Principais preocupações do trabalhador do setor da construção civil -

Arena Pernambuco

Fatores

A - Acidentes de trabalho

B - Baixos salários

C - Bom relacionamento na empresa

D - Desemprego

E - Falta de incentivos

$F$ - Falta de treinamento

G - Melhorar a produtividade

H - Problemas de saúde

I - Previdência social e aposentadoria

Média

\begin{tabular}{|c|c|c|c|c|c|c|c|c|c|}
\hline \multicolumn{9}{|c|}{ Frequência Absoluta } & \multicolumn{4}{|c|}{ Frequência Relativa * 100 } \\
\hline $\mathbf{1}$ & $\mathbf{2}$ & $\mathbf{3}$ & $\mathbf{4}$ & $\mathbf{5}$ & $\mathbf{1}$ & $\mathbf{2}$ & $\mathbf{3}$ & $\mathbf{4}$ & $\mathbf{5}$ \\
\hline 1 & 2 & 6 & 16 & 23 & 2,08 & 4,17 & 12,50 & 33,33 & 47,92 \\
\hline 3 & 2 & 16 & 12 & 15 & 6,25 & 4,17 & 33,33 & 25,00 & 31,25 \\
\hline 1 & 6 & 13 & 14 & 14 & 2,08 & 12,50 & 27,08 & 29,17 & 29,17 \\
\hline 6 & 4 & 21 & 6 & 11 & 12,50 & 8,33 & 43,75 & 12,50 & 22,92 \\
\hline 10 & 14 & 21 & 2 & 1 & 20,83 & 29,17 & 43,75 & 4,17 & 2,08 \\
\hline 11 & 16 & 8 & 5 & 8 & 22,92 & 33,33 & 16,67 & 10,42 & 16,67 \\
\hline 1 & 7 & 7 & 19 & 14 & 2,08 & 14,58 & 14,58 & 39,58 & 29,17 \\
\hline 5 & 5 & 4 & 20 & 14 & 10,42 & 10,42 & 8,33 & 41,67 & 29,17 \\
\hline 3 & 7 & 18 & 5 & 15 & 6,25 & 14,58 & 37,50 & 10,42 & 31,25 \\
\hline $\mathbf{5}$ & $\mathbf{7}$ & $\mathbf{1 3}$ & $\mathbf{1 1}$ & $\mathbf{1 3}$ & \multicolumn{1}{|c}{} \\
\hline
\end{tabular}

Fonte: Elaborada pela autora desta pesquisa.

Gráfico 17 - Principais preocupações do trabalhador do setor da construção civil -

Arena Pernambuco

\section{Como trabalhador do setor da construção} civil, quais são suas principais preocupações?

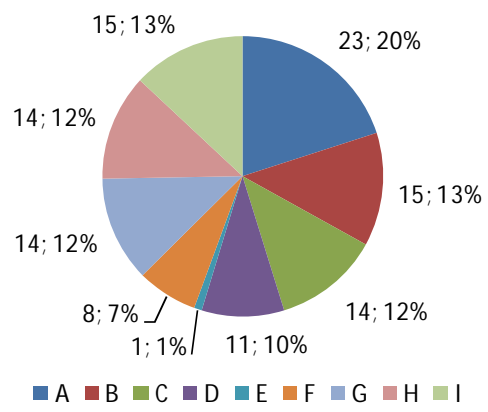

Fonte: Elaborado pela autora desta pesquisa. 


\section{- Total (Arena Fonte Nova e Arena Pernambuco)}

Tabela 26 - Principais preocupações do trabalhador do setor da construção civil -

Total (Arena Fonte Nova e Arena Pernambuco)

Fatores

A - Acidentes de trabalho

B - Baixos salários

C - Bom relacionamento na empresa

D - Desemprego

E - Falta de incentivos

$F$ - Falta de treinamento

G - M elhorar a produtividade

H - Problemas de saúde

Previdência social e aposentadoria

Média

\begin{tabular}{|c|c|c|c|c|c|c|c|c|c|}
\hline \multicolumn{5}{|c|}{ Frequência Absoluta } & \multicolumn{5}{|c|}{ Frequência Relativa * 100 } \\
\hline $\mathbf{1}$ & $\mathbf{2}$ & $\mathbf{3}$ & $\mathbf{4}$ & $\mathbf{5}$ & $\mathbf{1}$ & $\mathbf{2}$ & $\mathbf{3}$ & $\mathbf{4}$ & $\mathbf{5}$ \\
\hline 12 & 6 & 13 & 32 & 139 & 5,94 & 2,97 & 6,44 & 15,84 & 68,81 \\
\hline 22 & 19 & 46 & 37 & 80 & 10,78 & 9,31 & 22,55 & 18,14 & 39,22 \\
\hline 21 & 15 & 34 & 33 & 100 & 10,34 & 7,39 & 16,75 & 16,26 & 49,26 \\
\hline 33 & 16 & 44 & 19 & 91 & 16,26 & 7,88 & 21,67 & 9,36 & 44,83 \\
\hline 42 & 32 & 60 & 20 & 49 & 20,69 & 15,76 & 29,56 & 9,85 & 24,14 \\
\hline 51 & 29 & 25 & 25 & 73 & 25,12 & 14,29 & 12,32 & 12,32 & 35,96 \\
\hline 7 & 23 & 34 & 51 & 89 & 3,43 & 11,27 & 16,67 & 25,00 & 43,63 \\
\hline 44 & 18 & 18 & 39 & 84 & 21,67 & 8,87 & 8,87 & 19,21 & 41,38 \\
\hline 21 & 15 & 42 & 28 & 96 & 10,40 & 7,43 & 20,79 & 13,86 & 47,52 \\
\hline $\mathbf{2 8}$ & $\mathbf{1 9}$ & $\mathbf{3 5}$ & $\mathbf{3 2}$ & $\mathbf{8 9}$ & \multicolumn{7}{|c}{} \\
\hline
\end{tabular}

Fonte: Elaborada pela autora desta pesquisa.

Gráfico 18 - Principais preocupações do trabalhador do setor da construção civil -

Total (Arena Fonte Nova e Arena Pernambuco)

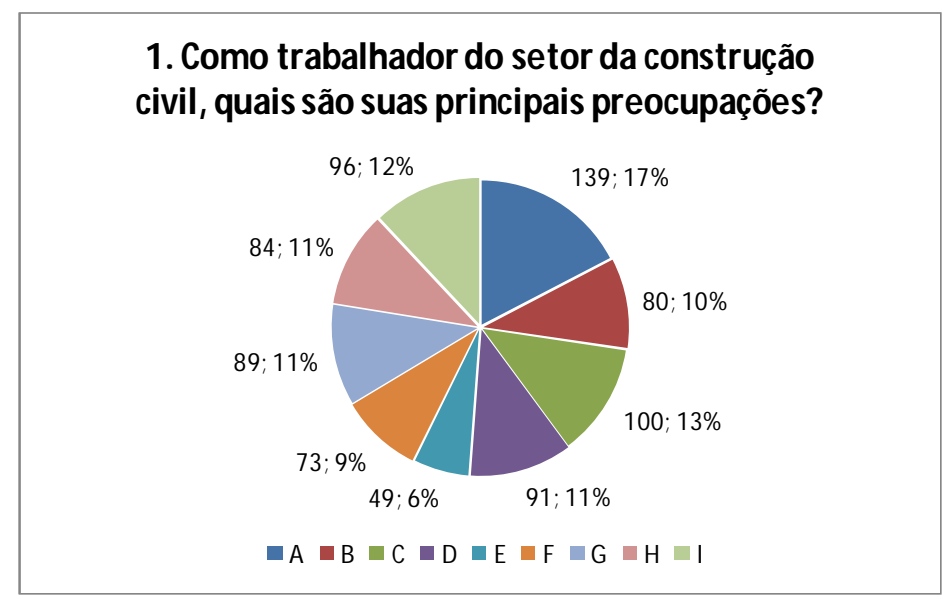

Fonte: Elaborado pela autora desta pesquisa. 
Pergunta 2: Você faz separação do lixo da sua casa?

\section{- Arena Fonte Nova}

Tabela 27 - Separação do lixo em casa - Arena Fonte Nova

\begin{tabular}{l|r|r|}
\hline \multirow{4}{*}{$\begin{array}{l}\text { Frequência } \\
\text { Absoluta }\end{array}$} & $\begin{array}{c}\text { Frequência } \\
\text { Relativa (\%) }\end{array}$ \\
\cline { 2 - 3 } Não & 127 & 81,41 \\
\hline Número de Amostras & 29 & 18,59 \\
\cline { 2 - 3 } & 156 & 100 \\
\hline
\end{tabular}

Fonte: Elaborada pela autora desta pesquisa.

Gráfico 19 - Separação do lixo em casa - Arena Fonte Nova

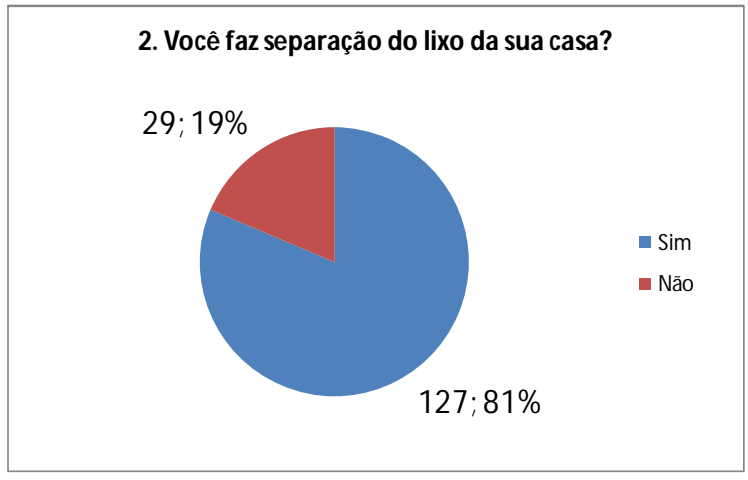

Fonte: Elaborado pela autora desta pesquisa.

\section{- Arena Pernambuco}

Tabela 28 - Separação do lixo em casa - Arena Pernambuco

\begin{tabular}{l|r|r|}
\cline { 2 - 3 } & $\begin{array}{c}\text { Frequência } \\
\text { Absoluta }\end{array}$ & \multicolumn{1}{c|}{$\begin{array}{c}\text { Frequência } \\
\text { Relativa (\%) }\end{array}$} \\
\cline { 2 - 3 } Não \\
Número de Amostras \\
Fonte: Elaborada pela autora desta pesquisa.
\end{tabular}


Gráfico 20 - Separação do lixo em casa - Arena Pernambuco

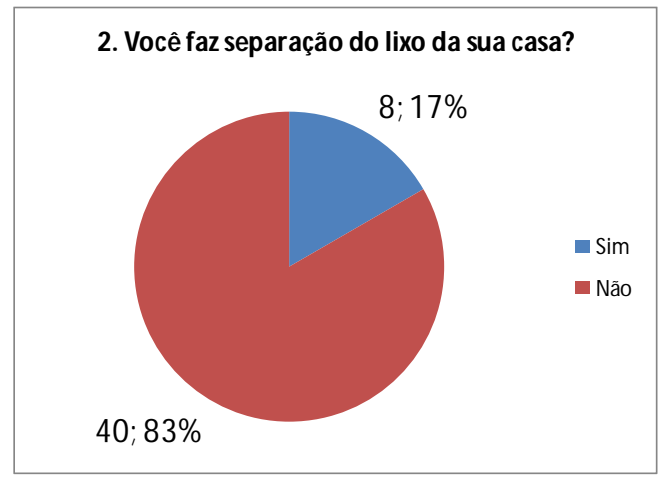

Fonte: Elaborado pela autora desta pesquisa.

\section{- Total (Arena Fonte Nova e Arena Pernambuco)}

Tabela 29 - Separação do lixo em casa - Total (Arena Fonte Nova e Arena Pernambuco)

\begin{tabular}{l|l|r|}
\cline { 2 - 3 } & $\begin{array}{l}\text { Frequência } \\
\text { Absoluta }\end{array}$ & \multicolumn{1}{|l|}{$\begin{array}{l}\text { Frequência } \\
\text { Relativa (\%) }\end{array}$} \\
\cline { 2 - 3 } Não & 135 & 66,18 \\
\hline Número de Amostras & 69 & 33,82 \\
\cline { 2 - 3 } & 204 & 100 \\
\hline
\end{tabular}

Fonte: Elaborada pela autora desta pesquisa.

Gráfico 21 - Separação do lixo em casa - Total (Arena Fonte Nova e Arena Pernambuco)

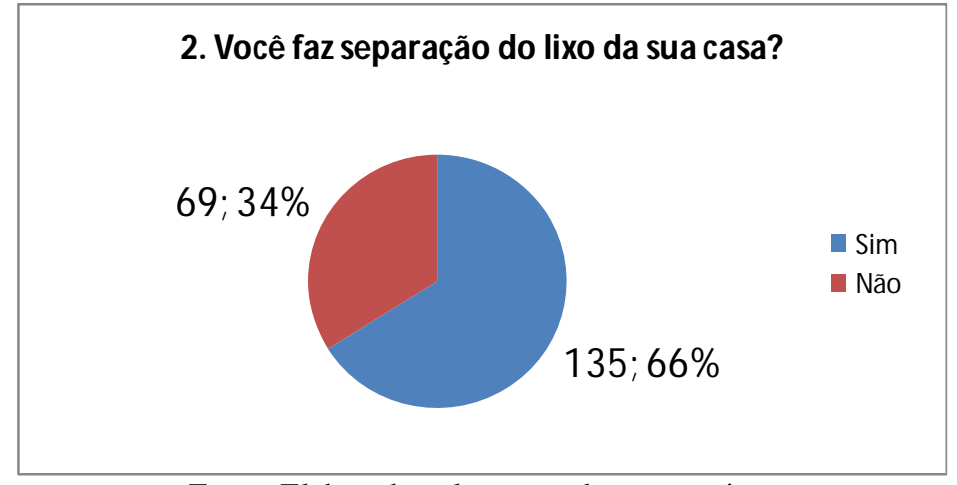

Fonte: Elaborado pela autora desta pesquisa.

O resultado dessa pergunta foi bastante interessante, principalmente em virtude da grande diferença nas respostas. Isso pode ser explicado por vários motivos, incluindo o grau de informação a que os colaboradores de cada obra estão expostos.

Considerando que $83 \%$ dos colaboradores da Arena Pernambuco não fazem a separação do lixo nas suas casas, isso pode ser decorrente da falta de informação no ambiente 
familiar, falta de educação ambiental e/ou falta de instrução no ambiente de trabalho quanto à importância de se realizar a separação do resíduo na fonte geradora.

Contrariamente a essa situação estão os colaboradores da Arena Fonte Nova, os quais $81 \%$ fazem a separação do lixo em casa. O fato de morarem numa cidade grande pode vir a facilitar a obtenção de informações, além de atividades educativas realizadas na cidade e no próprio ambiente de trabalho.

Analisando o total dos entrevistados, o cenário é bastante otimista, pois mostra que $66 \%$ das pessoas fazem a separação do lixo em casa.

Muitas são as razões que podem vir a interferir na conscientização ambiental dos colaboradores. Para tentar encontrar uma explicação mais próxima da realidade, foi feito um cruzamento de informações, em que as mesmas respostas foram analisadas em relação à escolaridade dos colaboradores.

\section{- Arena Fonte Nova}

Tabela 30 - Escolaridade x separação do lixo em casa - Arena Fonte Nova

\begin{tabular}{|l|c|c|}
\hline \multicolumn{1}{|c|}{ Nível de Escolaridade } & SIM & NÃO \\
\hline Analfabeto & 0 & 1 \\
\hline Fundamental Incompleto & 46 & 8 \\
\hline Fundamental Completo & 7 & 4 \\
\hline Médio ou Técnico Incompleto & 20 & 1 \\
\hline Médio ou Técnico Completo & 45 & 15 \\
\hline Superior Incompleto & 6 & 0 \\
\hline Superior Completo & 0 & 0 \\
\hline Indefinido & 3 & 0 \\
\hline Número de Amostras & $\mathbf{1 2 7}$ & $\mathbf{2 9}$ \\
\hline
\end{tabular}

Fonte: Elaborada pela autora desta pesquisa. 
Gráfico 22 - Escolaridade x separação do lixo em casa - Arena Fonte Nova

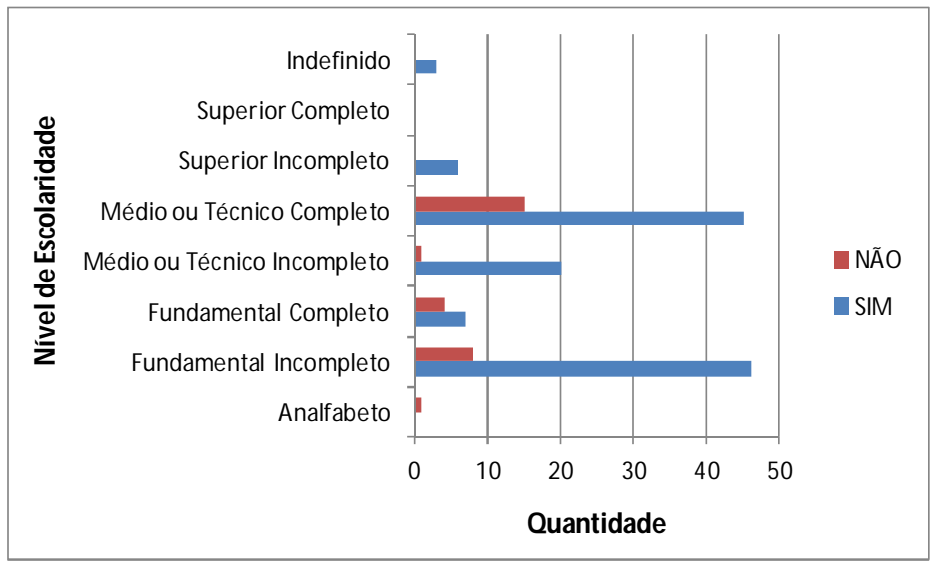

Fonte: Elaborado pela autora desta pesquisa.

\section{- Arena Pernambuco}

Tabela 31 - Escolaridade x separação do lixo em casa - Arena Pernambuco

\begin{tabular}{|l|c|c|}
\hline \multicolumn{1}{|c|}{ Nível de Escolaridade } & SIM & NÃo \\
\hline Analfabeto & 0 & 0 \\
\hline Fundamental Incompleto & 1 & 6 \\
\hline Fundamental Completo & 1 & 11 \\
\hline Médio ou Técnico Incompleto & 1 & 5 \\
\hline Médio ou Técnico Completo & 4 & 18 \\
\hline Superior Incompleto & 0 & 0 \\
\hline Superior Completo & 0 & 0 \\
\hline Indefinido & 1 & 0 \\
\hline Número de Amostras & $\mathbf{8}$ & $\mathbf{4 0}$ \\
\hline
\end{tabular}

Fonte: Elaborada pela autora desta pesquisa. 
Gráfico 23 - Escolaridade x separação do lixo em casa - Arena Pernambuco

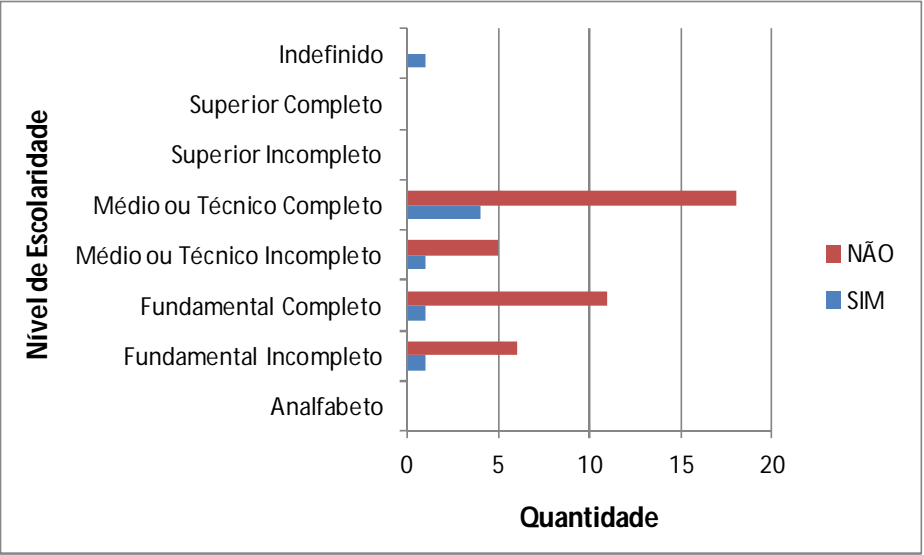

Fonte: Elaborado pela autora desta pesquisa.

\section{- Total (Arena Fonte Nova e Arena Pernambuco)}

Tabela 32 - Escolaridade x separação do lixo em casa - Total (Arena Fonte Nova e Arena Pernambuco)

\begin{tabular}{|l|c|c|}
\hline \multicolumn{1}{|c|}{ Nível de Escolaridade } & SIM & NÃO \\
\hline Analfabeto & 0 & 1 \\
\hline Fundamental Incompleto & 47 & 14 \\
\hline Fundamental Completo & 8 & 15 \\
\hline Médio ou Técnico Incompleto & 21 & 6 \\
\hline Médio ou Técnico Completo & 49 & 33 \\
\hline Superior Incompleto & 5 & 0 \\
\hline Superior Completo & 0 & 0 \\
\hline Indefinido & 1 & 0 \\
\hline Número de Amostras & $\mathbf{1 3 1}$ & $\mathbf{6 9}$ \\
\hline
\end{tabular}

Fonte: Elaborada pela autora desta pesquisa. 
Gráfico 24 - Escolaridade x separação do lixo em casa - Total (Arena Fonte Nova e Arena Pernambuco)

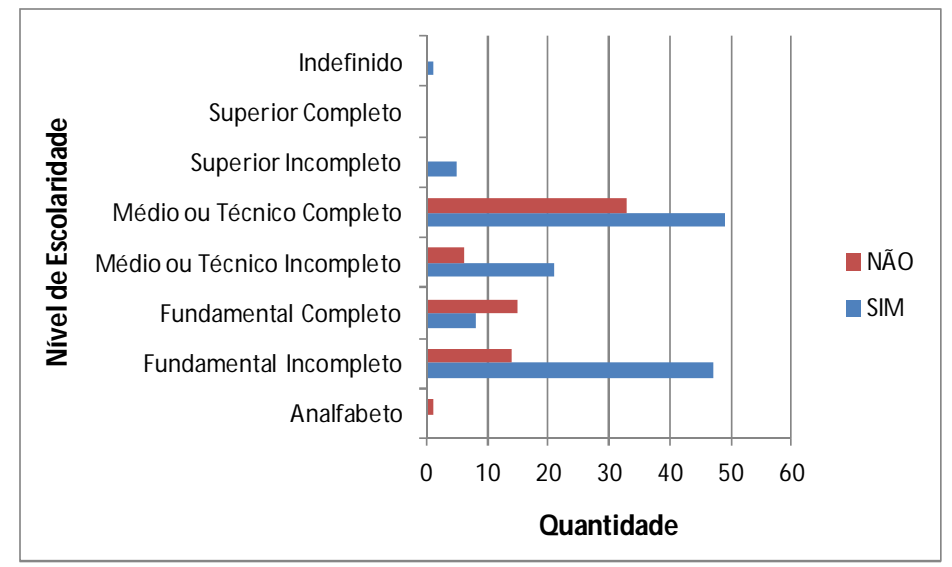

Fonte: Elaborado pela autora desta pesquisa.

Analisando a questão da separação do lixo realizada no domicílio dos colaboradores em virtude de sua escolaridade, observa-se que dos $83 \%$ dos funcionários da Arena Pernambuco que afirmaram não realizar a separação do lixo em casa, 45\% são de nível médio ou técnico. Observe-se que do total de funcionários dessa obra, 45\% são de nível médio ou técnico. Pode-se concluir, então, que a maioria dos colaboradores entrevistados é de nível técnico e não tem a cultura de separar o lixo.

Enquanto isso, na Arena Fonte Nova, dos $81 \%$ dos entrevistados que afirmaram fazer a separação do lixo em casa, 36\% são de nível fundamental completo e 35\% são de nível médio ou técnico.

Esses dados mostram que colaboradores com o mesmo nível de escolaridade possuem atitudes diferentes e, mais ainda, culturas diferentes relativas ao meio ambiente. 
Pergunta 3: Em sua opinião, a quantidade de lixo gerado na obra é:

\section{- Arena Fonte Nova}

Tabela 33 - Quantidade de lixo gerado na obra da Arena Fonte Nova

\begin{tabular}{r|r|r|}
\cline { 2 - 3 } Muito Grande & $\begin{array}{l}\text { Frequência } \\
\text { Absoluta }\end{array}$ & $\begin{array}{c}\text { Frequência } \\
\text { Relativa (\%) }\end{array}$ \\
\cline { 2 - 3 } Grande & 66 & 42,31 \\
\cline { 2 - 3 } Normal & 52 & 33,33 \\
\cline { 2 - 3 } Pequena & 29 & 18,59 \\
\cline { 2 - 3 } Muito Pequena & 6 & 3,85 \\
\cline { 2 - 3 } Número de Amostras & 3 & 1,92 \\
\cline { 2 - 3 } & 156 & 100 \\
\hline
\end{tabular}

Fonte: Elaborada pela autora desta pesquisa.

Gráfico 25 - Quantidade de lixo gerado na obra da Arena Fonte Nova

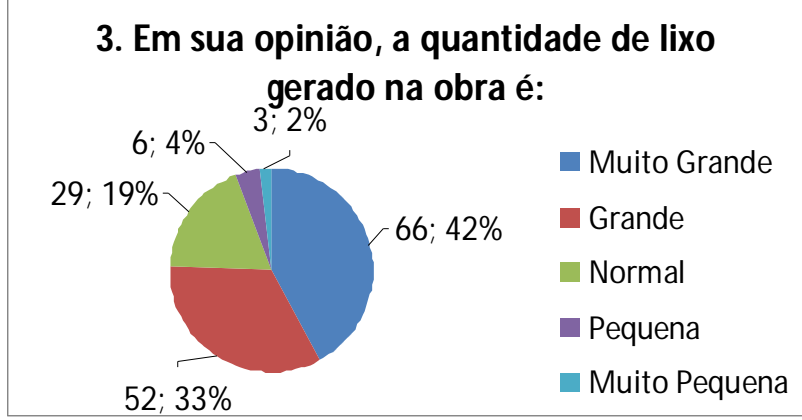

Fonte: Elaborado pela autora desta pesquisa.

\section{- Arena Pernambuco}

Tabela 34 - Quantidade de lixo gerado na obra da Arena Pernambuco

\begin{tabular}{r|r|r|}
\cline { 2 - 3 } Muito Grande & \multicolumn{1}{c|}{$\begin{array}{c}\text { Frequência } \\
\text { Absoluta }\end{array}$} & $\begin{array}{c}\text { Frequência } \\
\text { Relativa (\%) }\end{array}$ \\
\cline { 2 - 3 } Grande & 14 & 29,17 \\
\cline { 2 - 3 } Normal & 11 & 22,92 \\
\cline { 2 - 3 } Pequena & 5 & 10,42 \\
\cline { 2 - 3 } Muito Pequena & 2 & 4,17 \\
\cline { 2 - 3 } Número de Amostras & 16 & 33,33 \\
\cline { 2 - 3 } Fonte: Elaborada pela autora desta pesquisa.
\end{tabular}

Fonte: Elaborada pela autora desta pesquisa. 
Gráfico 26 - Quantidade de lixo gerado na obra da Arena Pernambuco

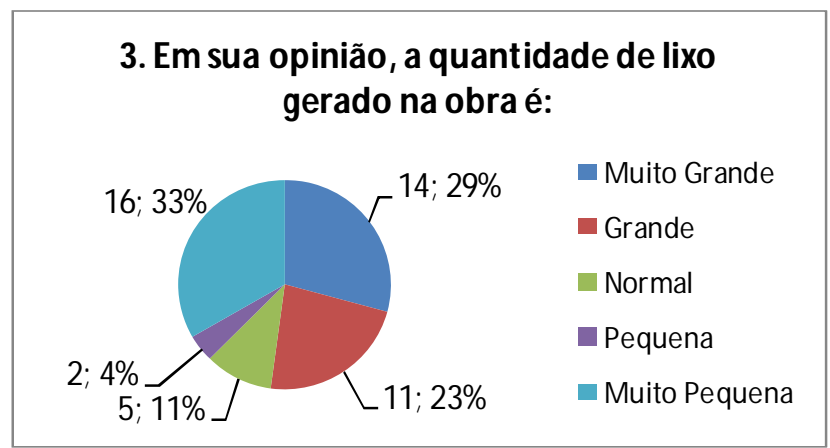

Fonte: Elaborado pela autora desta pesquisa.

\section{- Total (Arena Fonte Nova e Arena Pernambuco)}

Tabela 35 - Quantidade de lixo gerado nas obras da Arena Pernambuco e da Arena Fonte Nova

\begin{tabular}{r|r|r|}
\cline { 2 - 3 } Muito Grande & \multicolumn{1}{c|}{$\begin{array}{c}\text { Frequência } \\
\text { Absoluta }\end{array}$} & $\begin{array}{c}\text { Frequência } \\
\text { Relativa (\%) }\end{array}$ \\
\cline { 2 - 3 } Grande & 80 & 39,22 \\
\cline { 2 - 3 } Normal & 63 & 30,88 \\
\cline { 2 - 3 } Pequena & 34 & 16,67 \\
\cline { 2 - 3 } Muito Pequena & 8 & 3,92 \\
\cline { 2 - 3 } Número de Amostra & 19 & 9,31 \\
\cline { 2 - 3 } & 204 & 100 \\
\hline
\end{tabular}

Fonte: Elaborada pela autora desta pesquisa.

Gráfico 27 - Quantidade de lixo gerado nas obras da Arena Fonte Nova e da Arena Pernambuco

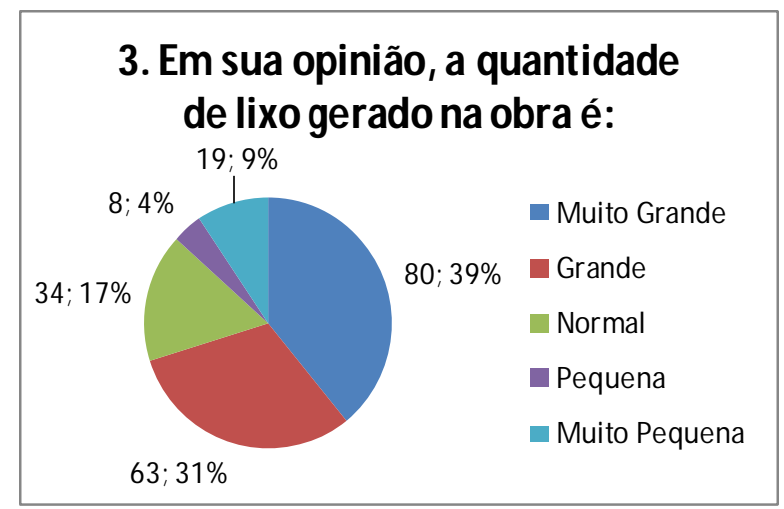

Fonte: Elaborado pela autora desta pesquisa. 
Analisando-se as tabelas, pode-se observar que as opiniões na Arena Pernambuco são bastante divergentes: $33 \%$ dos entrevistados acham que a quantidade de lixo gerado na obra é muito pequena, enquanto $29 \%$ dos entrevistados acham que essa quantidade é muito grande. Entretanto, de maneira geral, a maioria dos entrevistados acha que a quantidade de resíduos gerados na obra está entre muito grande (39\% no total) e grande (31\% no total).

\section{Pergunta 4: O que você entende por gerenciamento dos resíduos da construção civil?}

\section{- Arena Fonte Nova}

Tabela 36 - Gerenciamento dos resíduos da construção civil, segundo os entrevistados da Arena Fonte Nova

A - Separação dos vários tipos de lixo

B - Armazenamento em caçambas e containers

C - Destino correto

D - Limpeza do canteiro de obras

Todas as alternativas acima Número de Amostras

\begin{tabular}{|r|r|}
\hline $\begin{array}{c}\text { Frequência } \\
\text { Absoluta }\end{array}$ & $\begin{array}{c}\text { Frequência } \\
\text { Relativa (\%) }\end{array}$ \\
\hline 17 & 10,90 \\
\hline 6 & 3,85 \\
\hline 20 & 12,82 \\
\hline 21 & 13,46 \\
\hline 92 & 58,97 \\
\hline 156 & 100 \\
\hline
\end{tabular}

Fonte: Elaborada pela autora desta pesquisa.

Gráfico 28 - Gerenciamento dos resíduos da construção civil, segundo os entrevistados da Arena Fonte Nova

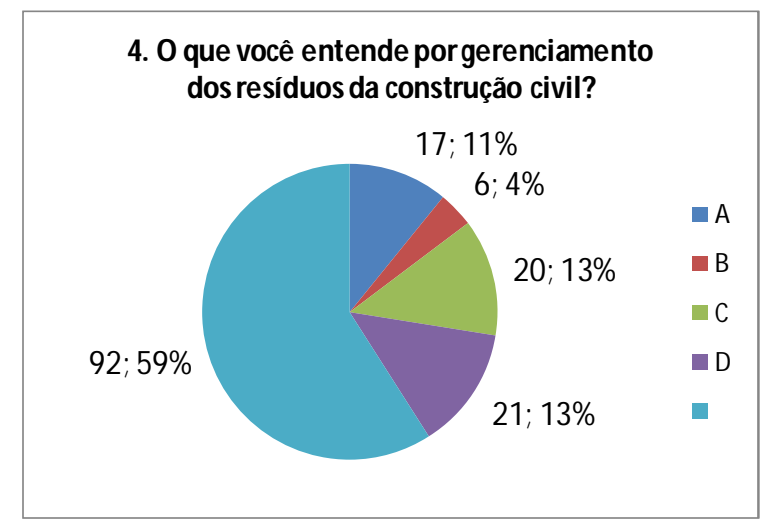

Fonte: Elaborado pela autora desta pesquisa. 


\section{- Arena Pernambuco}

Tabela 37 - Gerenciamento dos resíduos da construção civil, segundo os entrevistados da Arena Pernambuco

A - Separação dos vários tipos de lixo

B - Armazenamento em caçambas e containers

C - Destino correto

D - Limpeza do canteiro de obras

E - Todas as alternativas acima Número de Amostras

\begin{tabular}{|r|r|}
\hline $\begin{array}{c}\text { Frequência } \\
\text { Absoluta }\end{array}$ & $\begin{array}{r}\text { Frequência } \\
\text { Relativa (\%) }\end{array}$ \\
\hline 8 & 15,09 \\
\hline 4 & 7,55 \\
\hline 5 & 9,43 \\
\hline 7 & 13,21 \\
\hline 29 & 54,72 \\
\hline 53 & 100 \\
\hline
\end{tabular}

Fonte: Elaborada pela autora desta pesquisa.

Gráfico 29 - Gerenciamento dos resíduos da construção civil, segundo os entrevistados da Arena Pernambuco

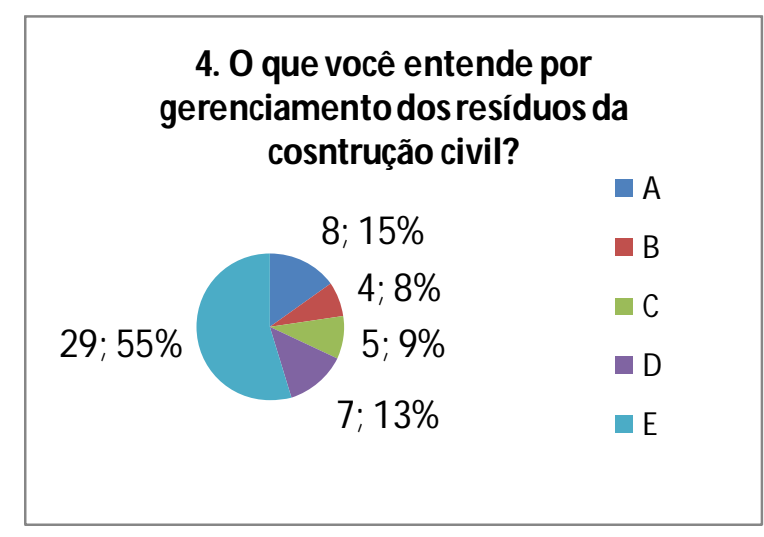

Fonte: Elaborado pela autora desta pesquisa.

\section{- Total (Arena Fonte Nova e Arena Pernambuco)}

Tabela 38 - Gerenciamento dos resíduos da construção civil, segundo todos os entrevistados

A - Separação dos vários tipos de lixo

B - Armazenamento em caçambas e containers

C - Destino correto

D - Limpeza do canteiro de obras

E - Todas as alternativas acima

Número de Amostras

\begin{tabular}{|r|r|}
\hline $\begin{array}{c}\text { Frequência } \\
\text { Absoluta }\end{array}$ & $\begin{array}{c}\text { Frequência } \\
\text { Relativa (\%) }\end{array}$ \\
\hline 25 & 11,96 \\
\hline 10 & 4,78 \\
\hline 25 & 11,96 \\
\hline 28 & 13,40 \\
\hline 121 & 57,89 \\
\hline 209 & 100 \\
\hline
\end{tabular}

Fonte: Elaborada pela autora desta pesquisa. 
Gráfico 30 - Gerenciamento dos resíduos da construção civil, segundo todos os entrevistados

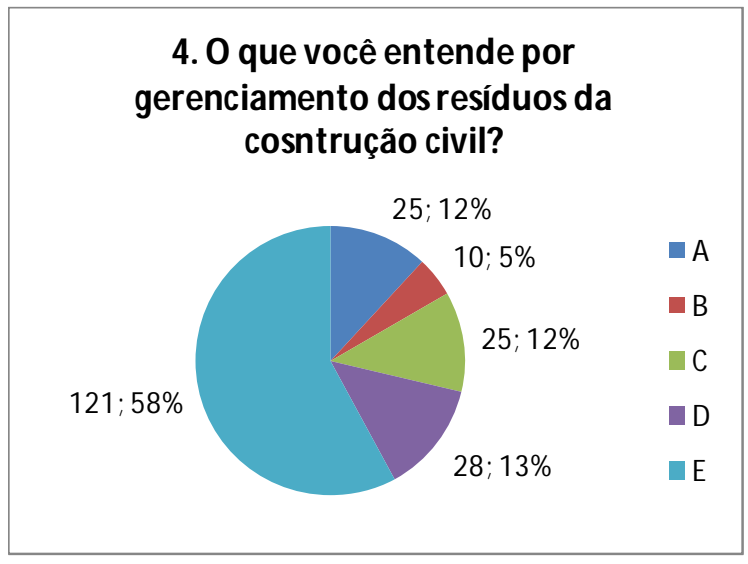

Fonte: Elaborado pela autora desta pesquisa.

Essa pergunta, ainda que todas as respostas possíveis serem corretas, se considerada a definição de gerenciamento dos resíduos da construção civil, tem uma única opção que define melhor os objetivos do GRCC, analisando do ponto de vista das pessoas que, de fato, são as responsáveis pela mecanização do processo. O que se pode analisar é que a maioria dos entrevistados sabe a correta definição de GRCC. Essa informação é muito importante, pois mostra que as empresas estão implantando os seus sistemas de Gestão e Gerenciamento dos Resíduos da Construção Civil de maneira correta, ao promover treinamentos e a educação ambiental no ambiente de trabalho. 
Pergunta 5: Em sua opinião, quais os fatores que dificultam a separação do lixo gerado durante a execução dos serviços na obra? (atribua notas 1, 2, 3, 4 e 5 para os fatores a seguir descritos, sendo 1 ao fator de menor preocupação e 5 ao de maior preocupação)

\section{- Arena Fonte Nova}

Tabela 39 - Fatores que dificultam a separação do lixo gerado durante a execução dos serviços na obra da Arena Fonte Nova

Fatores

A - Diminuição da produção

B - Trabalho não remunerado

C - Falta de tempo

D - Falta de conscientização ambiental

E - Falta de regras da empresa

$F$ - Falta de incentivos

G - Ausência de treinamento

$\mathrm{H}$ - Falta de locais específicos para o

acondicionamento na obra

I - Outras prioridades da obra

Média

\begin{tabular}{|r|r|r|r|r|c|c|c|c|c|}
\hline \multicolumn{7}{|c|}{ Frequência Absoluta } & \multicolumn{5}{|c|}{ Frequência Relativa (\%) } \\
\hline 1 & \multicolumn{1}{|c|}{$\mathbf{2}$} & $\mathbf{3}$ & $\mathbf{4}$ & $\mathbf{5}$ & $\mathbf{1}$ & $\mathbf{2}$ & $\mathbf{3}$ & $\mathbf{4}$ & $\mathbf{5}$ \\
\hline 16 & 13 & 46 & 24 & 56 & 10,32 & 8,39 & 29,68 & 15,48 & 36,13 \\
\hline 26 & 20 & 32 & 16 & 61 & 16,77 & 12,90 & 20,65 & 10,32 & 39,35 \\
\hline 36 & 19 & 38 & 29 & 33 & 23,23 & 12,26 & 24,52 & 18,71 & 21,29 \\
\hline 14 & 16 & 20 & 22 & 83 & 9,03 & 10,32 & 12,90 & 14,19 & 53,55 \\
\hline 32 & 19 & 26 & 28 & 50 & 20,65 & 12,26 & 16,77 & 18,06 & 32,26 \\
\hline 31 & 27 & 25 & 23 & 48 & 20,13 & 17,53 & 16,23 & 14,94 & 31,17 \\
\hline 35 & 19 & 30 & 22 & 49 & 22,58 & 12,26 & 19,35 & 14,19 & 31,61 \\
\hline 29 & 19 & 28 & 16 & 63 & 18,71 & 12,26 & 18,06 & 10,32 & 40,65 \\
\hline 27 & 21 & 51 & 18 & 36 & 17,65 & 13,73 & 33,33 & 11,76 & 23,53 \\
\hline $\mathbf{2 7}$ & $\mathbf{1 9}$ & $\mathbf{3 3}$ & $\mathbf{2 2}$ & $\mathbf{5 3}$ & & & & & \\
\hline
\end{tabular}

Fonte: Elaborada pela autora desta pesquisa.

Gráfico 31 - Fatores que dificultam a separação do lixo gerado durante a execução dos serviços na obra da Arena Fonte Nova

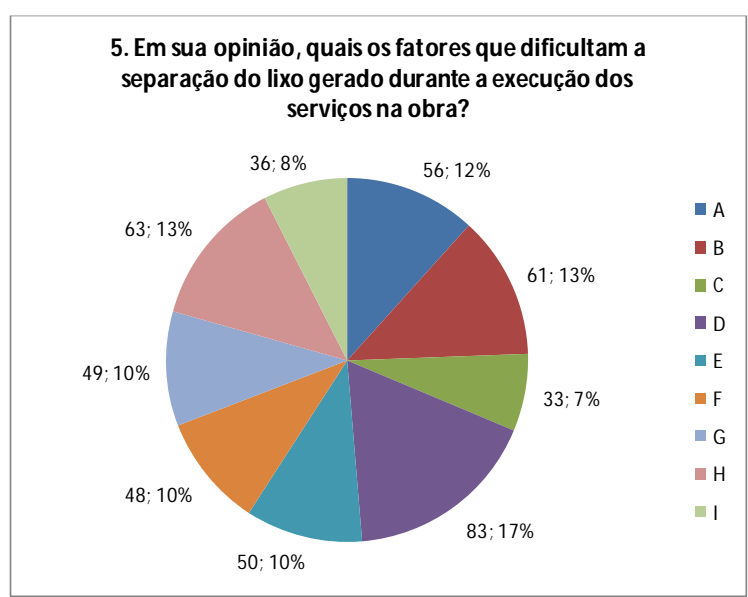

Fonte: Elaborado pela autora desta pesquisa. 


\section{- Arena Pernambuco}

Tabela 40 - Fatores que dificultam a separação do lixo gerado durante a execução dos serviços na obra da Arena Pernambuco

A - Diminuição da produção

B - Trabalho não remunerado

C - Falta de tempo

D - Falta de conscientização ambiental

E - Falta de regras da empresa

$F$ - Falta de incentivos

G - Ausência de treinamento

$\mathrm{H}$ - Falta de locais específicos para o

acondicionamento na obra

I - Outras prioridades da obra

Média

\begin{tabular}{|r|r|r|r|r|c|c|c|c|c|}
\hline \multicolumn{7}{|c|}{ Frequência Absoluta } & \multicolumn{5}{|c|}{ Frequência Relativa (\%) } \\
\hline $\mathbf{1}$ & $\mathbf{2}$ & $\mathbf{3}$ & $\mathbf{4}$ & $\mathbf{5}$ & $\mathbf{1}$ & $\mathbf{2}$ & $\mathbf{3}$ & $\mathbf{4}$ & $\mathbf{5}$ \\
\hline 7 & 23 & 11 & 3 & 4 & 14,58 & 47,92 & 22,92 & 6,25 & 8,33 \\
\hline 21 & 13 & 6 & 6 & 2 & 43,75 & 27,08 & 12,50 & 12,50 & 4,17 \\
\hline 13 & 23 & 6 & 2 & 4 & 27,08 & 47,92 & 12,50 & 4,17 & 8,33 \\
\hline 35 & 4 & 3 & 2 & 4 & 72,92 & 8,33 & 6,25 & 4,17 & 8,33 \\
\hline 32 & 4 & 1 & 4 & 7 & 66,67 & 8,33 & 2,08 & 8,33 & 14,58 \\
\hline 32 & 8 & 3 & 1 & 4 & 66,67 & 16,67 & 6,25 & 2,08 & 8,33 \\
\hline 28 & 10 & 5 & 2 & 3 & 58,33 & 20,83 & 10,42 & 4,17 & 6,25 \\
\hline 33 & 5 & 3 & 1 & 6 & 68,75 & 10,42 & 6,25 & 2,08 & 12,50 \\
\hline 20 & 19 & 8 & 0 & 0 & 42,55 & 40,43 & 17,02 & 0,00 & 0,00 \\
\hline $\mathbf{2 5}$ & $\mathbf{1 2}$ & $\mathbf{5}$ & $\mathbf{2}$ & $\mathbf{4}$ & \multicolumn{7}{|c|}{} \\
\hline
\end{tabular}

Fonte: Elaborada pela autora desta pesquisa.

Gráfico 32 - Fatores que dificultam a separação do lixo gerado durante a execução dos serviços na obra da Arena Pernambuco

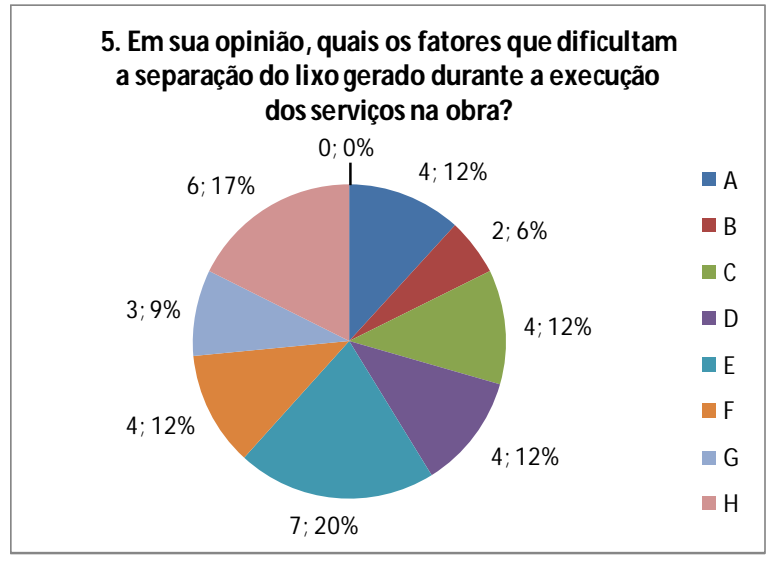

Fonte: Elaborado pela autora desta pesquisa. 
- Total (Arena Fonte Nova e Arena Pernambuco)

Tabela 41 - Fatores que dificultam a separação do lixo gerado durante a execução dos serviços nas obras da Arena Fonte Nova e da Arena Pernambuco

$\quad$ Fatores
A - Diminuição da produção
B - Trabalho não remunerado
C - Falta de tempo
D - Falta de conscientização ambiental
E - Falta de regras da empresa
F - Falta de incentivos
G - Ausência de treinamento
H - Falta de locais específicos para o
acondicionamento na obra
I- Outras prioridades da obra
$\quad$ Média

\begin{tabular}{|r|r|r|r|r|c|c|c|c|c|}
\hline \multicolumn{7}{|c|}{ Frequência Absoluta } & \multicolumn{6}{c|}{ Frequência Relativa (\%) } \\
\hline $\mathbf{1}$ & \multicolumn{1}{|c|}{$\mathbf{3}$} & $\mathbf{3}$ & $\mathbf{4}$ & $\mathbf{5}$ & $\mathbf{1}$ & $\mathbf{2}$ & $\mathbf{3}$ & $\mathbf{4}$ & $\mathbf{5}$ \\
\hline 23 & 36 & 57 & 27 & 60 & 11,33 & 17,73 & 28,08 & 13,30 & 29,56 \\
\hline 47 & 33 & 38 & 22 & 63 & 23,15 & 16,26 & 18,72 & 10,84 & 31,03 \\
\hline 49 & 42 & 44 & 31 & 37 & 24,14 & 20,69 & 21,67 & 15,27 & 18,23 \\
\hline 49 & 20 & 23 & 24 & 87 & 24,14 & 9,85 & 11,33 & 11,82 & 42,86 \\
\hline 64 & 23 & 27 & 32 & 57 & 31,53 & 11,33 & 13,30 & 15,76 & 28,08 \\
\hline 63 & 35 & 28 & 24 & 52 & 31,19 & 17,33 & 13,86 & 11,88 & 25,74 \\
\hline 63 & 29 & 35 & 24 & 52 & 31,03 & 14,29 & 17,24 & 11,82 & 25,62 \\
\hline 62 & 24 & 31 & 17 & 69 & 30,54 & 11,82 & 15,27 & 8,37 & 33,99 \\
\hline 47 & 40 & 59 & 18 & 36 & 23,50 & 20,00 & 29,50 & 9,00 & 18,00 \\
\hline $\mathbf{5 2}$ & $\mathbf{3 1}$ & $\mathbf{3 8}$ & $\mathbf{2 4}$ & $\mathbf{5 7}$ & & & & & \\
\hline
\end{tabular}

Fonte: Elaborada pela autora desta pesquisa.

Gráfico 33 - Fatores que dificultam a separação do lixo gerado durante a execução dos serviços nas obras da Arena Fonte Nova e da Arena Pernambuco

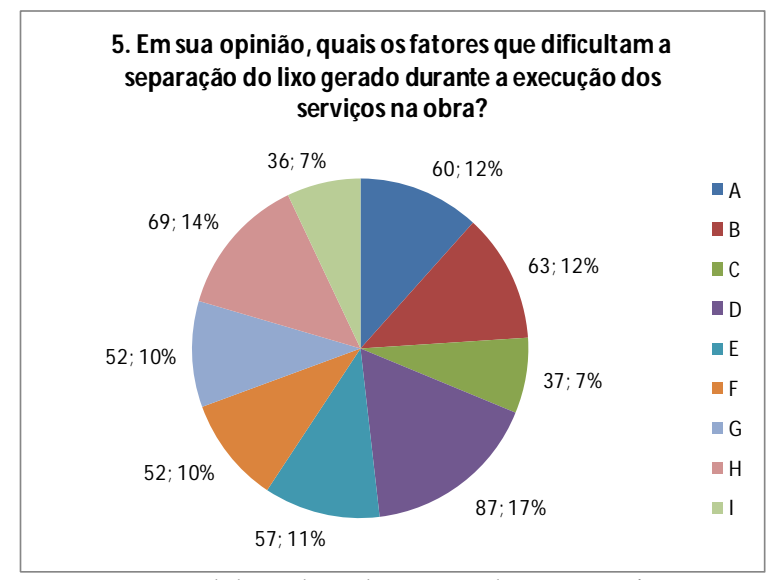

Fonte: Elaborado pela autora desta pesquisa.

Ao se analisar os gráficos com as respostas dadas a essa pergunta, e tendo em vista o número de opções que os entrevistados tiveram em relação ao grau de preocupação e a todas as opções de escolha, já que foram nove fatores propostos como dificultadores da separação dos resíduos da obra, é possível verificar que todos são considerados como importantes no processo. Alguns com um maior percentual, outros com um menor.

Contudo, analisando a tabela total, vemos que há certo antagonismo, uma vez que, em média, quase o mesmo número de pessoas considerou todos os fatores como de muita e de pouca preocupação (52 entrevistados - pouca; 57 entrevistados - muita). Outro aspecto analisado é que as respostas da Arena Pernambuco consideraram, em sua maioria, todos os itens como não sendo de muita preocupação, enquanto na Arena Fonte Nova ocorreu o 
oposto. Essa situação provoca um questionamento além das respostas, que é o motivo pelo qual obras tão parecidas podem ter opiniões tão divergentes, se a maioria dos processos relacionados ao sistema de Gestão e Gerenciamento de Resíduos da Construção Civil é parecido.

\section{Pergunta 6: Quais os fatores que dificultam o correto armazenamento do lixo no canteiro de obras? (atribua notas 1, 2, 3, 4 e 5 para os fatores a seguir descritos, sendo 1 ao fator de menor preocupação e 5 ao de maior preocupação)}

\section{- Arena Fonte Nova}

Tabela 42 - Fatores que dificultam o correto armazenamento do lixo no canteiro de obras da Arena Fonte Nova

Fatores

A - Falta de espaço no canteiro de obras

B - Falta de infraestrutura necessária

C - Falta de recursos financeiros

D - Ausência de treinamento

E - Falta de conscientização ambiental

$F$ - Falta de regras da empresa

$G$ - Falta de incentivos

$\mathrm{H}$ - Trabalho não remunerado

I - Custos de caçambas, conteiners, etc

J - Outras prioridades da obra

Média

\begin{tabular}{|r|r|r|r|r|r|c|c|c|c|}
\hline \multicolumn{7}{|c|}{ Frequência Absoluta } & \multicolumn{5}{c|}{ Frequência Relativa (\%) } \\
\hline $\mathbf{1}$ & \multicolumn{1}{|c|}{$\mathbf{2}$} & $\mathbf{3}$ & $\mathbf{4}$ & $\mathbf{5}$ & $\mathbf{1}$ & $\mathbf{2}$ & $\mathbf{3}$ & $\mathbf{4}$ & $\mathbf{5}$ \\
\hline 34 & 15 & 29 & 21 & 56 & 21,94 & 9,68 & 18,71 & 13,55 & 36,13 \\
\hline 24 & 30 & 37 & 30 & 34 & 15,48 & 19,35 & 23,87 & 19,35 & 21,94 \\
\hline 61 & 17 & 18 & 14 & 44 & 39,61 & 11,04 & 11,69 & 9,09 & 28,57 \\
\hline 41 & 23 & 22 & 26 & 43 & 26,45 & 14,84 & 14,19 & 16,77 & 27,74 \\
\hline 27 & 15 & 23 & 24 & 66 & 17,42 & 9,68 & 14,84 & 15,48 & 42,58 \\
\hline 37 & 25 & 24 & 24 & 45 & 23,87 & 16,13 & 15,48 & 15,48 & 29,03 \\
\hline 30 & 26 & 32 & 23 & 44 & 19,35 & 16,77 & 20,65 & 14,84 & 28,39 \\
\hline 46 & 19 & 27 & 22 & 41 & 29,68 & 12,26 & 17,42 & 14,19 & 26,45 \\
\hline 35 & 22 & 30 & 28 & 40 & 22,58 & 14,19 & 19,35 & 18,06 & 25,81 \\
\hline 34 & 29 & 45 & 16 & 29 & 22,22 & 18,95 & 29,41 & 10,46 & 18,95 \\
\hline $\mathbf{3 7}$ & $\mathbf{2 2}$ & $\mathbf{2 9}$ & $\mathbf{2 3}$ & $\mathbf{4 4}$ & \multicolumn{7}{|c}{} \\
\hline
\end{tabular}

Fonte: Elaborada pela autora desta pesquisa.

Gráfico 34 - Fatores que dificultam o correto armazenamento do lixo no canteiro de obras da Arena Fonte Nova

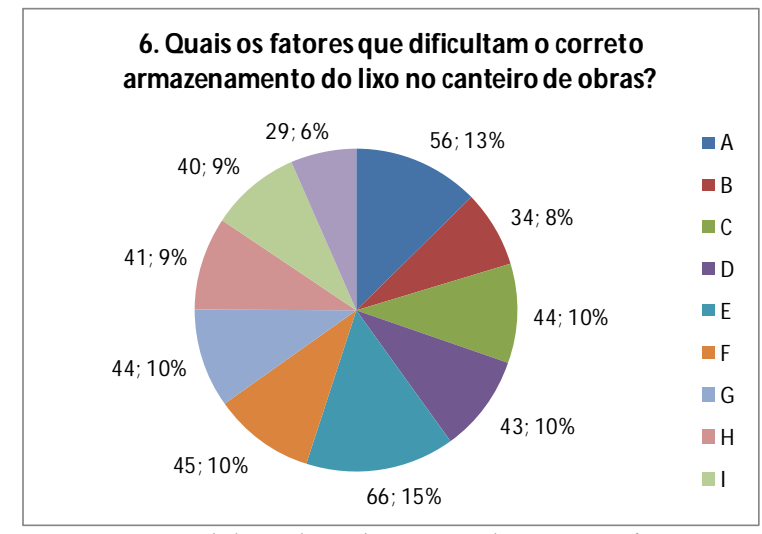

Fonte: Elaborado pela autora desta pesquisa. 


\section{- Arena Pernambuco}

Tabela 43 - Fatores que dificultam o correto armazenamento do lixo no canteiro de obras da Arena Pernambuco

\begin{tabular}{|c|c|c|c|c|c|c|c|c|c|c|}
\hline \multirow[b]{2}{*}{ Fatores } & \multicolumn{5}{|c|}{ Frequência Absoluta } & \multicolumn{5}{|c|}{ Frequência Relativa (\%) } \\
\hline & 1 & 2 & 3 & 4 & 5 & 1 & 2 & 3 & 4 & 5 \\
\hline A - Falta de espaço no canteiro de obras & 34 & 8 & 1 & 0 & 5 & 70,83 & 16,67 & 2,08 & 0,00 & 10,42 \\
\hline B - Falta de infraestrutura necessária & 33 & 6 & 4 & 3 & 2 & 68,75 & 12,50 & 8,33 & 6,25 & 4,17 \\
\hline C - Falta de recursos financeiros & 39 & 3 & 3 & 1 & 2 & 81,25 & 6,25 & 6,25 & 2,08 & 4,17 \\
\hline D - Ausência de treinamento & 31 & 9 & 3 & 1 & 4 & 64,58 & 18,75 & 6,25 & 2,08 & 8,33 \\
\hline E - Falta de conscientização ambiental & 28 & 11 & 2 & 1 & 6 & 58,33 & 22,92 & 4,17 & 2,08 & 12,50 \\
\hline F - Falta de regras da empresa & 29 & 7 & 6 & 2 & 4 & 60,42 & 14,58 & 12,50 & 4,17 & 8,33 \\
\hline G - Falta de incentivos & 33 & 6 & 3 & 1 & 5 & 68,75 & 12,50 & 6,25 & 2,08 & 10,42 \\
\hline H - Trabalho não remunerado & 11 & 23 & 8 & 3 & 3 & 22,92 & 47,92 & 16,67 & 6,25 & 6,25 \\
\hline I - Custos de caçambas, conteiners, etc & 33 & 3 & 5 & 3 & 4 & 68,75 & 6,25 & 10,42 & 6,25 & 8,33 \\
\hline J - Outras prioridades da obra & 17 & 6 & 22 & 2 & 1 & 35,42 & 12,50 & 45,83 & 4,17 & 2,08 \\
\hline Média & 29 & 8 & 6 & 2 & 4 & & & & & \\
\hline
\end{tabular}

Fonte: Elaborada pela autora desta pesquisa.

Gráfico 35 - Fatores que dificultam o correto armazenamento do lixo no canteiro de obras da Arena Pernambuco

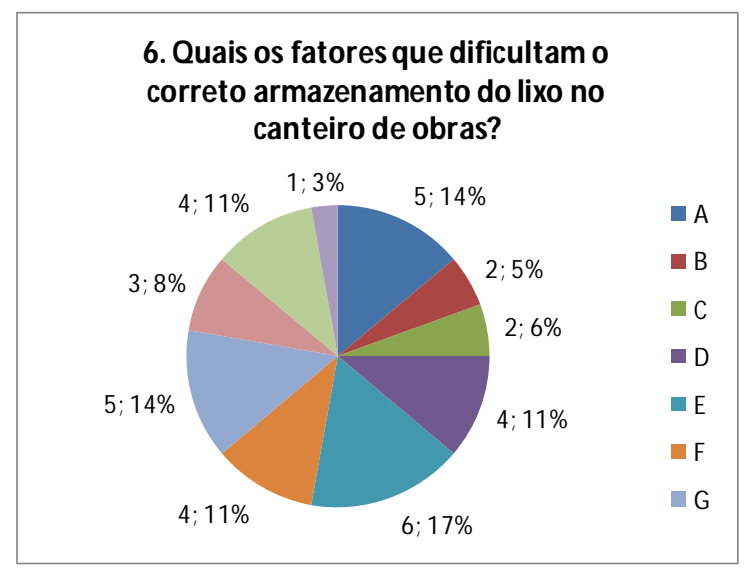

Fonte: Elaborado pela autora desta pesquisa. 


\section{Total (Arena Fonte Nova e Arena Pernambuco)}

Tabela 44 - Fatores que dificultam o correto armazenamento do lixo no canteiro de obras da Arena Fonte Nova e da Arena Pernambuco

Fatores

A - Falta de espaço no canteiro de obras

B - Falta de infraestrutura necessária

C - Falta de recursos financeiros

D - Ausência de treinamento

E - Falta de conscientização ambiental

$F$ - Falta de regras da empresa

$G$ - Falta de incentivos

$\mathrm{H}$ - Trabalho não remunerado

I - Custos de caçambas, conteiners, etc

J - Outras prioridades da obra

Média

\begin{tabular}{|r|r|r|r|r|c|c|c|c|c|}
\hline \multicolumn{7}{|c|}{ Frequência Absoluta } & \multicolumn{5}{c|}{ Frequência Relativa (\%) } \\
\hline $\mathbf{1}$ & \multicolumn{1}{|c|}{$\mathbf{2}$} & $\mathbf{3}$ & $\mathbf{4}$ & $\mathbf{5}$ & $\mathbf{1}$ & $\mathbf{2}$ & $\mathbf{3}$ & $\mathbf{4}$ & $\mathbf{5}$ \\
\hline 68 & 23 & 30 & 21 & 61 & 33,50 & 11,33 & 14,78 & 10,34 & 30,05 \\
\hline 57 & 36 & 41 & 33 & 36 & 28,08 & 17,73 & 20,20 & 16,26 & 17,73 \\
\hline 100 & 20 & 21 & 15 & 46 & 49,50 & 9,90 & 10,40 & 7,43 & 22,77 \\
\hline 72 & 32 & 25 & 27 & 47 & 35,47 & 15,76 & 12,32 & 13,30 & 23,15 \\
\hline 55 & 26 & 25 & 25 & 72 & 27,09 & 12,81 & 12,32 & 12,32 & 35,47 \\
\hline 66 & 32 & 30 & 26 & 49 & 32,51 & 15,76 & 14,78 & 12,81 & 24,14 \\
\hline 63 & 32 & 35 & 24 & 49 & 31,03 & 15,76 & 17,24 & 11,82 & 24,14 \\
\hline 57 & 42 & 35 & 25 & 44 & 28,08 & 20,69 & 17,24 & 12,32 & 21,67 \\
\hline 68 & 25 & 35 & 31 & 44 & 33,50 & 12,32 & 17,24 & 15,27 & 21,67 \\
\hline 51 & 35 & 67 & 18 & 30 & 25,37 & 17,41 & 33,33 & 8,96 & 14,93 \\
\hline $\mathbf{6 6}$ & $\mathbf{3 0}$ & $\mathbf{3 4}$ & $\mathbf{2 5}$ & $\mathbf{4 8}$ & & & & &
\end{tabular}

Fonte: Elaborada pela autora desta pesquisa.

Gráfico 36 - Fatores que dificultam o correto armazenamento do lixo no canteiro de obras da Arena Fonte Nova e da Arena Pernambuco

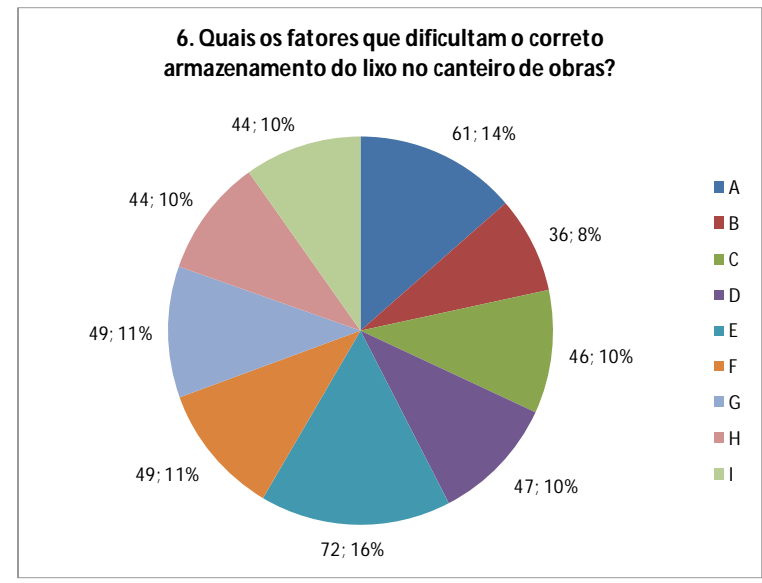

Fonte: Elaborado pela autora desta pesquisa.

Nesse quesito, a conscientização ambiental foi considerada em ambas as obras como o fator de maior preocupação dos entrevistados. E isso também pode ser analisado no gráfico geral da pergunta anterior.

Cabe a avaliação do seguinte: até que ponto a falta de conscientização ambiental é, de fato, um fator preocupante para os entrevistados, se foi verificado anteriormente que a grande maioria tem noção do que se trata o gerenciamento dos resíduos da construção civil, e que o armazenamento correto faz parte desse processo?

Contudo, assim como na resposta anterior, todos os itens foram considerados preocupantes, em suas devidas proporções. 
Pergunta 7: Em sua opinião, qual deveria ser o destino dado para o lixo da obra? (atribua notas 1, 2, 3, 4 e 5 para os fatores a seguir descritos, sendo 1 ao fator de menor preocupação e 5 ao de maior preocupação)

\section{- Arena Fonte Nova}

Tabela 45 - Destino que deveria ser dado ao lixo da obra da Arena Fonte Nova

\begin{tabular}{|c|c|c|c|c|c|c|c|c|c|c|}
\hline \multirow[b]{2}{*}{ Destinos } & \multicolumn{5}{|c|}{ Frequência Absoluta } & \multicolumn{5}{|c|}{ Frequência Relativa (\%) } \\
\hline & 1 & 2 & 3 & 4 & 5 & 1 & 2 & 3 & 4 & 5 \\
\hline \multirow{5}{*}{$\begin{array}{l}\text { A - Reutilização na própria obra } \\
\text { B - Terrenos baldios } \\
\text { C - Empresas de coleta } \\
\text { D - Pedreiras desativadas ou em funcionamento } \\
\text { E - Ecopontos do município }\end{array}$} & 23 & 12 & 28 & 14 & 79 & 14,74 & 7,69 & 17,95 & 8,97 & 50,64 \\
\hline & 45 & 16 & 21 & 15 & 59 & 28,85 & 10,26 & 13,46 & 9,62 & 37,82 \\
\hline & 23 & 6 & 21 & 35 & 71 & 14,74 & 3,85 & 13,46 & 22,44 & 45,51 \\
\hline & 38 & 25 & 33 & 21 & 37 & 24,68 & 16,23 & 21,43 & 13,64 & 24,03 \\
\hline & 27 & 18 & 41 & 21 & 48 & 17,42 & 11,61 & 26,45 & 13,55 & 30,97 \\
\hline \multirow{2}{*}{$\begin{array}{l}\text { F - Aterros sanitários } \\
\text { G - Lixeiras }\end{array}$} & 32 & 12 & 14 & 22 & 76 & 20,51 & 7,69 & 8,97 & 14,10 & 48,72 \\
\hline & 35 & 14 & 18 & 18 & 71 & 22,44 & 8,97 & 11,54 & 11,54 & 45,51 \\
\hline $\mathrm{H}$ - Aterros de inertes & 22 & 12 & 38 & 18 & 64 & 14,29 & 7,79 & 24,68 & 11,69 & 41,56 \\
\hline \multirow{3}{*}{$\begin{array}{l}\text { I - Rios } \\
\text { J - Reciclagem }\end{array}$} & 55 & 10 & 8 & 9 & 73 & 35,48 & 6,45 & 5,16 & 5,81 & 47,10 \\
\hline & 24 & 6 & 6 & 14 & 106 & 15,38 & 3,85 & 3,85 & 8,97 & 67,95 \\
\hline & 32 & 13 & 23 & 19 & 68 & & & & & \\
\hline
\end{tabular}

Fonte: Elaborada pela autora desta pesquisa.

Gráfico 37 - Destino que deveria ser dado ao lixo da obra da Arena Fonte Nova

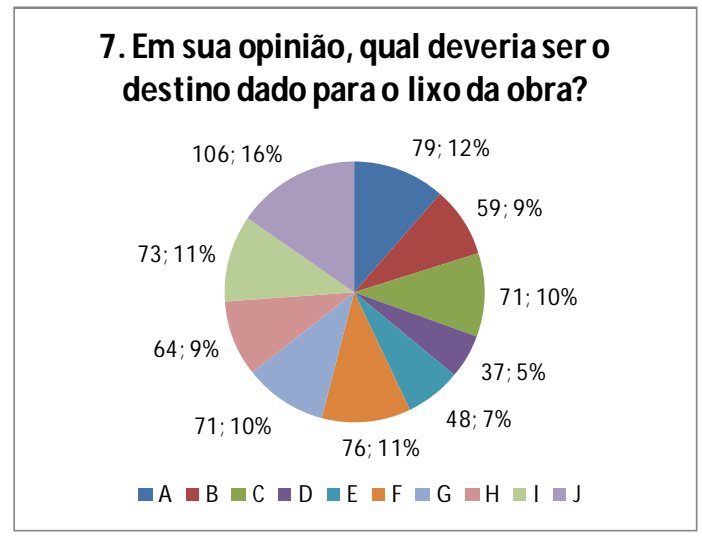

Fonte: Elaborado pela autora desta pesquisa. 


\section{- Arena Pernambuco}

Tabela 46 - Destino que deveria ser dado ao lixo da obra da Arena Pernambuco

\begin{tabular}{|c|c|c|c|c|c|c|c|c|c|c|}
\hline \multirow[b]{2}{*}{ Destinos } & \multicolumn{5}{|c|}{ Frequência Absoluta } & \multicolumn{5}{|c|}{ Frequência Relativa (\%) } \\
\hline & 1 & 2 & 3 & 4 & 5 & 1 & 2 & 3 & 4 & 5 \\
\hline A - Reutilização na própria obra & 3 & 5 & 3 & 8 & 29 & 6,25 & 10,42 & 6,25 & 16,67 & 60,42 \\
\hline B - Terrenos baldios & 29 & 11 & 1 & 3 & $\overline{4}$ & 60,42 & 22,92 & 2,08 & 6,25 & 8,33 \\
\hline C-Empresas de coleta & 3 & 4 & 4 & 23 & 14 & 6,25 & 8,33 & 8,33 & 47,92 & 29,17 \\
\hline D - Pedreiras desativadas ou em funcionamento & 34 & 8 & 4 & 1 & 1 & 70,83 & 16,67 & 8,33 & 2,08 & 2,08 \\
\hline E - Ecopontos do município & 8 & 6 & 28 & 2 & 4 & 16,67 & 12,50 & 58,33 & 4,17 & 8,33 \\
\hline F - Aterros sanitários & 5 & 8 & 26 & 5 & 4 & 10,42 & 16,67 & 54,17 & 10,42 & 8,33 \\
\hline G - Lixeiras & 11 & 22 & 4 & 4 & 7 & 22,92 & 45,83 & 8,33 & 8,33 & 14,58 \\
\hline $\mathrm{H}$ - Aterros de inertes & 7 & 4 & 3 & 25 & 9 & 14,58 & 8,33 & 6,25 & 52,08 & 18,75 \\
\hline I - Rios & 36 & 8 & 0 & 0 & 4 & 75,00 & 16,67 & 0,00 & 0,00 & 8,33 \\
\hline J - Reciclagem & 4 & 2 & 3 & 6 & 33 & 8,33 & 4,17 & 6,25 & 12,50 & 68,75 \\
\hline Média & 14 & 8 & 8 & 8 & 11 & & & & & \\
\hline
\end{tabular}

Fonte: Elaborada pela autora desta pesquisa.

Gráfico 38 - Destino que deveria ser dado ao lixo da obra da Arena Pernambuco

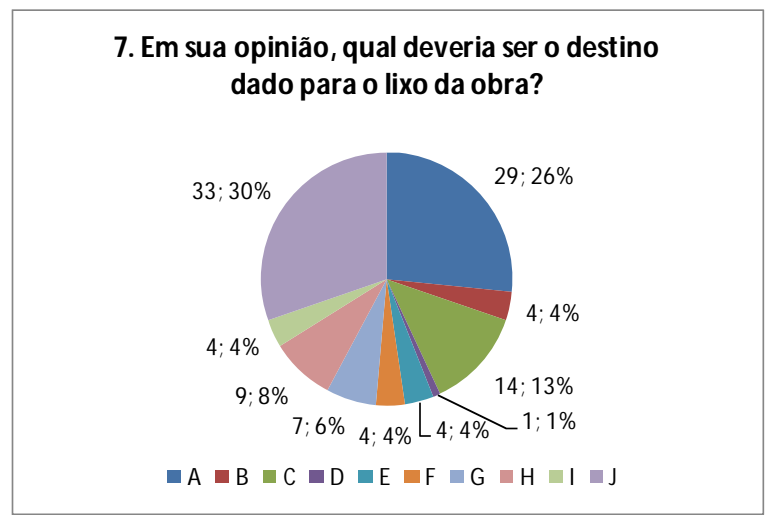

Fonte: Elaborado pela autora desta pesquisa.

\section{- Total (Arena Fonte Nova e Arena Pernambuco)}

Tabela 47 - Destino que deveria ser dado ao lixo das obras da Arena Fonte Nova e da Arena Pernambuco

\section{Destinos}

A - Reutilização na própria obra

B - Terrenos baldios

C - Empresas de coleta

D - Pedreiras desativadas ou em funcionamento

E - Ecopontos do município

F - Aterros sanitários

$G$ - Lixeiras

$\mathrm{H}$ - Aterros de inertes

I- Rios

J - Reciclagem

\begin{tabular}{|r|r|r|r|r|c|c|c|c|c|}
\hline \multicolumn{5}{|c|}{ Frequência Absoluta } & \multicolumn{5}{|c|}{ Frequência Relativa (\%) } \\
\hline \multicolumn{1}{|c|}{$\mathbf{2}^{\mathbf{1}}$} & $\mathbf{3}$ & \multicolumn{1}{|c|}{$\mathbf{4}$} & $\mathbf{5}$ & $\mathbf{1}$ & $\mathbf{2}$ & $\mathbf{3}$ & $\mathbf{4}$ & $\mathbf{5}$ \\
\hline 26 & 17 & 31 & 22 & 108 & 12,75 & 8,33 & 15,20 & 10,78 & 52,94 \\
\hline 74 & 27 & 22 & 18 & 63 & 36,27 & 13,24 & 10,78 & 8,82 & 30,88 \\
\hline 26 & 10 & 25 & 58 & 85 & 12,75 & 4,90 & 12,25 & 28,43 & 41,67 \\
\hline 72 & 33 & 37 & 22 & 38 & 35,64 & 16,34 & 18,32 & 10,89 & 18,81 \\
\hline 35 & 24 & 69 & 23 & 52 & 17,24 & 11,82 & 33,99 & 11,33 & 25,62 \\
\hline 37 & 20 & 40 & 27 & 80 & 18,14 & 9,80 & 19,61 & 13,24 & 39,22 \\
\hline 46 & 36 & 22 & 22 & 78 & 22,55 & 17,65 & 10,78 & 10,78 & 38,24 \\
\hline 29 & 16 & 41 & 43 & 73 & 14,36 & 7,92 & 20,30 & 21,29 & 36,14 \\
\hline 91 & 18 & 8 & 9 & 77 & 44,83 & 8,87 & 3,94 & 4,43 & 37,93 \\
\hline 28 & 8 & 9 & 20 & 139 & 13,73 & 3,92 & 4,41 & 9,80 & 68,14 \\
\hline $\mathbf{4 6}$ & $\mathbf{2 1}$ & $\mathbf{3 0}$ & $\mathbf{2 6}$ & $\mathbf{7 9}$ & & & & & \\
\hline
\end{tabular}

Fonte: Elaborada pela autora desta pesquisa. 
Gráfico 39 - Destino que deveria ser dado ao lixo das obras da Arena Fonte Nova e da Arena Pernambuco

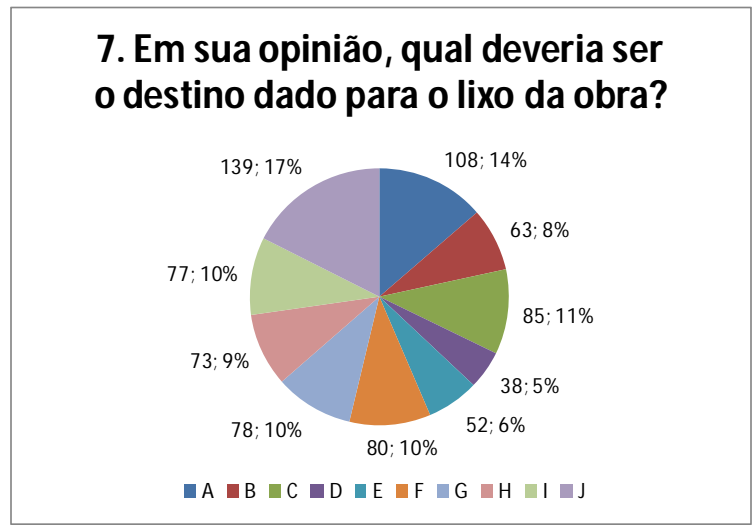

Fonte: Elaborado pela autora desta pesquisa.

Nessa pergunta, dois aspectos importantes podem ser analisados: um é que a maioria dos entrevistados demonstrou ter consciência ambiental ao responder que o destino correto a ser dado aos resíduos da obra é a reciclagem e a reutilização na obra. Contudo o outro aspecto é alarmante, pois ainda há pessoas que acham que os rios e terrenos baldios devem ser destino para os resíduos. Logo, pergunta-se novamente: até que ponto há, de fato, conscientização ambiental e real compreensão do tratamento a ser dado aos resíduos gerados na obra?

\section{Pergunta 8: Em sua opinião, a limpeza da obra deve ser feita:}

\section{- Arena Fonte Nova}

Tabela 49 - Frequência de limpeza da obra da Arena Fonte Nova

A - Uma vez a cada quinze dias

B - Uma vez por semana

$C$ - Duas vezes por semana

D - Todos os dias

E - Quando necessário

Número de Amostras

\begin{tabular}{|r|r|}
\hline $\begin{array}{c}\text { Frequência } \\
\text { Absoluta }\end{array}$ & $\begin{array}{c}\text { Frequência } \\
\text { Relativa (\%) }\end{array}$ \\
\hline 1 & 0,65 \\
\hline 3 & 1,94 \\
\hline 9 & 5,81 \\
\hline 134 & 86,45 \\
\hline 8 & 5,16 \\
\hline 155 & 100 \\
\hline
\end{tabular}

Fonte: Elaborada pela autora desta pesquisa. 
Gráfico 41 - Frequência de limpeza da obra da Arena Fonte Nova

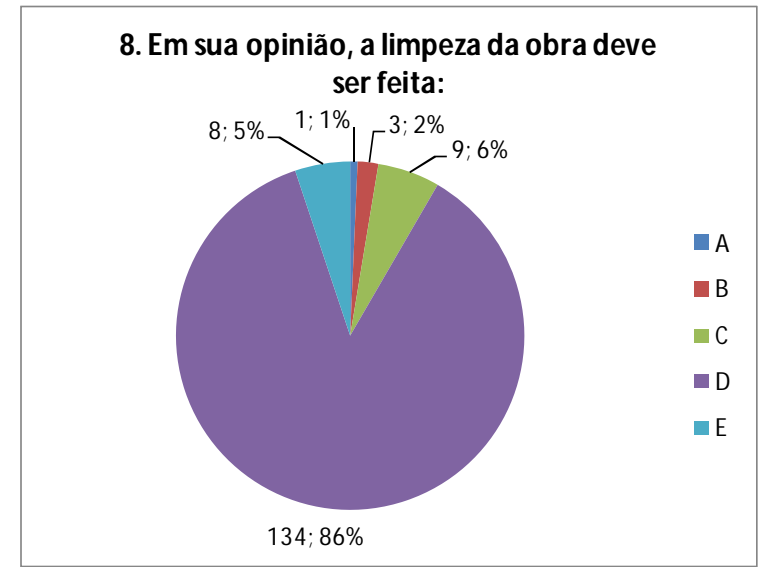

Fonte: Elaborado pela autora desta pesquisa.

\section{- Arena Pernambuco}

Tabela 48 - Frequência de limpeza da obra da Arena Pernambuco

\begin{tabular}{|c|c|c|}
\hline \multirow{7}{*}{$\begin{array}{l}\text { A - Uma vez a cada quinze dias } \\
\text { B - Uma vez por semana } \\
\text { C - Duas vezes por semana } \\
\text { D - Todos os dias } \\
\text { E - Quando necessário } \\
\quad \text { Número de Amostras }\end{array}$} & $\begin{array}{c}\text { Frequência } \\
\text { Absoluta }\end{array}$ & $\begin{array}{l}\text { Frequência } \\
\text { Relativa (\%) } \\
\end{array}$ \\
\hline & 0 & 0,00 \\
\hline & 0 & 0,0 \\
\hline & 3 & 6,2 \\
\hline & 33 & 68,75 \\
\hline & 12 & 25,0 \\
\hline & 48 & \\
\hline
\end{tabular}

Fonte: Elaborada pela autora desta pesquisa.

Gráfico 40 - Frequência de limpeza da obra da Arena Pernambuco

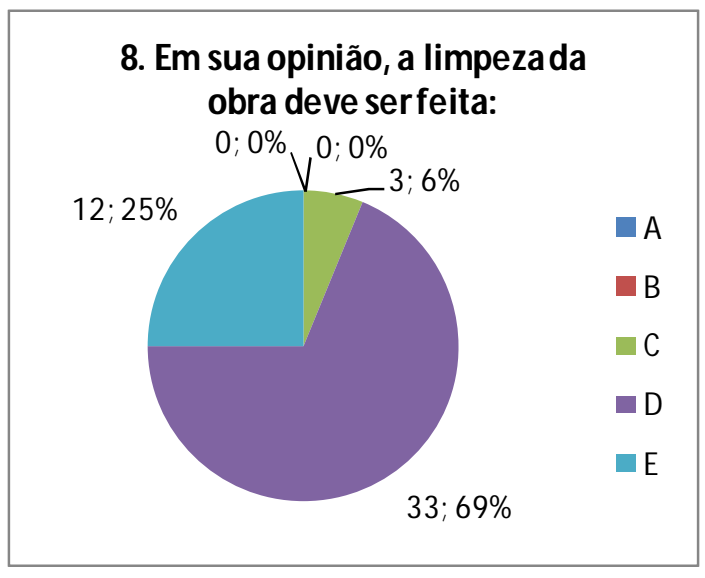

Fonte: Elaborado pela autora desta pesquisa. 


\section{- Total (Arena Fonte Nova e Arena Pernambuco)}

Tabela 50 - Frequência de limpeza das obras da Arena Fonte Nova e da Arena Pernambuco

\begin{tabular}{|c|c|c|}
\hline \multirow[b]{2}{*}{ A - Uma vez a cada quinze dias } & $\begin{array}{c}\text { Frequência } \\
\text { Absoluta }\end{array}$ & $\begin{array}{l}\text { Frequência } \\
\text { Relativa (\%) }\end{array}$ \\
\hline & 1 & 0,46 \\
\hline \multirow{5}{*}{$\begin{array}{l}\text { B - Uma vez por semana } \\
\text { C - Duas vezes por semana } \\
\text { D - Todos os dias } \\
\text { E - Quando necessário } \\
\quad \text { Número de Amostras }\end{array}$} & 3 & 1,37 \\
\hline & 12 & 5,48 \\
\hline & 175 & 79,91 \\
\hline & 28 & 12,79 \\
\hline & 219 & 100 \\
\hline
\end{tabular}

Fonte: Elaborada pela autora desta pesquisa.

Gráfico 42 - Frequência de limpeza das obras da Arena Fonte Nova e da Arena Pernambuco

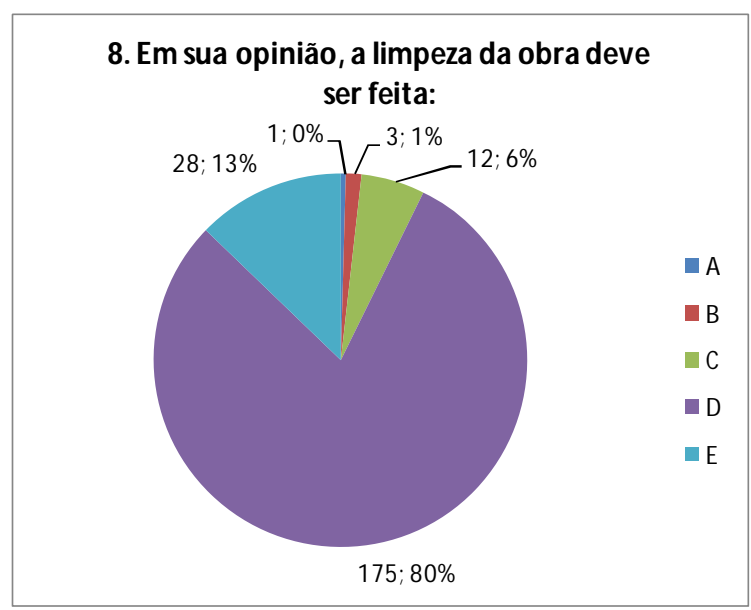

Fonte: Elaborado pela autora desta pesquisa.

A maioria dos entrevistados ( $80 \%$ no total) acha que a limpeza da obra tem de ser feita diariamente, e $13 \%$ acham que deve ser feita quando necessário. Isso mostra que 93\% dos entrevistados têm consciência da importância do ambiente de trabalho estar sempre limpo e, consequentemente, saudável. 


\section{CONCLUSÕES}

Após analisar todos os resultados obtidos no estudo, foi possível verificar que há a aplicação da Resolução CONAMA e da PNRS pelas empresas responsáveis pela construção da Arena Fonte Nova no município de Salvador-BA e da Arena Pernambuco no município de São Lourenço da Mata-PE.

Dessa forma, todos os objetivos específicos da pesquisa foram atingidos, uma vez que foi possível verificar a existência de Projeto de Gerenciamento de Resíduos da Construção Civil (PGRCC) nas obras em estudo, cuja análise crítica foi realizada não só à luz da Resolução CONAMA e de suas atualizações, mas também à da PNRS. Foi possível também definir os principais indicadores e técnicas de avaliação do Gerenciamento dos Resíduos da Construção Civil (RCC) adotado nas duas obras em estudo, por meio da obtenção das informações constantes no quadro de variáveis e indicadores, elaborado com base no objetivo principal do estudo. E, finalmente, pode-se proceder à análise comparativa do modelo de gerenciamento de RCC adotado nas obras e do preconizado pela literatura existente.

Tendo em vista o objetivo geral da pesquisa, que é analisar o gerenciamento dos resíduos da construção civil adotado em duas obras de grande porte: construção da Arena Pernambuco-PE e da Arena Fonte Nova-BA, após sancionar as Resoluções CONAMA no 307/2002, 431/2011 e 448/2012 e a Política Nacional de Resíduos Sólidos, Decreto n ${ }^{\circ}$ $7.404 / 2010$ que regulamenta a Lei n 12.305 , além de todas as observações obtidas nas obras e apresentadas anteriormente, foi elaborado um questionário aplicado aos colaboradores da empresa. Este questionário foi muito importante pois propiciou a realização de algumas análises além dos dados obtidos nas obras, uma vez que ainda que haja informações sobre escolaridade, idade e função de cada entrevistado, foi observado que sua cultura relativa ao meio ambiente independe desses aspectos. Muitas pessoas têm valores e comportamentos que são influenciados pela sua cultura e suas tradições. Mesmo com a realização, nas obras pesquisadas, de medidas mitigadoras, por meio de treinamento e conscientização dos integrantes e parceiros, as repostas aos questionários foram diversificadas e mostraram que muito deve ser feito para se reestruturar a cultura. 


\section{CONSIDERAÇÕES FINAIS}

Os resíduos da construção civil representam um passivo ambiental que, se não for gerenciado de forma adequada, resulta em grandes impactos ambientais. Portanto, é de grande importância o disciplinamento da gestão dos resíduos, por meio da adoção de soluções tecnicamente corretas e de ferramentas institucionais que privilegiem as ações preventivas em consonância às corretivas.

Evitar a geração de passivos e usar os recursos de forma responsável é o caminho a ser seguido por empresas que desenvolvem a gestão ambiental de forma eficiente e em busca do desenvolvimento sustentável.

Os resíduos da construção civil causam tantos problemas à vida urbana e ao meio ambiente que a melhor solução é que eles sejam vistos como fontes de materiais que podem ser reutilizados na construção civil e na pavimentação. Caso contrário, esses resíduos, além de atraírem a deposição de outros resíduos no local, também acarretam um ciclo vicioso de gastos públicos com limpeza.

A reciclagem na construção civil pode gerar inúmeros benefícios, como: redução no consumo de recursos naturais não renováveis, quando substituídos por resíduos reciclados; e a redução de áreas necessárias para aterro, pela minimização da quantidade de resíduos pela reciclagem. Dessa forma, torna-se evidente o fato de que a melhor solução para os resíduos é a reciclagem no próprio canteiro de obras, principalmente quando há um grande volume gerado e pouca disponibilidade de áreas para disposição.

Com um conhecimento prévio dos resíduos que serão gerados, é possível elaborar um planejamento detalhado e conciso para que a gestão e o gerenciamento desses resíduos sejam realizados corretamente. Assim, de forma ordenada, pode-se realizar o gerenciamento interno dos resíduos, no próprio canteiro, e externo, ao se definir a sua destinação final, otimizando os processos executivos e obtendo-se êxitos, tanto na redução de custo com a disposição dos resíduos, quanto na redução de custo com a compra de matéria-prima.

Além da elaboração de um planejamento detalhado e conciso, é preciso que haja a conscientização de toda a equipe envolvida da importância do trabalho desempenhado, pois esses colaboradores estão diretamente em contato com os resíduos gerados durante a construção, sendo os atores principais do sucesso do empreendimento.

Por mais que haja todo um planejamento executivo da obra visando a redução da geração dos resíduos, não será possível eliminá-los completamente, por isso é importante que, durante a execução dos serviços, seja feito um contínuo monitoramento e controle. Para isso, 
faz-se necessário a realização de medições de campo, que consistem no levantamento das entradas de insumos e saídas de resíduos, e de quantificações, que se tratam das avaliações e do acompanhamento de indicadores ambientais, de processos e de desempenho.

Do ponto de vista das empresas de construção civil, a conscientização, os interesses e a preocupação dos clientes e da sociedade em geral em relação ao tema do meio ambiente, bem como a sua crescente influência na definição dos seus empreendimentos de engenharia; a importância do tema na formação da imagem qualificada dessas empresas e de seus negócios; o maior rigor e os riscos envolvidos com os aspectos de meio ambiente para os projetos de maior porte; os custos de recuperação ambiental que poderão representar parcela importante nos valores contratuais; o movimento internacional de qualidade e certificação sustentável para abranger o tema; o fato de que o mercado de serviços e obras ambientais será um dos de maior crescimento no país; e o processo de aprendizado interno pela convivência de prática e aculturamento, que são requisitos essenciais para se assegurar vantagens competitivas no mercado, são considerações importantes que devem ser levadas em conta quando do investimento das empresas na gestão e no gerenciamento dos resíduos sólidos, de maneira geral, nas obras de grande porte.

Contudo, a falta da gestão e do gerenciamento efetivo do Poder Público impactam no processo de destinação dos resíduos, dificultando a destinação responsável dos grandes geradores. Isso ocorre por diversos motivos, seja pela falta de áreas para disposição, seja pelas grandes distâncias das áreas licenciadas, ou ainda pelas dificuldades burocráticas para o licenciamento. Além disso, o mercado possui poucas empresas que preenchem os requisitos legais do ponto de vista ambiental. A falta de incentivos e de alternativas para utilização dos resíduos como agregado são outros grandes entraves encontrados pelas empresas para aproveitamento dos resíduos da construção civil. Estas dificuldades acabam favorecendo a disposição clandestina dos resíduos, pois os transportadores buscam reduzir custos nos deslocamentos, uma vez que as áreas licenciadas são muito distantes, quando existem.

Além das dificuldades encontradas pelas empresas em relação ao Poder Público, a maior delas está na execução dos processos de gerenciamento dos resíduos sólidos, pois, conforme mencionado, os colaboradores dessas empresas são os principais atores. Portanto, é muito importante que todas as pessoas envolvidas nas etapas do projeto estejam cientes da necessidade de se ter uma consciência verde ao se objetivar o menor consumo dos bens, a maior reutilização dos resíduos e evitar o desperdício. O planejamento é a base inicial do sucesso, contudo, se não houver o respeito aos processos necessários para a execução de todas as atividades, o sistema de gestão e gerenciamento não terá êxito. Logo, é necessário que haja 
disciplina e colaboração de todos, visando um objetivo comum que é, nesse caso, além do lucro, a preservação ambiental.

Por mais que sejam feitos treinamentos e palestras na tentativa de educá-los e conscientizá-los em relação a essa importância, a mudança deve ocorrer na maneira em que eles veem a questão ambiental em geral, e isso não se ensina em escola ou por meio de palestras. A educação é um meio, mas não é a questão, portanto é preciso mudar a cultura do indivíduo, e para tanto deve haver uma reestruturação da cultura, com a transformação de valores, tradições e comportamentos.

Ao se afirmar a necessidade de reestruturação da cultura não se está fazendo referência apenas a um ponto específico, mas a todos os aspectos e níveis hierárquicos da sociedade. Não adianta gastar com coletores e depósitos específicos de coleta se as pessoas não estão aculturadas à separação correta. Do mesmo modo que se deve ter uma coleta eficiente, para que as pessoas possam fazer sua parte com a separação na fonte.

Esse processo torna-se um ciclo vicioso se não for bem gerido e gerenciado, e essa é uma obrigação de todos. As gerações atuais precisam ter o dever social de preservar o meio ambiente para si e para as gerações futuras, e isso só é possível com a conscientização de todos.

Os valores da sociedade, de maneira geral, estão corrompidos e não atendem à sustentabilidade. As pessoas precisam mudar também seus comportamentos e atitudes, e isso pode ser iniciado por meio de um consumo responsável e criterioso, ao limitá-lo quanto à quantidade, parando de consumir status.

Essa pesquisa, cujo objetivo é analisar e comparar os sistemas de gestão e gerenciamento das obras de grande porte, tem como obrigação alertar todas as pessoas da importância da conscientização ambiental e da responsabilidade de cada um, como indivíduo, para com o meio ambiente. Essa responsabilidade não pode ser passada para uma empresa, um órgão ambiental ou um governante, pois depende da junção de forças de todos, em prol de um bem comum que é a sobrevivência. Não é à toa que o assunto sustentabilidade está tão evidente. E, a cada dia, mais uma vertente diferente da sustentabilidade é criada ou, simplesmente, atentada por todos.

A sustentabilidade sempre foi vital para todos e somente agora as pessoas estão dando a devida importância, contudo tem-se de mudar a maneira de agir e isso só será possível se todos tiverem o mesmo interesse.

Independente de tratar-se de sustentabilidade ambiental, econômica, social ou tantas outras que estão sendo discutidas atualmente, a sustentabilidade que deve ser levada em 
consideração é a sustentabilidade do Planeta e essa só será atingida se todas as outras estiverem sendo tratadas em conjunto e todas as pessoas estiverem conscientes disso, pois, intrinsecamente, o que está em perigo são os seres vivos e não o Planeta. 


\section{SUGESTÕES PARA PESQUISAS FUTURAS}

Conforme o trabalho foi desenvolvido, algumas pesquisas futuras poderão ser realizadas, para dar prosseguimento ao mesmo. Dessa forma e, considerando a publicação recente do Manual de Orientação para os Planos de Gestão de Resíduos Sólidos, uma das sugestões é a realização de uma Avaliação dos Sistemas de Gestão e Gerenciamento das Obras em função do Plano Nacional de Resíduos Sólidos.

Ademais, no âmbito comportamental e social, sugere-se a elaboração de um Estudo de como se realizar a transformação da cultura relacionada à Consciência e Responsabilidade Ambiental, visando a Sustentabilidade. 


\section{REFERÊNCIAS BIBLIOGRÁFICAS}

A TARDE. Salvador, 19 de agosto de 2010. 3 fotografias, coloridas. Salvador, 2010.

ABNT. Associação Brasileira de Normas Técnicas. NBR 10.004: Resíduos Sólidos classificação. Rio de Janeiro, 2004.

. NBR 15.112: Resíduos da construção civil e resíduos volumosos - áreas de transbordo e triagem - diretrizes para projetos, implantação e operação. Rio de Janeiro, 2004a.

. NBR 15.113: Resíduos sólidos da construção civil e resíduos inertes - aterro diretrizes para projetos, implantação e operação. Rio de Janeiro, 2004b.

. NBR 15.114: Resíduos sólidos da construção civil - áreas de reciclagem - diretrizes para projetos, implantação e operação. Rio de Janeiro, 2004c.

. NBR 15.115: Resíduos sólidos da construção civil - execução de camadas de pavimentação - procedimentos. Rio de Janeiro, 2004d.

. NBR 15.116: Agregados reciclados de resíduos sólidos da construção civil utilização em pavimentação e concretos sem função estrutural - requisitos. Rio de Janeiro, 2004e.

ABRELPE. Associação Brasileira de Empresas de Limpeza Pública e Resíduos Especiais. Panorama Nacional dos Resíduos Sólidos 2010. Disponível em: <http://www.abrelpe.org.br/panorama_envio.cfm?ano=2010>. Acesso em: dez. 2011.

BRASIL. Ministério do Meio Ambiente. Conselho Nacional do Meio Ambiente (CONAMA). Resolução no 307, de 05 de julho de 2002. Dispõe sobre gestão dos Resíduos da Construção Civil. Brasília, 2002. Disponível em:

<http://www.mma.gov.br/port/conama/res/res02/res30702.html>. Acesso em: jan. 2011.

. Presidência da República. Casa Civil. Lei 12.305, de 02 de agosto de 2010. Institui a Política Nacional de Resíduos Sólidos; altera a Lei no 9.605, de 12 de fevereiro de 1998; e dá outras providências. Brasília, 2010. Disponível em:

<http://www.planalto.gov.br/ccivil_03/_ato2007-2010/2010/lei/112305.htm>. Acesso em: jan. 2011.

. Ministério do Meio Ambiente. Conselho Nacional do Meio Ambiente (CONAMA).

Resolução $\mathbf{n}^{\mathbf{0}}$ 431, de 24 de maio de 2011. Altera o art. 3ํ da Resolução n⿳0 307, de 5 de julho de 2002, do Conselho Nacional do Meio Ambiente - CONAMA, estabelecendo nova classificação para o gesso. Brasília, 2011. Disponível em:

<http://www.mma.gov.br/port/conama/legiabre.cfm?codlegi=649 >. Acesso em: abr. 2012.

. Ministério do Meio Ambiente. Conselho Nacional do Meio Ambiente (CONAMA).

Resolução $\mathbf{n}^{\mathbf{0}}$ 448, de 18 de janeiro de 2012. Altera o arts. $2^{\circ}, 4^{\circ}, 5^{\circ}, 6^{\circ}, 8^{\circ}, 9^{-}, 10,11$ da Resolução n⿳⺈ 307, de 5 de julho de 2002, do Conselho Nacional do Meio Ambiente - 
CONAMA. Brasília, 2012. Disponível em:

<http://www.mma.gov.br/port/conama/legiabre.cfm?codlegi=672 >. Acesso em: abr. 2012.

Ministério do Meio Ambiente. ICLEI - Brasil. Planos de gestão de resíduos

sólidos: manual de orientação. Brasília, 2012. Disponível em:

<http://www.meioambiente.ba.gov.br/upload/manual_de_residuos_solidos.pdf >. Acesso em: jun. 2012.

CADERNO Técnico ConstruBusiness 2010. $9^{\circ}$ Congresso Brasileiro da Construção. Brasil 2022: planejar, construir, crescer. São Paulo: FIESP, 2010. Disponível em:

<http://www.fiesp.com.br/construbusiness/pdf/apresentacoes/ConstBusiness2010Portugues.p df>. Acesso em: nov. 2011.

CBIC. Câmara Brasileira da Indústria da Construção. Ranking das maiores construtoras no Brasil - 2010. Belo Horizonte: CBIC, 2010. Disponível em:

$<$ http://www.cbicdados.com.br/pesq_grupo.asp?idItem $=12 \&$ Tipo $=1 \&$ idGrupo $=8 \&$ NomeGrup $\mathrm{o}=$ Empresas $\% 20 \mathrm{de} \% 20 \mathrm{Constru} \% \mathrm{E} 7 \% \mathrm{E} 3 \mathrm{o} \&$ NomeItem $=$ Classifica\%E7\%E3o\%20das\%20Mai ores\%20Empresas\%20da\%20Constru\%E7\%E3o>. Acesso em: abr. 2011.

Composição da cadeia produtiva da construção civil - 2009. Belo Horizonte: CBIC, 2009. Disponível em: <http://www.cbicdados.com.br>. Acesso em: 28 nov. 2011.

Importância do setor de construção civil na economia brasileira. Belo Horizonte: CBIC, 1998. Disponível em: <http://www.cbicdados.com.br/files/textos/027.pdf>. Acesso em: 12 fev. 2011.

CARNEIRO, A. P. et al. Características do entulho e do agregado reciclado. In:

BRUM, I. A. S.; CASSA, J. C. S (Org.). Reciclagem de entulho para a produção de materiais de construção: Projeto Entulho Bom. Salvador: EDUFBA/Caixa Econômica Federal, 2001. p. 144-187.

CHAGAS, L. R. B. Engenharia da construção - obras de grande porte. São Paulo: PINI, 2008.

CHELSOM, J. V.; PAYNE, A. C.; REAVILL, L. R. P. Gerenciamento para engenheiros, cientistas e tecnólogos. Rio de Janeiro: LTC, 2006.

CINTRA, G. A.; PEDROSO, R. Rotatividade de pessoal: um estudo de caso em uma empresa no ramo de construção civil. Revista Olhar Científico, Porto Velho, v. 1, n. 2, p. 6099, ago./dez. 2010.

CII. CONSTRUCTION INDUSTRY INSTITUTE. Constructability: a primer. Austin, TX, publication 3-1, July, 1986.

CÓRDOBA, R. E. Estudo do sistema de gerenciamento integrado de resíduos de construção civil e demolição do município de São Carlos. 2010. 372 f. Dissertação (Mestrado em Engenharia Hidráulica e Saneamento) - Escola de Engenharia de São Carlos, Universidade de São Paulo, São Carlos-SP, 2010. 
DCCE. Departamento de Comunicação da Comissão Europeia. Portal Oficial da União Europeia. Síntese da legislação da EU: recomendação 2003/361/CE relativa à definição de micro, pequenas e médias empresas. Jornal Oficial da Comissão das Comunidades Europeias de 20 de maio de 2003. Disponível em:

<http://europa.eu/legislation_summaries/enterprise/business_environment/n26026_pt.htm>. Acesso em: 01 fev. 2011.

DIEESE. Departamento Intersindical de Estatística e Estudos Socioeconômicos. Estudo Setorial da Construção Civil, 2010. Estudos e Pesquisas, no 51, maio de 2010, Disponível em: <http://www.dieese.org.br/esp/estpesq51ConstrucaoCivil.pdf >, Acesso em: jan. 2011.

FRANCO, L. S.; AGOPYAN, V. Implementação da racionalização construtiva na fase de projeto. São Paulo: EPUSP, 1993. (Boletim Técnico da Escola Politécnica da Universidade de São Paulo).

FNP. Fonte Nova Negócios e Participações. Sequência de execução da demolição e implosão do antigo estádio da Fonte Nova. Salvador, 2010.

. PGRCC. Plano de Gerenciamento dos Resíduos da Construção Civil. Projeto Fonte Nova. Fevereiro, 2012.

GOOGLE EARTH. Estádio da Fonte Nova, Salvador, Bahia. 1 imagem de satélite. 2011. Disponível em: <http://www.google. com/earth>. Acesso em: 19 fev. 2011.

IBGE. Instituto Brasileiro de Geografia e Estatística. Pesquisa Anual da Indústria da Construção. Rio de Janeiro: IBGE, 2008. Disponível em:

<http://www.ibge.gov.br/home/presidencia/noticias/imprensa/ppts/0000000010.pdf>. Acesso em: 01 fev. 2011.

Pesquisa Anual da Indústria da Construção. Rio de Janeiro: IBGE, 2009.

Disponível em:

<http://www.ibge.gov.br/home/presidencia/noticias/imprensa/ppts/0000000470.pdf>. Acesso em: 28 nov. 2011.

. PIB cresce $1,2 \%$ em relação ao $1^{\circ}$ trimestre e chega a $\mathbf{R} \$ 900,7$ bi. Rio de Janeiro: IBGE, 2010. Disponível em:

<http://www.ibge.gov.br/home/presidencia/noticias/noticia_visualiza.php?id_noticia=1705\&i d_pagina $=1 \&$ titulo=PIB-cresce-1,2\%-em-relacao-ao-1\%BA-trimestre-e-chega-a-R \$-900,7bi>. Acesso em: dez. 2011.

ISATTO, Eduardo L. et al. Lean construction: diretrizes e ferramentas para o controle de perdas na construção civil. Porto Alegre: SEBRAE-RS, 2000. (Série SEBRAE Construção Civil, v. 5).

KOSKELA, L. Application of the new production philosophy to construction. Stanford, EUA: CIFE, 1992. (Technical Report nº 72).

LAKATOS, M. A; MARCONI; E. M. Metodologia do trabalho científico: procedimentos básicos, pesquisa bibliográfica, projeto e relatório, publicações e trabalhos científicos. São Paulo: Atlas, 2010. 
LAUFER, A.; TENAH, A K. Introducing management information systems in medium sized construction companies. International Journal of Project Management, v. 3, n. 3, p. 169176, ago. 1985.

LEITE, W. C. A. Estudo da gestão de resíduos sólidos: uma proposta de modelo tomando a Unidade de Gerenciamento de Recursos Hídricos (UGRHI-5) como referência. 1997. 270 f. Tese (Doutorado em Hidráulica e Saneamento) - Escola de Engenharia de São Carlos, Universidade de São Paulo, São Carlos, 1997.

LIPSMEIER, K; GÜNTHER, M. Institute for Waste Management and Contaminated Sites Treatment of Dresden University of Technology. Manual Europeu de Resíduos da Construção de Edifícios - Volume III - Anexos. Traduzido por Said Jalali e Luís Pereira. Guimarães, Portugal: TecMinho/Universidade do Minho. 2002.

MARQUES NETO, J. C. Estudo da gestão municipal dos resíduos da construção civil na Bacia Hidrográfica do Turvo Grande (UGRHI-15). 2009. 669 f. Tese (Doutorado em Ciências) - Escola de Engenharia de São Carlos, Universidade de São Paulo, São Carlos-SP, 2009.

MATTOS, A. D. Planejamento e controle de obras. São Paulo: PINI, 2010.

MELO, M. B. F. V. Influência da cultura organizacional no sistema de gestão da segurança e saúde no trabalho em empresas construtoras. 2001. 180 f. Tese (Doutorado em Engenharia de Produção) - Universidade Federal de Santa Catarina. Florianópolis, 2001.

ODEBRECHT. Odebrecht Infrestrutura na Copa. Salvador, 2012. Disponível em: <http://www.odebrechtnacopa.com.br>. Acesso em: mar. 2012.

OLIVEIRA, K. T. L. L.; MATA, H. T. C., CUNHA, R. C. Reflexões sobre o método e desenvolvimento do conceito de PIB verde como medida de desempenho econômico. In: Encontro Nacional da Sociedade Brasileira de Economia Ecológica, 9. 2010, Brasília. Anais eletrônicos... Brasília: SBEE, 2010. Disponível em:

<http://www.ecoeco.org.br/conteudo/publicacoes/encontros/ix_en/GT5-249-220-

20110620221250. pdf $>$. Acesso em: fev. 2012.

PMI. PROJECT MANAGEMENT INSTITUTE. Um guia do conhecimento em gerenciamento de projetos (Guia PMBOK). 4. ed. Pennsylvania: PMI, 2008.

PNUD, Programa das Nações Unidas para o Desenvolvimento. Desenvolvimento Humano IDH. Brasília, 2012. Disponível em: 〈http://www.pnud.org.br/IDHDetails.aspx>. Acesso em jun. 2012.

RAMOS, C. A.; CARNEIRO, F. G. Os determinantes da rotatividade do trabalho no Brasil: instituições x ciclos econômicos. Nova Economia, v. 2, n. 12, p. 31-56, jul./dez. 2002.

SANDRONI, P. Dicionário de Economia do século XXI. Rio de Janeiro: Record, 2005. 
SCHALCH, V.; CÓRDOBA, R. E. Estratégia para gestão de resíduos sólidos. Material didático elaborado para a disciplina de Gestão Ambiental. Escola de Engenharia de São Carlos, Universidade de São Paulo, São Carlos, SP, 2011.

SENAI. Serviço Nacional de Aprendizagem Industrial. Estudo setorial da construção civil características do setor. Rio de Janeiro: SENAI, 1995.

SILVA, C. E. S.; GUIMARÃES, S. M. A importância da construtibilidade na gestão de projetos de construção civil. IN: SIMPÓSIO DE ENGENHARIA DE PRODUÇÃO, 13., 2006, Bauru, SP. Anais eletrônicos... Bauru, SP: UNESP, 2006. Disponível em:

<http://www.simpep.feb.unesp.br/anais/anais_13/artigos/886.pdf>. Acesso em: nov. 2011.

SINDUSCON. Sindicato da Indústria da Construção Civil do Estado de São Paulo. 44a

Sondagem Nacional da Indústria da Construção. São Paulo, 2011. Disponível em:

<http://www.sindusconsp.com.br/msg2.asp?id=3961 >. Acesso em: 01 fev. 2011.

SPE ARENA PERNAMBUCO. Sociedade de Propósito Específico Arena Pernambuco

Negócios e Investimentos S.A. Arena Multiuso Pernambuco: área desmatada para a construção da arena. São Lourenço da Mata, PE, 25 nov. 2010.

2011.

. PGRS. Programa de Gerenciamento de Resíduos Sólidos. São Lourenço da Mata, PE,

VAlle, A. B. et al. Fundamentos do Gerenciamento de Projetos. Rio de Janeiro: Editora FGV, 2007. 
APÊNDICE A - Questionário - Colaboradores

\section{QUESTIONÁRIO COLABORADORES}

Nome da Obra :

Data:

Função que exerce :

Idade :

Escolaridade :

Período que trabalha com construção :

1. Como trabalhador do setor da construção civil, quais são suas principais preocupações?

(atribua notas 1, 2, 3, 4 e 5 para os fatores a seguir descritos, sendo 1 ao fator de menor preocupação e 50 de maior preocupação)

\begin{aligned} Fatores & \multicolumn{1}{c}{ Notas } \\ \cline { 2 - 2 } Acidentes de trabalho & \\ Baixos salários & \\ Bom relacionamento na empresa & \\ Desemprego & \\ Falta de incentivos & \\ Falta de treinamento & \\ Melhorar a produtividade & \\ Problemas de saúde & \\ Previdência social e aposentadoria & \end{aligned}

2. Você faz separação do lixo da sua casa?

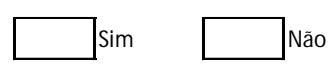

Por quê?

3. Em sua opinião, a quantidade de lixo gerado na obra é:

\begin{tabular}{r|l} 
Muito Grande & \\
Grande & \\
Normal & \\
Pequena & \\
Muito Pequena &
\end{tabular}

4. 0 que você entende por gerenciamento dos resíduos de construção e demolição?

Separação dos vários tipos de lixo Armazenamento em caçambas e containers Destino correto

Limpeza do canteiro de obras Todas as alternativas acima

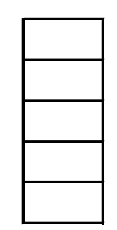


5. Em sua opinião, quais os fatores que dificultam a separação do lixo gerado durante a execução dos serviços na obra?

(atribua notas 1, 2, 3, 4 e 5 para os fatores a seguir descritos, sendo 1 ao fator de menor preocupação e 5 o de maior preocupação)

\begin{tabular}{|c|c|c|}
\hline Fatores & Notas & \\
\hline Diminuição da produção & & (Produz menos na obra) \\
\hline Trabalho não remunerado & & (Não recebe nada por isso) \\
\hline Falta de tempo & & (Não tem tempo para fazer) \\
\hline Falta de conscientização ambiental & & (Não é importante para a natureza) \\
\hline Falta de regras da empresa & & (A empresa não obriga) \\
\hline Falta de incentivos & & (A empresa não solicita nem premia) \\
\hline Ausência de treinamento & & (Falta de treinamento para isso) \\
\hline Falta de locais específicos para o acondicionamento na obra & & (Falta de locais apropriados para o armazenamento na obra) \\
\hline Outras prioridades da obra & & (Existem atividades mais importantes) \\
\hline
\end{tabular}

6. Quais os fatores que dificultam o correto armazenamento do lixo no canteiro de obras?

(atribua notas 1, 2, 3, 4 e 5 para os fatores a seguir descritos, sendo 1 ao fator de menor preocupação e 5 o de maior preocupação)

\begin{tabular}{|c|c|c|}
\hline \multirow{2}{*}{$\begin{array}{r}\text { Fatores } \\
\text { Falta de espaço no canteiro de obras }\end{array}$} & Notas & \\
\hline & & \\
\hline Falta de infraestrutura necessária & & (Falta de locais adequados) \\
\hline Falta de recursos financeiros & & (Falta de dinheiro e investimentos da empresa para isso) \\
\hline Ausência de treinamento & & (Falta de treinamento para isso) \\
\hline Falta de conscientização ambiental & & (Não é importante para a natureza) \\
\hline Falta de regras da empresa & & (A empresa não obriga) \\
\hline Falta de incentivos & & (A empresa não solicita nem premia) \\
\hline Trabalho não remunerado & & (Não recebe nada por isso) \\
\hline Custos de caçambas, conteiners, etc & & (Depósitos apropriados são caros) \\
\hline Outras prioridades da obra & & (Existem atividades mais importantes) \\
\hline
\end{tabular}

\section{Em sua opinião, qual deveria ser o destino dado para o lixo da obra?}

(atribua notas 1, 2, 3, 4 e 5 para os fatores a seguir descritos, sendo 1 ao fator de menor preocupação e 5 o de maior preocupação)

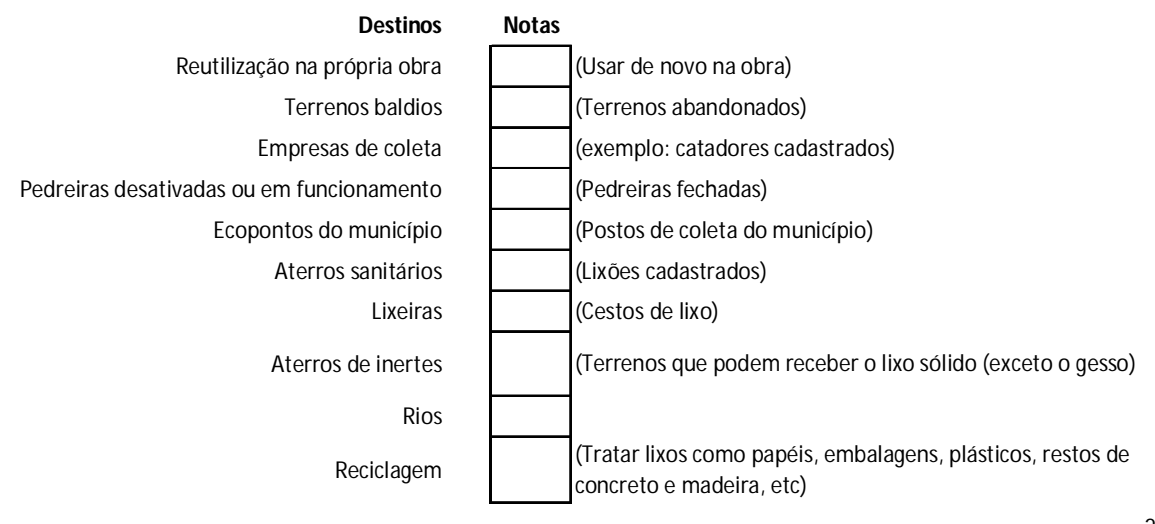


8. Em sua opinião, a limpeza da obra deve ser feita:

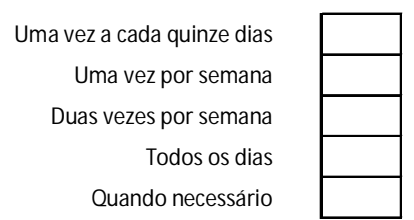

9. Na sua opinião, o que poderia ser feito para a redução dos resíduos de sua obra? 
ANEXO A - Plano de Gerenciamento dos Resíduos da Construção Civil da Arena Fonte Nova

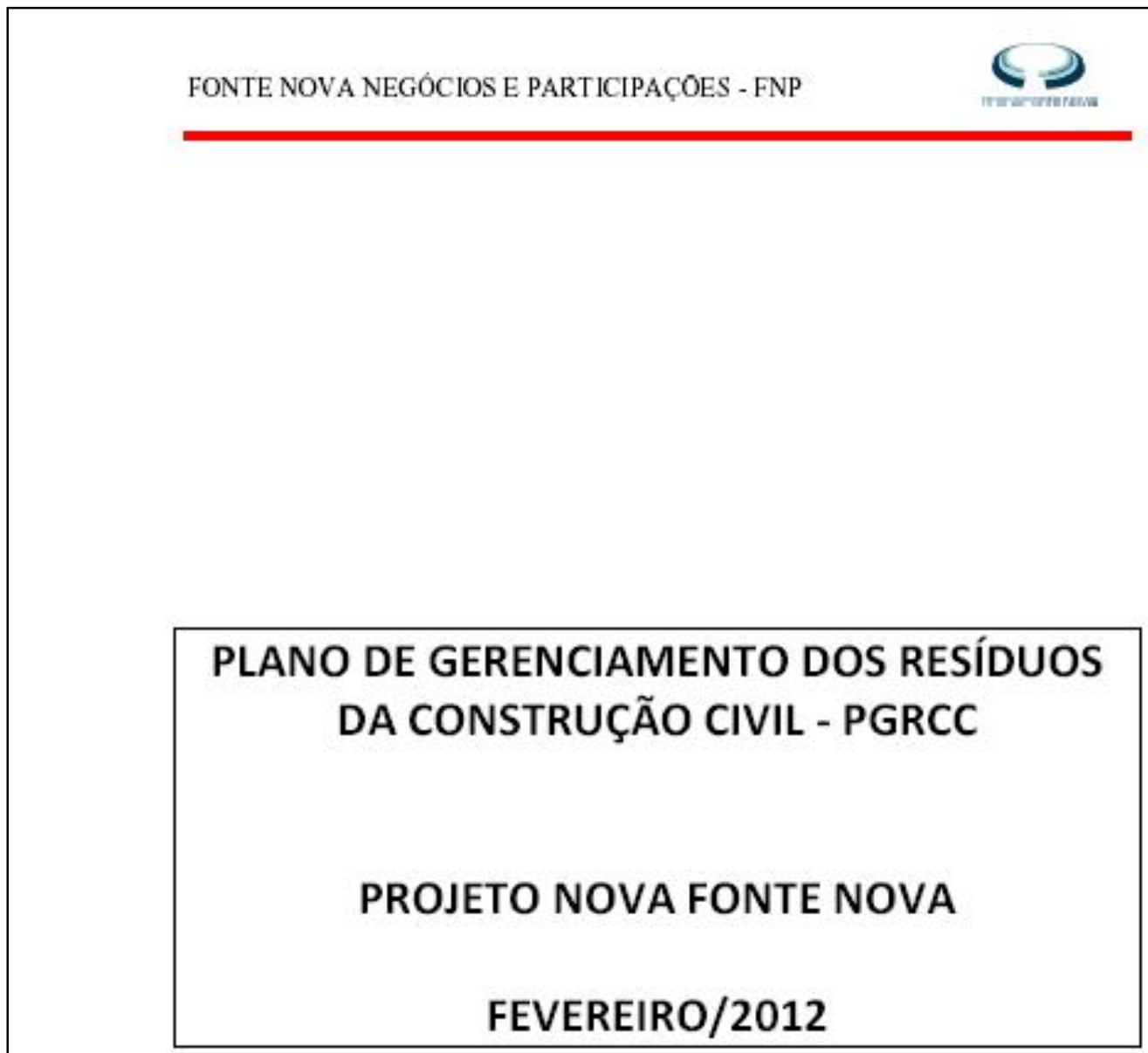

2012 


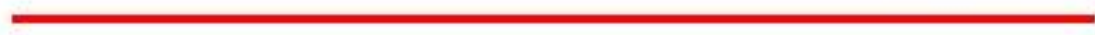

\section{DESCRIÇÃO DAS REVISÕES}

\begin{tabular}{|c|c|c|c|}
\hline REVISÁO & DATA & ATUAUZZAC,Ão & OBS. \\
\hline 19 & $05 / 01 / 2012$ & Atualizaçäo dados das Tabelas $\|-A\|-B \|-A$ e II-B & $17^{a}$. Revisäo \\
\hline 20 & $06 / 02 / 2012$ & Atualizacão dados das Tabelas $\|-A\|-B \|-A$ e $\| I-B$ & 183. Revisäo \\
\hline & & & \\
\hline & & & \\
\hline & & & \\
\hline & & & \\
\hline & & & \\
\hline & & & \\
\hline RESPONS: & EL PELO PGRCC & RILDO DOS SANTOS GOMES - CREA-BA 35969 & \\
\hline
\end{tabular}




\section{APRESENTAÇĀO}

1. IDENTIFICAÇÅO DO GERADOR 5

2. DESCRIÇÅO DA ATIVIDADE 5

3. DEFINIÇÖES 6

4. RESIDUOS GERADOS 8

4.1 Classificaçäo dos Residuos $\quad 10$

5. PLANO DE MOVIMENTAÇÃO DE RESIDUOS 11

6. PLANO DE GERENCIAMENTO 11

7. LEGISLAÇÅOO BASICA INCIDENTE

8. RESPONSAVEL TÉCNICO 16

Anexos

Anexo I: Manifesto de Residuos

Tabela I: Identificaçäo do Gerador

Tabelas II-A e II-B: Residuos Gerados

Tabelas III-A e III-B: Plano de Movimentaçāo dos Resíduos

Gráficos dos Indicadores de Residuos 


\section{APRESENTAÇĀO}

Este Plano de Gerenciamento dos Residuos da Construçäo Civil (PGRCC) do projeto da Nova Fonte Nova (NFN) contempla os aspectos referentes à minimizaçāo na geraçāo, segregaçāo, acondicionamento, identificaçāo, coleta, estocagem temporária, tratamento e disposiçăo final dos residuos sólidos gerados durante a demoliçäo mecanizada e implosäo do Estádio, bem como daqueles que seräo gerados no canteiro de obras, terraplenagem e implantaçäo do novo complexo esportivo, no municipio de Salvador.

Conforme definido pela Resoluçäo CONAMA N ${ }^{\circ} 307 / 2002^{1}$, in verbis:

\section{Art. $2^{\circ}$}

(...) os residuos da construçao civil sao aqueles provenientes de construçoes, reformas, reparos e demaliçaes de obras de construçao civil, $\theta$ as resultantes da preparaçao $\theta$ da escavaçao de terrenos, tais como: tijolos, blocos cerâmicos, concreto em geral, salos, rochas, metais, resinas, colas, tintas, madeiras e compensados, forros, argamassa, gesso, telhas, pavimento asfáltico, vidros, plásticos, tubulaçøes, fiaçao elétrica, entre outros, comumente chamados de entulhos de obras, caliça ou metralha.

\footnotetext{
${ }^{1}$ RESOLUÇAO CONAMA $n^{\circ} 307$, de 5 de julto de 2002, publicada no DOU $n^{\circ} 136$, de 17 de julho de 2002, Seçäo 1, páginas 95-96. Estabelece diretrizes, critérios e procedimentos para a gestào dos residuos da construçào civit.
} 


\section{IDENTIFICAÇĀO DO GERADOR}

\section{Razäo Social}

Fonte Nova Participaçōes e Negócios - FNP

CNPJ: 08.906.994/0001-11

\section{Endereço}

Ladeira Fonte das Pedras, s'n, Nazaré CEP: 40050-565 Salvador-Ba

\section{Tipo de Atividade}

A atividade de construçäo civil está enquadrada no CNAE - Código Nacional de Atividades Econômicas sob o Código 4299-5/01.

\section{DESCRIÇÄO DA ATIVIDADE}

Trata-se da reconstrução do antigo Estádio da Fonte Nova, de modo a adequá-lo aos critérios e padröes internacionais de segurança exigidos pela FIFA, sendo necessária a demoliçăo da estrutura e reconstruçăo de novo equipamento, no mesmo terreno de aproximadamente $110.000 \mathrm{~m}^{2}$.

O novo estádio será constituido de dez niveis, contemplando a implantaçäo de edificio garagem, museu do futebol, lojas, saläo multifuncional, restaurantes e escritórios, entre outros equipamentos associados ao empreendimento, compreendidos de:

MIVEL 1 - Acesso de Jogadores e Estacionamentos

MIVEL 2 - Estacionamento VIP

MIVEL 3 - Abertura $\theta$ Estacionamentos

MIVEL 4 - Vestiärios e Zona Mista

MIVEL 5 - Distribuiçao e Arquibancada do Anel Inferior

MIVEL 6 - Tribuna de Honra, Museu e Hospitalidade

MIVEL 7 - Entrada, Camarotes, Centro de Convençoes e Restaurante 
MVEL 8 - Distribuiçao do Anel Superior e Imprensa

MIVEL 9 - Apoio Técnico

MIVEL 10 - Arquibancadas

O campo de futebol será construido no tamanho oficial exigido pela FIFA: $105 \mathrm{x}$ $68 \mathrm{~m}$ e a capacidade total da Nova Fonte Nova será de 50.058 lugares, em uma área construida de aproximadamente $120.000 \mathrm{~m}^{2}$.

Para implantaçäo do empreendimento Nova Fonte Nova (NFN) torna-se necessário promover a demoliçäo das estruturas do antigo Estádio Otávio Mangabeira, Ginásio Antônio Balbino $\ominus$ Parque Aquático, as quais seräo desmobilizadas pelo processo de demoliçäo mecanizada e implosão.

A identificaçāo do gerador encontra-se especificado na Tabela I, anexo a este PGRCC.

\section{DEFINIÇŌES}

Para efeito deste PGRCC entende-se como:

Gerenciamento de Residuos: é o sistema de gestäo que visa reduzir, reutilizar ou reciclar residuos, incluindo planejamento, responsabilidades, práticas, procedimentos e recursos para desenvolver e implementar as açöes necessárias ao cumprimento das etapas.

Geradores: säo pessoas, físicas ou juridicas, públicas ou privadas, responsáveis por atividades ou empreendimentos que gerem os residucs definidos nesta Resoluçäo;

Transportadores: são as pessoas, físicas ou juridicas, encarregadas da coleta e do transporte dos residuos entre as fontes geradoras e as áreas de destinaçäo; 
Agregado Reciclado: é o material granular proveniente do beneficiamento de residuos de construçäo que apresentem características técnicas para a aplicaçäo em obras de edificaçāo, de infraestrutura, em aterros sanitários ou outras obras de engenharia; previstas em programas e planos;

Triagem/Segregaçäo: $\dot{e}$ a operaçäo de separaçäo realizada pelo próprio gerador, com a participaçāo dos colaboradores, objetivando a coleta seletiva dos residuos gerados;

Reutilizaçäo: é o processo de reaplicaçào de um residuo, sem transformaçäo do mesmo;

Reciclagem: é o processo de reaproveitamento de um residuo, após ter sido submetido à transformaçāo;

Beneficiamento: é o ato de submeter um residuo a operaçöes e/ou processcs que tenham por objetivo dotá-los de condiçöes que permitam que sejam utilizados como matéria-prima ou produto;

Aterro de residuos da construçäo civil: è a área onde seräo empregadas técnicas de disposiçāo de resíduos da construçäo civil Classe "A" no solo, visando à preservaçāo de materiais segregados de forma a possibilitar seu uso futuro e/ou futura utilizaçäo da área, utilizando princípios de engenharia para confiná-los ao menor volume possivel, sem causar danos à saúde pública $e$ ao meio ambiente;

Áreas de destinaçäo de residuos: säo áreas destinadas ao beneficiamento ou à disposiçäo final de residuos. 


\section{RESIDUOS GERADOS}

Para melhor caracterizaçäo dos resíducs gerados na implantaçāo da Nova Fonte Nova (NFN), este PGRCC descreve a geraçäo dos residuos em consonância com as fases das obras do empreendimento, correspondendo:

a) Demoliçào (mecanizada e implosào)

b) Canteiro de Obras, Terraplenagem e Implantaçäo do novo Estádio

Os residuos gerados na etapa "a) demoliçào (mecanizada e implosào)" correspondem ao material removido das áreas especificadas abaixo e estäo descritos na Tabela II-A, anexas a este PGRCC, contendo o quantitativo da geraçăo, classificaçäo, freqüência, acondicionamento, tratamento e estocagem.

\begin{tabular}{|l|c|}
\hline LOCAL & VOLUME TOTAL $\left(\mathrm{m}^{2}\right)$ \\
\hline Parque Aquático & 1.495 \\
\hline Vestiánios & 9.120 \\
\hline Tribuna de Honra & 1.850 \\
\hline Anel inferior & 4.691 \\
\hline Ginásio Antônio Balbino & 4.760 \\
\hline Anel superior & 11.180 \\
\hline TOTAL GERAL & 33.096 \\
\hline
\end{tabular}




\begin{tabular}{|l|c|}
\hline MATERIAIS & VOLUME $\left(\mathrm{m}^{2}\right)$ \\
\hline Concreto & 28.852 \\
\hline Alvenaria & 1.986 \\
\hline Outros & 2.258 \\
\hline TOTAL GERAL & 33.096 \\
\hline
\end{tabular}

Os residuos gerados nas operaçöes "b) Canteiro de Obras, Terraplenagem e Implantaçäo do novo Estádio", de igual modo encontram-se relacionadcs nas Tabelas II-B, anexa a este PRGCC.

$\mathrm{Na}$ fase terraplenagem seräo movimentados $280.000 \mathrm{~m}^{2}$ de material, sendo que destes $56.000 \mathrm{~m}^{2}$ seräo utilizados como aterro e o restante seguirá para bota-fora.

\subsection{Classificaçäo dos Residuos}

Para a dassificaçäo dos residuos de construçäo civil gerados no projeto da Nova Fonte Nova (NFN) foi utilizada a classificaçäo (Classe A, B, C e D), de acordo com o dispcsto na Resoluçäo CONAMA 307/02:

\begin{tabular}{|c|c|c|}
\hline $\begin{array}{c}\text { Classificaçäo } \\
\text { do Residuo }\end{array}$ & $\begin{array}{c}\text { Caracteristica } \\
\text { do Residuo }\end{array}$ & Descriçäo \\
\hline Classe A & $\begin{array}{c}\text { Reutilizáveis ou } \\
\text { recidáveis como } \\
\text { agregados. }\end{array}$ & $\begin{array}{c}\text { Residuo de demoliçäo e } \\
\text { parvimentaçāo, Componentes } \\
\text { argamascos (tijolos, blocos), concreto, } \\
\text { terraplanagem, peças pré-moldadas } \\
\text { (blocos, tubos, meio-fios) etc. }\end{array}$ \\
\hline Classe B & Reutilizáveis ou & Madeira, vidro, plástico, \\
\hline
\end{tabular}




\begin{tabular}{|c|c|c|}
\hline & $\begin{array}{r}\text { recicláveis para } \\
\text { outras destinaçöes. }\end{array}$ & pepelpapeläo, metal. \\
\hline Classe C & $\begin{array}{c}\text { Năo dispöe de } \\
\text { tecnologias } \\
\text { economicamente } \\
\text { viáveis para } \\
\text { recidagem } \\
\text { Recuperaçäo }\end{array}$ & Resíduo de gesso, sacos de cimento. \\
\hline Classe D & Residuos Perigosos & $\begin{array}{r}\text { Tintas, solventes, ólecs, lata de tinta, } \\
\text { telhas de amianto, etc. }\end{array}$ \\
\hline
\end{tabular}

Para os residuos resultantes dos serviços ambulatoriais utilizou-se da classificaçäo prevista na Resoluçáo CONAMA n³58, de 29 de abril de 2005, e na RDC ANVISA, Resoluçāo da Diretoria Colegiada, de 7 de dezembro de 2004, que dispöe sobre o tratamento e a disposiçäo final dos residuos dos serviços de saúde e dá outras providências.

Para os demais resíduos, originados dos refeitórios, sanitários, serviços administrativos, entre outros, utilizou-se da classificaçäo prevista na norma NBR-10004 da ABNT.

\section{PLANO DE MOVIMENTACCĀO DE RESIDUOS}

O Plano de movimentaçäo dos resíduos resultantes das etapas "a) demoliçào (mecanizada e implosäo) $\ominus$ b) Canteiro de Obras, Terraplenagem e Implantaçäo do novo Estádio", contemplando a previsāo da destinaçāo final encontra-se descrito nas Tabelas III-A e III-B, anexas a este PGRCC. 
Ressaltamos de que a destinação só será realizada mediante prévia comprovaçāo da regularizaçäo ambiental do respectivo receptor.

\section{PLANO DE GERENCIAMENTO}

O Plano de gerenciamento estabelece a melhor forma para a eficiência do processo de Gestäo de Residuos. Além disso, estabelece medidas de controle e mitigaçäo para emergências ambientais $e$ a soluçäo correta para os destinos dos residuos gerados pela Nova Fonte Nova.

\subsection{ATRIBUIÇOEES DA EQUIPE SSTMA}

- Orientar e fazer cumprir as legislaçöes pertinentes referentes ao gerenciamento de residuos sólidos;

- Inspecionar a realizaçào dos devidos ensaios e testes de caracterizaçăo dos residuos sólidos para verificaçäo de seu potencial de poluiçäo e definição de açöes de controle;

- Desenvolver e apoiar os gestores de processo na definiçäo de opçöes de näo geraçāo, reduçào, re-utilizaçào, recuperaçāo e recidagem de residuos sólidos;

- Desenvolver e selecionar altemativas para o gerenciamento de resíducs sólidos com abrangência para todas as etapas do manejo sustentado;

- Elaborar Manifestos, Fichas e Envelopes de Emergência para transporte extemo dos residuos sólidos perigcsos, nos termos da legislaçāo aplicável;

- Obter eventuais autorizaçöes e providenciar as comunicaçöes necessárias junto aos órgäos ambientais para envio de resíduos sólidos para recidagem, recuperaçăo ou reutilizaçāo, tais como: Manifestos, Certificados, Autorizaçöes, entre outros; 
- Administrar os locais de armazenamento temporário de residuos sólidos, denominados "Centrais de Gerenciamento de Residuos Sólidos";

- Definir conjuntamente com os Supervisores e Líderes de cada Processo / Atividade / Frentes de Trabalho os locais de armazenamento interno de residuos sólidos para coleta;

- Inspecionar e aplicar Listas de Verificaçäo (anexo IV) periodicamente nos locais de armazenamento temporário de residucs sólidos;

- Monitorar o processo de gerenciamento de resíduos e manter os registros do envio de residuos sólidos para transporte externo, tratamento, disposiçäo final, reciclagem, recuperaçào ou re-utilizaçăo;

- Aprovar, manter e revisar este procedimento, sempre que necessário.

\subsection{GERENCIAMENTO}

Para o gerenciamento de residuos da obra da Nova Fonte Nova seräo contempladas as seguintes etapas:

- Caracterizaçāo, onde seräo identificados e quantificados cs residucs;

- Triagem, a ser realizada na origem da geraçäo dos residuos, ou nas áreas de destinação licenciadas para esta finalidade, respeitando as classes de residucs;

- Armazenamento temporário, onde os residuos seräo acondicionados após a geraçào até a etapa de transporte, assegurando em todos os casos em que seja possivel, as condiçöes de reutilizaçäo e reciclagem, como por exemplo, 
reutilizar quando possivel água de reaproveitamento de lavagens de betoneiras;

- Transporte, a ser realizado em conformidade com as etapes anteriores e de acordo $\mathrm{com}$ as normas técnicas vigentes para o transporte de residuos;

- Destinaçäo, prevista de acordo com o estabelecido na Resoluçäo CONAMA $307 / 02$.

Os resíduos dasse A seräo destinados adequadamente até que seja definido o uso em obras de interesse do Consórcio. Estes residuos seräo transportados através de caçambes lonadas, dentro do volume permitido legalmente.

Para o gerenciamento dos residuos das classes B, C e D seräo seguidas as orientaçöes presentes neste PGRCC, conforme descrito nas tabelas em anexo.

\subsection{MEDIDAS MITIGADORAS}

Como forma de minimizar a geraçäo dos residucs seräo adotadas durante toda a obra, as seguintes medidas:

- Distribuiçäo de coletores identificados pelas áreas, visando despertar a importância da recidagem;

- Treinamento e conscientizaçäo com integrantes e parceiros com a divulgação dos programas, planos de gerenciamento;

- Fomento a reutilizaçào de residucs, principalmente os de dasse A, bem como otimização na compra de insumos e materiais. 
- Informativos de meio ambiente em todos os coletores de residuos, mostrando a importância de seperar cada residuo no seu local adequado.

\subsection{REGISTROS}

Toda e qualquer remessa de resíduos será registrada através de formulário de Manifesto de Transporte de Resíduo (anexo IV), onde constará a assinatura do responsável da área pela verificaçäo da carga na hora do carregamento. Constarāo também as assinaturas dos responsáveis pelo transporte e do receptor dos residuos no Bota Fora. O referido manifesto é preenchido em 4 vias para o controle, a primeira via será conservada com o gerador, a segunda com o transportador, a terceira com o receptor e a quarta permanece no talonário. Os formulários seräo entregues diariamente pelo responsảvel da área para o técnico de meio ambiente, que fará o controle e o arquivamento no setor de meio ambiente estando disponivel à fiscalização.

\section{LEGISLAÇẢO BÁSICA INCIDENTE}

Para elaboraçäo deste PGRCC foram utilizados como referência, especialmente os seguintes dispositivos normativos:

- RESOluÇÃO CONAMA n 307, de 5 de julho de 2002, que estabelece diretrizes, critérios e procedimentos para a gestăo dos resíduos da construçäo civil.

- RESOluçÃO CONAMA n 275 , de 25 de abril de 2001, que estabelece o código de cores para os diferentes tipos de residucs, a ser adotado na identificaçäo de coletores e transportadores, bem como nas campanhas informativas para a coleta seletiva. 
- RESOLUÇÄO RDC/ANVISA 306/04, Resoluçäo da Diretoria Colegiada, de

7 de dezembro de 2004, que estabelece a classificaçào dos resíducs do Serviço de Saúde.

- RESOLUÇÄO CONAMA n ${ }^{\circ} 358$, de 29 de abril de 2005 , que dispöe sobre o tratamento e a disposiçäo final dos resíduos dos serviços de saúde e dả outras providências.

- NBR-10004 da ABNT - Classificação dos Residucs Sólidos.

- NBR-13221 da ABNT - Classificaçāo do Transporte Terrestre.

- Lei Estadual $\mathrm{n}^{\circ} 10.431 / 06$, regulamentada pelo Decreto Estadual $\mathrm{n}^{\circ}$ 11.235/08, que dispöe sobre a Política de Meio Ambiente e de Proteçào à Biodiversidade do Estado da Bahia e dá outras providências.

\section{RESPONSÁVEL TÉCNICO:}

Rildo dos Santos Gomes

Gerente de SSTMA

E-mail: rgomes@odebrecht.com

Telefone: (71) 3320-2237/ (71) 9171-3122 
ANEXOS

\section{Anexo I: Manifesto de Resíduos}

MANIFESTO DE TRANSPORTE DE RESIDUOS No

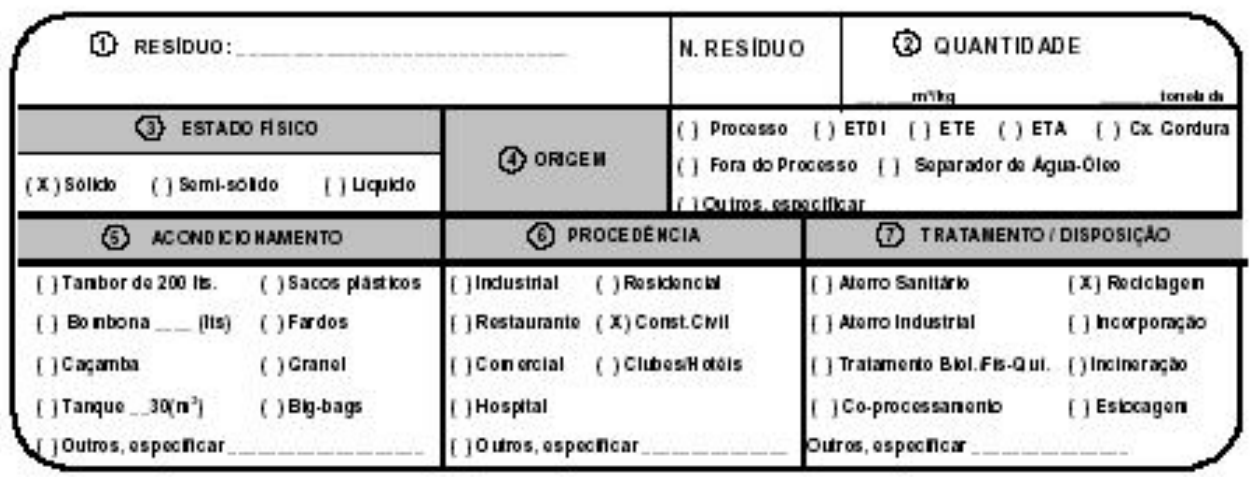

\begin{tabular}{|c|c|c|c|c|c|}
\hline \multicolumn{3}{|c|}{ 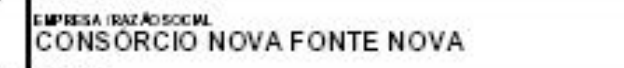 } & 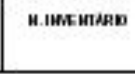 & \multirow{3}{*}{\multicolumn{2}{|c|}{ DUTA DAEH IE }} \\
\hline \multirow{3}{*}{$\begin{array}{l}\bar{\Phi} \\
0 \\
0\end{array}$} & \multicolumn{3}{|c|}{$\begin{array}{l}\text { MACKESDIRA FONTE DAS PEDRAS, S/N, N AZARE } \\
\text { LADEIRA }\end{array}$} & & \\
\hline & SALV ADOR & (71) $3013-5641$ & तथल & & \\
\hline & 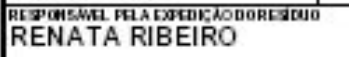 & \multicolumn{2}{|c|}{$\begin{array}{l}\text { FTOR } \\
\text { MEIO AMBIENTE }\end{array}$} & & 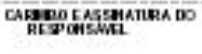 \\
\hline
\end{tabular}
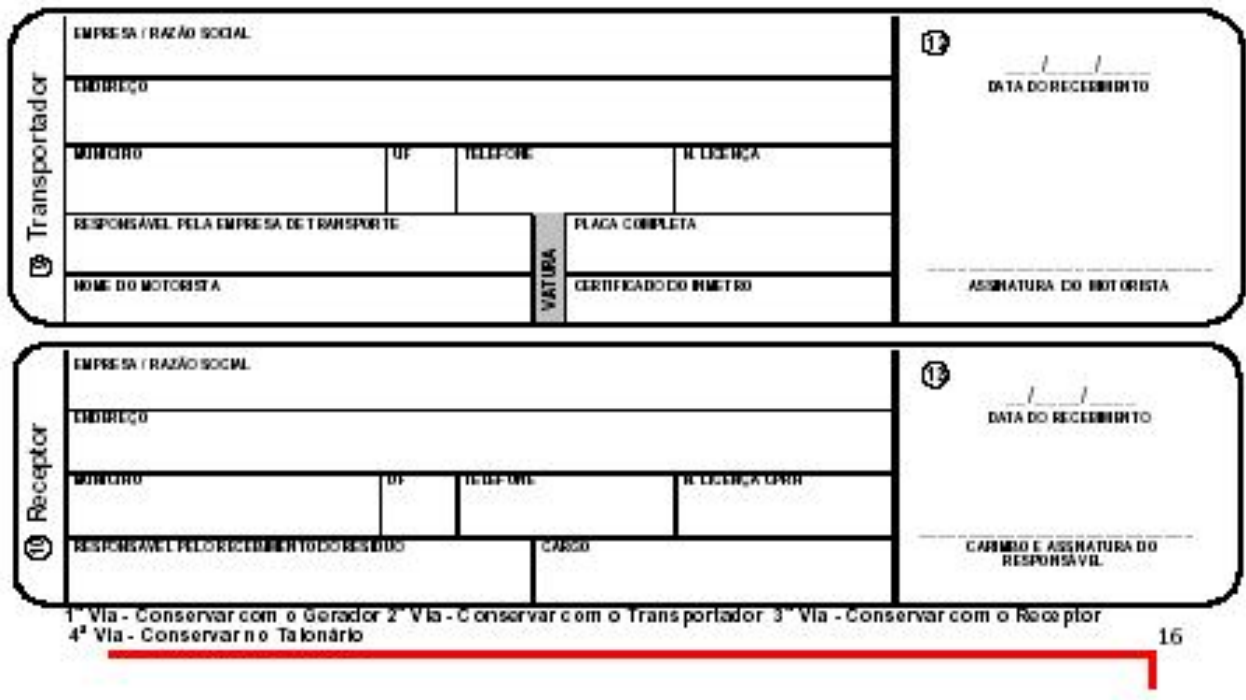
Tabela I - Identificação do Gerador

Razão Social: Fonte Nova Negócios e Participações - FNP

CNPJ: 08.906.994/0001-11

Nome Fantasia: NOVA FONTE NOVA - NFN

\begin{tabular}{|c|c|c|c|c|}
\hline \multicolumn{3}{|c|}{ Endereço: Ladeira Fonte das Pedras, s/n, Nazaré } & $\begin{array}{l}\text { Município } \\
\text { Salvador }\end{array}$ & $\begin{array}{l}\text { UF } \\
\text { BA }\end{array}$ \\
\hline \begin{tabular}{|l} 
CEP: \\
40050-565
\end{tabular} & $\begin{array}{l}\text { Telefone: } \\
\text { (71) 3013-5641 }\end{array}$ & $\begin{array}{l}\text { Fax: } \\
\text { (71) } 3013-5795\end{array}$ & \multicolumn{2}{|c|}{$\begin{array}{l}\text { e-mail: } \\
\text { rgomes@odebrecht.com }\end{array}$} \\
\hline \multirow{2}{*}{\multicolumn{2}{|c|}{\begin{tabular}{|l|} 
Área total: $110.000 \mathrm{~m}^{2}$ \\
Área Construída: $120.000 \mathrm{~m}^{2}$
\end{tabular}}} & \multicolumn{3}{|c|}{ Número de funcionários: } \\
\hline & & Próprios: 2.424 & \multicolumn{2}{|c|}{ Terceirizados: 151} \\
\hline
\end{tabular}

Responsável pelo PGRCC:

Rildo dos Santos Gomes

Responsável legal:

Dênio Dias Lima Cidreira - Presidente da FNP

\section{Descrição da atividade:}

Demolição e construção do novo Estádio da Fonte Nova, o qual será constituído de dez níveis, contemplando a implantação de edifício garagem, museu do futebol, lojas, salão multifuncional, restaurantes e escritórios, entre outros equipamentos associados ao empreendimento.

\begin{tabular}{|c|c|c|c|c|c|c|c|c|}
\hline & Nome & a empre & $\begin{array}{l}\text { Tabela II A - Resíduc } \\
\text { sa: FONTE NOVA NEGÓ }\end{array}$ & $\begin{array}{l}\text { los Gerados ( } \\
\text { ÓCIOS E PART }\end{array}$ & $\begin{array}{l}\text { emolição/Implc } \\
\text { CIPAÇÕES }\end{array}$ & losão) & & Foinan-1 \\
\hline Item & Resíduo & Classe & Unidade/ Eq.Gerador & Período & \begin{tabular}{|c|}
$\begin{array}{c}\text { Acondicion/ A } \\
\text { rmazen. }\end{array}$ \\
\end{tabular} & $\begin{array}{c}\text { Tratamento } \\
\text { adotado }\end{array}$ & $\begin{array}{c}\text { Frequência de } \\
\text { geração }\end{array}$ & $\begin{array}{c}\text { Quant. total } \\
\text { Estimada }\end{array}$ \\
\hline 1 & $\begin{array}{l}\text { Concreto Britado (brita graduada } \\
\text { simples) }\end{array}$ & A & $\begin{array}{l}\text { Demolicãão mecanizada } \\
\text { utilizando escavadeiras } \\
\text { hidráulicas eimplosão com uso } \\
\text { de explosivos }\end{array}$ & Jun/10 a nov/10 & Pilhas & \begin{tabular}{|l} 
Birtagem \\
transformando em \\
brita graduada \\
simples
\end{tabular} & Diária & $28.852 \mathrm{~m}^{3}$ \\
\hline 2 & Alvenaria & A & $\begin{array}{l}\text { Demoliç̧̃o manual ou } \\
\text { mecanizada }\end{array}$ & Jun/ 10 a nov/ 10 & Pilhas & Segregação & Diária & $1.986 \mathrm{~m}^{3}$ \\
\hline 3 & $\begin{array}{l}\text { Sucata Ferrosa (aço de concreto } \\
\text { armado e peças metálicas) }\end{array}$ & B & \begin{tabular}{|l|} 
Demolição mecanizada \\
utilizando escavadeiras \\
hidráulicas e implosão com uso \\
de explosivos
\end{tabular} & Jun/10 a nov/10 & Pilhas & Segregação & Diária & $1.400 \mathrm{~m}^{3}$ \\
\hline 4 & \begin{tabular}{|l} 
Fiose cabos de cobre \\
(instalaçoese elétricas)
\end{tabular} & $B$ & Remoção manual & Jun/10 a nov/10 & Baias & Segregação & Eventual & $5 \mathrm{~m}^{3}$ \\
\hline 5 & Madeira & $\mathrm{B}$ & $\begin{array}{l}\text { Demoliç̧ăo de portas e } \\
\text { acessórios }\end{array}$ & Jun/10 a nov/10 & CE.CR & Segregação & Eventual & $3 \mathrm{~m}^{3}$ \\
\hline 6 & Madeira & $B$ & Supressão vegetal & Jun $/ 10$ a nov/10 & CE.CR & Segregação & Eventual & $10 \mathrm{~m}^{3}$ \\
\hline 7 & \begin{tabular}{|l} 
Louças sanitárias \\
\end{tabular} & c & Demoliçăo & Jun/ 10 a nov/ 10 & CE.CR & Segregação & Eventual & $10 \mathrm{~m}^{3}$ \\
\hline 8 & $\begin{array}{l}\text { Esquadrias de alumínio } \\
\end{array}$ & $B$ & 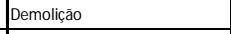 & Jun/ 10 a nov/10 & Baias & Segregação & Eventual & $50 \mathrm{~m}^{2}$ \\
\hline 9 & Alvenaria de pedra & $\mathrm{A}$ & Demolição & Jun $/ 10$ a nov/10 & Pilhas & Segregação & Eventual & $780 \mathrm{~m}^{3}$ \\
\hline \multicolumn{6}{|c|}{ Responsável pelo PRGCC: } & \multicolumn{3}{|l|}{ Assinatura:_. } \\
\hline \multicolumn{9}{|c|}{ Abrevią̧öes:CE=Caixa Estacinária/ CR=Central de Residuos/ SQ-Sanitário Químico/ TB=Tambor 2001ts/ CT=Contentor/ VC=Veículo/ BB=Bombona/Papa Pilha=Recipiente/ CD=Central Decantador } \\
\hline \multicolumn{9}{|c|}{ I Ginza=Näo reciclável//Vermelho=Plástico/ Laranja=Contaminado/ Azul=Papel/ Verde=Vidro/ Marron=Orgânico } \\
\hline
\end{tabular}




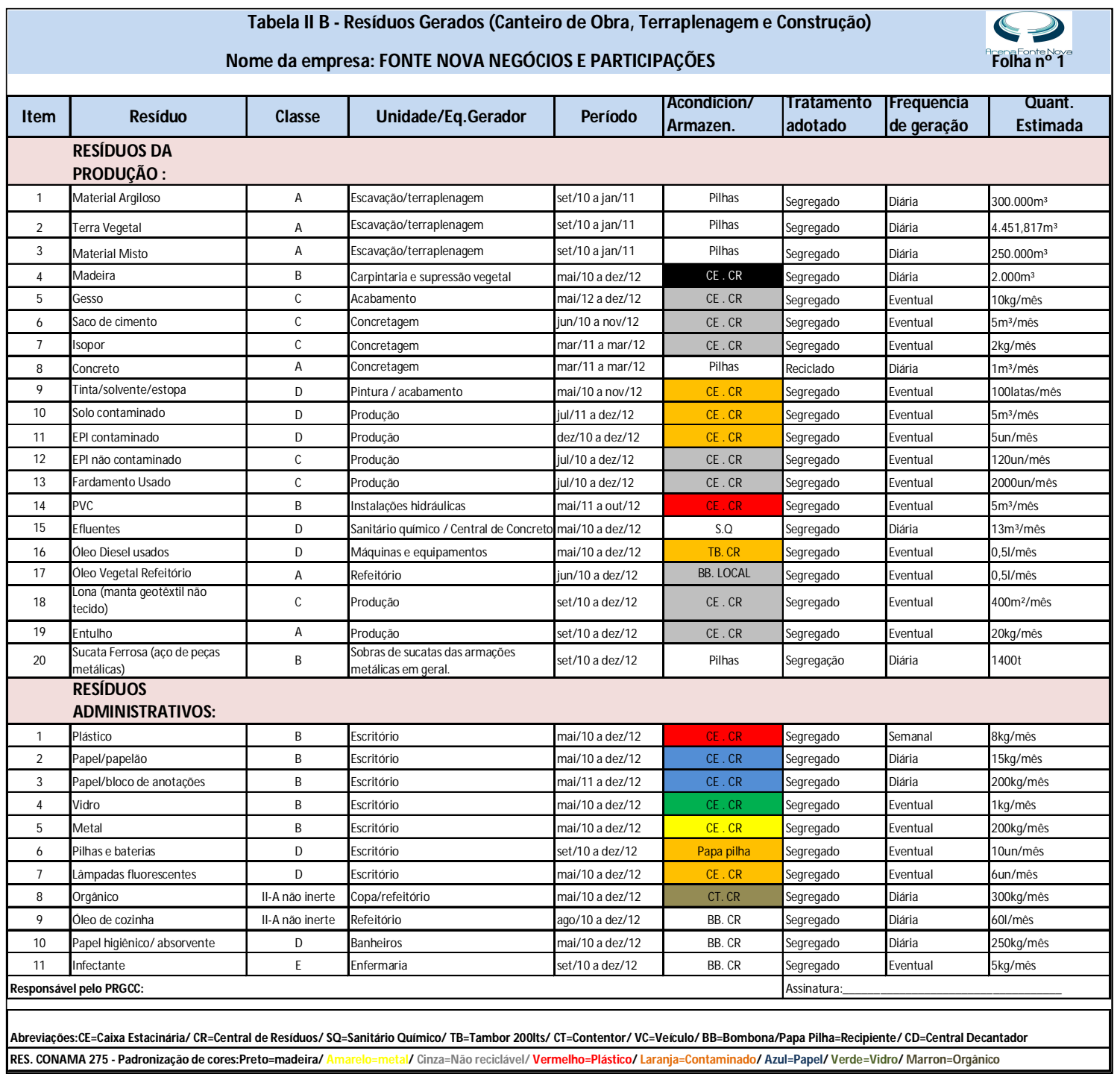

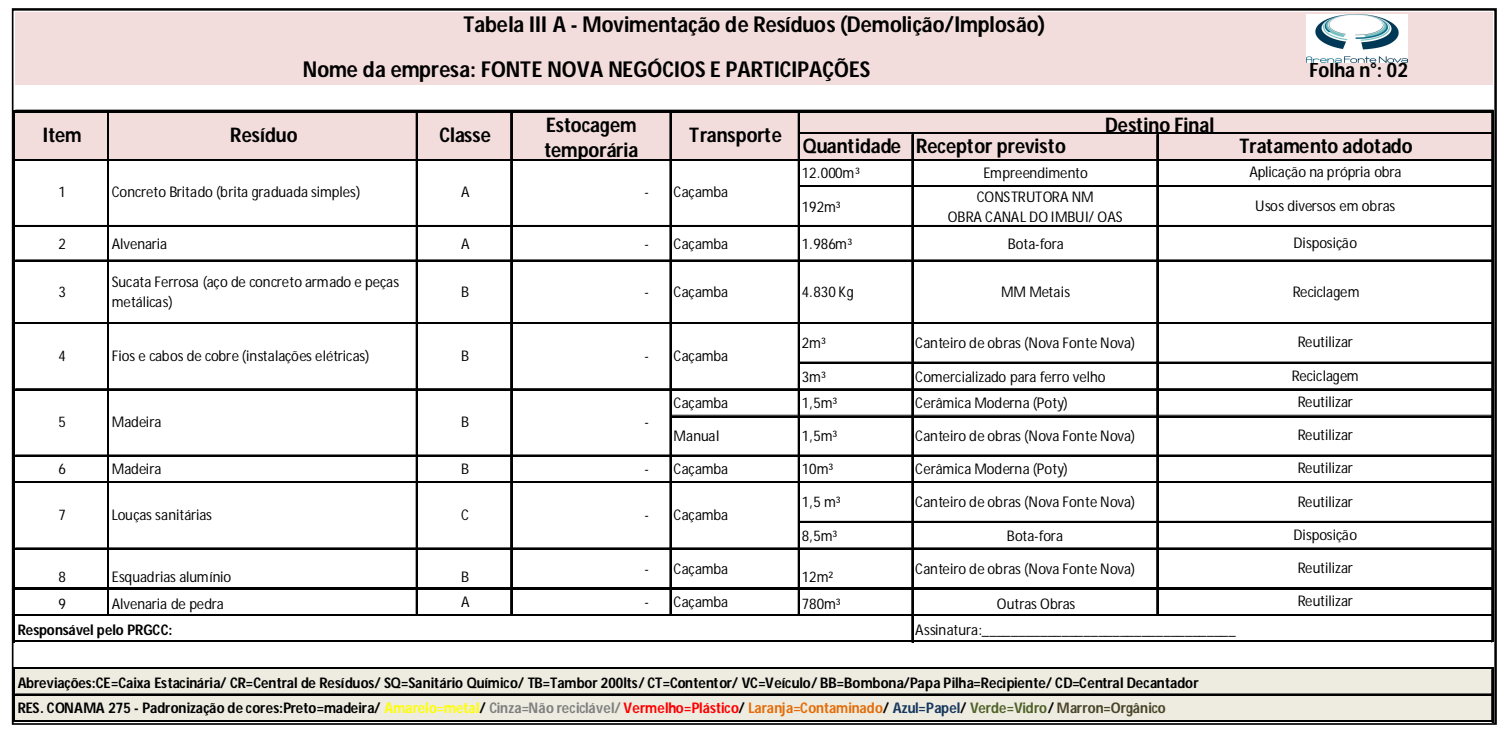




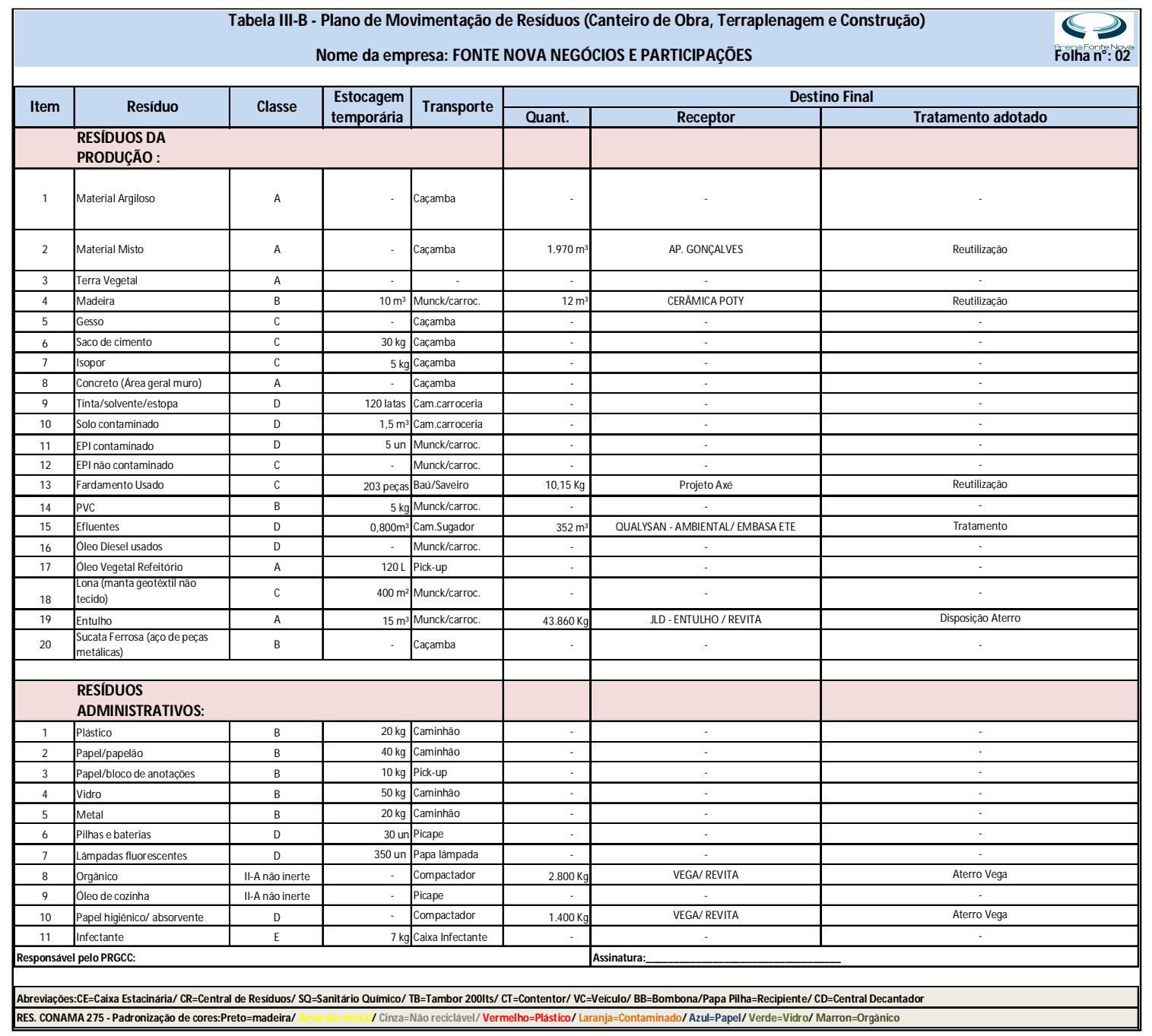


Gráficos dos Indicadores de Resíduos

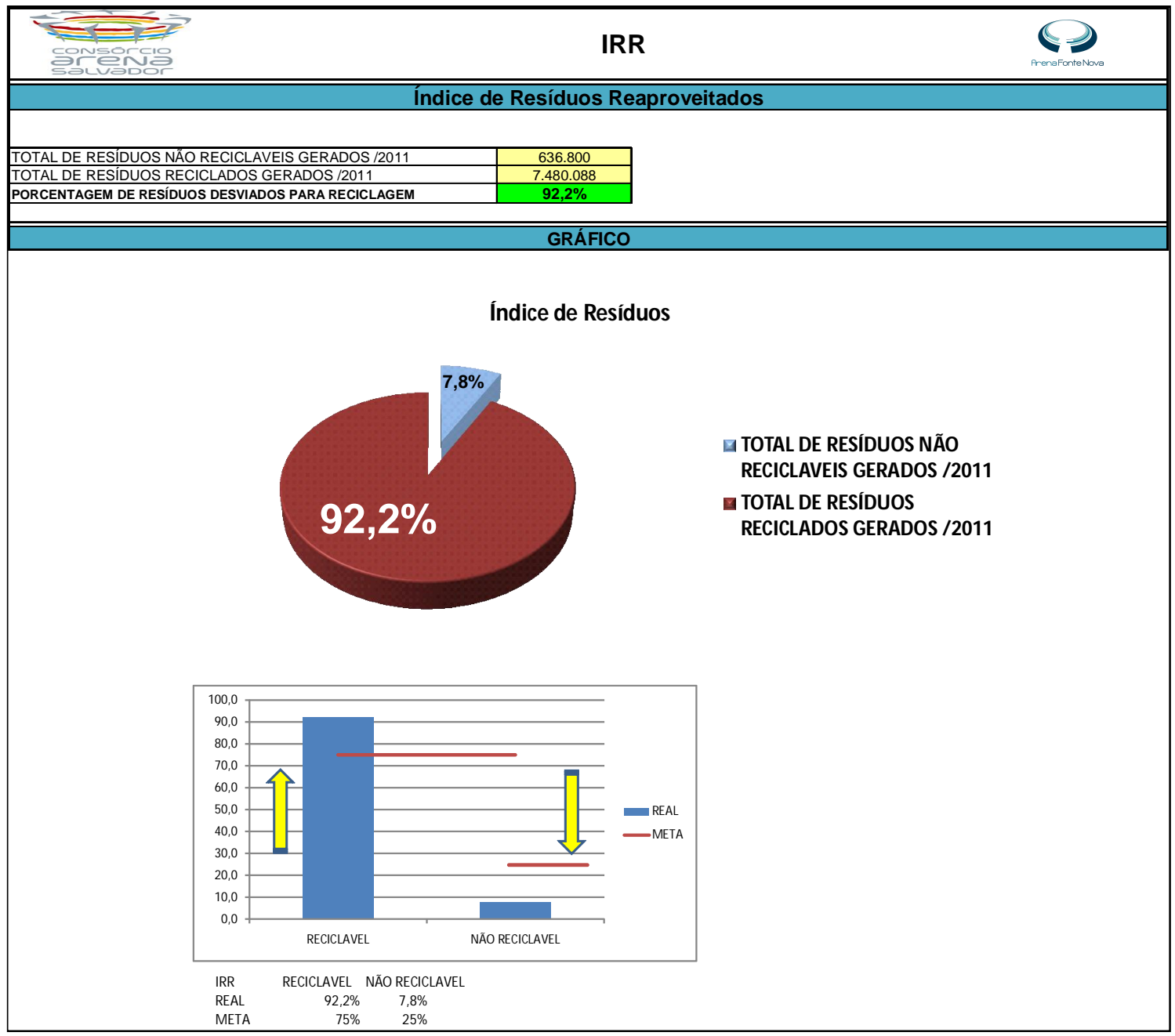

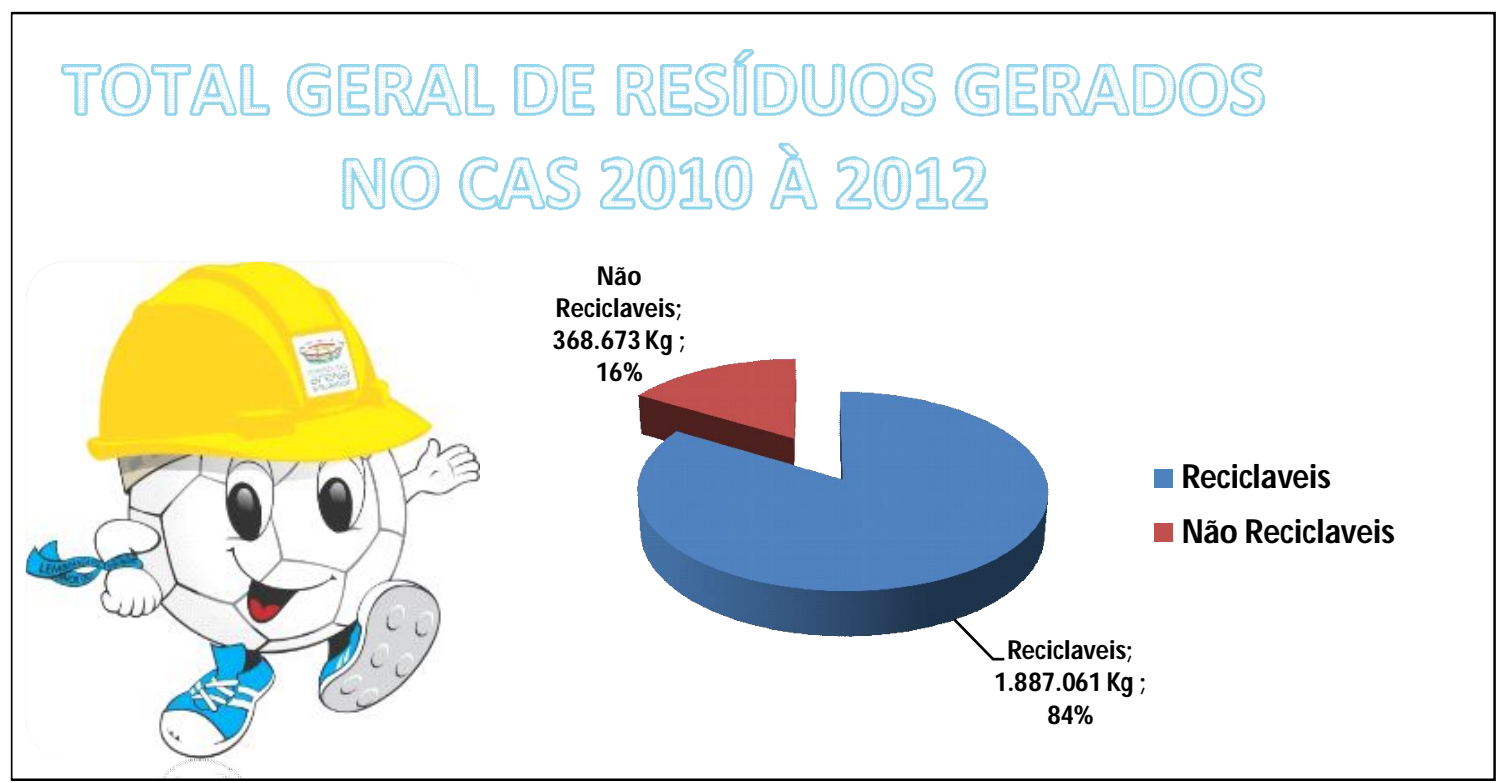


ANEXO B - Programa de Gerenciamento dos Resíduos Sólidos da Arena Pernambuco

\begin{tabular}{|l|l|c|c|c|}
\hline \multicolumn{1}{|c|}{$\begin{array}{c}\text { ODEBRECHT } \\
\text { Infraestrutura }\end{array}$} & \multicolumn{3}{c|}{ ARENA PERNAMBUCO } \\
\hline Titulo: & \multicolumn{3}{|c|}{ PROGRAMA DE GERENCIAMENTO DE RESíDUOS SóLIDOS } \\
\hline $\begin{array}{l}\text { Tipo: } \\
\text { Procedimento }\end{array}$ & Código: & Revisão: & Data: & Página: \\
& PI-PRE-MA-004 & 00 & $25 / 07 / 2011$ & $1 / 15$ \\
\hline
\end{tabular}

\begin{tabular}{|c|c|l|}
\hline \multicolumn{2}{|c|}{ REVISÕES } \\
\hline Revisão & Data & \multicolumn{2}{|c|}{ Descrição e/ou folhas atingidas } \\
\hline 00 & $25 / 07 / 2011$ & Emissão inicial \\
\hline & & \\
\hline & & \\
\hline & & \\
\hline & & \\
\hline & & \\
\hline & & \\
\hline & & \\
\hline & & \\
\hline & & \\
\hline & & \\
\hline & & \\
\hline
\end{tabular}

\begin{tabular}{|r|r|r|}
\hline & VERIFICADO & APROVADO \\
\hline Fabiane Vidal & Accácio Nunes & Bruno Dourado \\
Data: & Data: \\
\hline
\end{tabular}




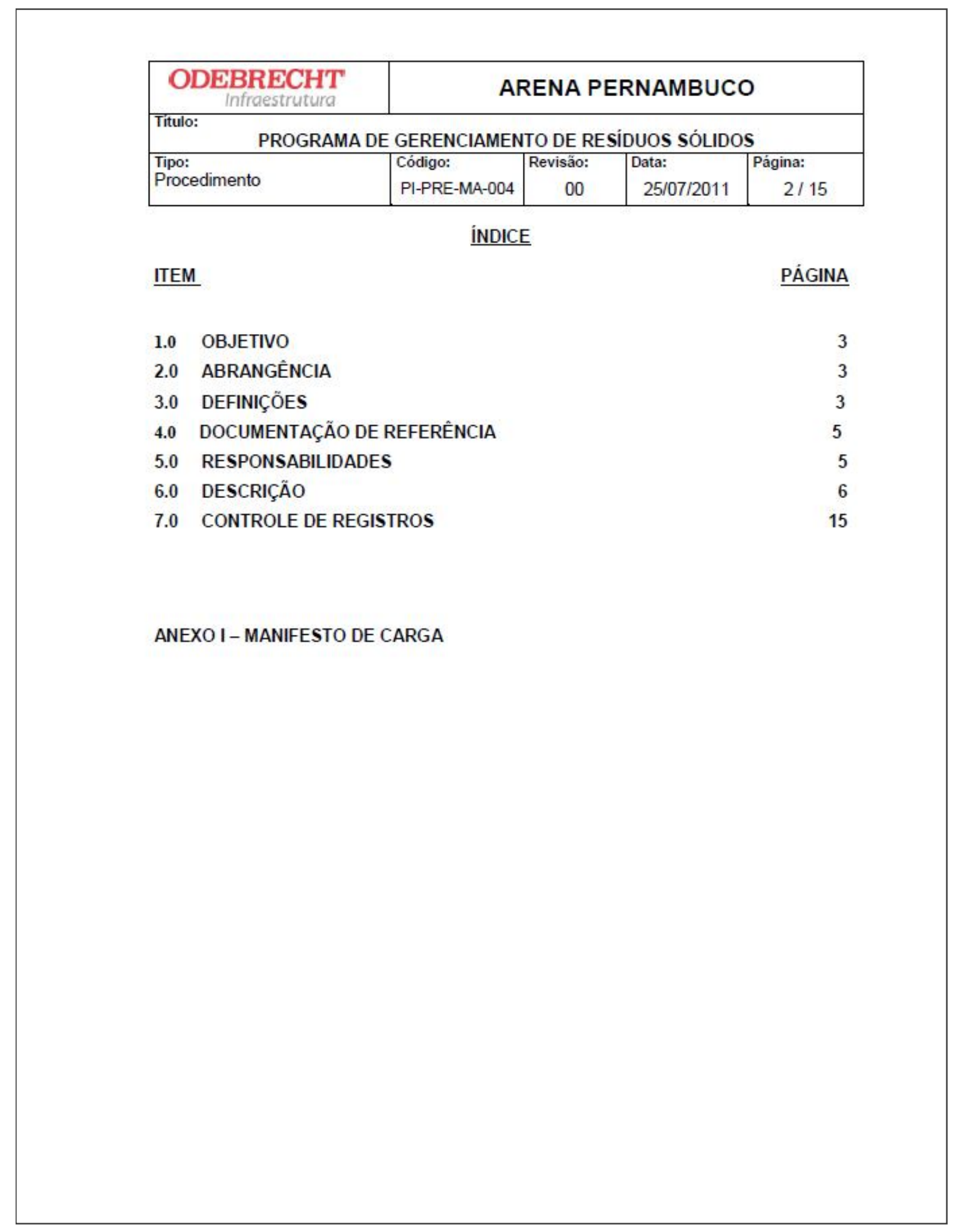




\begin{tabular}{|l|l|c|c|c|}
\hline \multicolumn{1}{|c|}{$\begin{array}{c}\text { ODEBRECHT } \\
\text { Infraestrutura }\end{array}$} & \multicolumn{4}{|c|}{ ARENA PERNAMBUCO } \\
\hline \multicolumn{4}{|c|}{ PROGRAMA DE GERENCIAMENTO DE RESÍDUOS SÓLIDOS } \\
\hline Titulo: & Código: & Revisão: & Data: & Página: \\
\hline Tipo: & PI-PRE-MA-004 & 00 & $25 / 07 / 2011$ & $3 / 15$ \\
\hline
\end{tabular}

\subsection{OBJETIVO}

Este programa visa implantar uma sistemática de gerenciamento de todos os resíduos sólidos gerados na obra Arena Pernambuco, garantindo o adequado manuseio, armazenamento e destinação final.

\subsection{ABRANGÊNCIA}

Este procedimento aplica-se a todas as instalações da obra Arena Pernambuco.

\subsection{DEFINIÇÕES}

Armazenamento Temporário - Estocagem temporária de resíduos para reuso, reciclagem, recuperação, tratamento ou disposição final adequada, que atendam aos requisitos de segurança, saúde e proteção ao meio ambiente;

Classificação de Resíduos - Ato de classificar os resíduos em função de suas propriedades físico-químicas e biológicas;

Disposição Final de Resíduos - Disposição ou destino definitivo dos resíduos de forma ambientalmente adequada, observando-se a legislação e normas específicas;

Fonte Geradora - Corresponde a toda atividade, processo industrial, e/ou obras civis de construção, instalação, montagem, reparos ou manutenção capaz de produzirem resíduos;

Ponto de Geração de Resíduos - Local ou operação onde o resíduo é gerado;

Reciclagem - Processo pelo qual os materiais recicláveis são coletados, transportados, separados, e re-processados ou re-manufaturados transformando-se em novos produtos; 


\begin{tabular}{|c|c|c|c|c|}
\hline ODEBRECHT & \multicolumn{4}{|c|}{ ARENA PERNAMBUCO } \\
\hline \multicolumn{5}{|c|}{ 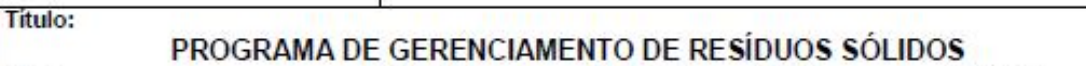 } \\
\hline $\begin{array}{l}\text { Tipo: } \\
\text { Procedimento }\end{array}$ & $\begin{array}{l}\text { Código: } \\
\text { PI-PRE-MA-004 }\end{array}$ & $\begin{array}{r}\text { Revisão: } \\
00\end{array}$ & $\begin{array}{l}\text { Data: } \\
25 / 07 / 2011\end{array}$ & $\begin{array}{r}\text { Página: } \\
4 / 15\end{array}$ \\
\hline
\end{tabular}

Recuperação - Reaproveitamento de resíduos ou de alguns dos seus componentes como insumo de outros processos;

Resíduos - Materiais inserviveis resultantes das atividades industriais, comerciais, hospitalares, administrativas, agrícolas e domésticas;

Resíduos Classe I, IIA e IIB - Resíduos que de acordo com a Norma Brasileira NBR 10.004, são classificados como: Resíduos Perigosos (Classe I), Resíduos não Perigosos não Inertes (Classe II A), e Resíduos não Perigosos Inertes (II B);

Resíduos da construção civil - são os provenientes de construções, reformas, reparos e demolições de obras de construção civil e os resultantes da preparação e da escavação de terrenos, tais como tijolos, blocos, cerâmicos, concreto em geral, solos, rochas, metais, resinas, colas, tintas, madeiras e compensados, formas, argamassa, gesso, telha, pavimento asfáltico, vidros, plásticos, tubulações, fiação elétrica etc., comumente chamados de entulho de obras, caliça ou metralha.

Reuso - Reutilização de um produto ou material mais de uma vez na sua forma original;

Transporte - Movimentação ou transferência de resíduos entre a fonte geradora e o local de armazenamento temporário, tratamento ou disposição final, através das modalidades rodoviária, ferroviária, aeroviária, marítima, fluvial ou através de dutos;

Tratamento - Processos e/ou operações aos quais os resíduos são submetidos, com o objetivo de eliminar ou atenuar seu potencial perigoso e/ou poluidor.

Não Conformidade: É o não atendimento a um requisito especificado no Programa Integrado de SSTMA, na legislação aplicável ou pelo cliente em diretrizes contratuais, quando se aplicar. 


\begin{tabular}{|l|l|c|c|c|}
\hline \multicolumn{1}{|c|}{$\begin{array}{c}\text { ODEBRECHT } \\
\text { Infraestrutura }\end{array}$} & \multicolumn{4}{|c|}{ ARENA PERNAMBUCO } \\
\hline Titulo: & \multicolumn{3}{|c|}{ PROGRAMA DE GERENCIAMENTO DE RESíDUOS SÓLIDOS } \\
\hline \begin{tabular}{l|l|c|c|c|}
\hline Tipo: \\
Procedimento
\end{tabular} & Código: & Revisäo: & Data: & Página: \\
& PI-PRE-MA-004 & 00 & $25 / 07 / 2011$ & $5 / 15$ \\
\hline
\end{tabular}

4.0 DOCUMENTAÇÃO DE REFERÊNCIA

PI-PRE-001 - MANUAL DO PROGRAMA INTEGRADO DE GESTÃO DA SUSTENTABILIDADE;

PI-PRE-MA-001 - PROGRAMA DE IDENTIFICAÇÃO E AVALIAÇÃO DOS IMPACTOS E ASPECTOS AMBIENTAIS;

PI-PRE-011 - OBJETIVOS E METAS DO PROGRAMAS DE GESTÃO DA SUSTENTABILIDADE;

PI-PRE-006 - QUALIMETRIA;

PI-PRE-MA-003 - MONITORAMENTO AMBIENTAL;

PI-PRE-009 - TRATAMENTO DE NÃO CONFORMIDADES, AÇÕES CORRETIVAS E PREVENTIVAS;

PCA - PLANO DE CONTROLE AMBIENTAL DA OBRA ARENA PERNAMBUCO

\subsection{RESPONSABILIDADES}

5.1 Cabe ao Diretor de Contrato - DC:

A responsabilidade em garantir a implementação deste procedimento por meio da disponibilização de recursos financeiros, materiais e humanos.

5.2. Cabe ao Setor de Serviços Gerais:

Administração, limpeza predial e o recolhimento dos resíduos sólidos comuns, Classe I, Classe IIA e Classe IIB gerados nas áreas 


\begin{tabular}{|c|c|c|c|c|}
\hline ODEBRECHT & \multicolumn{4}{|c|}{ ARENA PERNAMBUCO } \\
\hline \multicolumn{5}{|c|}{ PROGRAMA DE GERENCIAMENTO DE RESÍDUOS SÓLIDOS } \\
\hline $\begin{array}{l}\text { Tipo: } \\
\text { Procedimento }\end{array}$ & $\begin{array}{l}\text { Código: } \\
\text { PI-PRE-MA-004 }\end{array}$ & $\begin{array}{c}\text { Revisão: } \\
00\end{array}$ & $\begin{array}{l}\text { Data: } \\
\text { 25/07/2011 }\end{array}$ & $\begin{array}{r}\text { Página: } \\
6 / 15\end{array}$ \\
\hline
\end{tabular}

administrativas, canteiros de obras, frentes de serviços e o encaminhamento ao armazenamento temporário e destinação final, conforme recomendações do setor de Sustentabilidade.

\subsection{Cabe ao Setor de Sustentabilidade}

- A responsabilidade de cumprir o Programa de Gerenciamento de Resíduos Sólidos definido neste documento;

- Identificar os recursos materiais e humanos necessários e providenciá-los;

- Identificar locais adequados de destinação dos residuos sólidos, garantindo o cumprimento da legislação pertinente;

- Analisar os resultados obtidos com os controles, realizando análise crítica, para definição de ações de melhorias, quando necessário.

\subsection{DESCRIÇÃO}

\subsection{Classificação / Caracterização dos resíduos gerados}

Os resíduos gerados na obra são classificados, de acordo com a Norma Brasileira NBR 10004/04, da seguinte forma:

\begin{tabular}{|c|l|}
\hline CLASSE & \multicolumn{1}{|c|}{ DESCRIÇÃO } \\
\hline \multirow{2}{|l}{} & $\begin{array}{l}\text { Resíduos perigosos - São aqueles que apresentam periculosidade } \\
\text { ou pelo menos uma das seguintes características: inflamabilidade, } \\
\text { corrosividade, reatividade, patogenicidade ou toxicidade. São } \\
\text { exemplos destes resíduos na obra: areia contaminada com óleo, } \\
\text { argila contaminada com óleo, baterias usadas, borras geradas em } \\
\text { canaletas de drenagem contaminadas com óleo, embalagens }\end{array}$ \\
\hline
\end{tabular}




\begin{tabular}{|l|l|c|c|c|}
\hline \multicolumn{1}{|c|}{$\begin{array}{c}\text { ODEBRECHT } \\
\text { Infraestrutura }\end{array}$} & \multicolumn{4}{c|}{ ARENA PERNAMBUCO } \\
\hline \multicolumn{3}{|c|}{ PROGRAMA DE GERENCIAMENTO DE RESÍDUOS SÓLIDOS } \\
\hline Titulo: & Código: & Revisão: & Data: & Página: \\
\hline Tipo: & Pl-PRE-MA-004 & 00 & $25 / 07 / 2011$ & $7 / 15$ \\
\hline
\end{tabular}

\begin{tabular}{|l|l|}
\hline contaminadas com produtos químicos perigosos, lodo oriundo da \\
limpeza de equipamentos, resíduos de amianto, tonner de \\
impressora, resíduos químicos de laboratório, resíduos de \\
ambulatório, diversos com óleo.
\end{tabular}

\begin{tabular}{|l|l|}
\hline IIA & $\begin{array}{l}\text { Resíduos náo inertes não perigosos - São aqueles que não se } \\
\text { enquadram nas classificações de residuos perigos ou de residuos } \\
\text { inertes. Podem ter propriedades como: combustibilidade, } \\
\text { biodegradabilidade e solubilidade em água. São exemplos destes: } \\
\text { Papel de escritório, resíduos de refeitório, sucatas em geral (metal, } \\
\text { lata), madeira, resíduos de sanitários, lodo de esgoto doméstico. }\end{array}$ \\
\hline
\end{tabular}

\begin{tabular}{|l|l|}
\hline IIB & $\begin{array}{l}\text { Residuos inertes - Qualquer resíduo que, quando amostrados de } \\
\text { forma representativa e submetidos a ensaio de Solubilização de } \\
\text { Resíduos (NBR 10006) não tiverem nenhum de seus constituintes } \\
\text { solubilizados a concentrações superiores aos padrões de } \\
\text { potabilidade de água, excetuando-se os padrões de aspecto, cor, } \\
\text { turbidez e sabor. Como exemplo, tem-se: pedras, vidros e alguns } \\
\text { plásticos e borrachas de decomposição lenta. }\end{array}$ \\
\hline
\end{tabular}

Já de acordo com a Resolução CONAMA 307/2002, os resíduos da construção civil deverão ser classificados, para efeito dessa resolução, da seguinte forma:

\begin{tabular}{|c|l|}
\hline CLASSE & DESCRIÇÃO \\
\hline CLASSE A & $\begin{array}{l}\text { São os resíduos reutilizáveis ou recicláveis como agregados, tais } \\
\text { como: }\end{array}$ \\
\hline
\end{tabular}




\begin{tabular}{|c|c|c|c|c|}
\hline ODEBRECHT & \multicolumn{4}{|c|}{ ARENA PERNAMBUCO } \\
\hline \multicolumn{5}{|c|}{ PROGRAMA DE GERENCIAMENTO DE RESÍDUOS SÓLIDOS } \\
\hline $\begin{array}{l}\text { Tipo: } \\
\text { Procedimento }\end{array}$ & $\begin{array}{l}\text { Código: } \\
\text { PI-PRE-MA-004 }\end{array}$ & $\begin{array}{r}\text { Revisão: } \\
00\end{array}$ & $\begin{array}{l}\text { Data: } \\
25 / 07 / 2011\end{array}$ & $\begin{array}{r}\text { Página: } \\
8 / 15\end{array}$ \\
\hline
\end{tabular}

\begin{tabular}{|l|l|}
\hline a) De construção civil, demolição, reformas e reparos de \\
pavimentação e de outras obras de infraestrutura, inclusive \\
solos provenientes de terraplenagem; \\
b) De construção civil, demolição, reformas e reparos de \\
edificações: componentes cerâmicos (tijolos, blocos, telhas, \\
placas de revestimento etc.), argamassa e concreto.
\end{tabular}

\begin{tabular}{|c|l|}
\hline CLASSE B & $\begin{array}{l}\text { São os residuos recicláveis para outras destinações, tais como: } \\
\text { plásticos, papel/papelão, metais, vidros, madeira e outros; }\end{array}$ \\
\hline
\end{tabular}

\begin{tabular}{|l|l|}
\hline CLASSE C & $\begin{array}{l}\text { São os residuos para os quais não foram desenvolvidas tecnologias } \\
\text { ou aplicações economicamente viáveis que permitam a sua } \\
\text { reciclagem/recuperação, tais como os produtos oriundos do gesso; }\end{array}$ \\
\hline
\end{tabular}

\begin{tabular}{|l|l|}
\hline CLASSE D & $\begin{array}{l}\text { São residuos perigosos oriundos do processo de construção, tais } \\
\text { como tintas, solventes, óleos e outros, ou aqueles contaminados ou } \\
\text { prejudiciais à saúde oriundos de demolições, reformas e reparos de } \\
\text { clínicas radiológicas, instalações industriais e outros, bem como } \\
\text { telhas e demais objetos e materiais que contenham amianto ou } \\
\text { outros produtos nocivos a saúde. }\end{array}$ \\
\hline
\end{tabular}




\begin{tabular}{|l|l|c|c|c|}
\hline $\begin{array}{l}\text { ODEBRECHT } \\
\text { Infraestrutura }\end{array}$ & \multicolumn{4}{|c|}{ ARENA PERNAMBUCO } \\
\hline \multicolumn{3}{|c|}{ PROGRAMA DE GERENCIAMENTO DE RESíduOS SóLIDOS } \\
\hline Titulo: & Código: & Revisão: & Data: & Página: \\
Tipo: & Pl-PRE-MA-004 & 00 & $25 / 07 / 2011$ & $9 / 15$ \\
\hline
\end{tabular}

\subsection{Seqüência executiva}

\subsubsection{Identificação e acondicionamento}

Todo resíduo gerado pela obra, em qualquer setor, deve ser classificado de acordo com a Norma apresentada acima, no caso de residuo da construção civil, a Resolução CONAMA especifica. Com a identificação do tipo de resíduo, este deve ser acondicionado em condições seguras e devidamente identificado quanto à sua natureza, grau de risco e outras orientações necessárias.

$\mathrm{O}$ acondicionamento deve ser feito em recipientes específicos para cada tipo de resíduo seguindo as cores da Coleta Seletiva, conforme PI-PRE-MA-009 Coleta Seletiva.

\subsubsection{Coleta e Armazenamento temporário}

Todo transporte de resíduo deve ser executado com prévio conhecimento dos riscos e características de manuseio do mesmo.

Os colaboradores envolvidos nessa atividade devem utilizar todos os EPI's necessários para garantir sua segurança, conforme orientação da Segurança do Trabalho.

Os resíduos passiveis de reciclagem devem ser encaminhados a baia de resíduos que se encontra na Área Industrial, seguindo sua classificação.

Os residuos perigosos também devem ser armazenados na baia específica para este tipo de material, sendo devidamente acondicionados em recipiente que garanta a vedação e prevenção de vazamentos e/ou contaminação do solo.

Os demais devem ser encaminhados para o aterro sanitário licenciado ou reutilizados/doados, conforme Tabela I abaixo. 


\begin{tabular}{|c|c|c|c|c|}
\hline ODEBRECHT & \multicolumn{4}{|c|}{ ARENA PERNAMBUCO } \\
\hline \multicolumn{5}{|c|}{ PROGRAMA DE GERENCIAMENTO DE RESÍDUOS SÓLIDOS } \\
\hline $\begin{array}{l}\text { Tipo: } \\
\text { Procedimento }\end{array}$ & $\begin{array}{l}\text { Código: } \\
\text { PI-PRE-MA-004 }\end{array}$ & $\begin{array}{r}\text { Revisão: } \\
00\end{array}$ & $\begin{array}{l}\text { Data: } \\
25 / 07 / 2011\end{array}$ & $\begin{array}{r}\text { Página: } \\
10 / 15\end{array}$ \\
\hline
\end{tabular}

Em se tratando de resíduos da construção civil, os mesmos devem ser armazenados em local isolado e devidamente identificado para posterior destinação, sendo priorizada a destinação para local de reciclagem desses materiais. Caso as características do resíduo não permita sua reciclagem, deve ser encaminhado a aterro autorizado a receber este tipo de material.

\subsubsection{Tratamento e disposição final}

Toda disposição final deve obedecer à legislação pertinente e as diretrizes básicas para o gerenciamento de resíduos da obra.

A partir da classe do resíduo gerado, deverá ser dada adequada destinação, conforme Tabela I a seguir.

Tabela I: Tipos de resíduo, classificação e destinação final

\begin{tabular}{|c|c|c|c|c|}
\hline $\begin{array}{c}\text { Tipo de } \\
\text { resíduo }\end{array}$ & Classe & $\begin{array}{c}\text { Local de maior } \\
\text { geração }\end{array}$ & $\begin{array}{c}\text { Frequêência } \\
\text { de coleta }\end{array}$ & Destinação \\
\hline Orgânico & IIA & Refeitório & Diária & Aterro sanitário \\
\hline Madeira & IIA & $\begin{array}{c}\text { Frentes de } \\
\text { serviços/Carpintaria }\end{array}$ & 3 em 3 dias & Reuso/Reciclagem \\
\hline Metal & IIA & Frentes de Serviço/ & 3 em 3 dias & Reciclagem \\
\hline $\begin{array}{c}\text { Resíduo } \\
\text { contaminado }\end{array}$ & I & $\begin{array}{c}\text { Frentes de serviço/ } \\
\text { Oficina }\end{array}$ & Demanda & Incineração \\
\hline Ambulatorial & I & Ambulatório & Quinzenal & Incineração \\
\hline
\end{tabular}




\begin{tabular}{|l|l|c|c|c|}
\hline \multicolumn{1}{|c|}{$\begin{array}{c}\text { ODEBRECHT } \\
\text { Infraestrutura }\end{array}$} & \multicolumn{4}{c|}{ ARENA PERNAMBUCO } \\
\hline \multicolumn{4}{|c|}{ PROGRAMA DE GERENCIAMENTO DE RESÍDUOS SóLIDOS } \\
\hline Titulo: & Código: & Revisão: & Data: & Página: \\
Tipo: & PI-PRE-MA-004 & 00 & $25 / 07 / 2011$ & $11 / 15$ \\
\hline
\end{tabular}

\begin{tabular}{|c|c|c|c|c|}
\hline Não reciclável & $\begin{array}{c}\text { IIA e } \\
\text { IIB }\end{array}$ & $\begin{array}{c}\text { Refeitório/ } \\
\text { Escritório/ } \\
\text { Frentes de serviço }\end{array}$ & Diária & Aterro sanitário \\
\hline Papel/ Papelão & IIA & Escritório & Diária & Reciclagem \\
\hline Plástico & IIA & Escritório & Diária & Reciclagem \\
\hline $\begin{array}{c}\text { Construção } \\
\text { Civil }\end{array}$ & $\begin{array}{c}\text { Classe } \\
\text { A }\end{array}$ & Estaca raiz/sapatas & Demanda & Reuso/Reciclagem \\
\hline
\end{tabular}

\section{a) Resíduo orgânico}

Os resíduos orgânicos são os resíduos gerados nos refeitórios, tais como restos de comida. Estes devem ser coletados diariamente, após cada refeição, acondicionados em sacos plásticos resistentes e enviados a um aterro de resíduos ou reaproveitados, em pocilgas ou para compostagem, de acordo com determinações e controle do Setor Sustentabilidade.

\section{b) Madeira}

Resíduos de madeira gerados nas frentes de serviços e na carpintaria devem ser acondicionados em recipientes devidamente identificados para que sejam separados de outros tipos de residuos. Sua coleta deve atender à demanda, não excedendo 3 (três) dias. A madeira coletada pode ser armazenada, temporariamente, na baia de residuos até que se tenha um volume significativo, sendo suas destinações locais que aproveitem esse tipo de material, tais como cerâmicas, residências com fornos a lenha, dentre outros. Vale ressaltar que toda entrega de material a ser reaproveitado deve ser devidamente quantificado, com declaração de recebimento e Manifesto de Carga, para controle interno. 


\begin{tabular}{|l|l|l|l|l|}
\hline \multicolumn{1}{|c|}{$\begin{array}{c}\text { ODEBRECHT } \\
\text { Infraestrutura }\end{array}$} & \multicolumn{4}{|c|}{ ARENA PERNAMBUCO } \\
\hline \multicolumn{4}{|c|}{ PROGRAMA DE GERENCIAMENTO DE RESíduOS sóLIDOS } \\
\hline Título: & Código: & Revisão: & Data: & Página: \\
\hline Tipo: & PI-PRE-MA-004 & 00 & $25 / 07 / 2011$ & $12 / 15$ \\
\hline
\end{tabular}

c) Metal

Residuos metálicos são gerados tanto nas frentes de serviços quanto na central de armação e canteiro de obras. Esses residuos devem ser armazenados separadamente e devidamente identificados. Sua coleta deve acompanhar a demanda, sendo que nos locais de maior geração, não deve exceder 3 (três) dias. O material metálico deve ser armazenado na baia de resíduos específica, até que se tenha uma quantidade representativa e encaminhada a locais de reciclagem mais próximos.

\section{d) Resíduo contaminado}

Os resíduos contaminados são gerados, principalmente, na oficina, nos comboios e geradores. Trata-se de qualquer material que tenha tido contato com óleo, graxas e combustiveis. Devido ao seu potencial poluidor é considerado um resíduo perigoso. Dessa forma, deve ser separado e armazenado em recipientes devidamente identificados, sendo que seu armazenamento deve ser em recipientes que não possibilite qualquer vazamento e contato com o solo. Esses materiais não devem ser armazenados por muito tempo, atentando-se principalmente à oficina, onde a geração é maior. Os resíduos oleosos devem ser encaminhados a empresas especializadas de incineração.

\section{e) Resíduo ambulatorial}

Residuo ambulatorial consiste em todo o material proveniente de serviços de saúde. Trata-se de resíduo considerado perigoso e por isso deve ser armazenado separadamente e devidamente identificado. Deve ser manuseado com cuidado, sendo que o trabalhador para isso deve utilizar EPl's apropriados. Esse tipo de resíduo deve ser encaminhado para empresas de tratamento específico de resíduo hospitalar.

\section{f) Material não reciclável}

Material não reciclável consiste em resíduos como plásticos, copos e papéis sujos, embalagens dentre outros que, devido as suas características, não possuem locais de 


\begin{tabular}{|c|c|c|c|c|}
\hline ODEBRECHT & \multicolumn{4}{|c|}{ ARENA PERNAMBUCO } \\
\hline \multicolumn{5}{|c|}{ PROGRAMA DE GERENCIAMENTO DE RESÍDUOS SÓLIDOS } \\
\hline $\begin{array}{l}\text { Tipo: } \\
\text { Procedimento }\end{array}$ & $\begin{array}{l}\text { Código: } \\
\text { PI-PRE-MA-004 }\end{array}$ & $\begin{array}{c}\text { Revisão: } \\
00\end{array}$ & $\begin{array}{l}\text { Data: } \\
25 / 07 / 2011\end{array}$ & $\begin{array}{r}\text { Página: } \\
13 / 15\end{array}$ \\
\hline
\end{tabular}

recebimento para reciclagem e por isso, não precisam ser separados. Esse tipo de resíduo é caracterizado como não perigoso, sendo sua armazenagem feita em sacos plásticos resistentes e sua destinação final é o aterro sanitário.

\section{g) Papéis, Plástico e Papelão}

Papelão e papéis, materiais de grande geração principalmente nos escritórios, consistem em resíduo não perigoso e reciclável. Estes devem ser armazenados em recipientes devidamente identificados, serem coletados separadamente e armazenados na baia de residuos para posterior encaminhamento a recicladores esse material. Toda remessa de material a ser reciclado deve ser devidamente registrado por meio do Manifesto de Carga.

\section{h) Resíduos de Construção Civil}

Resíduos de construção civil gerados nas frentes de serviços e devem ser acondicionados em recipientes devidamente identificados para que sejam separados de outros tipos de residuos. Sua coleta deve atender à demanda. O resíduo coletada pode ser armazenado, temporariamente, em caçambas estacionárias até que se tenha um volume significativo, sendo sua destinação para locais que recicle esse tipo de material. Vale ressaltar que toda remessa de material a ser reciclado deve ser devidamente registrado por meio do Manifesto de Carga.

\subsubsection{Treinamento}

As pessoas envolvidas nas operações de coleta, manuseio, acondicionamento, transporte e destinação final de resíduos devem ser treinadas de modo a estarem capacitadas a desempenhar suas funções e cientes dos riscos que os residuos representam para a saúde humana e o meio ambiente. 


\begin{tabular}{|l|l|c|c|c|}
\hline $\begin{array}{l}\text { ODEBRECHT } \\
\text { Infraestrutura }\end{array}$ & \multicolumn{4}{|c|}{ ARENA PERNAMBUCO } \\
\hline \multicolumn{4}{|c|}{ PROGRAMA DE GERENCIAMENTO DE RESíduOS SóLIDOS } \\
\hline Titulo: & $\begin{array}{l}\text { Código: } \\
\text { Tipo: }\end{array}$ & Revisão: & Data: & Página: \\
Procedimento & PI-PRE-MA-004 & 00 & $25 / 07 / 2011$ & $14 / 15$ \\
\hline
\end{tabular}

6.3 Fluxograma de Gerenciamento de Resíduo

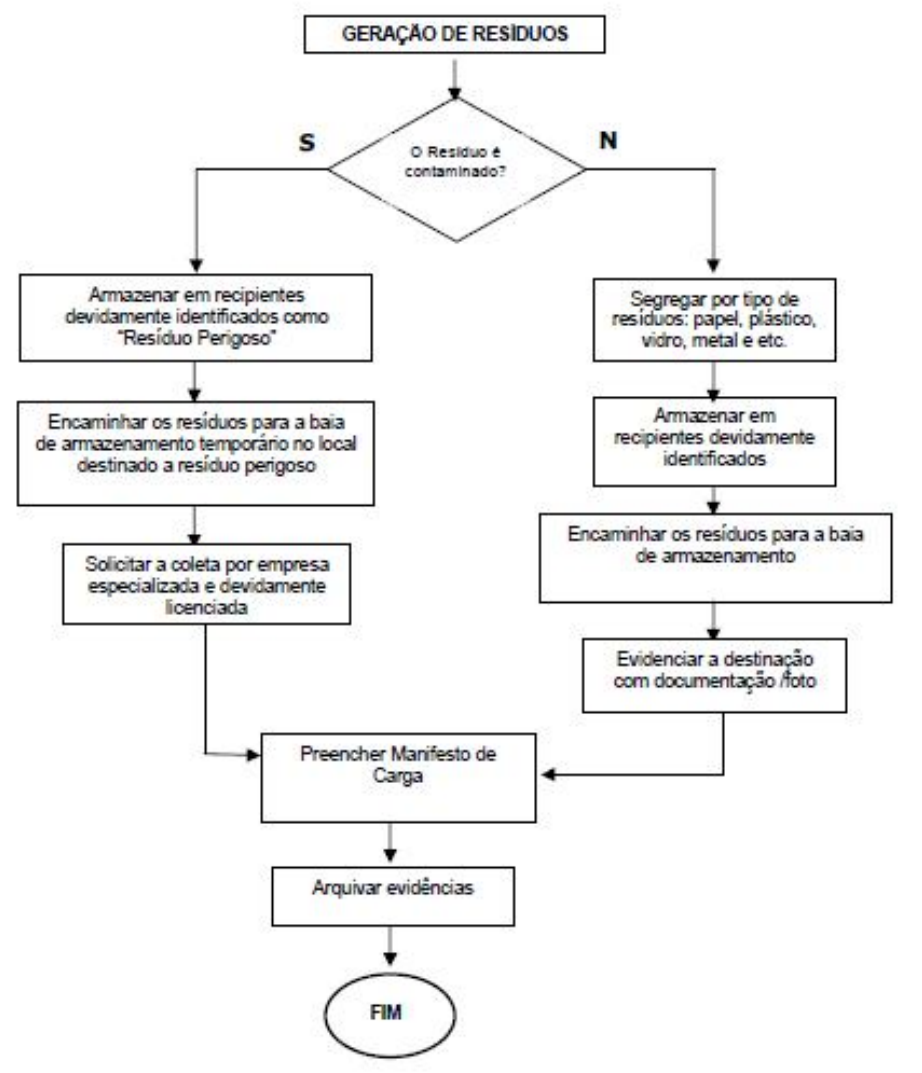




\begin{tabular}{|l|l|c|c|c|}
\hline \multicolumn{1}{|c|}{$\begin{array}{c}\text { ODEBRECHT } \\
\text { Infraestrutura }\end{array}$} & \multicolumn{4}{|c|}{ ARENA PERNAMBUCO } \\
\hline Titulo: & \multicolumn{3}{|c|}{ PROGRAMA DE GERENCIAMENTO DE RESíDUOS SÓLIDOS } \\
\hline \begin{tabular}{l|l|c|c|c|}
\hline Tipo: \\
Procedimento
\end{tabular} & Código: & Revisäo: & Data: & Página: \\
& PI-PRE-MA-004 & 00 & $25 / 07 / 2011$ & $15 / 15$ \\
\hline
\end{tabular}

7.0 CONTROLE DE REGISTROS

Todos os resíduos que forem encaminhados para destinação final devem ser devidamente registrados por meio do Manifesto de Carga, modelo Anexo I. 